\title{
Tuko Pamoja: Adolescent reproductive health and life skills curriculum
}

PATH

Population Council

Follow this and additional works at: https://knowledgecommons.popcouncil.org/departments_sbsr-rh

Part of the Demography, Population, and Ecology Commons, Family, Life Course, and Society Commons, Gender and Sexuality Commons, International Public Health Commons, and the Medicine and Health Commons How does access to this work benefit you? Let us know!

\section{Recommended Citation}

"Tuko Pamoja: Adolescent reproductive health and life skills curriculum." Nairobi: PATH and Population Council, 2006. 


\section{Tuko Pamoja}

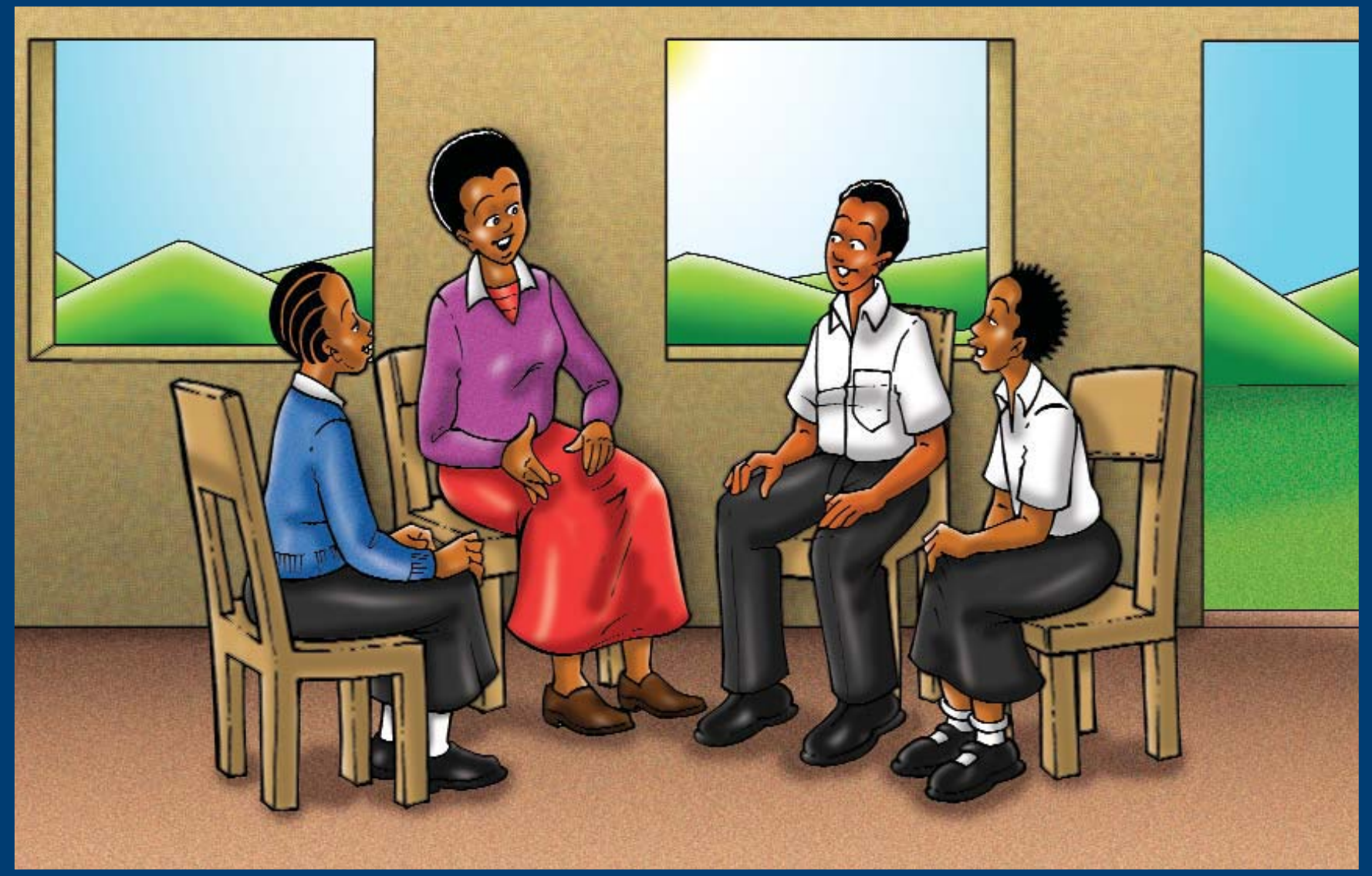

Adolescent Reproductive Health and Life Skills Curriculum

\section{\%: PRTH USAID I Population Council




\section{Tuko Pamoja}

\section{Adolescent Reproductive Health and Life Skills Curriculum}




\section{Acknowledgements}

This second edition of the Kenya Adolescent Reproductive Health Curriculum, Tuko Pamoja, was revised by Sabina Behague, Kaitlin Christenson, Stephanie Martin, and Megan Wysong with considerable input from Kennedy Kibusu. For their comments on drafts of this curriculum, we thank Ian Askew, Irene Chami-Otieno, Humphres Evalia, Oluoch Madiang', Eva Muthuuri, Carolyn Njue, Japheth Nyambane, Winnie Osulah, Rikka Trangsrud, and Monica Wanjiru. All illustrations are by Eric Muturi-Kioi.

This document draws from a number of adolescent reproductive health publications. We are grateful to these authors who paved the way with excellent information, activities and exercises. These publications include Advocates for Youth's Life Planning Education Manual; AMKENI's Field Agents' Handbook; AMREF's Parents of Tomorrow: A Guide to Adolescent Sexual and Reproductive Health; CEDPA's Choose a Future: A Sourcebook of Participatory Learning Activities; HDN and Ipas's Gender or Sex:Who Cares? Resource Pack; IMPACT's Life Skills Manual for the Kenya Girl Guide's Association; Kenya Scouts Association and PATH's Reproductive Health Manual for Scout Leaders; Lynda Madaras's book What's Happening to My Body?; PATH's Games for Adolescent Reproductive Health Handbook; PATH's Life Planning Skills: A Curriculum for Young People in Africa Manual;and Peace Corps' Life Skills Manual. Full references can be found in the reference section of this curriculum.

We wish to extend a special thank you to the participants and facilitators who provided valuable feedback on earlier drafts of this manual in Kakamega, Busia, and Vihiga Districts, and the teachers and students who shared their experiences. They provided a greater understanding of the needs and experiences of different age groups as well as the need for additional resources in carrying out the various activities suggested in this curriculum.

The development and publication of this curriculum was funded by the Office of Population of the United States Agency for International Development (USAID) and the President's Emergency Plan for AIDS Relief (PEPFAR), through the Frontiers in Reproductive Health Program of the Population Council. The opinions expressed herein are those of the author(s) and do not necessarily reflect the views of USAID.

Copyright (C) 2006, Program for Appropriate Technology in Health (PATH). All rights reserved. Any part of this manual may be photocopied or adapted without permission, provided that the parts copied are distributed free or at cost (not for profit) and that credit is given to KARHP, PATH, and Population Council.

\section{Revised March 2006}

\section{PATH}

ACS Plaza, 4th Floor

Lenana Road

P.0. Box 76634-00508

Nairobi, Kenya

Tel: 254-20-3877177

info@path-kenya.or.ke

\section{Population Council}

General Accident Insurance House

Ralph Bunche Road

P.0. Box 17643

Nairobi, Kenya

Tel: 254-20-2713480

publications@pcnairobi.org 


\section{Contents}

Foreword 1

Session 1 Values $\quad 7$

Session 2 Life Cycle $\quad 12$

Session 3 Adolescence and Puberty 14

Session 4 Male and Female Reproductive Systems 19

Session 5 Reproduction Myths 29

Session 6 Healthy Relationships $\quad 32$

Session 7 Communication $\quad 36$

Session 8 Friendship 38

Session 9 Romantic Relationships $\quad 41$

Session 10 Love and Infatuation $\quad 43$

Session 11 Managing Stress, Anger, and Conflict $\quad 47$

Session 12 Introduction to Gender 53

Session 13 Gender Stereotypes $\quad 56$

Session 14 Sexuality and Behaviour $\quad 60$

Session 15 Self-Esteem 65

Session 16 Being Assertive $\quad 71$

Session 17 Decision Making $\quad 75$

Session 18 Setting Goals $\quad 78$

Session 19 Abstinence 82

Session 20 Resisting Peer Pressure $\quad 86$

Session 21 Drug Use $\quad 90$

Session 22 Sexual Exploitation, Rape and Gender Violence 97

Session 23 Teenage Pregnancy 106

Session 24 Parenthood 109

Session 25 Unsafe Abortion 112

Session 26 HIV and AIDS 114

Session 27 Voluntary Counselling and Testing (VCT) 124

Session 28 Care and Support for People Living with HIV 127

Session 29 Sexually Transmitted Infections (STIs) 133

Session 30 Myths and Facts on STIs 139

\section{Facilitator Resources}

Resource 1 Facilitation Techniques 144

Resource 2 Guidance and Counselling 159

Resource 3 Condoms 162

Resource 4 Other Ways to Prevent Pregnancy 170

Resource 5 Students with Special Needs 176

$\begin{array}{ll}\text { References } & 177\end{array}$ 


\section{Foreword}

Adolescence is a time of dynamic change, filled with new feelings, physical and emotional changes, excitement, questions, and difficult decisions. During this time, young people need information about their own sexuality and skills to help them plan for a happy future. As they move through adolescence, young people begin to have different kinds of relationships with their peers, family members, and adults; good communication and other relationship skills can help ensure that these relationships are satisfying and mutually respectful. Young people need to learn how to manage new feelings about sexuality in order to make responsible decisions about their health, reproduction, and parenthood.

This curriculum, entitled Tuko Pamoja(We Are Together), can help facilitate dialogue between adults and young people on issues related to adolescent reproductive health. It for teachers; community, religious, and youth group leaders; health care professionals; and anyone working with young people. The curriculum is designed to delay sexual debut and promote sexual and reproductive health by addressing gender, reproductive health, preventive behaviours, sexually transmitted infections, HIV and AIDS, abstinence, gender violence, and decision-making, communication, and other important life skills.

Within this curriculum, facilitators can examine their own values and attitudes towards gender and relationships, build knowledge on sexual and reproductive health, and develop participatory facilitation skills to impart crucial life-saving information to young people. The objectives of this curriculum are to:

Increase adolescents' knowledge of reproductive health and sexuality.

Reinforce and promote attitudes and behaviours that will lead to a better quality of life for adolescents.

Instill skills among adolescents to enable them to overcome the challenges of growing up and become responsible adults including communication skills, decision-making, assertiveness, set-

ting goals, and resisting peer pressure.

\section{Audience}

This curriculum is for use with adolescent boys and girls aged 10 to19. Some of the material that is contained in the curriculum may not be suitable for younger learners. It is difficult and impractical to cover all of the material in the curriculum in one year for one age group. As the years progress, the same students will be moving up in grade levels and should be given new and more in-depth information as they mature. Much of the material can be repeated year after year with greater emphasis in certain areas or more time committed to others. The final decision on how to present the material is at the discretion of the facilitator. Many of the reproductive health sessions may be better conducted by an outside guest speaker. These topics include abstinence, unsafe abortion, sexual exploitation, rape, STIs, and HIV. Other topics may be better taught outside of a school setting including condom use and other contraceptive methods (available in the resource section).

Unless otherwise noted, activities are suggested for all ages. These shapes will be used to note whether optional activities are for younger or older adolescents:

10-14

\section{Curriculum Design}

The curriculum has thirty sessions which focus on Life Skills and Adolescent Health. Each session has clear learning objectives that are addressed through a variety of participatory learning activities. Each session outlines the learning objectives to be achieved, materials needed, and activities to be conducted. Background notes are also included for facilitators to familiarize themselves with the subject beforehand. General time limits have been assigned to aid in determining how many activities can be conducted in the given time frame.These time limits should not limit the facilitation of each activity because often learners may want to explore issues in greater depth or at other times they may work through the material more quickly. We also suggest that learners are allowed the space and time to synthesize all the issues covered in each session to develop their own understanding and application of the information into their lives. The aim of the curriculum is to assist young people in changing their behaviour and making healthy decisions. 


\section{Before Facilitating a Session}

You should familiarize yourself with the entire curriculum before beginning. Depending on the age of the learners, and your institution's policies, you may choose to complete only some of the sessions. Before facilitating a session, prepare all the required materials and carefully read the background notes and all of the activities for session. Think about how you will perform each step and what you will add to every session.

\section{Handouts, Background Notes, and Possible Questions and Answers}

All handouts and background notes are provided in each session section. Background notes should be read and understood by the facilitator prior to the session planning. Adolescents tend to be very inquisitive, so samples of possible questions and answers have been provided for some sessions. Supplementary answers can be retrieved from the background notes for each section.

\section{Sessions and Optional Exercises}

Most of the sessions include games and activities, which some learners and facilitators might object to initially as childish. Sometimes facilitators who are unfamiliar with participatory techniques would prefer to give a lecture and may find facilitating a game or other interactive exercise a bit challenging. However, a lecture is rarely as productive as an analysis of a game or an exercise. Games and activities provide learners with an opportunity to interact freely and generate more discussion that cannot be yielded by other methods. Many of the optional exercises delve deeper into the topics covered in the sessions. These should not be substituted for the session exercises but can be used to explore a subject in greater detail.

\section{Starting a Session}

It is advisable to introduce each session to the learners and explain the objectives of the session. Ask questions to help learners understand how the objectives relate to their daily lives. Also relate the session to the previous session, if applicable.

\section{Ending a Session}

Each session should end with a reinforcement exercise. Sample reinforcement exercises are provided in the Facilitation Techniques section of this curriculum.

\section{Games and Energizers}

Sample games and energizers are included in the Facilitation Techniques section. Use the games and energizers to keep learners' motivation and participation high. Add your own if it would make learners more comfortable. Alternatively, learners can lead the introductory or closing games or energizers.

\section{Seating Arrangements}

Sitting in circles rather than rows can encourage learners to feel like part of a group, as well as participate more fully. This seating arrangement allows eye contact between learners and the facilitator, creates a more relaxed atmosphere, and encourages participation.

\section{Guest Speakers}

Some topics and sessions might require a guest speaker, especially the sessions the facilitator does not feel confident about or those that require technical or professional guidance. In such sessions, it is encouraged to invite a guest speaker or facilitator. To ensure the session is successful, invite the guest ahead of time, provide the session guide that he or she is expected to facilitate, and make certain that all materials for the session are ready beforehand. Guest facilitators or health care workers are encouraged, particularly in sessions on preventive behaviours (contraceptive methods, STIs, abstinence, condom use, abortion and drug use). It is also essential that the facilitator ensures that the guest facilitator shares the principles and attitudes mentioned throughout the curriculum so that contradictions are not created. 


\section{Talking about Sensitive Topics}

Young people will be embarrassed talking about anything to do with sex or reproduction. Do not let this discourage you or make you uncomfortable. They need accurate information on these subjects to make healthy choices and feel more comfortable with the changes they are experiencing. Let the embarrassment pass and then focus on the information and skills they need.

\section{Tips for Tackling Difficult Subjects}

Clarify your own values before you facilitate your sessions. Think about how you feel about the issue before you discuss it with the learners.

Be prepared and plan ahead. Know what you want to achieve before the session. Find out as much information beforehand, so that you feel confident facilitating the session.

You do not have to know everything. Sometimes facilitators may not know the answer to a question. Be honest with learners. There is no shame in saying 'I don't know.' Turn it into a investigative project and ask learners to help you find the answer.

Do not dismiss or look down on what learners know. Learners have been exposed to a variety of information and experiences. Try to make them feel that their experiences have value and are important.Remember that you do not know everything about the learner's lives.

Set your own limits. Learners will be excited because you are prepared to talk about topics that interest them. Few adults guide them or give them this knowledge. So they may ask questions that make you feel embarrassed. It is important to be as open and honest as you can. But tell them when it is enough or when their behaviour is disrespectful. Explain when you feel uncomfortable answering a particular question.

You have a right to express your opinion. Share your wisdom and values with them. However, emphasize that it is your opinion. Share your feelings honestly and in a caring way without being judgemental.

Use guest speakers, if you are not comfortable facilitating a certain session or feel that learners would benefit from talking with an expert.

Get advice and help if you need it. Teaching life skills and reproductive health is not easy. If you had a difficult session, find another facilitator or someone who you trust, to talk with afterwards. However, respect the learners' privacy and do not share information that learners shared with you during the session.

\section{Working with Parents}

Parents are co-educators in teaching life skills and reproduction to their children. If teachers, community members, religious leaders, and parents can work together, then the young person will emerge a well-rounded, healthy individual. Unfortunately, it is not always so easy. Parents often have concerns when reproduction is taught and may not feel comfortable addressing these issues.

\section{Tips for Working with Parents}

Keep parents informed. Write a letter explaining what you are doing and why. Ask parents for their opinions. Listen to their concerns and try to address them.

Talk with parents about their concerns and fears around reproductive health and HIV and AIDS. Do this through Parent-Teacher Associations, prize giving days, parents' days, and board of governors' meetings. Invite parents to a meeting to discuss their concerns.

Know your community. Find out about its needs and concerns, as well as the skills and expertise of the parents. For example, a parent may be a nurse at a local clinic who could talk with the learners and give your advice and support.

Offer talks on parenting skills. Bring in experts to present their ideas, help improve parentchild communication, and share resources and materials.

Involve parents. Ask parents to check schoolwork and assign activities that require learners to talk with their parents. 


\section{Sample Letter to Parents}

Dear Parent:

We will be teaching life skills and reproductive health education this year. Research in several parts of the world has shown that this kind of education does not encourage sexual activity. Accurate information helps teenagers to delay sexual activity and make healthy choices for themselves. Young people are most at risk of unwanted pregnancy, sexually transmitted infections, sexual abuse and HIV and AIDS. They need honest and accurate information to help them make informed and healthy choices for their lives.

We will be using the Kenya Adolescent Reproductive Health Curriculum (Tuko Pamoja) which teaches young people about their bodies, HIV and AIDS and how to build better relationships. It also teaches skills that help to resist peer pressure, enhance decision making, set goals, and assess their values. The curriculum has been successfully tested with pupils and teachers and the results were found to be very positive.

Your child would really benefit from your support. If you would like to see the curriculum, or talk to us about the approach or topics we will be teaching, please do not hesitate to contact us.

Yours sincerely,

The Headmaster

\section{Mzazi Mpendwa:}

Kuanzia mwaka huu, shule yetu itampa mwanao elimu ya maisha ya jamii na afya ya kimwili. Utafiti umeonyeshakwamba masomo ya aina hii hayachochei vijana kujihusisha na ngono. Kuwa na maelezo sahihi na kamili kuhusumiili yao huwafanya vijana kujilinda kikamilifu na kuwawezesha kujizuia au kususia kufanya mapenzi kwa mudamrefu. Vijana wetu wako kwenye hatari kubwa sana ya kushika mimba isiyotarajiwa, kuambukizwa na maradhi yazinaa, kubakwa na hata kupata virusi vya ukimwi. Kwa sababu hii, wanahitaji masomo na maelezo kikamilifu iliwaweze kufanya uamuzi bora au wa busara kuhusu afya na maisha yao.

Tutatumia utaratibu wa mafunzo ujulikanao kama Kenya Adolescent Health Reproductive Health Curriculum (Tuko Pamoja), ambao huelimisha vijana kuhusu miili yao, ukimwi na jinsi ya kuunda uhusiano bora. Kadhalika, mafunzo jinsi ya kufanya uamuzi mwema na kuunda mpangilio bora wa maisha yatatolewa kupita muundo huu.

Mwanao atafaidika sana kama utampa mkono na usaidizi wako wakati wa masomo haya. Ukiwa na hamu ya kukagua utaratibu wa haya mafunzo, au ukiwa na maswali au mawaidha zaidi, tutafurahia sana ukiwasiliana nasi.

Wako mwaminifu,

Mwalimu Mkuu 


\section{Lesson Planning}

This curriculum was designed to be used with learners 10 to 19 years of age. There are sessions that may not be appropriate for younger learners. The outline below has examples of sessions appropriate for different ages. It is ultimately up to the discretion of the facilitator to decide which information is most relevant for his or her learners.

\section{0 to 14-year-olds}

Session 1 Values

\section{0-14}

Session 2 Life Cycle

Session 3 Adolescence and Puberty

Session 4 Male and Female Reproductive Systems

Session 5 Reproduction Myths

Session 6 Healthy Relationships

Session 8 Friendship

Session 11 Managing Stress, Anger, and Conflict

Session 12 Introduction to Gender

Session 13 Gender Stereotypes

Session 14 Sexuality and Behaviour

Session 15 Self-Esteem

Session 16 Being Assertive

Session 17 Decision Making

Session 18 Setting Goals

Session 19 Abstinence

Session 20 Resisting Peer Pressure

Session 21 Drug Use

Session 26 HIV and AIDS

Session 27 Voluntary Counselling and Testing (VCT)

Session 28 Care and Support for people with HIV

Session 29 Sexually Transmitted Infections

Session 30 Facts and Myths about STIs

\section{5 to 19-year-olds}

Session 1 Values

Session 2 Life Cycle

Session 3 Adolescence and Puberty

Session 4 Male and Female Reproductive Systems

Session 5 Reproduction Myths

Session 6 Healthy Relationships

Session 7 Communication

Session 8 Friendship

Session 9 Romantic Relationships

Session 10 Love and Infatuation

Session 11 Managing Stress, Anger, and Conflict

Session 12 Introduction to Gender

Session 13 Gender Stereotypes

Session 14 Sexuality and Behaviour

Session 15 Self-Esteem

Session 16 Being Assertive

Session 17 Decision Making

Session 18 Setting Goals

Session 19 Abstinence

Session 20 Resisting Peer Pressure

Session 21 Drug Use

Session 22 Sexual Exploitation, Rape and Violence

Session 23 Teenage Pregnancy

Session 24 Parenthood

Session 25 Unsafe Abortion

Session 26 HIV and AIDS

Session 27 Voluntary Counselling and Testing (VCT)

Session 28 Care and Support for people with HIV

Session 29 Sexually Transmitted Infections

Session 30 Facts and Myths about STIs 



\section{Session 1 Values}

\section{Learning Objectives}

By the end of this session, learners will be able to:

Define values

List values that are important to them

Explain the relationship between values and behaviour

Time 60 minutes

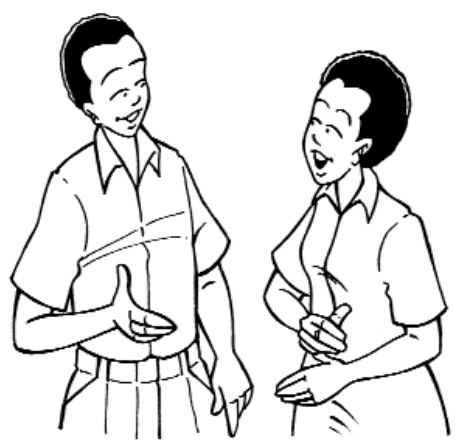

\section{Background Notes}

Values are:

\section{Things that are important to us}

Things we support or are against (give examples like sex before marriage, girls' right to education)

Things we choose freely (may be influenced by families, religious teachings, culture, friends, media)

Things we believe in and are willing to stand up for

Beliefs, principles, or ideas that are important to us and help define who we are

Things that guide our behaviour and lives

Even young adolescents may feel strongly about personal and family values, and discussing these values may bring up many emotions. Be sure that ground rules are followed at all times including confidentiality, not passing judgment on responses, and allowing everyone to participate. Emphasize that individual values differ and there are no right or wrong answers. Allow learners to express, explain, and defend their values. Encourage them to use I statements (expressing their own perspectives and feelings rather than making generalizations) and do not allow any negative comments about other learners. Examples of I statements are:

\section{I believe...}

I feel...

I do not like it when...

If there is an argument over a value-related issue, take immediate and overall control and ask each side to explain their point of view. Remind learners that people's values differ and that is normal to disagree or agree, then move on to another topic. If confusion and dissatisfaction remain, the teacher may want to schedule a formal debate of the issue at another time.

Remember that while you are monitoring the learners to ensure that they are non-judgmental, you must be non-judgmental as well. Be aware of your own personal values, especially when controversial topics like abortion, family planning, or premarital sexual intercourse are discussed. Pay attention to your comments and body language to avoid supporting one position or another. Support learners so that they will not feel overwhelmed or subordinated by the values and opinions of their peers. Make it clear that it is normal to change one's mind based on new information or a new way of looking at an issue.

Occasionally, one or two learners will express a particular value in opposition to the rest of the group. In such a case, it is your responsibility to support the right for someone to have a minority viewpoint. Use verbal comments, touch or physical proximity to show your support, but state clearly that you support the behaviour of standing up for one's values, even if they are in the minority, rather than the position. Whenever there is discussion about a topic and no one in the group expresses a commonly held position, remind the group of that position. You could say, "Other people might say..." and give reasons for that position. 
Teachers, and other authority figures, are often asked about their own values on various topics. It is appropriate to share some of your personal values and to discuss the values that you learned from your family, which helped you make positive decisions about professional goals or education. It is better not to share personal values related to highly controversial topics. Teachers are important figures in the lives of adolescents and can influence their values and behaviours. If asked about a controversial topic, say something like "I'm more interested in what you believe right now." If you do share personal values, be clear that the values are right for you, but not necessarily right for the learners.

\section{Instructions}

\section{Values (20 minutes)}

1. Ask learners to list ideas that are important to them, beliefs that are important to them, and ideas that help them to make decisions.

2. Ask learners what they understand by the word "values." Provide some examples like:

A man who values family, cares about his wife, his children, and his home life.

A person who values education, may strive to go to a National School.

A person who values friends, may spend time making sure his/her relationships are strong.

3. Facilitate a discussion on values by asking the following questions:

Where do you think we get our values?

What is one example of a value your family feels is very important?

What is an example of a religious value you may have been taught?

Which of your values come from your cultural beliefs?

What is a national value that may be less important in other countries?

Can you think of a value someone else has that you do not share? What is it?

4. Explain that learners will be asked to express their feelings about particular values. Designate three areas of the room as "Agree," "Disagree," and "Not sure".

5. Select five to seven of the statements below, and read each statement aloud. After each statement, ask learners to move to the part of the room to show whether they agree, disagree, or are not sure. Explain that there are no right or wrong answers and that everyone is allowed to have his or her opinion.

It is okay to have a child before marriage.

You can earn a decent salary without finishing school.

Boys should pay the bill when a boy and girl go to a restaurant.

Having a job you enjoy is more important than earning a lot of money.

When a man and woman have sex, making sure the woman does not become pregnant is her responsibility.

Children can be raped by a parent.

It is not okay for a boy or man to cry.

It is okay to have sex while you are still attending school if you love the person.

Waiting to have sexual intercourse until you are an adult is a good idea.

Girls should be allowed to inherit property.

Women should understand that a man needs to have many sexual partners at the same time, even if he is married. 
Boys and girls should have equal rights.

A girl who dresses in mini skirts and sexy clothing is asking to be raped.

A man who fathers a child but does not take responsibility should be punished.

It is important to follow traditions no matter what.

Men need to have sex more than women.

A 15-year-old girl who wants contraceptives should be able to get them.

When a girl says no to having sex, she really means yes.

It is preferable to have male children than female children.

It is okay for a boy to have pre-marital sex, but not a girl.

Having sex with an older man or woman for money or gifts is okay.

6. After this exercise, bring the group together and discuss:

Did you know right away how you felt or did you have to think about each one?

Did you ever change your mind?

Did anyone else in the group influence your vote?

How did you eel about the differences in values of the group?

\section{Values and Behaviours (40 minutes)}

1. Ask learners to name people they know (parents, siblings, teachers, politicians, religious leaders, TV personalities, writers, sportsmen and friends) who have felt very strongly about something and have acted because of their values. Allow plenty of time for learners to think of someone. Give an example if necessary to get the groups started.

2. Create three columns on the board headed, Person, Value, and Behaviour. Ask learners to fill them with the names of the person they have thought of, their values (principles, beliefs) and their specific activities or behaviours.

\begin{tabular}{|c|c|c|}
\hline Person & Value & Behaviour \\
\hline
\end{tabular}

3. Ask the group to think of examples of values that have influenced their own lives in some way. Give one example of a behaviour that resulted from your values, such as telling a friend a joke was inappropriate because you value treating people with dignity and respect, or donating money to help others because you believe people should help each other.

4. Ask learners to think of values learned from their families, communities, or religious leaders that have influenced their behaviour. Examples of values include "do not lie, cheat, or steal," "take care of your brother or sister" and "live in harmony with the world around you." Ask how such principles have influenced their behaviour.

5. Explain that you will read several statements, followed by a series of questions. They should not answer the questions out loud, but think about them and write notes to themselves. Each statement reflects a value. Questions will be about behaviours that support or ignore the value. When you have finished, ask the group to talk about the results.

6. Read aloud the following statements and questions (or substitute statements of your own):

(a) Your health is important to you.

Do you get regular exercise?

Do you eat healthy foods?

Are you a non-smoker?

Do you avoid using alcohol and other drugs? 
(b) Men and women should have equal opportunities.

Would you encourage a female friend to study pure physics?

Would you encourage a male friend to study home economics?

(c) Teens should not have sex unless they use contraception and protect themselves against HIV and other sexually transmitted infections.

If you have not had sexual intercourse:

Have you thought about what contraceptives you would use if you were sexually active?

Do you have information on how to get and use contraceptives when you need them?

Have you talked with your friends about the importance of using contraceptives?

If you are having sexual intercourse:

Have you talked to your partner about condoms and other contraceptives?

Have the two of you made a decision about what contraceptives to use, based on accurate information and your needs as partners?

Do you, or does your partner, always use condoms to prevent the spread of HIV infection?

7. Ask the group members to think about their answers to the questions for a few minutes and then write an ending to the following sentence:

Sometimes young people do not behave according to their values because...

8. Summarize the relationship between values and behaviour by discussing the following points:

People tell others about the values that are important to them.

People do what their values tell them to do or not to do.

People make decisions based on their values.

People stand up for their values.

People feel guilty if they do not behave according to their values.

9. Facilitate a discussion with the following questions:

How does it feel to stand up for your values when friends disagree with your position?

What happens when young people's behaviour goes against their parents' values? (Answers include: they argue; may lie to their parents; they may avoid talking about it)

What happens if their behaviour goes against the religious or spiritual values they were taught? (Answers include: They may stop attending religious services or avoid spiritual leaders because they feel guilty, embarrassed, or angry)

What influences people to behave in ways that are consistent with their values? Give an example. (Answers include: It feels good to follow one's values; parents and other adults reward behaviour that reflects the values they teach)

What influences people to behave in ways that are different from their values? Give an example. (Answers include: People may want to experiment, peer pressure, opportunity for personal gain, to rebel, or to get attention)

Will your values change or remain the same as you get older?

If your values and behaviour are different, which should you change, your values or your behaviour?

What are the consequences of picking bad values and behaviours? 


\section{Optional Activity}

\section{\#1 Value Ranking}

1. Explain that you will read several statements that reflect different values. Ask them to rank their values individually. Read the list of values to the learners. Ask them to write the list down as you read it, and allow them to add any others. Ask them to rank the following from 1-12 with 1 being the most important and 12 being the least important:

Being independent.

Getting good marks in school.

Preparing for my future.

Being on good terms with my parents.

Getting married.

Living by my religion.

Being artistic or creative.

Making money.

Being popular with my friends.

Having sex with someone I love.

Getting a job I really like.

Being good in sports.

2. Facilitate a discussion with the following questions:

Which was easier, choosing the most important or the least important?

Are there values on the list that you have never thought about before?

Were you surprised by your feelings about any particular value? 


\section{Learning Objectives}

By the end of this session, learners will be able to:

List physical and emotional changes that happen during different stages of life Explain that sexual feelings are normal

Time 45 minutes

\section{Background Notes}

The table below outlines different physical and emotional characteristics of each of the stages of the life cycle.

\begin{tabular}{|c|c|c|c|c|}
\hline \begin{tabular}{l}
\multicolumn{1}{c}{ INFANCY } \\
(Birth to 3 years) \\
Bond with parent \\
Get early needs \\
met \\
Learn to trust \\
Experience touch- \\
ing by another \\
person \\
Develop gender \\
identity \\
Boy and girl \\
stereotypes \\
learned \\
Explore genitals \\
Toilet training \\
Erection of penis \\
in boys \\
Lubrication of \\
vagina in girls
\end{tabular} & \begin{tabular}{l}
\multicolumn{1}{c}{ CHILDHO0D } \\
(4 to 12 years) \\
Learn gender role \\
Begin to be \\
independent \\
Childhood sex \\
play \\
Same-sex \\
friendships \\
Masturbation \\
Family life \\
education \\
Begin puberty \\
Vaginal discharge \\
in pre-pubescent \\
girls
\end{tabular} & \begin{tabular}{l}
\multicolumn{1}{c}{ ADOLESCENCE } \\
(13 to 20 years) \\
Puberty \\
Menstruation in \\
girls \\
Sperm production \\
in boys \\
Strong need for \\
independence \\
Learning how to \\
be a man or \\
woman from fami- \\
ly, friends, media \\
Masturbation \\
Experimentation \\
with boyfriends/ \\
girlfriends \\
Experimentation \\
with behaving as \\
a sexual adult \\
Possibility of \\
contraception \\
decision making \\
Possibility of \\
pregnancy or \\
impregnating \\
someone
\end{tabular} & \begin{tabular}{l}
\multicolumn{1}{c}{ ADULTHO0D } \\
(20 to 50 years) \\
Forming long- \\
term sexual \\
relationships \\
Setting long-term \\
goals and making \\
plans to reach \\
them \\
Possibility of \\
contraception \\
decision making \\
Possibility of \\
pregnancy or \\
impregnating \\
someone \\
Family life \\
education for \\
one's own \\
children \\
Possibility of \\
menopause for \\
women
\end{tabular} & \begin{tabular}{l}
\multicolumn{1}{c}{ OLD AGE } \\
(50 years or more) \\
Need for touching \\
and affection \\
If healthy, contin- \\
uing interest in \\
sex and ability to \\
perform \\
Women can no \\
longer become \\
pregnant \\
(menopause) \\
Grandparenthood \\
Death of a loved \\
one
\end{tabular} \\
\hline
\end{tabular}




\section{Instructions}

1. Explain that this session is about the physical and emotional changes people go through as they grow up.

2. List the five stages of the life cycle (infancy, childhood, adolescence, adulthood, older age) and write them as headings on a board. Ask learners to describe physical and emotional characteristics of each stage, starting with infancy. Ask questions like, "What can a baby do? How does a baby feel?" Write their comments on the board. As each response is given, ask if everyone in the group agrees with the comments. Facilitate a discussion if there is not agreement. Ask learners to think about their own experiences and their family situations. Continue with each stage.

3. When the lists are complete for each stage, review the changes mentioned for each and explore the most important ones in greater detail.

\section{Optional Activity}

\section{\#1 Puberty Skits}

1. In a large group, review the physical and emotional changes of adolescence and puberty in the life cycle.

\section{Ask for volunteers to speak about their personal experiences.}

3. Divide learners into groups of four and assign each group a physical or emotional change to use as a focus for a skit.

4. Give each group 15 minutes to prepare a short skit to present to the entire group. 


\section{Session 3 Adolescence and Puberty}

\section{Learning Objectives}

By the end of this session, learners will be able to:

Define adolescence

List physical and emotional changes that happen during adolescence

Explain that sexual feelings are normal

\section{Time 60 minutes}

\section{Background Notes}

Adolescence is the time in everyone's life when they change from a child into an adult. Adolescence is the age between 10 and 19 years of age.

\section{Puberty}

Puberty is a time when the bodies of boys and girls physically change - bodies grow bigger and taller, genitals mature, and hair often starts growing in new places on the body. During puberty, a girl becomes physically able to become pregnant and a boy becomes physically able to father a child. New chemicals produced by the body, called hormones, create changes in the body and turn young people into adults.

Puberty typically starts between ages 8 to 13 in girls, and ages 10 to 15 in boys, although some young people start puberty a bit earlier or later. People are different, so everyone starts and goes through puberty at their own pace. During puberty, young people are experiencing a major growth change. Puberty lasts for about 2-5 years. Some people grow four or more inches in one year. This growth during puberty will be the last time the body will grow taller. When the growth period is over, young people will be at their adult height.

\section{Body Changes in Boys}

Boy's shoulders will grow wider, and their bodies will become more muscular. Some body parts (especially hands and legs) may grow faster than others. Many boys have uncomfortable growing pains in their arms and legs as the bones grow faster than the muscles can stretch to keep up with them. Some boys develop swelling underneath their nipples, which looks like the start of breasts. This is caused by the hormones that are active throughout the body and will usually go away with time. During puberty, boys will start to have erections and wet dreams. An erection is when the penis gets stiff and becomes bigger than usual. They will notice other changes as well, such as the lengthening and widening of the penis and the enlargement of the testicles.

\section{Body Changes in Girls}

Girl's bodies usually become rounder and more womanly. They gain weight on their hips, and their breasts develop, starting with just a little swelling under the nipples. Sometimes one breast might develop faster than the other, but over time the slower one catches up. Girls will notice an increase in body fat and will occasionally feel sore under the nipples as the breasts start to enlarge. This is normal. Gaining some weight is part of developing into a woman, and it is unhealthy for girls to go on a diet to try to stop this normal weight gain.

About one to two years after girls' breasts start to develop, they usually experience their first menstrual period. Menstruation is one more sign that lets them know puberty is progressing. It means that the puberty hormones have been doing their job. Girls might see and feel a white or clear liquid from the vagina. This does not necessarily mean anything is wrong; it is usually just another sign of their changing body and hormones. 


\section{More Changes}

One of the first signs of puberty is hair growing where it did not grow before. Hair will grow in the armpits and in the pubic area (on and around the genitals). At first it is thin. Then it becomes longer, thicker, and heavier. Eventually, young men also start to grow hair on their faces and chests. Acne (pimples or spots) often starts around the beginning of puberty and can remain all through adolescence. It usually gets better or disappears by the end of adolescence. Young adults should wash their faces each day with soap and water to keep their skin clean.

A new odour under arms and elsewhere on the body might develop. This is body odour, and everyone gets it. The puberty hormones affect glands in the skin, and the glands make chemicals that have a strong odour. Bathing or washing every day helps reduce this odour, and so do perfumes and deodorants. Boys will notice that their voices may "break" and eventually get deeper. Girls' voices might get a little deeper, too. Boys' voices will stop breaking as they get older.

During puberty, young people might become sensitive or easily upset. Feeling nervous or uncomfortable about how their bodies look and change is one of the things young people are most sensitive about. It is common for young people to lose their tempers, get angry with friends or family members, or feel sad or depressed more than usual. Young people should talk to adults they trust about any feelings of anger, sadness, or depression they may have.

During puberty, it is normal to become more aware of the opposite sex and to feel more sexual. In boys, the main sign of sexual feelings is an erection of the penis. In girls, it is wetness of the vagina. Sexual feelings can come from reading a romantic novel or thinking about another boy or girl. Having sexual feelings is normal and is nothing to feel guilty about. Acting on such feelings, however, is a big responsibility, and it is best to wait until one is older.

\section{Instructions}

1. Divide learners into three groups and ask them to discuss and write down the changes that occur to boys and girls as they go through adolescence. Assign one of the following types of changes to each group: 1) boy's physical change, 2) girl's physical changes, 3) emotional changes

2. Ask one person from each group to share their group's list. Write the responses on the board. Ask the other three groups if they have other changes they would like to add to the list.

3. Point out any other changes that were not mentioned. Help them distinguish between physical and emotional changes. Use the tables below as a guide.

\begin{tabular}{|l|l|l|}
\hline \multicolumn{1}{|c|}{ Physical Changes in Boys } & \multicolumn{1}{|c|}{ Physical Changes in Girls } & \multicolumn{1}{|c|}{ Physical Changes in Both } \\
Shoulders broaden & Hips widen & Grow \\
Facial hair & Breasts develop & Gain weight \\
Voice deepens & Ovulation and menstruation & Pubic and underarm hair \\
Sperm production and ejaculation & & Genitals enlarge \\
Wet dreams & & Acne \\
\hline
\end{tabular}

Sexual feelings

Changes in mood

Feel embarrassed easily

Feel closer to friends than family

Feel shy

\section{Emotional Changes}

Better able to reason and solve problems

Rebel against parents, want to be independent

Concerns about being normal

Experimentation 
4. Discuss how these changes can also change adolescents' attitudes and behaviours. Ask them to list consequences of these attitudes and behaviours. Changes include the following:

Struggling with a sense of identity and questions about oneself

Moodiness, anger, and depression (being rude, self-centred)

Need for more independence and privacy

Experimentation (taking risks, using drugs, having sex)

Identification with peers and relationships with friends and opinions of others become more important (peer pressure, wanting to please friends even if it means getting into trouble)

More concern or worry about appearance and body

Worry about the future (school, family, job)

New "crushes" on friends, classmates, teachers, or celebrities

Curiosity about sexual organs

Feeling sexually attracted to people

Better able to reason (can learn quickly, can plan, dependable)

5. Ask learners which attitudes and behaviours adolescents need to monitor in order to avoid negative consequences? Make sure they include unprotected sex, giving in to peer pressure, and drugs.

6. Ask learners to brainstorm their fears about becoming adolescents and write these on the board.

7. Ask what skills adolescents need in order to cope with this growth period. Divide responses into "knowledge" and "skills," and use the table below as a guide. Tell the learners that knowledge and skills will be covered extensively in a series of upcoming sessions.

\begin{tabular}{|l|l|}
\hline \multicolumn{1}{|c|}{ Knowledge } & \multicolumn{1}{c|}{ Skills } \\
How the body changes & Decision-making \\
Consequences of unprotected sex & Being assertive about needs and wants \\
Abstinence & Negotiation \\
& Setting goals \\
\hline
\end{tabular}

8. End the session by reviewing the following:

All of these physical and emotional changes are normal.

Everyone develops at their own pace; some earlier, some later. It is important not to tease others who may develop earlier or later.

Young people often feel uncomfortable, clumsy, or self-conscious because of the changes in their bodies.

Menstruation and wet dreams are normal and will be talked about more in a later session.

During puberty, a girl becomes physically able to become pregnant and a boy becomes physically able to father a child.

9. Ask learners to list things they can be proud of as they become adolescents. Ask learners to share what they learned in this lesson. 
\#1 Role-Plays: Talking about Puberty (60 minutes)

1. Assign one of the following role-plays to a pair of learners that volunteer to present to the group. Away from the other learners review the role-play with the volunteers. Ask the pair to act out the situation using the information they just learned in the session. Encourage them to be creative and encourage girls to act out male roles or boys to act out female roles. Give learners a couple of minutes to prepare for the role-play. Present the role-play to the group. After the pair presents the roleplay have the other learners clap for their presentation.

\section{Role-play scenarios}

1. One person plays a 12-year-old boy; the other plays the older brother. The younger boy is sad because everyone at school teases him about his breaking voice. The older brother explains why his voice is breaking and what to say to people when they tease him.

2. Both people play 10 -year-old girls. One girl teases the other girl because she is taller than all the other girls in the group. The tall girl explains that boys and girls grow at different paces and to different heights. She also explains why she does not like being teased and asks the other girl to be a nicer person. The teasing girl apologizes.

3. One person plays a 13-year-old boy; the other plays his friend. The friend is worried because he is not as tall and big as the 13-year-old boy. The boy comforts his friend, letting him know that the age when boys start the physical changes of puberty varies.

4. One person plays a 12-year-old boy; the other plays his father (uncle, grandfather). The boy is worried because he is growing hair under his arms and a little on his face. The father (uncle, grandfather) comforts him and tells him that most boys develop hair in new places as they grow older.

5. One person plays an 11-year old girl; the other plays her friend. The friend is worried because she has not started her period but the 11-year-old girl has. The girl comforts her friend, letting her know that the age when girls start menstruation varies.

6. One person plays the mother (or aunt, or grandmother); the other plays a12-year-old girl. The girl is worried because she has not developed breasts, although most of her friends have. The mother (aunt, grandmother) comforts the girl, letting her know that the age when breasts start forming varies and that breast size varies.

2. Ask the group the following discussion questions and write the responses on the board:

What did you see? What did you hear the two characters say?

Does this happen here in our community (school, home)?

What problems does it cause?

What should we do when this happens? What should we do to avoid this?

What else could she or he have said to give more information?

3. Ask another two volunteers to do the same role-play only this time have them go into more depth and improve on the first role-play using some of the answers that were generated from the discussion. Have them perform and thank them for their participation afterwards.

4. Move on to the next role-play and ask for two more volunteers. Use the same discussion questions above for all role-plays. 
1. Divide the groups into small, same-sex groups. Ask each group to think of a list of questions that they would like to ask an adult of the opposite sex and same sex. Suggest that learners think of questions about physical changes and emotional changes that the adult went through during puberty. Possible questions include:

What did you like best about being age 10 to 14 ?

What did you like least about being age 10 to 14 ?

What emotional changes did you have during puberty?

How did your life change in puberty?

Where can I get accurate information about puberty?

Do you have any advice for anyone about to enter puberty?

2. Ask learners to use the questions their group has listed to interview an adult of their choosing.

3. Discuss the results of the interviews at the next session. Make a list of the changes the males and females experienced. Compare the lists to note similarities and differences between the two sexes.

\section{\#3 Letter to Sibling about Puberty (20 minutes)}

15-19

1. Ask learners to write a letter to an imaginary brother or sister about to enter puberty. In the letter, each learner should explain what he or she will go through and offer tips to better prepare for these changes. NOTE: For low-literate or younger learners, you can modify this activity by asking the learners to make up a poem, story, or song instead of writing a letter.

\section{Frequently Asked Questions about Puberty}

Is it normal for some boys and girls to mature earlier than others?

Yes, some boys start puberty at age 10, but others do not start until they are 14 or 15 . Some girls start puberty as early as age eight, and others do not start until they are 13 or 14 . However, if a girl does not start menstruating by the age of 16 , she should consult a health provider.

\section{Why do some parts of the body mature more quickly than others?}

During puberty, there is an order in which certain physical changes usually occur. For girls, breasts begin to grow; for boys, growth of the testicles is usually the earliest sign. However, bodily changes can occur in a different order and still be considered normal.

\section{Why do some boys experience breast tenderness during puberty?}

Occasionally one or both of a boy's breasts can become slightly enlarged or sore. This is related to the rising levels of hormones in the body.

\section{Why do some adolescents have skin problems?}

During puberty increased hormonal activity leads to increased activity in the skin glands. 0il produced by the glands block skin pores and mixes with bacteria to cause pimples or spots. To help keep skin clear, young people should wash their faces and hands frequently.

\section{How long does it take for breasts to fully develop?}

It takes a different amount of time for each girl. If a girl starts later than other girls, it does not mean that her breasts will always be smaller. There is no link between what size breasts will be and when they start to develop. 


\title{
Session 4 Male and Female Reproductive Systems
}

\section{Learning Objectives}

By the end of this session, learners will be able to:

List the main organs in the male and female reproductive systems

Explain the process of sperm production and ejaculation

Explain the process of menstruation and fertilization

\section{Materials Required}

\author{
Chalk \\ Handout 4.1 Reproductive System - Male \\ Handout 4.2 Reproductive System - Female \\ Handout 4.3 Reproductive System Story
}

Time 60 minutes

\section{Background Notes}

\section{Male Reproductive System}

Under the penis there is a small bag of skin containing the testicles. There are two of them and they produce sperm and testosterone. Testosterone is the male sex hormone and it makes pubic hair grow and boys' voices become deeper. Semen is the fluid that carries the sperm. Sperm makes babies when it joins up with women's eggs. Most of the time sperm is inside the body. There is only one exit for the sperm, which is through the hole at the end of the penis, called the urethra. When the penis is soft, that hole is used to urinate; when it is erect, it is used to release semen.

An erection occurs when the penis fills with blood and becomes hard and straight because a boy or man is sexually excited. Erections can happen when boys fantasize and think about sexual things, or sometimes for no reason at all. Boys do not have any control over when this will happen. It is very common for boys to wake up with an erection in the morning. While asleep at night, a boy's penis will probably become erect and then go down about five to seven times. This is completely normal and healthy. Having erections is not a sign that a boy needs to have sex.

When the penis is erect, a boy will find that he cannot urinate easily because a muscle closes off the bladder. He will have to wait until the erection goes down before he can urinate. Ejaculation is when semen comes out of an erect penis due to sexual excitement. A man does not have to ejaculate every time he has an erection. If he waits, the erection will go down without causing any harm.

When a boy begins puberty, the ejaculated semen tends to be slightly clear or yellow. As the boy grows into an adult, he begins making a large amount of mature sperm, and his ejaculation will probably become more whitish. Boys are not born with sperm; they begin to produce them during puberty. A boy begins to produce sperm and continues to produce them through his entire life. If the sperm is ejaculated into the woman's vagina, she may become pregnant. The semen can also carry diseases that could infect another person.

A wet dream is when a boy's penis becomes erect, and he ejaculates while sleeping. This causes the boy's underwear or the bed to be a little wet when he wakes up. If a boy does not know about wet dreams, he could be worried or confused. Wet dreams are completely natural and normal. A boy cannot stop himself from having wet dreams. 


\section{Female Reproductive System}

The female external genital organs are called the vulva. It includes the two folds of skin called the labia, the clitoris, and the vagina. The external genitalia, or the labia, has two sets of rounded folds of skin called the outer and inner lips. The labia cover and protect the vaginal opening. The inner and outer lips come together in the pubic area. Near the top of the lips, inside the folds, is a small cylindrical body called the clitoris. The clitoris is made up of the same type of tissue as the tip of the penis and is very sensitive. The clitoris has no other function than to help a woman have sexual pleasure. The urethra is a short tube that carries urine from the bladder to the outside of the body. The opening to the urethra is very small, and can be hard to find by touch or sight. It is right above the opening to the vagina. The vagina is where a man puts his penis during sexual intercourse. Also, menstrual blood and babies come out of the vagina. The vagina is an incredibly elastic muscle that can stretch wide enough to allow a baby to pass through.

Every female is born with thousands of eggs in her ovaries. The eggs are so small that they cannot be seen by the naked eye. Once a girl reaches puberty, a tiny egg matures in one of her ovaries and then travels down a fallopian tube on its way to the uterus. This release of the egg from the ovary is called ovulation. The uterus prepares for the egg's arrival by developing a thick and soft lining like a pillow. If the girl has had sex in the last few days before or the day after ovulation, by the time the egg arrives in the fallopian tube, there might be some sperm waiting to unite with the egg. If the arriving egg is united with the sperm (called fertilization) the fertilized egg travels to the uterus, and attaches to the lining of the uterus (called implantation) and a pregnancy begins. If the egg is not fertilized, there is no pregnancy and the uterus does not need the thick lining it has made to protect the egg. It discards the lining, along with some blood, body fluids, and the unfertilized egg. All of this flows through the cervix and then out of the vagina. This flow of blood is called the "period" or menstruation. The blood and tissue usually leave the body slowly over three to seven days.

\section{Menstruation and Ovulation}

Menstruation happens for most women about once a month, and that is why it is commonly called the "monthly period." It usually lasts between three and seven days. It is a sign that a girl or woman can become pregnant if she has sexual intercourse. Women stop menstruating while they are pregnant and may or may not menstruate when they are breastfeeding.

Just as some girls begin puberty earlier or later than others, the same is true for periods. Some girls may begin to menstruate at age nine or ten, others may not get their first period until a few years later. A woman knows that she has started her period when a little blood comes out of her vagina. The blood does not pour like water from a tap. It comes out slowly, like a dribble. Usually by the time she has noticed a feeling of unusual wetness, her panties have absorbed any blood that has come out. This is why it is important to anticipate when each month she will start bleeding, so she can wear a sanitary pad or other protection to prevent clothing stains.

The amount of blood that comes out of the vagina can vary widely from person to person. Usually, an entire period consists of a few to several spoonfuls of blood - how much blood depends on the individual. The blood often starts off as a rusty or deep brown colour and then gets redder. It lightens to a rust colour again until it stops. The amount of blood can also vary from day to day.

The menstrual cycle is the period of time beginning on the first day of a woman's period until the day before she begins her next period. Since this happens regularly, it is called a "cycle." The length of time between one period and the next varies for each woman. For some, the cycle is 21 days (or fewer). For others, it is as long as 35 days or more. Irregular periods are common in girls who are just beginning to menstruate. It may take the body a while to adjust to all the changes taking place. For example, a girl may have the same length cycle for two months, then miss a month, or have two periods with fewer days in between them. Her menstrual cycle will probably become more regular, although she may continue to have irregular periods into adulthood. Sometimes she might have some spotting of blood for a day or two in the middle of her cycle. This is usually nothing to worry about. Stress or infections can disrupt a regular menstrual cycle. 
Ovulation is the periodic release of a mature egg from the ovary. The time from ovulation to the next period is a very consistent length of 12 to 16 days and is controlled by hormones. The two weeks or so before ovulation and the two weeks after make a menstrual cycle about four weeks or a month long.

\section{Vaginal Secretion}

Girls can sometimes see secretions on their underpants or experience a feeling of wetness. These secretions are a whitish liquid. Girls often have vaginal secretions around the time of ovulation, when the body is ready to receive and nurture a fertilized egg. Secretions help sperm travel through the uterus to meet the egg for fertilization, so when a girl has secretions, she knows that this is the time when she is fertile.

Paying attention to vaginal secretions helps girls understand their bodies. Knowing what is normal for the body helps girls recognize things that are not normal. For example, yellow or strongsmelling secretions are not normal. These kinds of secretions are often a sign of infection, and should be checked by a health provider.

\section{Menopause}

Menopause is when a woman's menstruation ends. It ends because the hormones that cause eggs to mature in her ovaries stop. When this happens, women can no longer become pregnant. Menopause usually happens after age 45. But, menopause can take place earlier or later than this. Some women may stop menstruating by the time they are 35 , and some not until their late fifties.

\section{What Do Girls Use During Menstruation?}

Clean pieces of cloth: These are cut to fit in the panty area by sewing several layers of cotton cloth on top of each other. These must be clean. They must be washed thoroughly and hung in a private but sunny place to dry. They should not be shared.

Toilet tissue: She can use a thick, long wad of toilet tissue. Sometimes toilet tissue is too rough, and it can irritate the skin. It also may not be sufficient to absorb the quantity of blood.

Pads or sanitary towels: These are designed to fit the panty area close to the body. They have strips of tape that keep them attached to the panties, and the panties help to hold the pads close to the opening of the vagina. Pads have a plastic lining to minimize the spill of blood. If a woman uses pads, she needs to throw them down a pit latrine, bury them, or burn them after use. They should not be left in the garbage pile or flushed down the toilet.

Tampons: These are small, compressed cotton objects, formed into solid, tube-like shapes, which are pushed up into the vagina during menstruation. The cotton softens as it absorbs the blood that comes into the vagina from the uterus. Attached to the tampon is a strong, soft cotton string, which hangs out of the vagina. Pulling this string removes the tampon. A girl must always wash her hands before and after inserting a tampon. Tampons need to be changed often, it could cause infection if left in. One should never leave a tampon in for more than eight hours.

Whatever a girl uses, she should change it frequently to avoid staining or odour. A girl can usually ask her sister, mother, or other close female relative what she uses. A girl might be worried that her friends might see her carrying such products with her. She should know that placing these in a simple plastic bag in a handbag or school bag, usually prevents any embarrassment. If a girl's panties or clothes get stained with blood, she can soak them in cool, mildly salty water. Hot water will cause the blood to set and remain as a permanent stain.

\section{Instructions}

\section{Body Mapping Exercise: Male and Female Reproductive Systems (30 minutes)}

1. Explain that the purpose of this lesson is for learners to better understand their own bodies, feel more comfortable with their bodies, and have information so they can ask questions. 
2. Divide learners into two groups. One group will do the male reproductive system and one group will do the female reproductive system. Ask each group to draw on outline of a body (either on paper or using chalk). Explain that the easiest way to do this is for one to learner lie down on the floor and for someone to draw around his or her body.

Ask all learners in the group to discuss among themselves and draw the following body parts:

Eyes, nose, and mouth

Heart and lungs

Stomach and liver

Male reproductive organs (where male sperm are produced, where the sperm travel through, used for sexual intercourse)

Female reproductive organs (where the egg matures, where egg and sperm unite, where the baby grows, where sex occurs)

3. As learners are drawing, move around and observe the exercise without giving comments or correcting any mistakes.

4.. Ask each group to present their drawing and explain the different parts. Allow members of the other group to ask questions. Correct any misinformation.

\section{Sperm Production and Ejaculation (15 minutes)}

1. Ask learners what sperm is. Allow them to share their ideas. Then ask what they know about how sperm is produced.

2. Divide the learners into pairs and give them each a copy of Handout 4.1. Have them label the parts of the male reproductive system.

3. Review the completed handouts and make sure that all the points are clear and they understand the process of sperm production and ejaculation. Ask learners to discuss information they have learned that will be useful in their lives.

4. Ask volunteers to share something new they learned. Ask if they have learned something that is different from what they thought they knew before. Clarify any myths or misconceptions that learners might have. (The myth that if a boy waits to long to have sex, he will not be able to have children.)

\section{Ovulation and Menstruation (15 minutes)}

1. Ask learners what they have heard about menstruation from their sisters, mothers, aunts, female friends and relatives, media, school, etc. After you let them speak, confirm or correct their statements.

2. Ask for a volunteer to explain how menstruation occurs. Allow other learners to help.

3. Ask learners what they know about ovulation and the menstrual cycle. Allow them to exchange their ideas. Listen carefully to their answers as many misconceptions regarding ovulation and menstruation may come out.

4. Ask learners to explain ovulation. The following should be discussed:

Ovulation is the release of a ripe egg from one of the ovaries once in a month.

This egg is picked up by the broad, funnel shaped end of the fallopian tube and starts moving in the tube towards the womb.

Fertilization is the joining of a released egg and sperm after sexual intercourse.

Usually only one egg is released during ovulation. Sometimes, however, two eggs are released at the same time. If this happens and both are fertilized, twins will be born.

If an egg is not fertilized the lining of the uterus sheds and menstruation occurs. 
5. Divide learners into pairs and give them each a copy of the Handout 3.2. Ask them to label all the parts of the female reproductive system. Review the completed handout and ensure all the points are clear and learners understand the process of ovulation and menstruation.

\section{Facilitate a discussion with the following questions:}

What have they learned in this lesson that can be useful in their lives?

Have they learned something they did not know before? What?

Have they learned something that contradicts what they knew before?

7. Ask volunteers to share what they have learned. Emphasize the following:

The menstrual cycle is not the same for all girls and women and that it can change for many reasons (stress, change in diet, change in environment, sickness).

Some girls and women may experience discomfort and pain, and describe some pain management techniques (exercise, medication).

Menstrual hygiene is important.

8. Discuss any myths that learners may have heard.

9. Let learners know that there will be a session to talk about these myths in greater detail. Ask learners to bring all the materials they used in this session (male and female) to the next session.

\section{Frequently Asked Questions on the Reproductive System}

\section{Do boys get a period?}

Boys do not get a period, or menstruate, because they have a different reproductive system than girls. Menstruation is the breaking away of the lining of the uterus - the place where a foetus develops during a pregnancy. Since only women have a uterus, only they have periods.

\section{What is the normal length of the penis?}

The average penis is between 11 and 18 centimetres long when it is erect. There is no normal penis size, shape, or length. Some are wide and short. Others are long and thin. There is no truth to the idea that a bigger penis is a better penis. It is also normal for a boy to have a curving penis. It will usually become straight when it is erect.

Is it normal to have one testicle hanging lower than the other one?

Yes. Most men's testicles hang unevenly.

How does a girl know when her period is about to start?

Most girls begin menstruating between the ages of 12 and 16 . The best way to know is to look for signs. Underarm hair and a whitish discharge from the vagina are signs that the period will start soon.

\section{What if a girl's period never starts?}

Periods will start sooner or later. However, if a girl reaches age 16 and has not yet had her first period, she should visit a health provider.

Can a woman get pregnant during her period?

Yes. If a woman has a short cycle - typically 21 days from first day to last day - then she is ovulating on day seven of her cycle (the seventh day from the first day of her period). Some periods last seven days, so it is possible that she would be ovulating when she has her period.

\section{Is menstruation painful?}

As hormone levels rise and fall during a woman's menstrual cycle, they can affect the way she feels, both physically and emotionally. Some experience cramping in their stomachs before or during their period. This pain is usually not a serious problem and can be treated with paracetamol or other pain reliever, exercise, a hot bath, or a hot water bottle. A young girl may also experience back pain, headaches, nausea, vomiting, and constipation. The pain usually lasts just two or three days at the beginning of the period. Period pain is usually worse during adolescence and may subside as the young woman becomes an adult. 


\section{Optional Activities}

\section{\#1 Reproductive System Sculptures}

Creating two or three-dimensional works of art allows learners to look more closely at the reproductive system than they ever have before.

Materials: Any (or all) of these materials can be used: Felt, clay or modelling dough, fruit or vegetables, or "found objects" (silverware, bottles, boxes, paper plates for cutting). Scissors, tape, glue, paper, as needed. Learners will also need Handouts 4.1 and 4.2.

\section{Instructions}

1. Have individuals or teams work together to create a sculpture of the male or female reproductive system. Give them a time frame and ask them to take the time to create something interesting. Hold an art exhibit and allow them to show off their masterpieces.

2. Facilitate a discussion with the following questions:

Have you ever looked so closely at the male and female reproductive systems?

Was there anything surprising about them?

Did their design affect your choice of art materials?

Can you imagine these systems inside your own bodies?

Do you think about these organs inside you every day?

Do you think they are important? Why?

What can you do to keep them healthy?

10-14 1. Ask learners to form five or six small groups. If culturally appropriate, have boys and girls mixed together.

2. Display the products used during a woman's period (pad, tampon, cotton, cloth) and a cup or glass of water. (Use products that are readily available and commonly used among women within your community.)

3. Ask learners to identify the products. Ask the learners in each group to explain how the products are used and disposed of. Tell each group to place the products in water or pour water on them. Explain that the products absorb water like a sponge and this is what they do for blood during the menstrual period.

4. Encourage the learners to ask questions and allow other learns to answer.

5. Facilitate a discussion with the following questions:

Why use these products?

How do they work?

How often do they need to be changed?

How should they be disposed of or cleaned?

Where can you get these products? 


\section{\#3 Pair Exercise: Talking about our Fertility}

1. Assign one of the following role-plays to a pair of learners who volunteer to act it out for the group. Away from the other learners review the role-play with the volunteers. Ask the pair to act out the situation using the information they just learned in the session. Encourage them to be creative and encourage girls to act out male roles or boys to act out female roles. Give learners a couple of minutes to prepare for the role-play. Present the role-play to the group. After the pair presents the role-play have the other learners clap for the presentation.

2. Ask the group the following discussion questions, one at a time, and write the responses on the board:

Does this happen here in our community (school, home)?

What problems does it cause?

What should we do when this happens?

What should we do to avoid these problems or this situation?

What else could she or he have said to give more information?

3. Ask another two learners to volunteer to do the same role-play only this time have them go into more depth and improve on the first role-play using some of the answers that were generated from the discussion. Have them perform and thank them for their participation.

4. Move on to the next role-play and ask for two more volunteers. Use the same discussion questions for all other role-plays.

Role-play \#1: One person plays the aunt; the other plays a 12-year-old girl. The girl is worried because she has not gotten her period yet, but her friends have. The aunt comforts the girl, letting her know that the first period starts as early as age 9 or 10, but can also start a few years later.

Role-play \#2: One person plays a 10-year-old girl; the other plays the older sister. The girl is afraid because she began her period and does not understand it. The older sister explains menstruation.

Role-play \#3: One person plays the father; the other plays the 13-year-old son. The son is worried because he keeps waking up, and the bed is a little wet. He asks his father what is wrong with him. The father explains to him what wet dreams are and that they are normal.

Role-play \#4: One person plays a 12-year-old girl; the other plays her mother or father. The girl has stained her clothes with menstrual blood at school and is too embarrassed to return to school because she thinks everyone saw. The parent comforts her and tells her that every woman has an occasional spot on her clothes. The mother or father explains what to use to stop the blood in her panties.

Role-play \#5: One person plays the older brother; the other plays a 12-year-old boy. The boy is worried because he ejaculated and now thinks his sperm is floating in the air and might get someone pregnant. The brother explains to him about wet dreams and ejaculation.

\section{\#4 Fertility Dance}

1. As a group, design a space to represent female reproductive organs including ovaries, fallopian tubes, uterus, vagina, and vulva. Doors and hallways may be used, or tape or chalk on the floor. Assign roles, eggs and sperm (the majority of dancers in the role of sperm). One player may be a narrator with a calendar. Music to play during the action can be an extra element of fun.

2. Allow students to perform the dance, with a discussion during and after the performance. Bring in spectators if possible. Repeat to allow dancers the chance to perform different parts. Then have a contest: individuals or teams must read a scenario for students to choreograph (fraternal twins are conceived, identical twins are conceived, or different types of contraception are used (including abstinence).

3. Ask the "dancers" to re-enact their dance, stopping at times to explain what is going on. Ask the dancers to explain which parts were confusing to demonstrate, and what they learned. Have dancers or the audience suggest other issues to demonstrate. 
Handout 4.1 Male Reproductive System
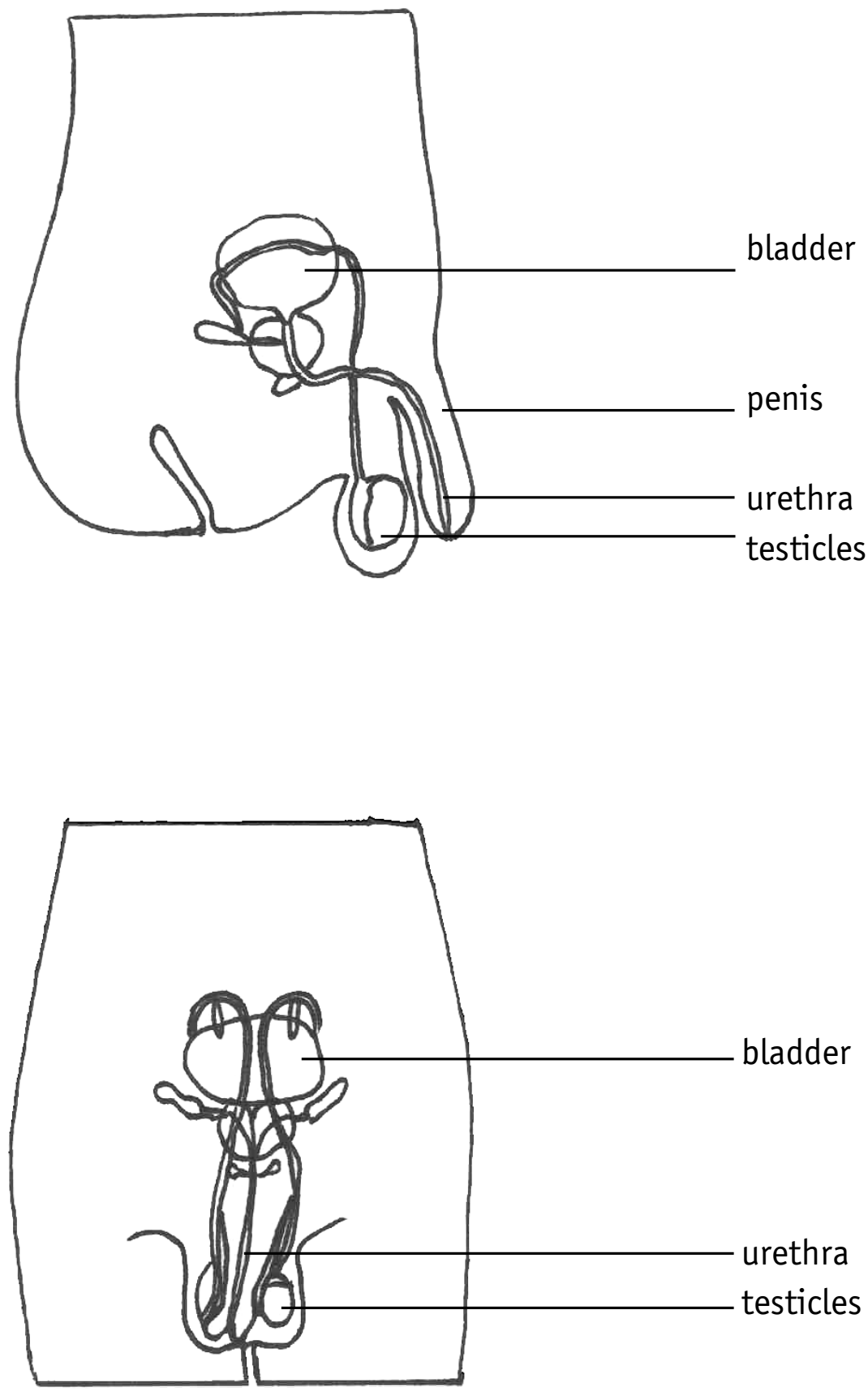
Handout 4.2 Female Reproductive System
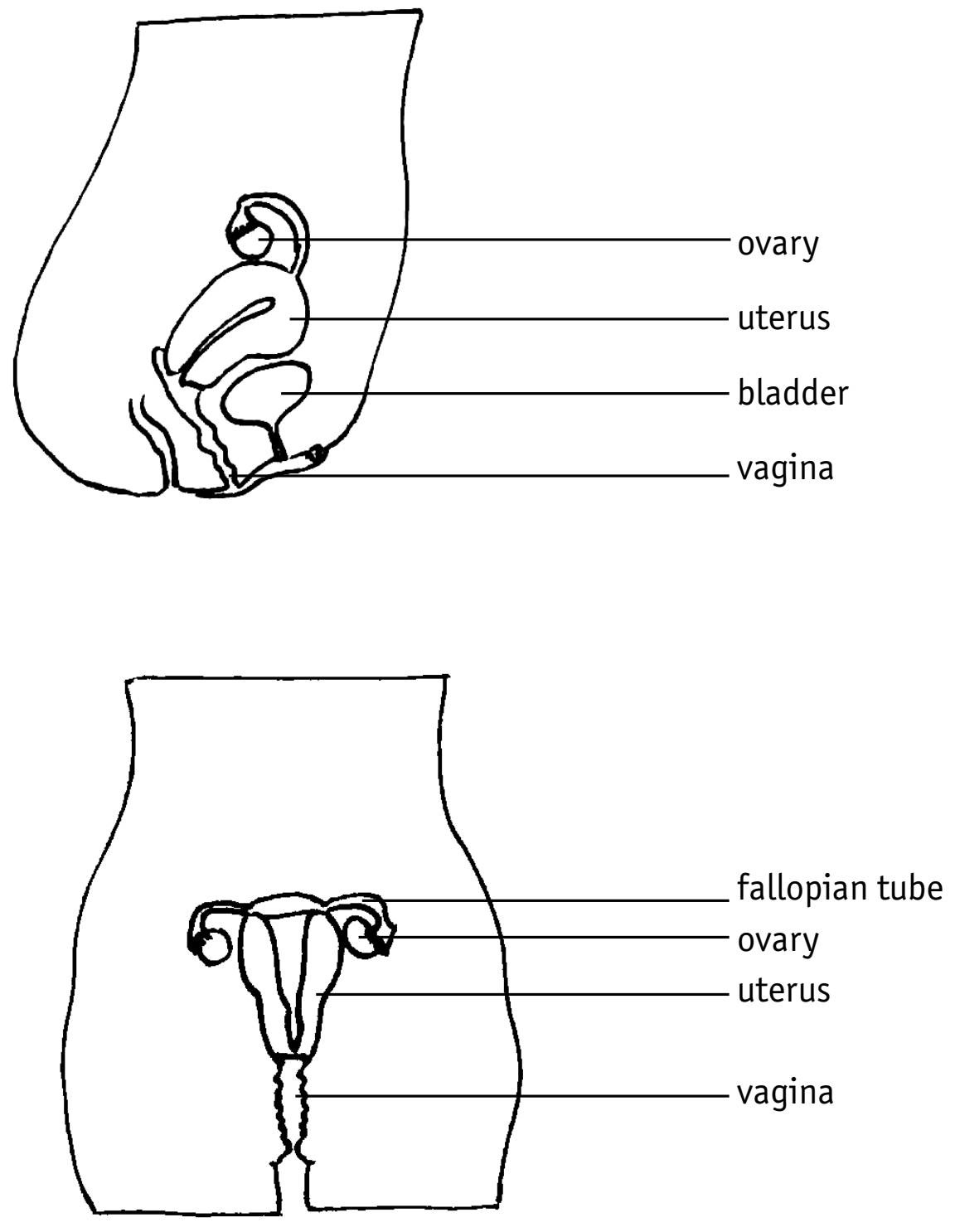


\section{Handout 4.3 Reproductive System Story}

Below are two stories. The events are out of order. Use a sheet of paper and write the stories so that they make sense. Find a topic sentence to begin your paragraph. Make sure that the last sentence is a good conclusion.

\section{Male Reproductive System}

I am produced in the testicles.

The Life of a Sperm Cell

I go through a woman's vagina in search of an egg cell.

When the penis becomes erect, I leave the body through the urethra in a white, milky fluid in a process called ejaculation.

Without me, an egg cell couldn't begin the process of reproduction.

If I can find the egg before the other sperm do, I will be the winner: part of a fertilized egg!

\section{Female Reproductive System}

The egg travels to the uterus.

The egg is released by the ovary.

About two weeks later, since the lining of the uterus is not needed for a pregnancy, it comes out through the vagina.

If the egg doesn't meet a sperm, it dissolves.

The Menstrual Cycle

While the egg is developing, the lining of the uterus is getting thick and soft.

An egg starts to develop in the ovary.

\section{Facilitator Notes Reproductive System Story Answers}

\section{Male Reproductive System}

The Life of a Sperm Cell

I am produced in the testicles.

When the penis becomes erect, I leave the body through the urethra in a white, milky fluid in a process called ejaculation.

I go through a woman's vagina in search of an egg cell.

If I can find the egg before the other sperm do, I will be the winner: part of a fertilized egg!

Without me, an egg cell couldn't begin the process of reproduction.

\section{Female Reproductive System}

The Menstrual Cycle

An egg starts to develop in the ovary.

While the egg is developing, the lining of the uterus is getting thick and soft.

The egg is released by the ovary.

The egg travels to the uterus.

If the egg doesn't meet a sperm, it dissolves.

About two weeks later, since the lining of the uterus is not needed for a pregnancy, it comes out through the vagina. 


\section{Session 5 Reproduction Myths}

\section{Learning Objectives}

By the end of this session, learners will be able to:

Differentiate between reproductive system facts and myths

Apply knowledge of the reproductive system to dispel myths

\section{Time 60 minutes}

\section{Background Notes}

A myth is a traditional story or collection of stories told among a group of people, that may be based on a truth or real story, but is not true. It often is based on the cultural ideals or commonly held beliefs or emotions in a community. Myths form part of the beliefs of a community or society. A fact is something that is true and has been proven with evidence.

Although most young people have some basic information about sex and reproduction, they often believe myths about reproduction. It is important to let learners talk about these tales they have grown up with in order to bring the myths out into the open so they can be dispelled and replaced with facts. Myths can range from the less harmful to the highly dangerous ones, like those concerning sexual health. Partial and incorrect information can lead adolescents to make risky decisions for themselves. Long-held, culturally approved beliefs or myths that peers swear are true are often extremely difficult to change. But the misinformation must be cleared away and real facts provided, so that choices can be based on knowledge instead of ignorance.

\section{Instructions}

\section{Reproduction myths (60 minutes)}

1. Ask learners to define the word "myth." Write their responses on the board. Responses should include: opinions, beliefs, fables, stories or fantasies that are not true. Ask learners to discuss how their definition of "myths" is different from "facts."

2. Explain that "facts" are things that are known to be true; events that have actually occurred; and things that are real, actual, and can be proved. For example, if you throw a ball in the air, it will come down or Jomo Kenyatta was the first president of Kenya. Myths are ideas, sayings or beliefs that people create and are not or cannot be proven. Usually, myths are a mixture of truths and untruths passed around verbally within a community, to explain an issue that people do not fully understand. For example, in some communities, people say that if a woman thatches a roof, she will go blind. (Use an appropriate example of a myth in your community.) Myths are distorted or misunderstood truths. Emphasize that while some myths are quite harmless, many of them can be dangerous because they are the opposite of known facts and acting on them can lead a person into trouble or negative consequences. For example, some people say that you cannot get pregnant the first time you have sex and in fact, you can get pregnant anytime you have sex without using contraception, even the first time.

3. Ask learners to list myths that they have heard about the reproductive system functions and processes. For example, if a girl or boy does not have sex, she or he will get backaches. Collect the information without discussion.

4. Once a list of myths has been collected, divide learners into groups of four or five. Assign one or two myths to each group and ask them to work as a team to use their knowledge to dispel each myth.

5. Ask a representative from each group to present back to the group. Allow others to ask questions 
6 . End the session by emphasizing that there are many myths and misconceptions about reproduction and acting on them can have negative consequences and it is important to only consider the facts about reproduction when making decisions about sexual activity. If they are not sure about the facts, they should ask a knowledgeable person, such as a counsellor, doctor, or nurse, and not rely on friends who may not have accurate information.

\section{Optional Activities}

\section{5-19 \\ \#1 Small Group Activity or Homework Assignment: Myth Tracing \\ Have learners collect reproductive health myths among their family and friends. Trace the origin of certain specific myths in Kenya. Write up an essay on why the myth is incorrect.}

\section{3-14 \\ 2} \#2 Myths Role-Play

Divide learners into small groups and assign one reproductive health myth to each group. Ask each group to act out their myth and the consequences of the misinformation and then resent them to the group.

\section{3-14} \#3 Large Group Game: Fertility Myths and Facts

1. Explain that the group is going to play a game that will focus on signs of female and male fertility, specifically menstruation and wet dreams, and that this game will help them identify and correct myths around the topic.

2. Divide the group into two teams and place them on opposite sides of the room. Have each team choose a name. Read one of the following statements to the first member of Team A. That person should consult with the rest of the team to determine whether the statement is a "myth" or "fact."

3. Once the first player responds, say whether the answer is correct and mark the score on the board. Award one point for each correct answer. If the answer is correct, ask the player to say why this is correct. If the answer is incorrect, provide the right response and briefly explain why.

4. Continue by reading another statement to the first member of Team $B$, then alternate teams until everyone has had a chance to respond. After you have read each of the myths and facts, ask the teams to come up with two things that they have heard about menstruation and wet dreams and share these. Have the opposite team state if it is a myth or fact, and again, tell them if they are correct and why. Afterward, add up the score and announce the winning team.

\section{MYTH or FACT?}

The blood coming from a woman during menstruation means that she is sick (MYTH)

Cold drinks do not cause menstrual cramps (FACT)

Women should not eat spicy or sour foods during menstruation (MYTH)

If a woman misses her period, this could mean she is pregnant (FACT)

If men do not ejaculate, sperm will collect and make their penis or testicles burst (MYTH)

It is perfectly safe for a woman to wash her hair or take a bath during her period (FACT)

Having menstrual blood means a woman is dirty (MYTH)

When a boy or a man has a wet dream, it means he needs to have sex (MYTH)

When a man has an erection, he must always ejaculate (MYTH)

Most boys have wet dreams during puberty (FACT)

If a penis is touched a lot, it will become permanently larger (MYTH)

If a person jumps over the legs of a pregnant woman the child will look like the jumper (MYTH)

If a person masturbates a lot, they will go blind (MYTH) 


\section{Reproduction Myths}

MYTH: One cannot get pregnant with one sexual act.

FACT: One runs the risk of pregnancy each and every time one has unprotected sex, even the very first time.

MYTH: The safest time to have sex is between periods.

FACT: For women with menstrual cycles between 26 to 32 days, they can become pregnant from the 8th to 19th day or halfway between periods. This is the least safe time to have sexual intercourse.

MYTH: You need your parent's permission to find out about contraception and reproductive health.

FACT: Knowledge about contraception can protect against consequences of unprotected sex like unplanned pregnancies and STIs. Knowledge of reproductive health makes one fully aware of one's body, its functions and its care. So, it is not necessary to seek parent's permission for it. Adolescent reproductive health and development policy in Kenya gives young people the right to access information and services.

MYTH: Ejaculating during the night ("wet dreams") is harmful to boy's health.

FACT: Ejaculating while sleeping is normal and natural during adolescence and is not harmful.

MYTH: A woman becomes "dirty" or "untouchable" during menstruation.

FACT: Menstruation is normal and occurs with all women. The blood that comes out is not dirty.

MYTH: One should not take a bath during menstruation.

FACT: Menstruation is natural and there is no restriction regarding having a bath. In fact, it is very important to keep the body clean during this time, to avoid infection of the reproductive tract.

MYTH: If the hymen is broken then a girl is not a virgin.

FACT: The hymen can break even without sexual intercourse, by certain physical activities like sports, exercise, and the use of tampons during menstruation. Sometimes the hymen may be loose or absent and there is no breaking of the hymen.

MYTH: Contraceptive methods are harmful to your health.

FACT: Contraceptive methods can improve the family's health and women's reproductive health.

MYTH: Contraceptive pills make women barren.

FACT: The use of pills does not make a woman barren. Most women find that on stopping the pill, they become pregnant within three months.

MYTH: Condoms have holes and are laced with viruses.

FACT: Condoms do not have holes and do not allow HIV to pass. HIV can only get through if the condom has been damaged or torn. The presence of microscopic pores in some condoms does not matter much, since HIV cannot move on its own and is often attached to white blood cells, which are much larger than the virus. Condoms have of two or three layers of latex, and pores would have to be lined up in order for the virus to pass through. Then, enough of the virus (more than 15,000 ) would have to pass through to cause infection. The authors of a study investigating leakage concluded that if a condom does not break, it provides 10,000 times more protection than no condom at all. 


\section{Session 6 Communication}

\section{Learning Objectives}

By the end of this session, learners will be able to:

Define and demonstrate effective non-verbal communication

Describe effective communication skills

List good listening skills

Time 80 minutes

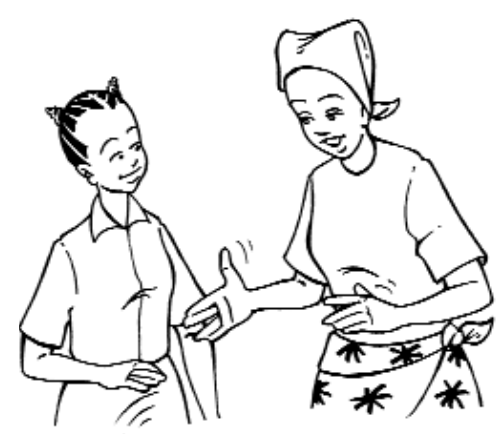

\section{Materials Required}

Large sheets of paper and markers for each group (or notebooks and pencils)

\section{Background Notes}

Communication is the process of sending and receiving information or thoughts through words, actions, or signs. People communicate to share knowledge and experiences give information, express feelings, and solve problems or arguments. Communication is a skill and forms the basis of all relationships. The quality of communication affects the quality of a relationship.

Non-verbal communication or body language gives meaning to what is said and includes tone of voice, facial expressions (smiling, frowning, etc.), eye contact, body position (sitting, standing, pacing, leaning forward or backward), touch, and actions. Body language can influence communication negatively or positively.

Verbal communication is when one person talks and others listen and react. The conversation can be informative, in the form of questions, a negotiation, statements, instructions, or a story. In relationships communication is usually informal. Communication misunderstandings and problems can happen when one person talks for too long, speaks too softly, interrupts the speaker, does not listen carefully, or when there are loud noises in the background or other distractions.

Listening carefully is essential for effective communication. Many times the listener is busy thinking about what they are going to say and does not pay close attention to what the speaker is saying. This can cause misunderstanding and confusion. It is important to listen closely to everything that is said without interrupting and then react afterwards.

\section{Instructions}

\section{Non-verbal Communication}

1. Divide learners into pairs. Explain that this session will start with an exercise called "house-treedog." Give each pair one marker and one piece of paper. Read the following instructions:

The exercise is to be done without talking.

Each pair sits facing each other, with the paper between them.

Both people hold the marker together and jointly draw a house, a tree, and a dog. Still without talking, they should write their names on the picture.

2. When all learners have finished, they should present their drawings to the group and describe their experiences creating it. Ask the following questions:

How was drawing together without speaking?

Was it difficult? Why?

Did one person take control? How did this make the other person feel? 
3. Write down key words described by each pair and facilitate a discussion as a way of introducing communication. Explain that communication is so much a part of our daily lives that we take it for granted. It is not as easy as we might think to be a good communicator; it is a skill that requires practice.

4. Ask learners to list the different types of communication (written, spoken, non-verbal/body language). Explain that much of communication is non-verbal and that people use it to express many different emotions.

5. Divide learners into groups. Assign each group feelings/actions from the following list and ask them to practice silently acting them out without letting the other groups see:

$\begin{array}{ll}\text { Anger } & \text { Shyness } \\ \text { Rejection } & \text { Excitement } \\ \text { Satisfaction } & \text { Disappointment } \\ \text { Fear } & \text { Exhaustion/tired } \\ \text { Worried/stressed } & \text { Regretful } \\ \text { Happy } & \text { Be quiet } \\ \text { Yes } & \text { No } \\ \text { Come here } & \text { Stop }\end{array}$

6. Ask each group to act out their feelings/actions without speaking. Ask the others to guess the word.

7. After each group has acted out their words, facilitate a discussion about non-verbal communication using the following questions:

What are other gestures or expressions that we commonly use?

Why do people use nonverbal communication instead of expressing themselves verbally?

Is it possible not to use nonverbal communication?

Can non-verbal communication contradict verbal communication? (For example, a person is visibly upset but says she is "fine.")

\section{Importance of Clear Communication}

1. Explain to the learners that communication is a process. Ask them to take out a piece of paper. Explain that you will give them instructions and they are to listen to them and draw what you say. Do not tell them that you are having them draw an elephant. Give them the following instructions, pausing for several seconds after each instruction, so they complete the instruction before hearing the next instruction.

\section{Draw a body \\ Draw four legs \\ Draw two ears \\ Draw a head \\ Draw a trunk}

2. Ask them to look at each other's pictures. Explain that you were having them draw an elephant. Do any of the pictures look like an elephant? When everyone was given the same instructions do all of the pictures look the same? Why not? Explain that even with good communication everyone understands messages differently.

3. Ask the learners if there is a difference between "hearing" and "listening." Explain that people hear through their ears and have no control over what they hear. Hearing is natural and people are hearing all the time (unless they are deaf). A person listens by paying attention to and thinking about what someone is saying. Deaf people can listen even though they cannot hear. Most of the time, people hear but they do not listen. Listening is a learned skill and gets better with practice. 
4. Divide learners into pairs. Ask one person to tell the other a story about a happy time they spent with a friend or family member. Explain that the partner who is listening cannot talk but can show interest and understanding without words. After two minutes ask participants to switch roles. Have the listening partner retell the story that the speaking partner just told.

5. In the group, ask learners to talk about their experience. Did the listening partner retell the story correctly? Were they listening well? Ask the listening partners how they felt listening and not being able to talk. Did they feel they listened better when they knew they could not speak?

6. Ask learners to return to their pairs and switch roles. After two minutes ask all the pairs to come back to the group and discuss their experience in the different role. Emphasize that:

It is difficult to listen and think at the same time.

You listen better when you do not interrupt.

You listen better when you pay attention.

It takes practice to be a good listener.

7. Ask the group to think about someone who it is easy for them to talk with. Ask for volunteers to name that person and their relationship. Ask what makes it easy for them to talk with that person. Write the characteristics on the board. Ask the group to think about someone who it is difficult to talk to. Ask for volunteers to name that person and their relationship. Write those characteristics. Ask learners to talk about the importance of good communication in relationships.

\section{Optional Activities}

\section{5-19}

\section{\#1 Group Exercise: Good Communication}

1. Ask the learners to form pairs. Give them these instructions:

One person is Person A and one person is Person B

Person A should talk for 2 minutes about some problem or concern they have. For example, a girl could be talking to her friend about a boyfriend who is pressuring her into having sex. Or, a man could be talking to his brother about his desire to stop drinking so much.

Person B should try to communicate interest, understanding and help in any way they wish except that they may not speak.

At the end of 2 minutes, have pairs switch roles and repeat the exercise.

At the end of the second 2 minutes, the pairs should talk freely for another minute about the problems previously discussed.

2. Facilitate a discussion with the following questions:

How did it feel to talk for two minutes without being interrupted? (Shy, uncomfortable) How did it feel to not be allowed to speak? (Frustrating, wanting to interrupt)

Did you feel that your partner understood you? How did you know? (Expression, body movement, eye contact)

Did anyone feel helped by the listener? (Yes, by nods and smiles. No, wanted verbal acknowledgement)

Why is silence so uncomfortable? (We need feedback)

What specific body behaviours communicate understanding and support? (Eye contact, leaning forward) 

act it out for the group. Away from the other learners review the role-play with the volunteers. Ask the pair to act out the situation using the information they just learned in the session. Encourage them to be creative and encourage girls to act in male roles or boys to act in female roles. Give learners a couple of minutes to prepare for the role-play.

\section{Role-play scenarios}

1: A young couple that has been dating for some time and has decided to have sex for the first time and the young woman is asking the man to use a condom.

2: A boy is approaching his girlfriend to ask her to begin using a form of contraception.

3: A young woman has just been diagnosed and treated for an STI. She is telling her partner and asking him to go for treatment as well.

4: An adolescent boy is visiting a health clinic and is asking to be tested and treated for an STI.

5: A mother is worried that her 15 -year-old daughter is having sex and wants to talk with her.

2. Ask the group the following discussion questions, after each role-play:

What happened? What did you hear the two characters say?

Does this happen here in our community (school, home)?

What problems does it cause?

What should we do when this happens? What should we do to avoid these problems or this situation? What else could she/he have said to give more information?

3. Ask another two learners to volunteer and do the same role-play only this time have them go into more detail and improve on the first role-play based on the answers that were asked during this discussion. Ask for volunteers to act out the other scenarios. Facilitate discussions using the questions above.

\section{\#3 Role-Play: Foundation for a successful relationship}

1. Explain that communicating well is a skill that takes time and practice to develop. Good relationships depend on both people being able to express their feelings, their preferences, their dreams and ambitions, and their fears. Ask for two volunteers to act out one of the role-plays below. Select one (or more) of the following role-plays, according to which seems most appropriate for your audience:

2. When they are finished, ask other learners to comment on the conversation between the boy and girl, and how they think it could be improved. Afterwards, ask the group to brainstorm tips and effective strategies for bringing up a sensitive topic with a boyfriend or girlfriend.

\section{Role-play scenarios}

1. Asha, 18, and Hassan, 20 have been in a sexual relationship for two years and are quite serious. Hassan is in his last year of college where he is studying mechanics. Asha is about to finish her secondary education and wants to go for further studies. Hassan wants to get married and to start a family immediately.

2. Rose, 14, and Solomon, 16, have been dating for four months and Solomon wants to start having sexual intercourse. Rose likes him a lot, but does not want to have sex until she is married.

3. Mary, 16, and John, 17, have been dating for a year and a half. They are very serious about each other and have decided that they want to start having sexual intercourse. John really thinks they should use condoms, but Mary thinks that only people who sleep with prostitutes need to use condoms. 


\section{Session 7 Healthy Relationships}

\section{Learning Objectives}

By the end of this session, learners will be able to:

Identify four qualities that contribute to a fulfilling relationship

Name four qualities that contribute to a breakdown of relationships

\section{Time 60 minutes}

\section{Background Notes}

Good relationships are based on love, mutual respect and willingness to work at the relationship. In a good relationship, both people are honest with each other. Both people feel safe in the relationship and do not worry that the other will betray their trust. Both people usually find enjoyment and pleasure in the relationship and neither person tries to control the other person or to pressure him or her into doing things. Neither person exploits or takes advantage of the other in any way.

\section{What are Healthy Relationships?}

There are several qualities that make a relationship healthy. The best relationships result from both people contributing all of these qualities:

Respect: To respect another person means to honour them, to hold them in high regard or esteem, and to treat them as if they are worthwhile even if they are different from you.

Responsibility: To be responsible means that others can depend and rely on you, that you do as you said you would, and you are able to distinguish right from wrong. For example, you take responsibility for taking care of your own health and well-being and that of your partner and your family.

Understanding: To be understanding means to be knowledgeable about another person, to try to understand his or her position or feelings, or to listen and support someone. It means trying to 'put yourself in someone else's shoes', in order to understand what life looks like from their point of view.

Cooperation: To work at a relationship means to put effort into the relationship, and not take the other person for granted. It involves willingness to work with someone to be in a relationship and sustain it.

Caring: To be concerned and interested in another person's feelings and needs, and to want what is best for that person. It means feeling love or a liking for a person and wanting to protect that person.

\section{Instructions}

\section{Healthy Relationships (60 minutes)}

1. Ask learners to name different relationships (Possible answers: child/parents, other family relationships, girlfriend/boyfriend, same-sex friendship, married couples, teacher/students, employer/employee, father/mother, etc.)

2. Ask learners to discuss what makes a relationship successful. Write down their responses on the board. (Possible answers: respect, dependability, honesty, caring, understanding, etc.)

3. Divide learners into pairs and assign them each a relationship (mother/child, girl/girl, mother/father, etc.) Ask them to create a role-play that will demonstrate the qualities of the relationship assigned. Have each pair act out their role-play for the whole group, and review:

What are some of the actions and words in the role-plays that illustrated the various elements of respect, understanding, caring, and responsibility?

What other actions or words could be added to this role-play to show this quality? 
4. Facilitate a discussion using the following questions:

Which of the qualities discussed are the most important to you?

How do we put these qualities into our relationships?

How would you feel about a friend who did not respect you? Who did not put much effort into the relationship? What could you do?

How would you feel if a parent or guardian didn't understand you? What would you do to improve the relationship?

5. Ask learners to describe qualities of bad relationships and give examples. Write their responses on the board. Help the learners understand that these are the opposite of what makes a fulfilling relationship: disrespect, lack of understanding, lack of caring, irresponsibility. One example that might be mentioned is gender violence or rape. If it is, tell the learners that this subject will be talked about in more detail later.

\section{Optional Activity}

\section{\#1 Assessing Relationships}

1. Explain that there are several qualities that make a relationship special. Write these five words on a flip chart: respect, responsibility, understanding, cooperation, and caring. Ask for volunteers to define each word. Explain that the best relationships result from both people contributing all of these qualities, though many relationships are far from perfect.

2. Explain to the learners that they will identify behaviours people can use in their relationships to show their respect, responsibility, understanding, work, and caring for one another. Divide them into five groups and go over the following instructions for this activity:

Each group will be assigned one of the five qualities of a good relationship and will be asked to give an example of a relationship that shows that quality - with a parent, friend, or boyfriend/ girlfriend.

Each group should develop two examples of what the young person in each case study could do to demonstrate the assigned quality.

3. Review the following information about the qualities that contribute to a healthy relationship:

Respect: you can show respect for a parent or guardian by obeying the rules they set for you.

Responsibility: you can show your friend responsibility by coming to an agreed upon event on time.

Understanding: you can show understanding for a friend who is having problems at home by being a good listener and spending time together.

Cooperation: you can show cooperation by being tolerant, communicating honestly, and creating trust in a romantic relationship.

Caring: you can show caring by helping a family member who is sick, taking them to the clinic or helping them in the shamba.

4. After 10 minutes, ask each group to present their results and share them with the larger group.

5. Facilitate a discussion with the following questions:

What is the most important quality in your relationship with a parent or another trusted adult? What about a relationship with a friend? Romantic partner? Why?

What can we do to be sure we have the five qualities and practice them in our relationships? (Answers: by observing and imitating others in their relationships with us, by listening to what others say about their good and bad relationships, by reading books and magazines that describe relationships and how to communicate better in a relationship).

Can you give me examples of good and bad relationships? Describe why it is good or bad. 


\section{Session 8 Friendship}

\section{Learning Objectives}

By the end of this session, learners will be able to:

Identify qualities of a good friend

Assess whether they are a good friend

Recognize different kinds of friendships

List at least three ways to maintain a friendship

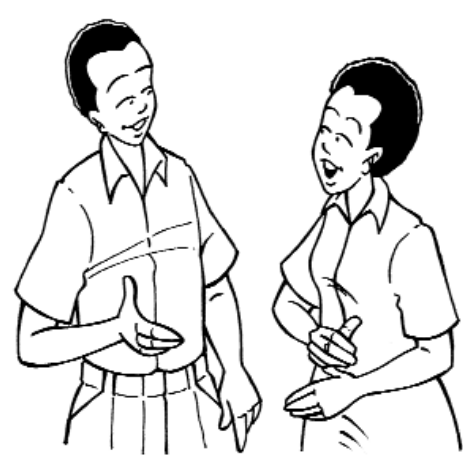

\section{Time 40 minutes}

\section{Background Notes}

As young people try to understand the changes they experience in adolescence they often become more and more attached to their friends who are going through the same changes. They seek acceptance and respect from these friends. During this time it is important to feel like they belong to a group They often do things for the sake of pleasing friends and will follow most of what peers tell them, wanting to feel like part of their peer group. At the same time, many adolescents find it difficult to completely ignore adults since they live with their parents and still want to please them.

Adolescents' behaviour can be strongly influenced by their peers. If friends smoke, drink alcohol or make other unhealthy choices, in all likelihood they will do the same to be accepted by the group. But peers can also be helpful during adolescence. They help make the transition from a family orientation to a peer or society orientation. They also provide opportunities for adult-like relationships. They form a reference group for judging behaviour and help adolescents clarify personal identities. Adolescents should choose friends and relationships that are going to develop their personality positively.

\section{Friendships}

Friendship can provide a source of support beyond what family or peer groups can offer. Adolescents may spend time with just one friend or a small group of friends. These friends can be quite important. They can help young people share ideas, thoughts and experiences without fear or betrayal. They may share experiences about bodily changes, which helps them feel normal. In such friendly groupings, adolescents can explore and discover themselves as people; which is part of the search for identity. Adolescents tend to select friends with characteristics similar to their own as a way of confirming their own opinions and sense of self worth.

\section{Instructions}

\section{Friendship Circles (40 minutes)}

1. Ask learners to describe what a friend is. (Answers may include: a person who you have a good relationship with, not a relative, share something in common). Have the group list the characteristics of a good friend and discuss. Explain that during adolescence not only do their bodies change, but so do their understanding of themselves and their friendships.

2. Explain that not all friends are "best friends" or even very close friends. In fact, friends can range from very close to not-so-close. Ask learners if they can think of examples of different kinds of friends they have in their lives.

3. Display the large illustration of circles of friends (Handout 8.1). Explain that this represents circles of friendships, with closest friends in the circle closest to the centre, casual friends in the next circle and acquaintances (or people they know) in the outside circle. 
4. Ask learners to copy the circles into their own notebooks and make their own friendship circles. Read the following directions out loud to the group:

Write your name in the centre circle.

Write name(s) of your closest friend or friends in the innermost circle.

Write the names of casual friends - friends you know well enough to talk to, but not as well as your closest friends - in the middle circle.

Write the names of acquaintances - people you speak to sometimes, but do not consider your friends - in the outer circle.

Allow learners a few minutes to complete their circles.

5. Facilitate a discussion with the following questions:

Some people have many best friends while others have one special friend; some have more casual friends and others have more acquaintances. What did you learn about your own friendships from this activity?

How did you decide who is in your inner circle? The middle circle? The outer circle?

What are the ages of your closest friends? Casual friends? Acquaintances? Why do people choose friends of different ages? Are there advantages of having an older teen or an adult as a friend? Disadvantages?

In which circles did you place friends of the same sex? Opposite sex? Why?

Where did you place your friends of another religion? Why?

What are two things that you would talk about with close friends but not with casual friends or acquaintances? Why?

Would you like to make changes in your friendship circles? Which ones?

What things could you do to get to know an acquaintance or casual friend better?

6 . Write the following on the board:

If you want to keep a friend, it helps to...

Ask the learners to complete the sentence, either in their notebooks or aloud. Let several learners share what they wrote.

7. Facilitate a discussion to summarize these points:

Everyone values different things in friendships.

Each of us is valuable as a friend for one reason or another.

As we grow up what we look for in a friend changes.

There are many ways to maintain friendships but friendships.

Friendships should not be taken for granted. 


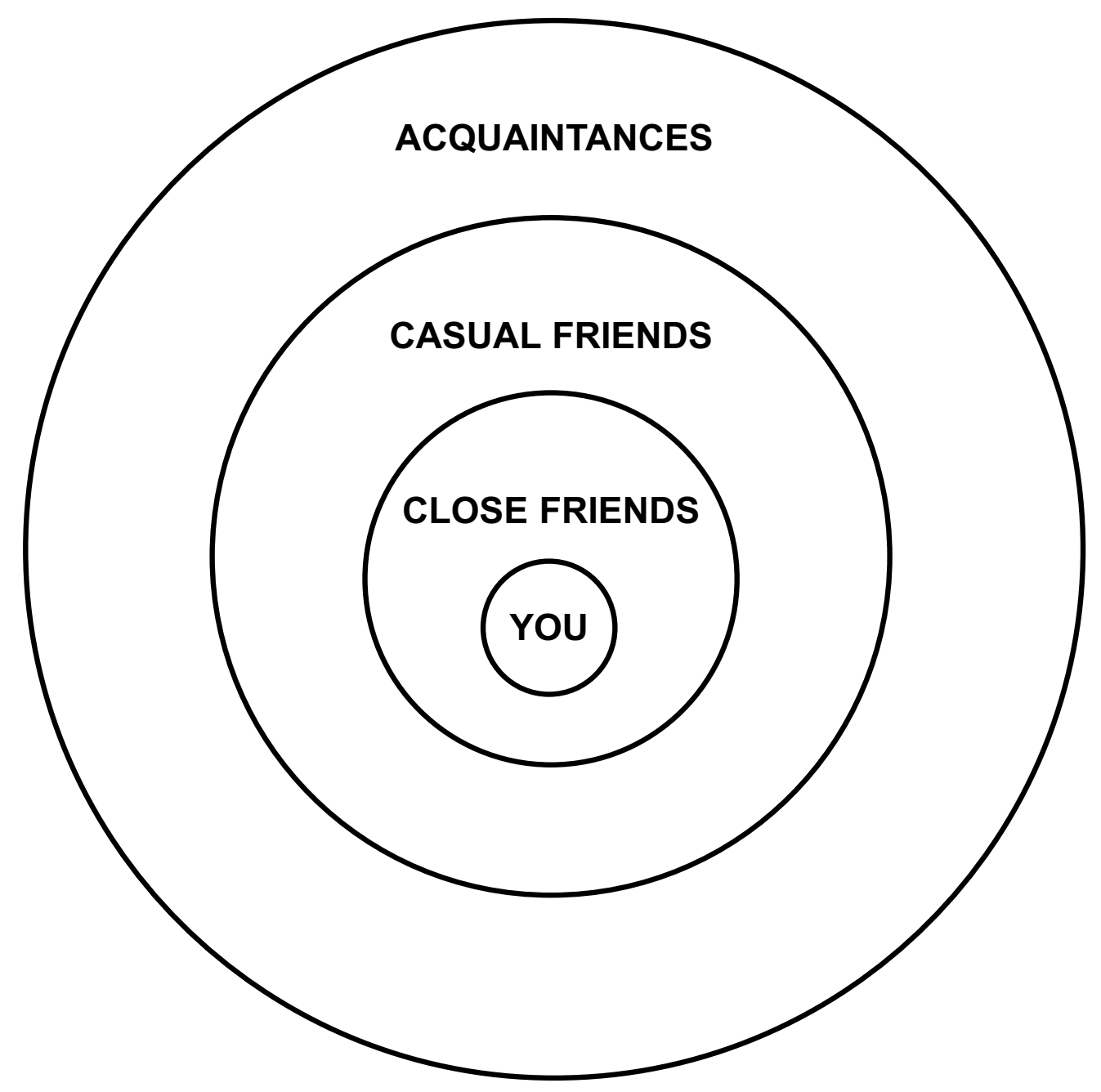




\section{Session 9 Romantic Relationships}

\section{Learning Objectives}

By the end of the session, learners will be able to:

List qualities of healthy romantic relationships

Identify three skills needed to overcome challenges in romantic relationships

Time 45 minutes

\section{Background Notes}

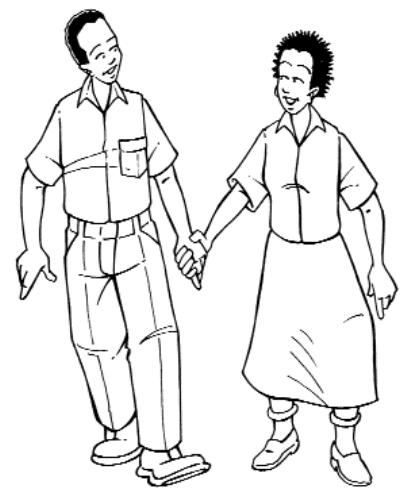

As young people move through puberty and adolescence, many begin to have boyfriends or girlfriends. Having a boyfriend or girlfriend can involve going places or spending time with someone in order to get to know him or her better or having feelings for each other and wanting to be more than just friends. This can be fun and exciting, but it can also create problems. For instance, young people may want to date before their parents think they are old enough or they may not feel ready to date but their parents or peers push them into it. Sometimes group activities are more comfortable and safer than individual or private dates.

\section{Instructions}

\section{Qualities in an Ideal Mate (15 minutes)}

1. Ask learners to explain what having a boyfriend or girlfriend means.

2. Divide learners into two groups: one boy group and one girl group. Explain to learners that there are qualities we each look for in a partner or relationship. Ask each group to brainstorm the qualities that are important in choosing an ideal mate or partner and write them down. These qualities should include emotional, physical and personality characteristics. Once they have finished brainstorming, ask them to select ten qualities, which they agree are most important and why these qualities are important. Ask them to pick the three most important qualities.

3. Bring everyone together and ask them to share their lists. Ask the following questions:

How similar were the lists?

What kinds of qualities were similar on the lists?

Were there differences between the sexes in the order in which they ranked certain qualities?

How do you find the qualities you are looking for in your ideal person?

\section{Challenges in Romantic Relationships (15 minutes)}

1. Ask learners to discuss their opinions on the following (one issue at a time). Explain that every opinion is to be respected.

At what age do girls and boys start having relationships? What kinds of relationships?

Why do people get involved in relationships? What are some of the good qualities of being in a relationship? (learning to relate to members of the opposite sex outside of family members)

What are some of the negative consequences of boy/girl relationships? (unplanned pregnancies.)

2. Write down their responses in a chart similar to the one that follows. Add additional challenges and possible consequences that they do not mention. 


\section{Challenges}

Communicating different ideas

Lack of negotiation skills

Lack of decision-making skills

Differences in expectations

Differences in self-esteem

\section{Possible Consequences}

Disappointment, pregnancy, date rape

Unwanted sex, unprotected sex (possible STI, HIV infection, pregnancy), guilt

Negative peer influence, stuck in abusive or undesirable relationships, make rash decisions

Disappointment, selfishness, frustration

Dominant/submissive relationships lead to low self-esteem

3. Ensure that the following are discussed:

Different expectations (girls may think of having a boyfriend, boys may think of "sex").

Differences in self-esteem (boys may tend to dominate the relationships).

Differences in societal expectations of sexual behaviour for girls and boys (as expressed by their parents and other adults): "good" girls don't have sex before marriage, but it is acceptable for boys to experiment.

Prejudice (religion, tribes, family background) can create family conflicts.

Because of socialization, boys and girls do not have the same ideas and expectations. For example, when a girl says "no" the boy may interpret it as "yes."

\section{Skills to Overcome Challenges (15 minutes)}

1. Ask learners to discuss what boys and girls can do to make their relationships more fulfilling. Examples include:

Respect their partner

Express feelings and expectations using good communication skills

Make decisions together based on values and goals

Resolve conflicts immediately

Uphold each other's self-esteem

Be assertive

Make sure each person feels valued in the relationship

2. Explain that these life skills are important not just in boy-girl relationships, but also throughout their lives. They may have already learned about some of these life skills in previous sessions and there will have a chance to learn about more. Remind participants of the following:

We will not find all the behaviours or qualities that we expect or like in one person.

We should get to know people well enough to know what qualities they bring to the relationship.

No one is perfect. Everyone has weaknesses and makes mistakes at some time.

We should not judge others, but learn to accept people for who they are, while at the same time respecting our serves and knowing our limits. 


\section{Session 10 Love and Infatuation}

\section{Learning Objectives}

By the end of the session, learners will be able to:

Differentiate between love and infatuation

Identify the qualities of love

Explain the importance of communication in relationships

\section{Time 50 minutes}

\section{Background Notes}

\section{What is Love?}

Love is a complex emotion, and every person may define love differently based on his or her own experience with loving relationships. Generally, love refers to a deep feeling of fondness, attraction, respect, caring and understanding for another person, despite their weaknesses or faults. It is important to remember that sexual intercourse is not the only way of showing love to someone. Also, having sex does not mean that two people will fall in love. Remember, love is about respect and caring for each other. Love is never a good reason to do anything that puts your health and future at risk.

Love is a word that is used loosely in conversation but rarely discussed. Young people often mistake infatuation for love. They feel very strong attraction and feelings toward another person and the intensity of the emotion leads them to believe it must be love. This can get them into trouble, because infatuation is usually short lived and fades as quickly as it begins.

\section{Relationships and Sex}

Good friendships and relationships help people feel good about themselves. Good friends help with problems, introduce new ideas and share dreams for the future. Good friends can be people of the same sex or people of the opposite sex. Boys and girls, men and women, can be good friends without having a sexual relationship. The words "boyfriend" or "girlfriend" do not necessarily mean that the relationship is a sexual one. Any two people can have a close and loving relationship without sex.

Getting along with the opposite sex can be hard because many men and women are not sure what the other wants in a relationship. Remember, most people want the same thing in a relationship. They want respect, trust, honesty, understanding and caring.

Building a good relationship takes time and patience. Sex is not a way to build a close relationship. In fact, sex can ruin a relationship. Having sex does not necessarily mean that two people love each other or that they are close. Sex without true friendship is dangerous for a person's health and heart.

Two people can share time together and become very close without having sex. By talking and sharing experiences, they can learn important things about each other. They can learn how each views life, how they would make decisions together, what kind of partner and parent each person would make, and how each feels about the other's plans for his or her life. Touching each other (without sexual intercourse) can be satisfying by itself and is not dangerous as long as it does not lead a person to lose control or sex before he or she is ready.

It can take a long time to develop a good relationship, but one of the most important things in a relationship is good communication. In order to understand and care for each other, people need to be able to talk with each other and make their feelings understood. By talking to each other and being honest about their feelings, two people might discover that neither one really feels ready to have a sexual relationship. They might find that both of them want to wait until they are sure it is the right time. 


\section{Instructions}

\section{Love and Infatuation (30 minutes)}

1. Ask for a volunteer to define the word love and another to define infatuation. Divide the group into two teams and tell them they are going to play a game called What's the difference?

2. Divide learners into two teams. One team is love and one team is infatuation. Explain that you will read a statement and if they think it is about love, the love team should raise their hand; if they think it is about infatuation, then the infatuation team should raise their hand.

It comes gradually between two people. They grow into it after many experiences together. [love]

Others often do not understand their relationship. [infatuation]

One person uses the other for personal pleasure, security or other personal gain. [infatuation]

It involves the entire personality. [love]

Each person respects the mind and body of the other. [love]

It focuses on the present and feels like it cannot wait. [infatuation]

It is insecure, distrustful, jealous and fearful. [infatuation]

It is based on knowing and understanding each other. [love]

There is a focus on physical contact and feeling good. [infatuation]

It thinks of the other person, wants to protect him/her and does things to make him/her happy. [love]

It is trustful, calm, secure, hopeful and self-confident. [love]

It happens suddenly after two people meet. They think they are "in love." [infatuation]

It is mostly based on attraction. [infatuation]

People are often embarrassed about the relationship or secretive with parents and others. [infatuation]

It is patient and says, "We want to be together forever! We can wait! Nothing can happen to our love for each other." [love]

Its physical expression has tender meaning and comes slowly, naturally and sincerely. [love]

It causes one to be proud of the other person and wants to introduce him/her to others, including parents and other adults. [love]

It makes the other person happy and makes him or her a better person. [love]

3. Facilitate a discussion with the following questions:

What new things did you learn about infatuation? Love?

How can you help people understand the differences between love and infatuation?

Do you have to like someone in order to love them? How do you know if you like someone?

\section{Understanding Love (10 minutes)}

1. Divide learners into small groups. Ask them to discuss the following questions:

Is love the same for men and women?

Do women have a greater capacity for love than men do? Why?

Do you believe in love at first sight? Why?

In what ways is love important to all of us?

Is hate the opposite of love? If not, what is? 
2. Explain how you develop a loving relationship.

Can you love more than one person at a time?

Is jealousy always a part of love?

Are loving and being in love the same thing?

How do you know when you love someone?

How do you know when you are loved?

3. Bring learners back together to talk about some of the points discussed in their groups.

\section{Qualities of Love (10 minutes)}

1. Divide learners into four groups. Assign each group one of the following:

Parent/child love

Brother/sister love

Close friends love

Romantic love

2. Ask each group to describe at least three qualities they would show and three qualities they would expect from their assigned relationship. (For example, if they are assigned the part of a parent/child relationship, what qualities would they expect from their parents, which qualities would they show their parents to express love.)

3. Allow each group to share their responses. Discuss any differences and similarities in qualities.

\section{Optional Activity}

\#1 Sexual Decision-making (60 minutes)

1. Explain that one of the most difficult decisions young people have to make is whether to have sexual intercourse before they marry. The failure to make a decision about sex that is right for themselves is one reason so many adolescents have unplanned pregnancies and become infected with sexually transmitted infections, including HIV. Explain that young people have a right to understand how the body responds when sexually aroused, that feelings of sexual arousal are natural and that just because one feels aroused, it is not necessary for him or her to act upon those feelings. If a young person does decide to act on his or her feelings, they must be aware of the consequences of their decision.

2. Divide the learners into two groups. Ask one group to brainstorm all the reasons and arguments why a young person would say no to sex now. Ask the other group to brainstorm all the reasons and arguments why a young person would say yes to sex now. Ask them to put their reasons on the board. Allow about 15 minutes.

3. Ask each group to share their lists. Make sure the following points come out. 


\section{Reasons Young People Say No to Sex}

To follow personal, family, religious or cultural beliefs and values

To keep a romantic relationship from changing

To avoid unplanned pregnancy and infection with STIs, including HIV

To avoid hurting parents and feeling guilty

To avoid hurting your reputation

To reach future education and career goals

To find the right partner

To wait for marriage

\section{Reasons Young People Say Yes to Sex}

To stop pressure from friends or partners

To show loving feelings in a relationship

To avoid loneliness and get affection

To get or receive presents or gifts

To feel independent

To hold keep a boyfriend or girlfriend

To prove one is an adult

To become a parent

To satisfy curiosity

4. Ask them if they agree that some of the reasons (on both sides) seem better or stronger than other reasons. Have them rank the reasons using a mark from 1 to 3 (1: a reason, but not a very good one, 2: a fairly good reason and 3: an extremely good reason). Let them talk among themselves. Tell them to make sure they are ranking the items to how they personally feel about the reason not how others in the community might feel. Ask which reasons they ranked a three and why. Also ask, which reasons they ranked a one and why.

5. Facilitate a discussion using the following questions:

What influences the decision about whether or not to have sex before marriage? (Possible answers: sexual feelings, partner's desires, media messages, pressure, parent teachings, religious beliefs, drug use).

Can someone who decided to wait change his or her mind? Can someone who has had sex decide to abstain?

What is the worst thing that can happen to a young person who decides to abstain? One who decides not to abstain?

What does a young person need to know or be prepared to do if she or he is going to say no to sexual intercourse? (Possible answers include: feeling good about themselves, being assertive, communicating clearly, following through with a decision, resisting peer and partner pressure or their future goals).

What does a young person need to know if she or he is going to say yes to sexual intercourse? (possible answers include: risks of pregnancy and STIs, including HIV; how to talk with a partner about using condoms and contraception; which forms of contraception prevent pregnancy and/or infection most effectively; where to get condoms and other contraceptives; how to communicate with a partner; how to feel good about themselves; how to say no; how to be assertive.) 


\section{Session 11 Managing Stress, Anger, and Conflict}

\section{Learning Objectives}

By the end of this session, learners will be able to:

Describe ways to manage stress and anger

Use "I" statements to express their feelings

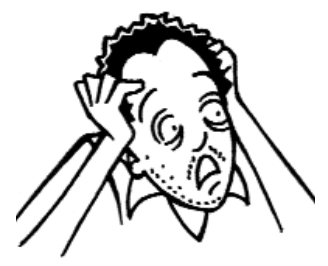

Distinguish between appropriate and inappropriate responses to anger

Successfully deal with situations that cause stress, anger and/or conflict

Time 80 minutes

\section{Background Notes}

\section{Managing Stress}

Stress occurs on a daily basis and can be healthy. At times stress can be overwhelming and adolescents may have trouble dealing with it. Adolescents are faced with a number of issues and make many major decisions, such as the decision to have sexual intercourse, the kind of career they want, what they want to do in the future or the attempt to develop a unique identity, which contribute to their burden of stress.

Too much stress can seriously affect your physical and mental well-being. Overtime, repeated stress can lower self-esteem, decrease academic performance and create a cycle of self-blame and selfdoubt. Stress is unique and personal to each of us. What is relaxing to one person may be stressful to another. The key to reducing stress is to find strategies that help you as an individual.

The best way to cope with unhealthy stress is to recognize when your stress levels are building. While we often think of stress as the result of external events, the events themselves are not necessarily stressful. It is the way we react to an event that causes stress. Stress signals fall into four categories: thoughts, feelings, behavior and physical symptoms. When you are under stress you may experience the following feelings, thoughts, behaviours or physical symptoms:

\begin{tabular}{|c|c|c|c|}
\hline $\begin{array}{l}\quad \text { Feelings } \\
\text { Anxiety } \\
\text { Irritability } \\
\text { Fear } \\
\text { Moodiness } \\
\text { Embarrassment }\end{array}$ & $\begin{array}{l}\quad \text { Thoughts } \\
\text { Self-criticism } \\
\text { Difficulty concentrating } \\
\text { or making decisions } \\
\text { Forgetfulness or mental } \\
\text { disorganization } \\
\text { Preoccupation with the } \\
\text { future } \\
\text { Repetitive thoughts } \\
\text { Fear of failure }\end{array}$ & $\begin{array}{l}\quad \text { Behaviours } \\
\text { Stuttering } \\
\text { Difficulty speaking } \\
\text { Crying } \\
\text { Acting impulsively } \\
\text { Nervous laughter } \\
\text { Yelling at friends and } \\
\text { family } \\
\text { Grinding teeth } \\
\text { Jaw clenching } \\
\text { Increased smoking, } \\
\text { alcohol or drug use } \\
\text { Accident prone } \\
\text { Increased or decreased } \\
\text { appetite }\end{array}$ & $\begin{array}{l}\text { Physical Symptoms } \\
\text { Tight muscles } \\
\text { Cold or sweaty hands } \\
\text { Headaches } \\
\text { Back or neck problems } \\
\text { Sleep disturbances } \\
\text { Stomach aches } \\
\text { More colds and } \\
\text { infections } \\
\text { Fatigue } \\
\text { Rapid breathing } \\
\text { Pounding heart } \\
\text { Shaking hands } \\
\text { Dry mouth }\end{array}$ \\
\hline
\end{tabular}




\section{Tips for Stress Management}

There are many ways to manage unhealthy stress. Everyone needs to find ways that work best for them.

1. Take a Deep Breath. Stress often causes us to breathe shallowly and this almost always causes more stress! Try taking a minute to slow down and breathe slowly. Breathe in through your nose and count as you breathe out through your mouth. Inhale enough so your lower abdomen rises and falls.

2. Talk It Out. When you feel stressed, try to express your feelings. Keeping feelings inside can increase stress. Share your feelings. Perhaps a friend, family member, teacher or church leader can help you see your problem in a new way. Talking with someone else can help clear your mind of confusion so that you can focus on problem solving. Even if it is slightly embarrassing, asking for help soon after a problem occurs may avoid serious problems later. Writing down thoughts and feelings can help clarify the situation and give a new perspective.

3. Take a "Minute" Holiday. Create a quiet place in your mind. You cannot always run away, but you can dream. Imagining a quiet place can take you out of a stressful situation. When you have the chance, take a moment to close your eyes and imagine a place where you feel relaxed and comfortable. Notice all the details of your chosen place, including pleasant sounds, smells and temperature.

4. Pay Attention to Physical Comfort. Be as physically comfortable as the situation will allow. Wear comfortable clothing. If it's too hot, go somewhere where it's not. If your chair is uncomfortable, move. Do not wait until your discomfort turns into a real problem.

5. Move! Physical activity can help reduce and prevent stress. Being a student involves a lot of sitting, and sitting around can mean letting stress build up in your body. When you feel nervous, angry or upset, release the pressure through exercise or physical activity. Try to find something you enjoy and make regular time for it. Running, walking or dancing can be done anywhere. Working in the garden, cleaning or playing with younger children can relieve stress, relax you and energize you!

6. Take Care of Your Body. Healthy eating and adequate sleep fuels your mind as well as your body. Avoid eating too much caffeine and sugar. Well-nourished bodies are better able to cope with stress.

7. Laugh. Maintain your sense of humor, including the ability to laugh at yourself. Share jokes and funny stories with your friends. Laughter is good for you!

8. Manage Your Time. Plan ahead and make a realistic schedule for yourself and include time for stress reduction as a regular part of your schedule. Trying to take care of everything at once can seem overwhelming and may keep you from accomplishing anything. Instead, make a list of what you have to do, then do one at a time, checking them off as you finish. Do the most important ones first. If a particularly unpleasant task faces you, do it early in the day and get it over with; the rest of your day will be less stressful. Too much studying is actually inefficient and can lead to burnout. Recognize when you are most stressed and allow yourself some reasonable breaks. When things feel especially difficult, take a walk or otherwise change your scenery.

9. Know Your Limits. When in a stressful situation, ask yourself: is this my problem? If it isn't, leave it alone. If it is, can you resolve it now? Once the problem is settled, leave it alone. Do not agonize over the decision, and try to accept situations you cannot change. There are many circumstances in life beyond your control. If a problem is beyond your control and cannot be changed at the moment, learn to accept what is, for now, until such time when you can change things.

10. Must You Always Be Right? Do you get upset when things don't go your way? Consider cooperation or compromise rather than confrontation. It may reduce the strain and help everyone feel more comfortable.

11. Have a Good Cry. It is normal for people of all ages to cry. A good cry during stressful times can be a healthy way to bring relief to your stress, and may prevent a headache or other physical consequences of stress. However, crying daily can be a sign of depression.

12. Look for the Good Things Around You. It is easy to see only the negative when you are stressed. Your thoughts can become like a pair of very dark glasses, allowing little light or joy into your life. Decide to notice five good things around you. These can be positive or enjoyable moments or interactions. These may seem like small events but as these good things add up they can often provide a big lift to energy and spirits and help you begin to see things in a new, more balanced way. 


\section{Affects of Anger and Conflict}

Unresolved anger or conflict can cause people to feel indifference, resentment or rage. It can lead to physical or verbal violence, withdrawal, depression, mean gossip or even addiction or other selfdestructive behaviour. When anger and conflict are unresolved, relationships can be damaged and youth can suffer social consequences such as rejection, teasing or humiliation. It is important to be able to manage anger and conflict effectively.

\section{Managing Anger}

Anger is a completely normal, usually healthy, human emotion. But when it gets out of control and turns destructive, it can lead to problems. Anger is an emotion that ranges from mild irritation to intense rage. Like other emotions, it causes physical changes. When you get angry, your heart rate, blood pressure and energy hormone levels go up. Anger can be caused by both external and internal events. You could be angry at a specific person or event or your anger could be caused by worrying about personal problems. Memories of traumatic events can also cause you to feel angry.

Anger is a natural, adaptive response to threats and inspires powerful, often aggressive, feelings and behaviours, which allow us to defend ourselves when attacked. A certain amount of anger is necessary for survival. We cannot, however, physically attack every person or object that irritates or annoys us; laws, social norms and common sense place limits on how far our anger can take us.

People use a variety of both conscious and unconscious processes to deal with their angry feelings. The three main approaches are expressing, suppressing and calming.

1) Expressing your angry feelings in an assertive-not aggressive-manner is the healthiest way to express anger. To do this, you have to learn how to make clear what your needs are, and how to get them met, without hurting others. Being assertive doesn't mean being pushy or demanding; it means being respectful of yourself and others.

2) Anger can be held in by not thinking about it or focusing on something positive. The purpose is to convert your anger into more constructive behaviour. If anger is not allowed out it can cause physical and emotional harm. Anger turned inward may cause hypertension, high blood pressure or depression. Or people can become hostile and critical which can negatively affect their relationships with others.

3) You can calm down inside by controlling your behaviour and your internal responses. Try to take steps to lower your heart rate, calm yourself down and let the anger go away.

The goal of anger management is to reduce both your emotional feelings and the physical responses that anger causes. You cannot get rid of, or avoid, the things or the people that make you angry, nor can you change them, but you can learn to control your reactions.

Psychologists now say that it is dangerous to express all of your angry feelings because it can actually make you angrier and does not help resolve the situation. It is best to find out what makes you angry, and then develop ways to keep those things from making you angry.

Sometimes, our anger and frustration are caused by very real, unavoidable problems in our lives. Not all anger is wrong, and often it is a healthy, natural response to difficult times. Not all problems have a solution. In these situations, try not to focus on finding the solution, but on how you handle the problem.

Make a plan, and check your progress along the way. Try your best, but do not punish yourself if an answer does not come right away. If you can approach the problem with your best intentions and efforts and make a serious attempt to face it, you will be less likely to lose patience and become angry, even if the problem does not get solved right away. 


\section{Anger Management Tips}

Ask yourself if this will matter in ten years. You may see things from a calmer perspective.

Acknowledge that it is frustrating, and it's understandable that you would be upset about it. At the same time it is not the end of the world and getting angry is not going to fix anything. .

Think about whether you have you ever done the same thing to someone else, even if by accident. Did you get angry at yourself? Ask yourself if the person did it on purpose. In many cases, you will see that they were just careless or in a rush, and really did not mean you any harm.

Remind yourself that getting angry is not going to fix anything and will not make you feel better (and may actually make you feel worse).

Try counting to ten before saying anything. This may not address the anger directly, but it can minimize the damage you will do while angry. Or try counting to ten with a deep slow breathe in between each number. Deep breathing helps people relax.

Imagine a relaxing experience. Close your eyes, and travel there in your mind.

Non-strenuous physical activities, like walking, can relax your muscles and help you feel calmer. Give yourself time and space alone. Physically move away from situations that make you angry.

\section{Resolving Conflict}

Conflict is natural and happens in almost every relationship. Since conflict is unavoidable we must learn to manage it. Conflict is a sign of a need for change and an opportunity for growth, new understanding and improved communication. Conflict can not be resolved unless it is addressed with the person or people involved. We face conflicts with people who think and act differently than we do or in ways that are different from our values and beliefs. Young people face conflicts with friends, siblings, parents, teachers and other adults. It is normal for people to disagree, but it is important to resolve these disagreements in a constructive and healthy way.

Respond; don't react. If you keep your emotions under control you have a better chance of hearing what the other person is trying to say.

Listen carefully without interrupting. Ask questions and wait for and listen to answers. Even if you "know" what the other person is going to say, resist the temptation to interrupt.

Acknowledge the other person's thoughts and feelings. You do not have to agree with the other person to acknowledge his or her feelings and why he or she may feel that way.

Give respect to get respect. Separate the people from the problem. Treat people the way you would like to be treated if you were in the same situation.

Communicate clearly and respectfully so your viewpoint can be understood. If you do not, you may not persuade anyone that your ideas are worth listening to.

Identify points of agreement and points of disagreement. Agree wherever you can. Your underlying interests may be more alike than you imagine.

Be open to change. Open your mind before you open your mouth. Remember the rule: one mouth and two ears and use in that ratio.

Look forward, not backward. Stay in the present and plan for the future, do not think about the past. Move to resolving the situation and away from justifying your position.

Stay focused on the topic at hand. If there are a number of issues, talk about them one at a time. Work together. This requires that each person stop placing blame and take ownership of the problem. Make a commitment to work together and listen to each other to solve the conflict.

Aim for mutual satisfaction, not victory. Conflicts don't have to end with a winner and a loser. Try to find a solution that is acceptable to both parties.

Be creative. Finding a resolution to the problem that satisfies everyone requires creativity and hard work. Be careful not to give in simply to avoid conflict or maintain harmony. Agreements reached too early usually do not last.

Be specific. Write things down and clarify unclear words that may be understood differently. 
An "I" statement is a useful way to share your opinion or perspective without placing blame on someone else. For example, instead of saying, "You made me feel angry" you can say, "I feel angry." Using an " $\mathrm{I}$ " statement is a constructive way to convey your message without making any demands. "I" statements should be clear, concise and free of judgment.

Steps to Resolve Conflict or Deal with Anger
Express your opinion calmly.
Allow others to express their opinions.
Listen while others speak and try to understand their views
Work with others to find a solution to the problem.
Use "I" statements.
Ask a respected adult to help if you are unable to reach agreement.
Leave the situation if you are unable to control your anger.

\section{Instructions}

\section{Managing Stress (30 minutes)}

1. Ask learners to explain what they understand by the word 'stress.' Once they have agreed on a definition, ask them to share times when they felt under stress.

2. Divide learners into groups of four or five and ask them to discuss techniques that can be used to help manage stress.

3. After 10 minutes, ask learners to return to the large group and have a representative from each group share the stress management techniques they listed. After each group has presented, mention any techniques that learners did not list.

\section{Dealing with Anger (20 minutes)}

1. Ask learners to brainstorm inappropriate expressions of anger (yelling, hitting, humiliating someone, name-calling, damaging property, throwing things or refusing to help someone in need).

2. Then, ask them to brainstorm appropriate expressions of anger (calmly expressing an opinion, leaving the situation or counting to ten before reacting).

3. Ask learners to name ways to manage anger. Review the anger management tips above.

\section{Resolving Conflict (30 minutes)}

1. Ask participants what is meant by "conflict." Write down their responses on the board. Make sure that participants discuss that conflict occurs when two sides have opposing views, perspectives or opinions about a particular issue or set of issues.

2. Ask participants to name issues that might cause conflict among adolescents. What about between adolescents and adults? Is conflict always bad?

3. Ask participants to suggest "I" statements that can help adolescents cope with or avoid a conflict. Some answers include:

"That upsets me and I would like to talk with you about it."

"It hurts my feelings when..."

"It makes me upset when..."

“I think we should talk about this situation. Tell me how you feel about..." 
5. Divide participants into groups of four or five. Ask them to create a role-play that shows how to manage anger or stress or resolve a conflict. Assign the groups one of the following scenarios or ask each group to develop their own:

Daniel is upset because his mother told him he was not allowed to go to a football game with his friends on Saturday afternoon, even though he had already made plans with his friends. What should Daniel say to his mother? (anger management and conflict resolution)

Alice has a big exam at school on Friday. On Thursday afternoon, she realizes that she is not well prepared for the exam and is worried that she will not pass. What should Alice do? (stress management)

Robert notices that his friend Joseph is playing with the same ball that was stolen from him last week. Joseph tells him that another friend let him play with the ball. How should Robert talk to Joseph? (anger management and conflict resolution)

Margaret stopped seeing her boyfriend George. Now he is telling other boys at school that they had sex, even though it is not true. What should Margaret say to George? (anger management and conflict resolution). 


\section{Session 12 Introduction to Gender}

\section{Learning Objectives}

By the end of the session, learners will be able to:

Define gender

Distinguish between sex roles and gender roles

\section{Materials Required}

One long rope
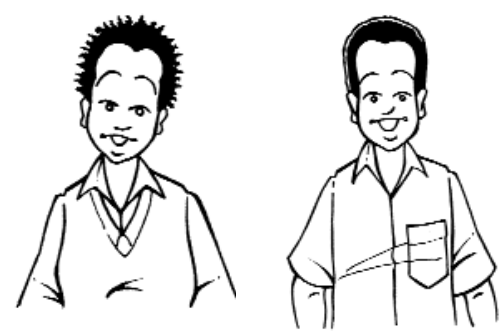

Time 105 minutes

\section{Background Notes}

\section{Gender}

Each person is born with either a girl's body or a boy's body. These physical differences determine a person's sex. Sex is the physical characteristics that identify a person as a male or a female:

Type of genital organs (penis, testicles, vagina, womb)

Type of predominant hormones circulating in the body

Ability to produce sperm or eggs

Ability to give birth and breastfeed children

Gender describes the ideas and expectations people have about men and women. These include ideas about what qualities and abilities are considered feminine and masculine and expectations about how men and women should behave in different situations. A person's gender is complicated, and is made up of roles, duties, appearance, speech, movement, and more. Ideas about gender are learned from family, friends, teachers, religious leaders, advertisements, the media, and opinion leaders.

\section{What are gender roles?}

Gender roles are the kinds of activities that are considered appropriate for individuals based on their sex. A person's gender role refers to the way a community defines what it is to be a female or a male. Each community expects women and men to think, feel and act in a certain way, simply because they are women or men. In most communities, for example, women are expected to fetch water and fuel, prepare food and care for their children and husband. Men are often expected to work outside the home to provide for their families and parents in old age and to defend their families from harm.

Unlike the physical differences between men and women, communities create gender roles, and the ideas and expectations associated with them. These roles are different depending on a community's traditions, laws, and religions.

\section{How gender roles are learned}

Gender roles are passed down from parents to children, as well as learned from other family members and community members. From the time we are very young, parents treat girls and boys differently - sometimes without even realizing they do so. As children grow up, they accept these roles because they want to please their parents and because parents have more authority. These roles help children know who they are and what is expected of them. So in the same way that children learn their own names, they also learn about their gender and what it means to be a woman or a man in their community. 
As the world changes, gender roles also change. Many young people want to live differently from their parents. But they sometimes find it difficult to change, because the family and community expect them to continue following old rules. As women struggle to gain the freedom to redefine their gender roles, they can also gain more control over the things that determine sexual and reproductive health.

\section{Instructions}

\section{Introduce Gender (20 minutes)}

1. Explain that a game will be played outside the classroom. Divide learners into two teams. Describe how to play Tug-of-War. Ask the two teams to stand facing each other and hold opposite ends of the rope. Mark a line across the middle of the area of which they must try to pull the other team. Start them off with "1, 2, 3, G0!" and let them pull until one team has pulled the other over the line.

2. Ask the learners to sit in a circle. Tie the rope in a large circle and hand it to them, so that everyone is sitting around the outside of it. This is called a "Tug-of-Peace." Ask the learners to pull together on the rope so that they can all stand up.

3. Ask learners to discuss what this exercise illustrates. Explain how it demonstrates that, instead of people pulling on opposite ends where only one team wins, we can use situations so that everyone benefits and feels good about the results.

4. Ask learners to discuss how this might relate to issues of men and women and girls and boys.

Note: This session should be approached from a factual point of view so that learners do not argue from an emotional perspective. A sense of seriousness should prevail to discourage learners from voicing their own attitudes and thus blocking their ability to learn and reason. At this time, talk about things in general rather than personal beliefs and experiences.

\section{Gender Roles (45 minutes)}

1. Ask each learner to write on a piece of paper one thing that women can do that men cannot do. Collect the pieces of paper and put them aside.

2. Ask each learner to write on a piece of paper one thing that men can do that women cannot do. Collect the pieces of paper and put them aside.

3. Divide the board in three parts and record the responses under the appropriate columns:

\begin{tabular}{|c|c|c|}
\hline What men can do & What women can do & What both can do \\
\hline
\end{tabular}

4. Review the responses under the "men" column one at a time and ask if women are also able to do each one. Remove any that women can also do and place them in the third column.

5. Review the responses under the "women" column one at a time and ask if men are also able to do each one. Remove any that men can also do and place them in the third column.

6. What should be left under the first two columns will be the biological differences between men and women.

7. Explain to the learners that these biological differences are called sex roles. Emphasize that they do not change over time and apply to all women and all men.

8. Shift the attention to the items that were put aside. Explain to the learners that these are called gender roles. Emphasize that they are created by society and therefore they vary from society to society and change over time as society changes. For example: 
Men can cut sugarcane but if women want money they can also cut cane.

Men can cook meals and clean the house.

Men can take care of babies and raise children

In some societies, women build the houses whereas in other societies it is taboo.

Ask learners to list more examples of how gender roles are different in different communities. Present the following definition of gender.

Women's and men's roles and responsibilities that are socially determined. How we are expected to think as men and women because the way society is organized, not because of our biological differences. These roles do not arise from biological differences at all.

\section{Gender Role Awareness (40 minutes)}

1. Read the following sentences to the learners and ask them to write the ending to the sentences in their notebook. Discuss the responses for each sentence one at a time. For some of the responses that perpetuate negative gender stereotypes ask the others if they agree or disagree with the response. Have them explain themselves.

Being a girl (or boy) makes me feel...

If I were the opposite sex, my life would be different because...

In ten years, I will probably spend most of my time...

In this country, males do...

In this country, females do...

One thing I would like to change about being a male/female...

Boys are better at...

Girls are better at... 


\section{Session 13 Gender Stereotypes}

\section{Learning Objectives}

By the end of the session, learners should be able to:

Define gender stereotypes

Explain how stereotypes can affect behaviours of young people

Time 35 minutes

\section{Background Notes}
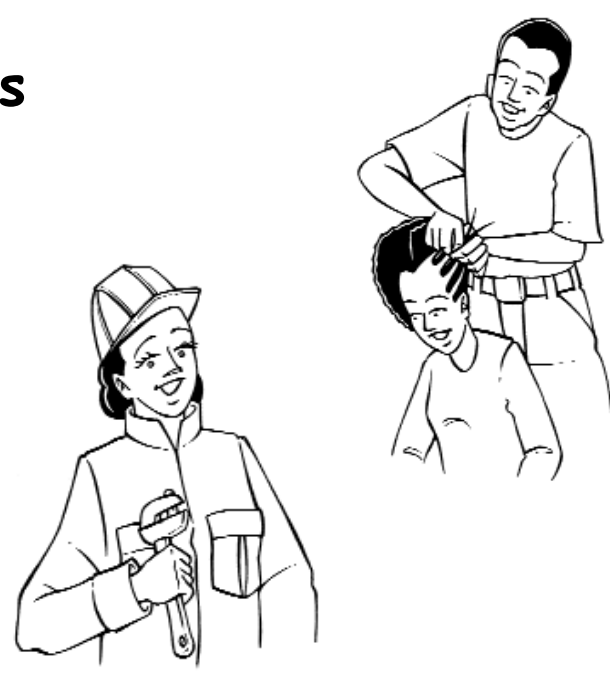

\section{When Gender Roles Cause Harm}

Every culture has expectations of how men and women should act and what their roles are in society. Fulfilling the roles expected by the community can be satisfying and can give women a sense of belonging. But these roles can also limit a woman's activities and choices, and make her feel less valued than a man. When this happens, everyone (the woman, her family, and her community) suffers.

In most communities, women are expected to be wives and mothers. Many women like this role because it can be very satisfying and it gives them status in the community. Some women would prefer to follow other interests, or they want to have only a few children, but their families and communities do not give them this choice. If she is expected to have many children, a woman may have less chance to learn new skills or go to school. Most of her time and energy will be spent taking care of others' needs. Or, if a woman is unable to have children, her community may value her less than other women.

Most communities value men's work more than woman's work. For example, if a woman has worked all day, and then cooks, cleans and cares for her children at night. But because her husband's work is considered more important, she is concerned about his rest and not her own. In this scenario, her children will grow up thinking men's work is more important, and value women's work and contributions less.

Women are often considered more emotional than men, and are free to express these emotions with others. Men, however, are often taught that showing emotions like sadness or tenderness is unmanly, so they hide their feelings. Or they express their feelings in angry or violent ways that are more acceptable to men. When men are unable to show their feelings, children may feel more distant from their fathers, and men are less able to get support from others for their problems.

Women are often discouraged from speaking at or forbidden to attend community meetings. This means the community only hears about what men think. Since women also have knowledge and experiences to share, the whole community suffers when they cannot discuss problems and offer suggestions.

\section{Gender Stereotypes}

A stereotype is an oversimplified or biased description of a group. Stereotypes are often negative and harmful. Gender stereotypes are generally used to describe the abilities of men versus those of women in the community in an oversimplified way. Stereotypes are often recognized as being illogical even though many people still believe them.

\section{Instructions}

\section{Gender Stereotypes (15 minutes)}

1. Explain that people often have beliefs and attitudes concerning the abilities of women compared to men and these are not based on reality. One example is that women are more caring than men. Ask learners to list other examples of characteristics that are often associated with either women or men. Together with the learners, develop a list of such stereotypes. 


\begin{tabular}{|l|l|}
\hline \multicolumn{1}{|c|}{ Female Stereotypes } & \multicolumn{1}{c|}{ Male Stereotypes } \\
Gentle and caring & Rough \\
Physically weak & Individualistic \\
Less intellectual & Physically strong \\
Submissive & More intellectual \\
Cannot lead followers in a household & Assertive \\
Gossip & Leaders and decision-makers \\
Cannot make decisions & Heads of household \\
\hline
\end{tabular}

2. Ask learners to think about whether or not these beliefs influence:

The way we feel about ourselves

How we behave

What we believe we can do

What goals we set for ourselves

\section{Stereotypes and Behaviours (20 minutes)}

1. Ask learners where we learn what is right or not right for boys and girls to do:

Home/family (the way we are brought up)

Media

School

Social groups, peers

2. Ask learners to list jobs that men hold and jobs that women hold in their community. Ask if there are jobs that both men and women hold.

3. Write the following two statements on the board. Ask learners to list as many responses as possible:

Boys may believe that to be masculine they should...

Girls may believe that to be feminine they should...

\begin{tabular}{|l|l|}
\hline \multicolumn{1}{|c|}{ Feminine } & \multicolumn{1}{c|}{ Masculine } \\
Be emotionally sensitive & Be in control \\
Be vulnerable & Appear unemotional \\
Submit to wishes of men & Be dominant \\
Be dependent & Be sexually active \\
Meet needs of others before self & Have many partners \\
Be physically attractive & Head the family \\
Be tolerant & Be the breadwinner \\
Avoid careers in math and sciences & Avoid household work \\
Have children when men want & Be strong (resolve conflicts with violence) \\
& Take risks \\
& Be in careers that are mechanical and analytical \\
\hline
\end{tabular}


4. Discuss how these stereotypes affect relationships between boys and girls or men and women.

Violence when women refuse to be submissive or accept men's decisions

Resentment when a woman has a job and a man does not, or when a woman earns more than a man

Rape

Discrimination in the workplace

Harassment

5. Conclude the session by reminding learners of the first activity in the gender section of what boys and girls can really do. Emphasizing that apart from the reproductive functions, which are dictated by biology, women can do everything that men can do and men can do everything that women can do. Everyone - boys and girls - should strive to be the best they can be at whatever they choose. Emphasize that:

Stereotypes are a form of discrimination

Stereotypes are wrong

Essential ingredients should be human relations and respect for all human beings

\section{Optional Activities}

\section{\#1 Famous Men and Women}

15-19

1. Remind the group that one of the most damaging results of stereotypes is the false belief that women and men should only have jobs in certain fields. In groups of threes, ask each group to brainstorm and develop a list of:

10 famous people worldwide

10 famous African men

10 famous African women

10 famous women in their community

10 famous men in their community

2. After a few minutes, ask volunteers to give you the names on their lists. Have one of the learners write these on a flip chart of the board. Ask the learners the following questions:

Was it difficult to name ten famous people worldwide?

Was it difficult to name ten famous African men? What about women?

Are any of these men or women are working in non-traditional careers?

Which list was the easiest to make? Which was the hardest? Why do you think this is so?

3. Divide the learners into two groups and ask each group to list non-traditional careers for men and non-traditional careers for women. Ask for volunteers from each group to write their lists on clip chart to be shared with the entire group.

4. Facilitate a discussion with the following questions:

What are the advantages/disadvantages of women/men working in a non-traditional career?

What is the greatest barrier to women/men working in non-traditional careers?

Are there jobs only men or women can or should do? Why or why not?

Are there clear-cut roles in your family as to who provides protection and nurturance? Why?

Is there any family role, which is decided by both males and females? Why? 


\section{\#2 Gender Roles and Relationships}

1. Explain that stereotypes about gender roles can affect our relationships this activity will explore situations where gender roles and stereotypes could affect goals, decisions and relationships for young people.

2. Divide learners into small groups and read the instructions for the activity:

Each small group will receive a case study involving issues of gender roles. Work to resolve your case study, then prepare to present your solution. You will have 10 minutes. When you present your solution, others can challenge it while you defend it. Be sure to have arguments to back up your solution.

\section{Case Studies}

1. Fatuma has been offered a place at the village polytechnic to study masonry. She is the only girl in the class and the boys are always teasing her about a girl trying to do a 'man's job.' When she scored higher than the boys in the exams, the boys stopped talking to her. She is feeling miserable because she has no friends in the class. What should she do?

2. Kamau wants to make a doll for his younger brother, but his friend Maina says "No way!" Kamau explains that dolls help teach little boys to take care of someone and be loving, but Maina argues that they just teach boys to be cowards. Kamau knows he is right but he's concerned about what Maina might say to their friends. What should Kamau do?

3. Nyambura and Njoroge, both in Form 3 finished school, have been writing to each other for four months. Njoroge has told Nyambura that he will show her how much he loves her in December. Nyambura has heard about the importance of safe sex. In December, she asks her friend Maria to accompany her to the chemist to buy some condoms. Maria says 'girls shouldn't buy condoms, that's the duty of boys.' What should Nyambura do?

4. Ali and Amina have been married for about one year. In the beginning, Ali would come home at all hours of the night and demand to be given food. Amina would wake up, quickly prepare it, and return to bed. Now when Ali comes home, he is usually drunk and when Amina wakes up to prepare his food, he often beats her and tells her she is not a good wife. She cannot tell him to stop the beatings and she dare not tell his family. What should she do?

3. When time is up, ask for a volunteer to present the case study and solution. Then invite any challenges. Arguments are okay as long as the group maintains ground rules. Allow the "debate" to go on for two or three minutes, assisting either side as appropriate, before moving on to a new group. Repeat the process until the group discusses and debates all case studies.

4. Facilitate a discussion with the following questions:

Is it easy or hard to look at male and female roles in a new and non-traditional way?

How do men or women accept the changes in gender roles? Why?

What are some of the ways changing gender roles have affected relationships between men and women in social settings? In families? In the workplace?

Would your parents reach the same or different solutions?

Which case study was the most difficult? Why?

If you could make one change in men's gender roles, what would it be? In women's gender roles? 


\section{Session 14 Sexuality and Behaviour}

\section{Learning Objectives}

By the end of this session, learners will be able to:

Define sexuality and sex

Explore messages about sexuality in society

Explain how sexuality affects behaviour

Explore their own feelings about sexuality

Explain the difference between "feeling" and "behaviour"

Describe the consequences of sexual behaviour for adolescents

Time 90 minutes

\section{Background Notes}

\section{Sexuality}

Sex and sexuality are often thought to refer to sexual intercourse and other sexual activities. However, sex is whether a person is male or female and is determined by which reproductive organs they have and how people express their gender. Sex is a part of sexuality.

Sexuality is an important part of who a person is and what she or he will become. It is much more than sexual feelings and sexual intercourse. Sexuality includes thinking of oneself as sexual; feeling attractive; and behaving, dressing, or communicating in a sexy way. It includes feeling, thinking or behaving as a male or female; being attractive; , being in love; and being in relationships with sexual intimacy and sexual activities.

Sexuality influences social behaviour. Human sexuality can also be understood as part of the social life of humans, governed by implied rules of behaviour. Sexuality influences a person's sexual identity. Sexual identity can be shaped by the social environment one is exposed to. Human physiology makes sexuality possible, but it does not predict sexual behaviour.

Human sexual choices are influenced by society and culture. Some may choose to abstain from sex before marriage because of their religious beliefs. Our culture, traditional beliefs, and gender roles play an important part in defining what we consider normal sexual feelings and behaviour for men and women. For example, some cultural traditions recognize that women have sexual desires and urges whereas other cultures do not. In some cultures it is very important for girls to be virgins when they get married, whereas men are expected to be sexually active by the time they are married.

\section{Aspects of Sexuality}

There are many aspects that make up sexuality. Each of these aspects are connected to each other and make a person who he or she is. The following are aspects of sexuality:

Body image: How we look and feel about ourselves, and how we appear to others.

Gender roles: The way we express being either male or female, and the expectations people have for us based on our sex.

Relationships: The ways we interact with others and express our feelings for others.

Intimacy: Sharing thoughts or feelings in a close relationship, with or without physical closeness.

Love: Feelings of affection and how we express those feelings for others.

Sexual arousal: The different things that excite us sexually.

Social roles: How we contribute to and fit into society.

Genitals: The parts of our bodies that define our sex. They are part of sexual pleasure and reproduction. 


\section{Family Life Education}

Many believe that education on sexuality, reproduction, HIV and AIDS and safe sex (often called family life education) will encourage adolescents to engage in sexual activity. In fact this type of information generally leads to more responsible and safer attitudes towards sex and sexual relationships. Studies have shown no evidence that education leads to an increase in sexual activity, rather in many cases it leads to a delay in sexual initiation. In many countries, research has shown that education significantly reduces rates of teenage pregnancy and abortion. Family life education education provides knowledge about reproductive functions, puberty, and pregnancy and STI prevention. Family life education emphasizes a broad approach to sexuality, focusing on a whole person and presenting sexuality as natural and a positive part of life. Telling the truth about sexuality could make it easier for young people to talk with parents, teachers, and religious leaders.

\section{Sexually Healthy Adolescents}

Adolescents can start working on being a sexually healthy person. They can make sure they are informed as much as possible so that they know the difference between fact and fiction when it comes to sex. Most importantly, they can take the time to think about choices related to sexual activity. One of their choices (discussed in the abstinence session) is "No Sex" or "Not Yet." They can wait and not rush into sexual intercourse. Or if they have sexual intercourse, they can limit their partners and remain faithful to one. They can also make sure they understand the consequences of unprotected sex and know how to best protect themselves.

Most people feel private, shy, or embarrassed about some aspects of sexuality. Some adolescents feel embarrassed asking questions or talking about changes in their bodies. Private feelings can centre on romantic and sexual feelings or activities. All of these feelings are completely normal. Many young people also feel guilty, ashamed, or bad about some aspects of their sexuality. When young people express these guilty feelings, suggest that they ask themselves if what they are feeling guilty about is something that is harmful (or could be) to themselves or others. If it is not, then suggest they let go of the guilty feelings.

Sometimes it is hard for adolescents to remain sexually healthy. They are not taught in school or at home what this means. Most adolescents get their information from peers, older siblings, music and magazines, which can be misleading and confusing. Sex is portrayed as being romantic and problem free in these sources and looks like it just happens without talking about whether or not they should have sex. They rarely discuss whether or not they should use condoms, and if they do not use condoms they rarely seem to get into trouble with an unwanted pregnancy or STIs.

An important part of healthy sexuality is being able to tell the difference between sexual behaviours that are healthy and those that are harmful. Before adolescents act on their sexual feelings, they should be encouraged to think about the consequences of their actions. They can ask themselves:

Will I or anyone else be put at risk for unwanted pregnancy, HIV, or other STIs?

Will acting on my sexual feelings cause any other problems in our relationship?

Will it make me or my partner feel uncomfortable? Will anyone's feelings get hurt?

Being sexually healthy means taking the time to think about the consequences before acting on sexual feelings.

\section{Setting Limits}

Some people think that sex is a powerful and uncontrollable force that just happens, like thunder or rain. But the truth is that sexual intercourse is a deliberate decision. When a person has sex it is not nature overcoming them. It is the person who made a decision. In fact, people make many decisions about sex: When? With whom? Why? Where? How often? With a condom? Without? Sex is a big decision. Adolescents can try to make sure it is their own decision and ignore people who say, "Everybody is having sex." Everybody is not having sex, in fact most 15 to 19 -year-olds have not had sex. 
When young people are deciding whether or not to have sex, it is important that they think about whether they are ready for the demands of safer sex - correct and consistent condom use, HIV counselling and testing, and more. Most adolescents are not ready to handle all these responsibilities. If someone does not feel ready, they should say no and wait until they are older. Ideally, sex will take place when the young person cares for their partner and the partner cares for them in return. Caring takes time. Friendship and closeness do not develop overnight. If sexual partners are not true friends, they may find sex embarrassing. This is a sure sign that this is not the right person or the right time for them.

\section{Instructions}

\section{Definition of Sexuality and Sex (20 minutes)}

1. Ask learners to write down on a piece of paper what first comes to mind when they hear the word "sexuality." Ask them to do the same for the word "sex."

2. Draw two columns on the board labelling one "Sex" and the other "Sexuality." Collect pieces of paper and write the responses on the board. A volunteer can read the responses as you write them.

3. Define sexuality. Explain that it is more than sex and sexual feelings; it exists throughout a person's life and is the total expression of who we are as human beings, male or female. It is an important part of who a person is and what he or she will become. Sexuality is constantly evolving as we grow and develop. It is a part of us from birth to death. It includes all the feelings, thoughts, and behaviours of being a girl or boy, including being attractive, being in love, and being in relationships that include sexual intimacy and physical sexual activity.

4. Define Sex. Explain that sex has to do with biology, anatomy, and physiology, and refers to one's reproductive system and behaviour as a girl or boy. Therefore, sex is part of one's sexuality. Emphasize that sexual intercourse is an activity done by the body, whereas sexuality is in the mind and is about the whole person.

\section{Aspects of Sexuality (20 minutes)}

1. Explain that sexuality has many aspects. Divide participants into eight groups and assign one of the following words to each group. Ask each group to discuss what they understand their word to mean and how it relates to sexuality.

1. Body image

2. Gender roles

3. Relationships

4. Intimacy

5. Love/affection

6. Sexual arousal

7. Social roles

8. Genitals

2. After five minutes, bring the groups back together and facilitate a discussion. Ask a representative from each group to share what they discussed about their word. Allow other learners to add additional information.

\section{Sexuality and Behaviour (25 minutes)}

15-19 1. Refer to the "Circles of Sexuality," and explain how each circle relates to sexuality. Draw the circles on the board to show how they intersect.

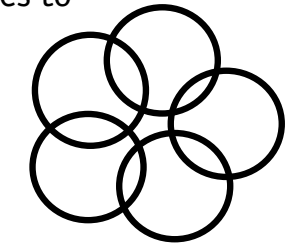


2. Facilitate a discussion with the following questions:

Are there any circles that they did not think of as being "sexual" before?

Which of the circles feel most familiar? Why?

Which circle is most important for friends your age to know about? Which is least important?

Which circle would you like to talk with your parents about? If none of them, why not?

Which circle would you like to talk with your friends or boyfriend/girlfriend about?

\section{Feelings about Sexuality (20 minutes)}

1. Ask learners to list some of the feelings young people have about sexuality (including fears and frustrations, uncertainty, embarrassment, confusion, shame, guilt, curiosity, satisfaction or pride).

2. Explain that as the body changes in adolescence, feelings are also changing. It is important to talk about these feelings with family, friends and other adults they trust because they affect their self-esteem, relationships and behaviour.

3. Divide learners into pairs. Read off the following statements about feelings. Have them copy them into their notebook, answer them and discuss them. Ask each pair to share their feelings about as many of the statements as they can. The feelings must be true for themselves.

When I think about my best friends or friends, I feel....

When I think about visiting someone I really like, I feel...

When I think about finding a girlfriend or boyfriend, I feel...

When I think about how things are between me and my parents/guardians, I feel....

\section{Feelings and Behaviour (5 minutes)}

1. Ask learners to discuss the difference between feelings and behaviour.

Feelings cannot be seen; they are carried within the individual

Behaviour can be observed and normally involves other people

2. Allow learners to discuss some sexual behaviours (kissing, sexual intercourse, oral sex). Ask learners to discuss the kinds of feelings that can sometimes lead to sexual behaviours. For example, feelings of intimacy and closeness can lead to kissing and sexual intercourse.

3. Ask learners whether these feelings always lead to these behaviours. Emphasize that these feelings are normal but the behaviours have certain negative consequences for young people. It is important to discuss the feelings with someone and consider alternatives to sexual behaviours. People cannot control their feelings but they can choose the way they behave and react to these feelings.

\section{Consequences of Sexual Behaviours (5 minutes)}

1. Ask learners to discuss possible consequences of sexual behaviour. The following should be mentioned:

Unplanned pregnancy

Sexually transmitted infections including HIV

Dropping out of school

Not reaching goals and losing opportunities for the future

Loss of self-esteem due to guilt and loss of reputation

Feeling badly or sad

2. Emphasize that some of the feelings that adolescents experience can be frightening because they are new and that is normal. Feelings do not control actions, people choose their actions and behaviours. Sexual behaviours have consequences and people need to think about the alternatives and the consequences for each action. 


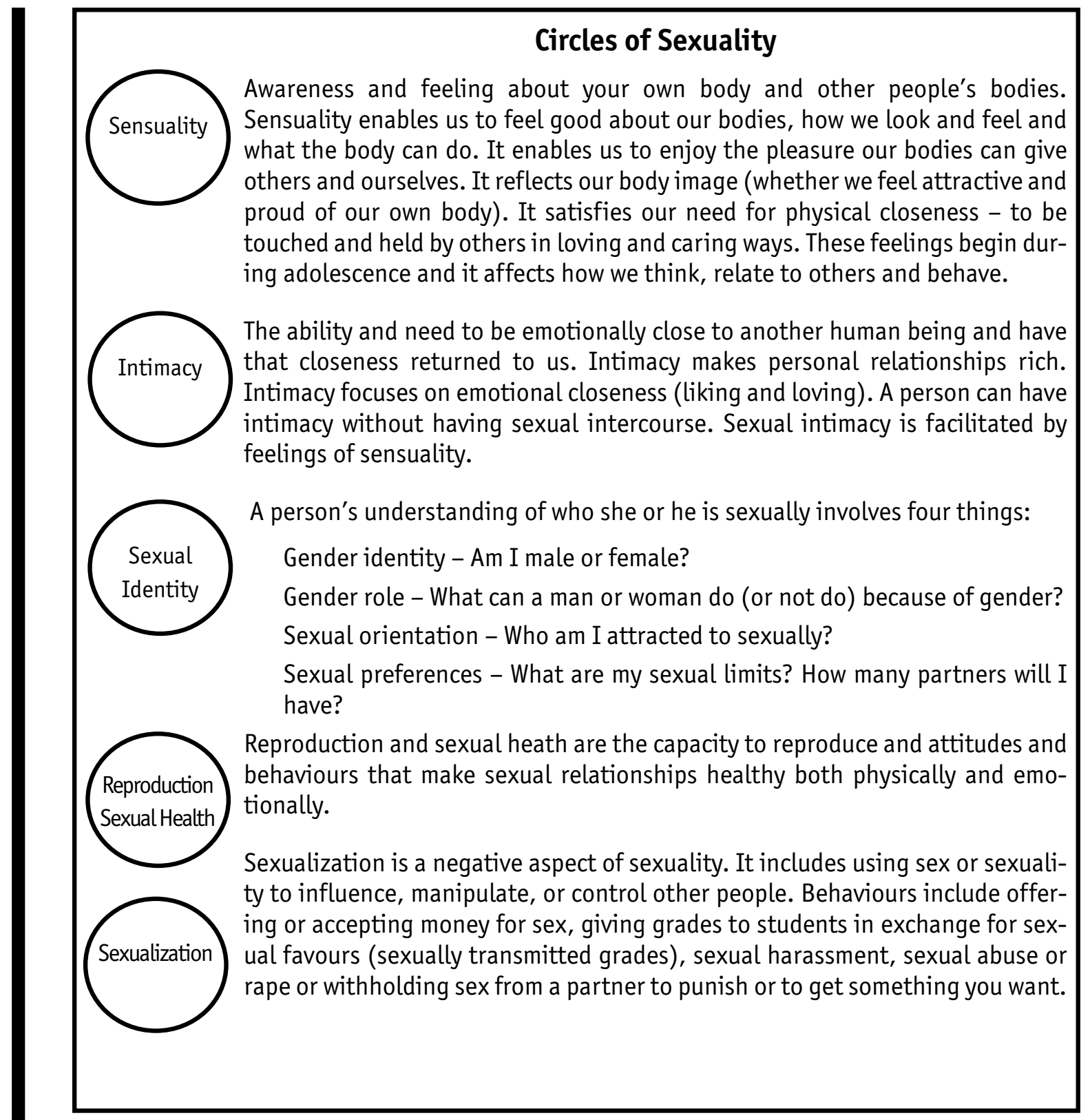

\section{Optional Activity}

\section{5-19}

\#1 Questions on Sex

1. Ask learners what questions they would like answered about sex, sexuality, or sexual activity. Tell them to write their questions on a piece of paper and pass it in anonymously (or to place them in a special box or basket or in a special place in the room). Answer all of these questions during another session. 


\section{Session 15 Self Esteem}

\section{Learning Objectives}

By the end of this session, learners will be able to:

Define self-esteem

List qualities they like about themselves

Explain ways to improve their own self-esteem

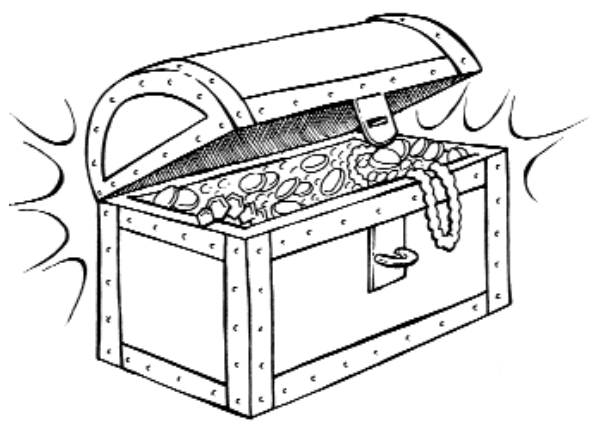

\section{Materials Required}

Chalkboard, chalk

Learner notebooks, pencils

\section{Time 105 minutes}

\section{Background Notes}

\section{Self-Esteem}

Self-esteem describes how people feel about themselves. How people feel about themselves influences their actions towards others and what they can accomplish in life. People with high selfesteem may have a high regard for themselves. They know that they are a worthy of love and respect. They respect themselves. When people feel worthy of love and respect, they expect it from others.

Having self-esteem does not mean that you never get upset or angry with yourself. Everyone gets frustrated at times. But someone with high self-esteem can accept his or her mistakes and move on. If another person tries to convince or persuade him or her to do something they really do not want to do, people who feel good about themselves will be less likely to fall under another person's pressure. They will feel more confident that their own decision is the right one and will make their own choices based on their own desires, and not the desires and values of others.

The opposite is also true. People with low self-esteem may be more likely to fall under the influence of others, not trusting their own values or decisions.

Self-esteem is important because how people feel about themselves influences what they accomplish in life. If people believe in themselves and in their own ability, then they are able to work hard, reach their goals and accomplish what they set out to do. High self-esteem allows us to:

Accept new challenges and try new activities.

Be more comfortable with others, and develop closer and healthier relationships.

Believe we can succeed.

Gain self confidence.

Be the person we want to be.

Be assertive and refuse to be pressured into what we do not believe in. 
People are not born with self-esteem. It is learned as children realize that they are loved and valued. As children hear positive remarks including praise, encouragement, and reassurance, about themselves and the things they do, their self-esteem is strengthened over time. Parents and family play a crucial role in building or damaging a young person's self-esteem and helping a child to grow up believing that he or she is both lovable and capable.

High self-esteem is different from pride or being conceited. People with high self-esteem like themselves, but that does not mean that they think they are perfect or better than other people. Selfesteem is something deep inside you. You can work on your self-esteem every day by:

Not comparing yourself with others. Set your own goals, and don't judge yourself according to someone else's achievements. Life is a long race. Sometimes you will be ahead, sometimes you will be behind.

Recognizing your special talents and appreciating yourself the way you are. Make a list of the things you do well. Are you an artist, athlete, singer, storyteller, footballer or dancer? In what subjects do you excel in school? What things do you do well at home?

Thinking about the kind of person you are and making a list of your best qualities. What do you like about yourself? Are you generous? Do you have a good sense of humour?

Being aware of the things you would like to improve about yourself, but not being overly selfcritical.

Being realistic. Set achievable goals so that you can be satisfied when you accomplish them.

Believing in yourself. Tell yourself: "I can do it!"

Spending time with people who care for you, make you feel good about yourself and boost your self-esteem.

Staying away from people who damage your self-esteem, particularly if they do it on purpose. Of course, working on your self-esteem does not mean that you will never feel badly, but it will help you get through difficult times. Self-esteem protects you. When someone treats you poorly, your sense of self-esteem shouts: "This is wrong. I do not want to be treated like this!"

\section{Instructions}

\section{Definition of Self-Esteem (20 minutes)}

1. Ask learners to stand up and form two circles, one inside the other, with about half of the learners in an outside circle and the other half in a smaller circle inside the larger circle. Ask the learners in the smaller circle to close their eyes, put their arms around each other, and lower their heads. Ask the learner in the big circle to walk around those in the smaller circle and while they are going around in circles, read the following instructions:

Give a pat on the back to someone who makes his or her own decisions and sticks to them.

Touch the head of someone who is friendly and understanding.

Give a pat on the arm to someone who works well with others.

Touch the shoulder of someone who is recognized and respected in his or her community.

Touch the shoulder of someone who makes us feel confident.

2. After a few minutes, change places and the members of the big circle switch to the small circle and vice versa. Continue the activity until everyone has been touched in some way by someone else. At the end, ask how they felt when the other classmates touched them? How did you feel when someone patted you on the back? (happy, good, proud, confident).

3. Write learners responses on the board. Review the information with them by saying: 
In this activity, our friends identified our strengths. We should also recognize that we have strengths and values that we should be proud of.

It is also good to recognize that we have some weaknesses that we can improve upon.

Explain that knowing ourselves and valuing ourselves is called self-esteem. Self-esteem can influence our actions towards each other and what we accomplish in life.

4. Ask learners to discuss why self-esteem is important and how we learn self-esteem. Explain that if people believe in themselves and their ability, then they are able to work hard, reach set goals and accomplish what they set out to do. Ask learners to brainstorm what feeling good or having high self-esteem about ourselves helps us to do. Some of the responses should include:

Accept new challenges and try new activities

Be more comfortable with others, and develop closer and healthier relationships

Believe we can succeed

Gain self confidence

Be the person we want to be

Be assertive and refuse to be pressured into what we do not believe in

\section{Self-Esteem (55 minutes)}

1. Explain that we are born with an imaginary empty treasure chest. As people love us, compliment us, appreciate us, spend time with us, and learn with us, we build up our treasure. As people criticize us, shout at us, and put us down, we lose our treasure. Explain that as the put-downs build up, the treasure chest can lock and that prevents us from feeling good about ourselves and others.

2. Read the following statements aloud one at a time. Ask learners to write a response to each statement.

What do you think is your greatest personal achievement to date?

What do you like most about your family?

What do you value most in life?

What are the three things you are good at?

What is one thing you would like to improve about yourself?

If you died today, what would you most like to be remembered for?

What do your friends like most about you?

What do members of the opposite sex like most about you? (for ages 15-19)

3. Divide learners into groups of three or four and share two or three of their responses. Ask the learners to discuss in their groups how they can give themselves and other people self-esteem treasure.

4. Ask learners to name different aspects of self-esteem. Write their suggestions on the board as they list them. When they have finished, discuss the following with them:

Know Ourselves: It is important for us to know who we are; our values, goals, dreams, and priorities.

Respect Ourselves: Some people can do certain things better than others. Our friends may play football better, work better, or learn faster. They are not better, just different. Never compare yourself to others.

Love Ourselves: We must love ourselves before we can love others. When we have a good relationship with ourselves, our relationship with others will improve.

Affirm Ourselves: Instead of hating ourselves for what we are not or have not done, we should give ourselves credit for what we are and what we have done.

Trust Ourselves: Trusting ourselves means knowing that we can be our own teacher, our own guide, and our own decision maker for matters relating to us. 
Accept Ourselves: Accept ourselves as we are. We are doing the best we can, now. Tomorrow we will do better. Treat ourselves lovingly and gently.

Show Ourselves: Let people know who we really are. A healthy personality is based on being honest about who we are.

Stretch Ourselves: When we were little, by age 6 or 7 , we had developed a mental picture of ourselves, called a "self-image." Our self-image is not easy to change, but it can be changed. Little by little, by doing things well, taking risks, acting differently and trying new things, our mental picture of who we are can be expanded, enlarged and embellished.

Self Discipline: Staying focused and having control over actions helps to achieve our goals.

Nourish Ourselves: Nourish ourselves with good friends, food, books, and experiences. Take care of our mind, body, and feelings, and take charge of our life.

Be Ourselves: The world tells us who we should be almost from the moment we are born. Sometimes it feels as though what we want is not important. It is important to be ourselves and be proud of who we are.

Share Ourselves: Once we feel good about ourselves, our time spent with others will be more satisfying and fulfilling. Sharing our life with others will help us to feel better about ourselves.

\section{Factors that Lower Self-Esteem (30 minutes)}

1. Explain that there are reasons why many young people have low self-esteem. Very often, the "negative" things about people are highlighted while the "positive" things are not spoken about.

2. Ask the learners to explain the meaning of the word "put-down," and write it in large letters on the board.

Put-down: a word, phrase, expression, statement, gesture, or situation that results in a person feeling not good enough, not important, not capable, or less valued or significant than before.

3. Ask learners to give examples of put-downs and write them on the board. Examples include:

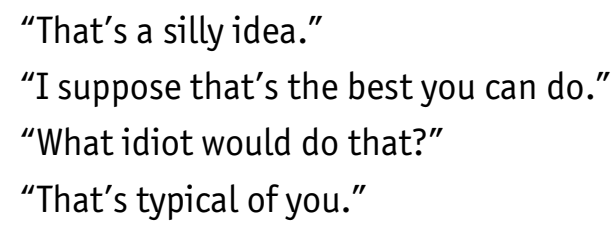

If working with older adolescents, ask them to discuss put-downs such as gestures, or even more subtle put-downs such as talking to one person in a way that excludes or ignores another.

4. Put the responses on the board. Then ask the learners to discuss whether it is only other people who put us down, or whether we also do it to ourselves, and how. Some ways we might put ourselves down include:

Not accepting compliments. "Oh, I'm not really that good, I was just lucky."

Giving credit to others when it rightfully belongs to us. "You did all the work, I just helped a little." "I couldn't do anything without him."

Giving others opinions before our own. "Our teacher always says..." "My friend thinks..." "I really don't know but my mother says..."

By responding when someone says, "Hey, stupid!"

By accepting nicknames like shorty, fatty or thick-head. 
5. Divide the learners into groups and have them discuss:

How do put-downs affect us?

How are we likely to feel about ourselves if we believe put-downs?

If someone is continually put down, how are they likely to behave towards themselves and others?

6. Emphasize that people who are used to being put down:

Find it difficult to interact with others or meet new people because they are afraid of rejection Are easily influenced or do things they do not want to do in order to be accepted Cannot stand up for their rights

Are shy

Lack confidence

Find it difficult to make decisions

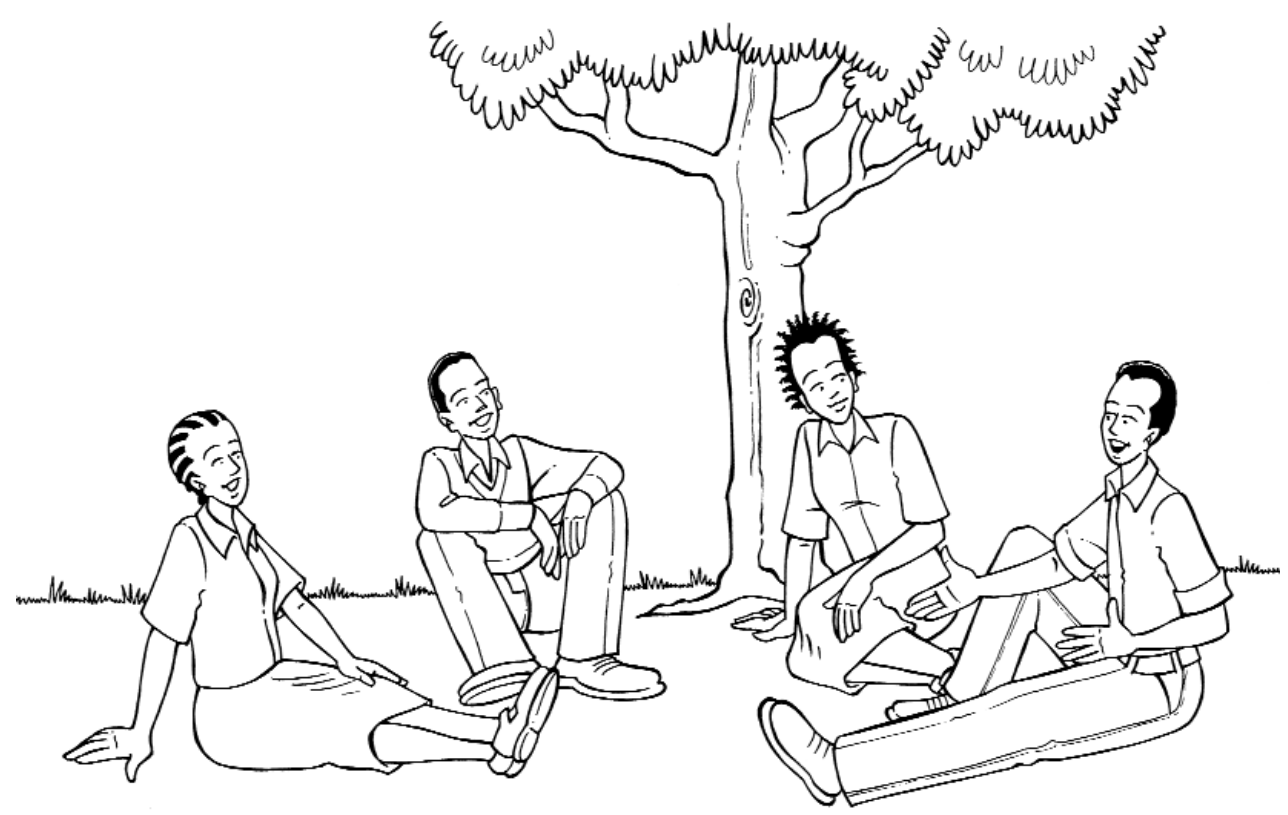




\section{Optional Activity}

\section{\#1 Promoting Self-Esteem (30 minutes)}

1. Ask learners to fix a large piece of paper to each other's backs. Have everyone walk around the room looking at people and then write on the sheets on their back any positive thing or feeling they have about them. There are two rules: it must be positive and it must be genuine.

2. Have learners take turns reading out three statements that have been written about them, beginning the sentence with "I am..."

3. Discuss how it can be difficult to accept praise. Ask each learner to add one positive characteristic or strength about his/herself to the list. Discuss. Ask learners if it was easy or difficult to recognize their own strengths?

4. Facilitate a discussion with the following questions:

How did this activity make you feel?

Were you afraid people would not have anything good to say about you?

What does it say about people who cannot write positive qualities about others?

Are we positive enough in the way we look at others?

How would it feel not to get praise? 


\section{Session 16 Being Assertive}

\section{Learning Objectives}

By the end of this session, learners will be able to:

Distinguish between assertiveness and aggression

Demonstrate effective assertiveness skills

\section{Time 40 minutes}

\section{Background Notes}

Assertiveness is an important skill for getting along with others. Being assertive means standing up for yourself and being straightforward and honest with yourself and others about what you need and want. Being assertive can help you protect yourself from dangerous situations and can help you resist peer pressure to do things that you are uncomfortable doing.

People who are not assertive are often submissive. Even if they are being treated poorly, they do not stand up for themselves. People who are not assertive often lack the confidence and self esteem to stand up for their own needs and to protect their feelings or body from being hurt.

Assertiveness is very different from being aggressive. People who are aggressive are rude and unkind. They do not care about other people's feelings. Being too aggressive is not very good for your emotional health because, deep down, you will feel bad about being unkind.

\section{How to Be Assertive}

Decide what you feel or want and say it. Don't be afraid to be honest about your feelings. Being confident about your own feelings will encourage others to respect them as well. Someone who truly loves you will not want to do things that make you feel unhappy.

Look people in the eye. Eye contact is an important part of being assertive. It tells the other person that you are serious about what you are saying and that you are paying close attention to whether or not they are listening to you.

Do not make excuses. Your feelings are the best reasons. For example, if you do not feel ready for sex, but your girlfriend or boyfriend is pressuring you, avoid using other people as excuses. Say what you really feel.

Do not seek approval from others. If you do not want to do something, say so clearly and do not ask if it is alright. Show other people that you know your own mind and are not looking for their approval.

Do not get confused by the other person's argument. Keep repeating what you want or do not want. Stand your ground and do not give in.

You have a right to change your mind. Perhaps you and your boyfriend talked about sex a few days ago and you told him that you would have sex with him. But you thought about it and now you feel sure that the time is not right - that you are not ready and that the relationship is not ready. He says: "But you agreed that we could have sex." Tell him: "I've changed my mind. I've decided I don't feel ready." If he truly loves you, he will respect your right to change your mind, and he will wait until you feel ready. 


\section{Instructions}

\section{Assertiveness and Aggression (30 minutes)}

1. Ask the learners to discuss what they understand by the terms assertiveness and aggression. Make sure their definitions are similar to the ones below. Ask them to list differences between being assertive and aggressive:

Assertiveness: expressing thoughts, feelings and beliefs in a direct, honest and appropriate way. Aggression: a feeling of hostility that may lead to attacks or an unprovoked violent action.

2. Make sure learners understand the two terms by explaining:

Being assertive is standing up for what you believe in and what you want. Young people are often tempted to give in to someone else's desires, whether because of peer pressure or something idealized in the media. However, if we say what we want or feel and explain why we have chosen a certain decision or action, then we can do what we really want without hurting another person. Assertiveness is part of effective communication. When you are assertive you can say no without feeling guilty, can ask for help when it is needed, avoid arguing, disagree without becoming angry, and feel better about yourself.

Being aggressive involves putting other people down, blaming, or criticizing them.

3. Read the following scenario aloud to the learners:

Mary was so glad that the school day was over. She had had two exams that day and was looking forward to meeting her friends at the nearby kiosk for some snacks. She had just enough money to buy a soda and some crisps. She bought them and went to sit with her friends. Just as she was about to start eating, John came up behind her and took one. "Good crisps," he said, "Can I have another?" Before Mary could answer, her friend Jane said, "Can I have one too? I'm still so hungry" and took some. Then another friend said, "If you sit here you have to share your food with us," and he proceeded to take more of Mary's crisps.

4. Ask the learners to think about the scenario and what they would do if they were in Mary's position. Then ask the learners to share their thoughts with the group. Divide learners into four groups, based on what they think Mary should do:

Group 1: Apologize to your friends for not sharing your crisps and let them eat all of them.

Group 2: Grab the crisps and say you are going to eat all of them yourself.

Group 3: Silently let the friends eat the crisps, then ignore them so they will know you are angry.

Group 4: Explain to your friends that you have been looking forward to having the crisps all week and that you'd share some with them as long as they leave enough for you.

5. Write the following terms on the board: passive, indirectly aggressive, directly aggressive, and assertive. Ask each of the four groups if they are able to match their responses to the terms.

6. Explain the following:

Passive: Group 1. Your friends told you what they wanted but you did not tell them what you wanted. Passive people may believe that others are always telling them what to do and they play the role of victim. They allow others to violate their rights. A passive response is not always in your best interest. However, there are some situations when a passive response is the most appropriate. Ask the learners to give some examples.

Directly Aggressive: Group 2. You say what you want in a threatening manner that offends others. This response is generally not in your best interest and often leads to conflict.

Indirectly Aggressive: Group 3. You pretend everything is fine, but then act with hostility towards your friends. Because you did not express your feelings, your friends are left to guess what they have done wrong. It leaves your friends and yourself frustrated.

Assertive: Group 4. You knew what you wanted and expressed it in a straightforward manner. You were sensitive to the feelings of your friends, which made you feel good about yourself, and your friends know where they stand with you. It is a solution that leaves everyone satisfied. 
7. Ask learners to imagine that aggressiveness, assertiveness, and passiveness are like a seesaw. The aggressive person is at the top, looking down on everyone else. The assertive person is perfectly balanced in the middle and quite comfortable with him/herself and others. The passive person is at the bottom, looking down at the ground and feeling bad. Ask the learners to think of different words to describe a person who is passive, a person who is assertive, and a person who is aggressive. Write down their suggestions on the board. Use the following as a guide:

\begin{tabular}{|c|c|c|}
\hline $\begin{array}{l}\quad \text { Passiveness } \\
\text { Giving in to the will of others } \\
\text { Hoping to get what you want } \\
\text { without having to say it } \\
\text { Leaving it to others to decide } \\
\text { for you. } \\
\text { Being submissive } \\
\text { Talking quietly, giggling, } \\
\text { looking down or away, sag- } \\
\text { ging shoulders, hiding the } \\
\text { face with hands } \\
\text { Avoiding disagreement }\end{array}$ & $\begin{array}{l}\quad \text { Assertiveness } \\
\text { Telling someone exactly what } \\
\text { you want in a way that does } \\
\text { not seem rude or threatening } \\
\text { Standing up for your rights } \\
\text { without endangering the } \\
\text { rights of others. } \\
\text { Knowing what you need and } \\
\text { want } \\
\text { Expressing yourself with "I" } \\
\text { statements say "I feel" not } \\
\text { "You..." } \\
\text { Looking people in the eye } \\
\text { Standing your ground }\end{array}$ & $\begin{array}{l}\quad \text { Aggressiveness } \\
\text { Expressing your feelings or } \\
\text { desires in a way that threat- } \\
\text { ens or punishes others } \\
\text { Insisting on your rights } \\
\text { while denying their rights. } \\
\text { Dominating, shouting, } \\
\text { demanding, not listening to } \\
\text { others. } \\
\text { Looking down on people. } \\
\text { Saying others are wrong. } \\
\text { Blaming, threatening, or } \\
\text { fighting with others. }\end{array}$ \\
\hline
\end{tabular}

Assertiveness Assessment (10 minutes)

1. Explain that this exercise is designed to help them discover how assertive they already are. Ask each learner to take out a sheet of paper. For each of the following statements, ask them to write an $\mathrm{M}$ for most of the time, $\mathrm{S}$ for some of the time, and $\mathrm{N}$ for almost never.

I can express my feelings honestly.

When I say how I feel, it is not to hurt someone else.

I express my view on important things, even if others disagree.

I offer solutions to problems instead of just complaining.

I respect others' rights while standing up for my own.

I ask my friends for a favour when I need one.

I take responsibility for my own feelings instead of blaming others.

If I disagree with someone, I don't use verbal or physical abuse.

I can admit when I'm angry.

I can say "no" without guilt or an apology.

I do not do risky things with my friends.

I ask for help when I am hurt or confused.

2. Ask learners to count how many times they each scored M. They can compare their scores as follows:

$0-4$ : Need to work hard at being assertive.

$5-9$ : Somewhat assertive, but could improve.

10 - 12: Good and keep practicing.

3. Facilitate a discussion with the learners using the following questions:

Why is it sometimes difficult to be assertive?

How can being assertive help in a relationship? In a family? 


\section{Optional Activity}

\section{\#1 Assertiveness Role-plays}

15-19 1. Tell the learners they will now have a chance to role-play assertive ways to ask for what they want or need. Point out this can be done by either asking for what you want and refusing what you do not want.

2. Assign one of the following role-plays to a pair of learners who volunteer to present it to the group. Away from the other learners review the role-play with the volunteers. Ask the pair to act out the situation using the information they learned in the session. Encourage them to be creative and encourage girls to act out male roles or boys to act out female roles. Give learners a couple of minutes to prepare for the role-play. Present the role-play to the group. After the pair presents the roleplay have the other learners clap for the presentation.

\section{Role-play scenarios}

1. You are attending a meeting to plan for an upcoming symposium. Every time you start to say something, an older boy interrupts you. Role-play the dialogue at the meeting.

2. You are boarding a crowded matatu and the tout shouts at you to hurry up and get in. You prefer to wait until someone moves and makes some space for you. Role-play your conversation with the tout and his responses.

3. You are in a school building and someone lights a cigarette. Smoking is not allowed in the school and the smoke is making you sick. Role-play your conversation with the smoker and the defence of his actions.

4. Your friend is having a sexual relationship with an older man who gives her dresses, perfumes, and pocket money. She wants you to go out with his friend, but you do not want to get into a relationship where money is exchanged for sex. Role-play the conversation with your friend.

5. You are a secondary school girl whose boyfriend is a 25- year- old businessman. He has been giving you gifts and taking you to the discos and cinemas. You are now worried about possible HIV infection and you want to ask him to use condoms. Role-play your conversation, how you would initiate it, and what happens.

3. Ask the group the following discussion questions, one at a time, and write the responses on the board:

What happened?

Does this happen here in our community (school, home)?

What problems does it cause?

What can we do when this happens? What can we do to avoid these problems or this situation?

What else could she/he have said to give more information?

2. Ask two more volunteers to act out the next role-play. Use the same discussion questions above on the subsequent role-plays as time allows. 


\section{Session 17 Decision Making}

\section{Learning Objectives}

By the end of this session, learners will be able to:

Explain the Three Cs decision-making process

Time 120 minutes

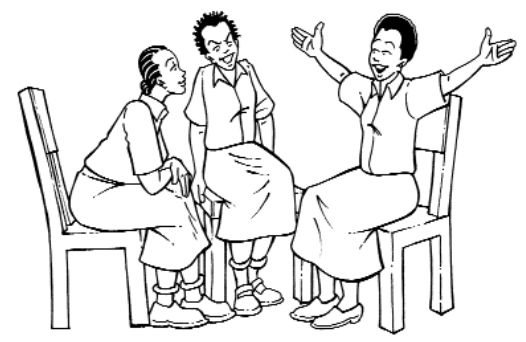

\section{Background Notes}

A decision is a choice that we make between two or more possible options. We all make decisions every day. We will need to make more and more decisions as we go through life and some of these decisions will affect us the rest of our lives.

One of the most important parts of decision making is looking ahead to see what might happen if you do something. This is called predicting outcomes or understanding consequences. The better you are at predicting outcomes, the better you will be at making decisions that result in the outcomes or consequences you want.

Key steps for good decision-making include:

Describe the problem, situation, or issue that needs a decision.

Get more information if you have questions about the situation.

Think about the possible consequences or outcomes of each course of action.

Think about your personal and family values, and which courses of action are consistent with these values.

Think about the ways in which your decision may affect other people.

Choose the decision that seems most appropriate based on your knowledge, values, morals, religious upbringing, and present and future goals.

Re-think the decision and how you feel about it. Be sure you carefully considered all the alternatives and feel comfortable with the choice you made.

\section{Instructions}

\section{Two Types of Decisions (30 minutes)}

1. Ask learners for examples of decisions they have made during the week. Write them on the board.

2. Discuss with the learners what kinds of decisions adolescents have to make as they grow up. Some examples are whom to choose as friends, whom to choose as a boyfriend/girlfriend, whether to have sex, which career or profession to choose, whether and when to marry, whether and when to have children and how many children to have. Record some of the decisions on the board.

\section{Explain that there are two types of decisions:}

Active decisions involve thinking about options and making a choice based on the careful consideration of the consequences of each alternative.

Passive decisions are made by allowing time, chance or someone else to decide for you.

4. Look at the list of decisions that the learners created in steps 1 and 2 and help the learners identify which ones were made actively and which were made passively. 


\section{Three C's for Decision Making (90 minutes)}

1. Explain that making decisions and knowing the consequences are important skills young people need. Explain that there are three steps for active decision making. Sometimes this is done very carefully, other times very quickly. Some decisions can take a few days, others can take years, while others are made instantly.

Present the Three C's for making decisions.

\section{Describe the CHALLENGE (or decision) you are facing}

List three CHOICES you have

Consider the positive and negative CONSEQUENCES of each choice

2. Ask learners to take out a piece of paper and write down a serious decision that they or their friends are currently facing. The decision can be about anything - school, a job, a family situation, or a friend. Instruct them to choose a decision where the consequences really matter, instead of something that will not make much difference. Assure them that what they write will remain confidential and they do not need to write their names.

3. Collect the papers in a basket or box. Read them quickly and choose five or six that are difficult decisions, and write them on the board. If what is written can be used to identify the writer, change it accordingly to maintain confidentiality.

4. Explain to the group that these are the kind of challenges many young people face, especially as they become older and more independent. Young people must make decisions and learn to live with the consequences of their choices.

5. Ask learners to choose one of the challenges listed. Ask the group to list several options that a person making this decision has and write them on the board. List those beside the word choices on the board and add any others that you can think of. Be sure there are at least three choices.

6. Remind learners that there are consequences to their decisions. Ask them to think of possible negative and positive consequences for each choice. Add any obvious consequences the group may leave out, especially negative ones.

7. Ask learners to look at the choices and consequences and make a choice together. Encourage learners to reach agreement or take a vote to determine the outcome. Explain that decisions are usually made alone, but people may seek other people's opinions before making a decision.

8. Divide learners into groups of four. Assign each group one of the other challenges from the list on the board. Have them follow the Three C's and make a decision. Once each group has made a decision, allow a representative from each group to share their decision and how they made it with the whole group.

9. Facilitate a discussion with the following questions:

Do certain choices warn you right away to choose something else? If so, what are they? (Possible answers: A risk to your health, a risk of going to jail, a risk of losing your integrity) What negative consequences relate to a person's feelings or values? (Possible answers: guilt about choosing against your values; feeling bad for doing something your parents, religion, traditions or culture, or friends would disapprove of; or feeling used or exploited)

When you have to make a difficult choice and are unsure of the decision to make, who could you ask for help? (Possible answers: friend who has gone through a similar decision, teacher, school counsellor, religious leader, parent or other trusted adult)

How can you explore all the possible consequences of a particular choice?

Are you facing a personal decision now? Can you use this decision making process to help you? 


\section{\#1: Choices and Consequences Role-plays}

1. Divide the group into three teams and describe a role-play scenario to each group. Tell the learners that they are now going to have a chance to practice using the Three C's model so they will be able to make major decisions themselves in the future.

\section{Role-play scenarios}

1. You have decided that a condom is your best protection against HIV, other STs and unwanted pregnancy. You want to use a condom during sex, but your partner does not want to use a condom and will try to persuade you not to use it. She insists that using the herbs she got from the traditional healer will be more effective. Use all the arguments you believe are relevant to support your decision to use condoms during sex.

2. You are away from home for a few months. Before you left, you and your boyfriend/girlfriend decided that neither of you would have sex with anyone else. You are out one night and meet a person at the disco who you find very attractive. The person looks very nicely dressed and smells clean. There is no way for your partner at home to find out whether or not you had sex with this person. Use all the arguments you believe are relevant to support your decision to remain "faithful."

3. Nanjala is one of the last to leave a party in Kakamega with friends. Baraza, her friend's older brother, is supposed to walk her home late at night through a sugar plantation, but he's been drinking and smoking bhang. He's not really drunk, but Nanjala's mother told her never to be alone and far away from people with someone whom she does not know that well and who has been drinking. Walking home alone at night through those isolated areas is very dangerous. What should she do?

2. Ask each group to identify the challenges from their role-play. For each challenge, they should spend 10 minutes discussing all the possible choices and consequences for each. Teams should make a decision and spend a few minutes preparing a role-play based on their decision. Ask each team to present their role-play. After the role-plays have been presented, take a few minutes to share any thoughts about these decisions with the group.

\section{Facilitate a discussion with the following questions:}

Is it hard to make good decisions? What makes it hard? (Possible answers: the effects of drugs or alcohol, pressure from peers or a partner, or not realizing a decision has to be made) What would make making good decisions easier? (Possible answers: knowing how to resist pressure, being sure about your values and goals)

In reality, how are most decisions made? (Possible answers: they are not made consciously, and events or things just happen)

In the past, have you made a decision that affected other people? What happened? 


\section{Session 18 Setting Goals}

\section{Learning Objectives}

By the end of this session, learners will be able to:

Explain the purpose of goal setting

Describe the process of setting and achieving goals

Set clear goals

\section{Time 60 minutes}

\section{Background Notes}

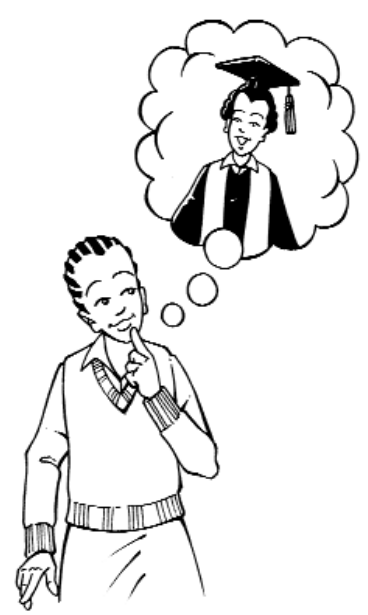

A goal is something that you want to achieve or accomplish. It can be something to do, someplace to go or something to have. Goals give us something to look forward to and can motivate us and give us energy. To set a goal, we must gather information and make decisions and choices. We must learn about what we want to achieve. Goals should be specific, practical and have a deadline. Something realistic and easy to manage makes achieving it easier and creates confidence to make other, greater goals. Thinking about the expected benefits can be motivating. To help reach a goal, it is helpful to have a plan with steps to achieve it, and also think about possible difficulties and how they can be overcome.

\section{Instructions}

1. Facilitate a discussion about goals. Ask the following questions to generate discussion.

What is a goal?

What are examples of goals?

Why do people set goals?

When do people set goals?

How do people set goals and work towards them?

What are the advantages of making a plan?

2. Explain that goals should be specific and practical. An example of a specific goal is to receive a certain mark in school. A non-specific goal would be being a good student.

3. Ask for someone to give an example of a goal. Ask the following questions to explain goal setting.

When do you want to accomplish this goal?

If you reach this goal, how will it help you?

What are the steps that you will take to reach your goal?

What are the things that might prevent you from achieving your goals?

What actions can you take to overcome these difficulties?

4. Encourage learners to continue thinking about goals with the following questions:

Do all people set goals for their lives?

What happens to those who do not?

Is it really necessary to set goals in order to be able to achieve what we want?

Do most people achieve all their goals? Why or why not?

Who can help you reach your goals? 
5. Emphasize the following:

To achieve something, we need to work hard, have faith, security, determination, and hope.

A negative way to look at a problem is to see it as an obstacle.

A positive way to look at problem is to think about it as a challenge and plan how to overcome it.

We cannot manage and plan our future if we see our lives as a random set of events that we do no have control over.

6. Ask each learner to write the ending to each statement in his or her notebook. Read each statement one at a time and allow time for learners to answer.

I would like to finish....

By the end of the year, I want to....

By next month, I'd like to....

I'd like to have enough money to...

What I want to change most about myself is...

Some place I'd like to see is...

One of my good qualities I'd like to develop further is...

7. Ask learners to spend a little more time answering these questions on a piece of paper. What do you want to be when you grow up? What are you doing now to achieve it? Have a couple of volunteers read their responses to the rest of the group.

\section{Optional Activities}

\section{\#1 Timeline}

1. Draw a timeline on the blackboard starting with " 0 " with tick marks every 5 years up to 30 years. Ask the learners to copy the same timeline on a piece of paper.

2. Tell the learners to think about their life up to this point and create a time line beginning with their birth and ending at 30 years of age. In the early years of the time line, ask them to write in special dates or events in their lives that have already happened, such as:

First day of school

Other family events (births, deaths, marriage)

Special relationships (friends, romantic partners)

Sad events experienced

Special awards or prizes

3. Ask them to write in at least three future events they hope will happen by age 20 or 25 . These may include:

Finishing secondary school or university

Getting a job

Getting married

Having a child

4. Finally, ask learners to write at least three future events they hope will happen after age 25. Mark where on the time line they want the events to occur. They may want to include:

Starting a business

Buying a shamba

Buying a car

Getting a better paying job 
5. Ask learners to share their time line with the entire group.

6. Facilitate a discussion with the following questions:

Do we have much to say about what happens in our lives before age 10 ? Why or why not? What happened to you that was out of your control?

Many adults think they control what happens to you during your teen years. Is it really true? Who is actually in control of your life at this point? Who decides what goals you want to achieve?

When it comes to life plans, is it more difficult to plan for ages 10 to 20 or those after age 20?

Which points on your future time line would change if you became a parent this year? Describe how they would change and why.

\section{\#2 Short and Long Term Goals}

1. Ask learners to think of an example of one of their goals. Give everyone an opportunity to answer. Without explaining why, ask each person to name a goal. Direct her or him to one side of the room or the other, depending on your determination of whether the goal is short-term or long-term. When everyone has named a goal, ask a volunteer to answer the following questions:

Why are you standing in two different groups?

What is the difference between the two groups?

2. When someone answers that one group named goals that can be achieved quickly (short-term goals) and the other group named goals that take longer to achieve (longer-term goals), ask everyone to take their seats.

3. Facilitate a discussion with the following questions:

What are some long-term goals that adults you live with have in mind for you?

How are goals related to personal and family values?

15-19

\#3 Making a Contract

Session 1

1. Tell the group they will practice setting goals with the help of a partner, who will support them and help them work toward achieving their goal. Working with others on setting goals helps to achieve them. It is the way many businesses operate.

2. Ask for a definition of "contract," like the contracts used in business. A contract is a signed agreement between two parties that describes what each party has promised to do.

3. Explain that when people work toward a goal, they often write a "contract" that describes what they plan to accomplish and what they get in return once they accomplish their goal. Go over your example, and explain each section of the contract:

Description of short-term goal

Target date, or the date by which the goal will be

Three or more steps to take to accomplish the goal

Rewards expected if the goal is achieved

4. Ask each learner to choose a partner. Explain that they will help one another write and accomplish their goals over the next few weeks. Read the following instructions: 
Choose a short-term goal and write a contract with your partner on a piece of paper, describe what you hope to accomplish, by when and the steps to get there. Your partner must choose a reward for you, for accomplishing your goal.

Complete your contract and then work with your partner's contract.

Bring your finished contracts to me and I will "witness" them by signing them.

5. Move around the group and offer help where needed.

6. After 10-15 minutes, let pairs know time is almost up. Suggest they complete the steps outlined in their contracts before the next session (if necessary). Collect and "witness" all completed contracts.

\section{Contract}

Name:

Goal:

Steps to achieve it:

1)

2)

3)

Target date:

Reward:

Witness:

\section{Session 2}

1. Distribute contracts to learners and ask them to find their partners to discuss whether or not they achieved their goals. Ask each learner to report on her or his progress.

2. Facilitate a discussion with the following questions:

There is a saying, "You can eat an elephant if you take it one bite at a time." What do you think that saying means? (Answer: If achieving a goal seems too big a task to ever accomplish, break it down into smaller, manageable steps) Is it easier to accomplish something if you take it one step at a time?

How did your partner help you achieve your goal? What other help could you have used? What makes it difficult to accomplish short-term goals at your age? (Answers include: competing priorities; peer pressure; lack of money and other resources; goals do not seem important at this stage in life.)

Is it common for people to fail to meet their goals? (Answer: Very common. People set goals all the time and then do not achieve them. Some people give up if they fail to achieve a goal, but most people set another goal - maybe a more realistic one - and then try again.)

Can you give an example of a young person or an adult you know who failed to meet a personal goal? How did she or he handle it?

Can you give an example of a young person or an adult you know who reached a personal goal? How did he or she accomplish it? 


\section{Session 19 Abstinence}

\section{Learning Objectives}

By the end of this session, learners will be able to:

Understand risk and rewards of certain behaviours

Explore risk at it relates to different activities and events

Understand how each act of abstinence reduces risk to zero

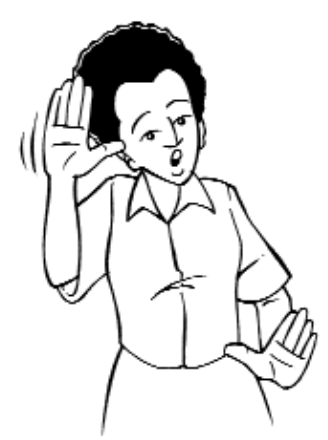

\section{Materials Required}

Board and chalk

Scissors

Time 60 minutes

\section{Background Notes}

Saying no to sex can be difficult for many young people. There may be pressure from peers who claim everyone is having sex, or pressure from partners who argue that sex is the best way to prove love and affection, or pressure from older friends and relatives who say having sex is a way to show that you are an adult. Adolescents may not feel they have many choices, but you can explain to young people that they can say no to sex. You can help them develop refusal skills by counselling them about abstinence or delaying sexual activity. One way to do this is to help them imagine situations in which they might find themselves and help them practice saying no.

Abstinence is a voluntary, conscious, deliberate decision not to do something. In the context of sexual intercourse, HIV, and unplanned pregnancies, abstinence is understood as not having sexual intercourse until marriage. Abstinence is the best and only certain way to prevent HIV transmission and unplanned pregnancy. Each time a young person performs an act of abstinence; he or she successfully postpones sexual intercourse. Even people who have already had sexual intercourse can decide to abstain from now on. This is called secondary abstinence.

Telling youth to abstain or say no to sex is not enough; young people should be guided on ways to achieve abstinence and must see the benefits of abstaining in their lives. Young people need support and skills to successfully abstain. Gaining self-esteem and having self-control in all matters, including sex, are best developed early in life.

\section{Instructions}

\section{Forbidden Activities (30 minutes)}

1. Ask learners to share some of the naughty or forbidden activities they did when they were young boys or girls under 10 years old. List these activities on the board as they are shared. Guide the discussion by saying you are interested in activities that teachers or parents did not allow or that were dangerous in some way. For example, wandering away from home, stealing sugar, talking with strangers, insulting peers and playmates, or eating at the neighbours are some common forbidden activities for children.

2. Choose one of the forbidden activities that have a clear risk or danger and ask:

Why was this activity forbidden?

Was there any danger in it for you?

Why did you still choose to do it?

What made it enjoyable for you even though it was forbidden or dangerous? 
3. Ask learners to share some of the forbidden or dangerous activities that their friends do. Write activities on the board. Examples: smoking, going to the disco, having sex, using drugs or alcohol.

4. For each activity listed, ask learners to identify the risk or danger it posed to their friend, and then why they still found it a risk worth taking. What did your friends do to reduce the risk of these activities that they listed?

5. Ask learners whether there are any activities in daily life that are completely free of risk? Use the following questions to provoke a discussion:

Is there any risk in eating sweets? Travelling by boda boda? Crossing a road? A busy highway? Does the person who smokes just one cigarette in his whole life have any risk? 20 cigarettes? Five cigarettes a day? 50 cigarettes a day? Who among these is the greatest risk? Do the others also carry some risk?

Is there any risk in drinking water? In eating food? What do people do to reduce the risk of drinking water or eating food?

6. Ask learners what they understand by the word risk. After a few have shared their definitions, explain that risk refers to the possibility of harm or danger in an action. For example, when a person smokes, there is a risk of getting cancer.

7. Explain that almost all activities carry some risk. Each person decides how much risk is acceptable. Ask learners to share what sort of risks they have knowingly taken and what have they done to reduce the risk.

\section{Abstinence (30 minutes)}

1. Ask learners to share a time when they abstained from doing something. List experiences on the board. Ask learners which experiences are the best examples of abstaining. Provoke the discussion with questions like:

If a person fasts during a period of religious feast or festival, is this an example of abstinence? What about a person who stops smoking? A person who never smoked?

Is abstinence a choice or required?

2. Explain that abstinence is a voluntary, conscious, deliberate choice made by an individual to not do something. Read the definitions below and make sure the learners understand each word:

Voluntary - Decision made by your own free will; no one forced you to make the decision.

Conscious - Realizing and recognizing that the choice is yours.

Deliberate - A choice that is thought about carefully and decided on.

3. Ask learners for what period of time a person needs to abstain from sexual intercourse in order for it to be called abstinence. Ask if choosing not to have sex for one day is an example of abstinence. Ask about a week or a month. Ask how many believe that abstinence means never ever having sex.

4. Explain that abstaining from sex is the only certain way to prevent HIV transmission or unplanned pregnancy. Explain that abstinence for a young unmarried person is defined as not having sexual intercourse until marriage.

5. Facilitate a discussion with the following questions:

Do you think that most young people are abstaining?

Is abstinence a practical choice for young people?

Can a person who has had sex before choose to abstain now?

What skills are needed to abstain?

Can you share examples of young people who have been able to abstain from sex until marriage? 


\section{Optional Activities}

15-19

\section{\#1 Sexual Decision-making (60 minutes)}

1. Explain that one of the most difficult decisions young people have to make is whether to have sexual intercourse before they marry. The failure to make a decision about sex that is right for themselves is one reason so many adolescents have unplanned pregnancies and become infected with sexually transmitted infections, including HIV. Explain that young people have a right to understand how the body responds when sexually aroused, that feelings of sexual arousal are natural and that just because one feels aroused, it is not necessary for him or her to act upon those feelings. If a young person does decide to act on his or her feelings, they must be aware of the consequences.

2. Divide the learners into two groups. Ask one group to brainstorm all the reasons and arguments why a young person would say no to sex now. Ask the other group to brainstorm all the reasons and arguments why a young person would say yes to sex now. Ask them to put their reasons on the board. Allow about 15 minutes.

3. Ask each group to share their lists. The following points may come out.

\begin{tabular}{|l|l|}
\hline \multicolumn{1}{|c|}{ Reasons Young People Say No to Sex } & \multicolumn{1}{c|}{ Reasons Young People Say Yes to Sex } \\
To follow personal, family, religious or cultural & To stop pressure from friends or partners \\
beliefs and values & To show loving feelings in a relationship \\
To keep a romantic relationship from changing & To avoid loneliness and get affection \\
To avoid unplanned pregnancy and infection & To get or receive presents or gifts \\
with STIs, including HIV & To feel independent \\
To avoid hurting parents and feeling guilty & To hold keep a boyfriend or girlfriend \\
To avoid hurting your reputation & To prove one is an adult \\
To reach future education and career goals & To become a parent \\
To find the right partner & To satisfy curiosity \\
To wait for marriage & \\
\hline
\end{tabular}

4. Ask them if they agree that some of the reasons (on both sides) seem better or stronger than others. Have them rank the reasons using a mark from 1 to 3 (1: a reason, but not a very good one, 2: a fairly good reason and 3: an extremely good reason). Let them talk among themselves. Tell them to make sure they are ranking the items to how they personally feel about the reason not how others may feel. Ask which reasons did you rank a three? Why? What about only a one? Why?

5. Facilitate a discussion using the following questions:

What influences decisions about whether or not to have sex before marriage? (Possible answers: sexual feelings, partners, media messages, pressure, parent teachings, religious beliefs, drug use).

Can people who decided to wait to have sex change their mind? Can someone who has had sex decide to abstain from now on?

What is the worst thing that can happen to a young person who decides to abstain? One who decides not to abstain?

What does a young person need to know or be prepared to do if she or he is going to say no to sexual intercourse? (Possible answers: feeling good about themselves, being assertive, communicating clearly, making decisions, resisting peer and partner pressure or their future goals).

What does a young person need to know if she or he is going to say yes to sexual intercourse? (possible answers: risks of pregnancy and STIs, including HIV; how to talk with a partner about using condoms and contraception; which forms of contraception prevent pregnancy and/or infection most effectively; where to get condoms and other contraceptives; how to communicate with a partner; how to feel good about themselves; how to say no; how to be assertive.)

*Note: This activity is also included in the decision-making session. 


\section{\#2 Group Exercise: Reasons to Abstain}

Introduce this exercise by mentioning that there are many good reasons for waiting to have sexual intercourse. Everyone has different reasons. Having sexual intercourse is a serious decision that one should consider carefully.

1. Read aloud to the group the following scenario:

Imagine that you have a younger sister who is 13 years old. She tells you she wants to have sex with her boyfriend who is 15 years old. You don't think she should have sex yet.

2. Next, read aloud each of the following statements, asking learners how they would respond to their younger sister for each one:

He really wants me to have sex, and we love each other. (What would you say?)

I'm going to do this someday, anyway. What's wrong with now? (What would you say?)

If I lose him, I'll just die. (What would you say?)

3. Then ask the learners to think about a new scenario:

Imagine that your friend, age 17, tells you that his girlfriend has been putting pressure on him to have sex.

4. Read aloud the following statements and ask learners how they would respond to their friend for each one:

She really wants to have sex, and she says she loves me. (What would you say?)

I'm afraid I'll lose her if I don't have sex. (What would you say?)

She said we could use a condom. (What would you say?)

Everyone else my age is doing it. What's the big deal? (What would you say?)

5. Point out any differences in their responses to their younger sister and their responses to the older friend. 


\section{Session 20 Resisting Peer Pressure}

\section{Learning Objectives}

By the end of the session, learners will be able to:

List different situations in which peer pressure occurs

Demonstrate effective skills to resist peer pressure

Time 70 minutes

\section{Background Notes}

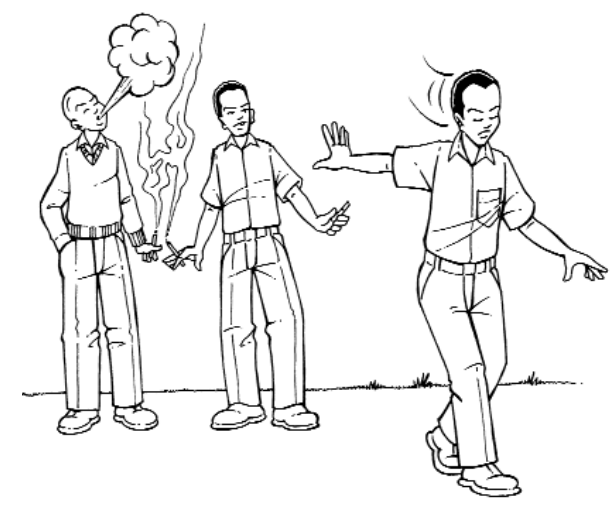

Even though young people often report that they learn more from friends when they reach adolescence, studies have found that these same adolescents would prefer to learn about a variety of important topics from their parents or other caring adults. Peer influence does increase during adolescence, but the influence of caring adults can remain strong if you've established a strong relationship during the earlier years. Most peer pressure for young people is just as subtle as it is for most adults.

This is why practicing saying no peer pressure is important. Finding creative ways to refuse alcohol, tobacco, drugs, and sex requires humour and lots of practice. Each young person can help develop his or her own ways of saying no, but it's your job to help them practice these so that they are prepared if the offer is more subtle or more direct than what was expected. A lot of this will depend on the age and attitude of the child, and the most important thing is to make sure the child is comfortable with what he or she wants to say. Your job is to coach them to use language and phrases that they come up with themselves to resist peers pressuring them to use drugs, have sex, or drink alcohol.

The younger the child, the more practice he or she will need. This cannot be a one-time session. You might find, that a 10 -year-old has no trouble saying no to a suggestion that he drink alcohol at a neighbour's house. However, three years later when the 17-year-old next door asks him if he wants a beer, he may hesitate because he is not as sure of himself and his convictions at 13 as he was at the age of 10 .

\section{Instructions}

\section{Resisting Peer Pressure (30 minutes)}

1. Ask learners to discuss reasons why adolescents begin to use drugs or have sex:

Peer pressure

Believing certain myths about drugs or sex that are not true

Being tricked into trying drugs or having sex

Curiosity

2. Explain that very often, people find it difficult to make choices that are different from what their friends are doing. This is often the case between boys and girls or men and women and even between close friends. Often people feel that by saying "no" they are hurting the other person or that they are being aggressive.

3. Discuss how young people get tricked into taking drugs without their knowledge or have sex when they wanted to abstain. Ask the learners to share some ways that young people could be tricked into doing something that they did not want to do.

\section{Practicing Resisting Peer Pressure (40 minutes)}

1. Remind learners of the Three C's model, the challenge, the choices, and the consequences (from Session 17 Decision Making). Point out that they can use the Three C's for decisions that could have a major impact on a person's health or future. 
2. Divide the group into four teams and assign a role-play scenario to each team. Tell the learners that this activity will give them a chance to practice using the Three C's model so they will be able to use it to make major decisions and resist peer pressure. Present the following instructions for this activity:

Each group will begin with the decisions from the role play and use the Three C's model to write out the challenges, choices and consequences for each decision on the board or on the handout. Spend 5-10 minutes on this.

Then, each team should spend 5-10 minutes preparing a role-play based on their scenario plus the choices they have made, and another 5 minutes to present it to the entire group.

After all the role-plays have been presented take 3-5 minutes to share your decisions with the entire group.

\section{Role-play scenarios}

1. You do not want to smoke. Your friend is trying to persuade you to have a cigarette. Use all your arguments to support your decision not to smoke.

2. You have decided that you want to abstain from sexual intercourse until you are married. Your boyfriend of one year says that he really loves you and wants to have sex so you can show how much you love each other. Use all your arguments to support your decision to abstain.

3. You have seen how your father's life has been damaged from drinking too much alcohol and have decided never to drink. Your new friend took a bottle of alcohol from his parents and wants to try it after school. He is trying to convince you to come with him and drink it. Use all your arguments to support your decision not to drink.

4. You just finished an exam and even though you studied you are sure you did not do well. Some of your classmates have offered you some marijuana (bhang) to smoke and tell you that it will make you feel better and will help you to not think about it for a while. You do not want to try drugs. Use all your arguments to support your decision to not use drugs.

\section{For 15-19-year-olds}

5. You have decided that a condom is your best protection against HIV, other STIs and pregnancy. You want to use a condom during sex, but your partner does not want to use one and will try to persuade you not to use it. Use all the arguments to support your decision.

6. You are away from home and you want to remain faithful to your partner. You really like the person you have just met and he/she wants you to have sex with him/her and will try to persuade you to do so. Use all the arguments you believe are relevant to support your decision.

3. Make sure the learners understand each role-play and the decisions made. Facilitate a discussion with the following questions:

Is it difficult to make good decisions? What makes it difficult? (Possible answers: the influence of alcohol, pressure from peers or a partner or not realizing a decision has to be made.) What makes it easier? (Possible answers: knowing how to resist pressure, being sure about your values and goals.)

In reality, how are most decisions made? (Possible answers: they are not made consciously, and events or things just happen).

In the past, have you made a decision that affected other people? What happened? Have you ever drifted into a decision or let someone lead you into a decision? What were the consequences?

Can you use the three Cs to help you make important decisions? 


\section{Optional Activity}

\section{\#1 Saying No to What You Don't Want}

15-19 1. Remind learners that there are two ways to get what you want or need: 1) by asking for what you want and 2) refusing what you do not want. Explain that in this session, learners will practice refusal skills.

\section{Ask learners to think about the following scenario:}

Alice and Mary are walking home after school. Alice wants to meet her boyfriend at the market and asks Mary to go with her. Mary's mother will be very upset if she is not home right after school. Alice tells Mary that she can just tell her mother that they had a health club meeting. Mary does not want to lie to her mother and she does not think that it is a good idea to go see Alice's boyfriend because he is older and does not seem like a very nice man. Alice promises Mary that they will not stay too long and also that her boyfriend's friend likes Mary and wants to talk with her.

3. Ask if anyone can describe what Mary is probably feeling in this situation. Write the feelings on the board. They should include emotions like pressured, confused, frustrated, nervous, or angry. Explain that it is also normal to feel angry if a friend pressures you to do something he or she knows is not in your best interest.

4. Explain that Mary has rights in this situation, like anyone does, when asked to do something. Go over the list of Alice rights:

The right to say how she feels in this situation.

The right to say no without feeling guilty.

The right to behave in a way that is best for her.

The right to change her mind (even if she had agreed to do what was asked).

5. Ask learners to discuss what advice they would give to Mary. Then mention that sometimes parents, teachers, employers or other adults in authority make requests of young people. The request may not please the young person and may not feel like it is in her or his best interest. Ask how a young person's rights are similar or different with a parent than a friend. Explain that some adults, such as teachers, parents and family members, do have the right to make requests of young people. Unless the adult is asking for something that is illegal, harmful or seriously disrespectful of the young person, it is often not appropriate for a young person to refuse the request. Young people do, however, have the right to say how they feel.

6. Ask the group to brainstorm the behaviours Mary needs to use to be assertive. Write their responses on the board or newsprint and be sure the list includes the following behaviours:

Say no with her words.

Say no with her body. Use strong language, make eye contact, stand back from Mary, who is pressuring her.

Keep repeating no without giving any excuses or reasons.

Turn the conversation around and tell Mary how she feels about being pressured into doing something that is not good for her.

Offer a compromise. Find a solution that does not require Mary to do something she does not want to do.

Leave the situation and refuse to discuss the matter anymore and walk away if necessary. 
7. Ask for a volunteer to role-play Mary, while you play Alice. Tell the rest of the group to coach the volunteer so she can remain assertive while being pressured.

8. Re-read the scenario. Then role-play with the volunteer using lines like the following to pressure her or him:

“Come on, you're supposed to be my best friend. I really want to see him and his friend really likes you."

"Your mother won't even know. We will only go for a little while."

"What's the matter, are you afraid? Irene would come with me if she were here."

Continue for a few minutes, encouraging the audience to coach Mary.

9. After the role-play, ask learners to identify the behaviours "Mary" used to be assertive. If there is time, have another volunteer try the role-play.

10. Facilitate a discussion with the following questions:

When could you use a coach when faced with real pressure from a friend or a romantic partner? Which is most difficult, speaking up for your wants or refusing what you do not want? Why? Think of a recent situation in which you wanted to refuse a request but were not able to. Which refusal skills could you have used?

Do you have a situation now where someone is pressuring you to do something that is not in your best interest? What could you do to be more assertive in that situation? 


\section{Session 21 Drug Use}

\section{Learning Objectives}

By the end of the session, learners will be able to:

Define and name the most commonly abused drugs among adolescents

Describe situations that can lead adolescents into drug abuse

Explain the effects and risks of commonly abused drugs

Time 50 minutes

\section{Materials Required}

Board, chalk

Index cards containing information about drug effects and risks

\section{Background Notes}

Drug abuse is a public health problem that increases adolescents' risk of risky sexual practices, poor academic performance, juvenile delinquency, developmental problems and accidents. Drug use can be defined as the use of any chemical substance that causes physical, mental, emotional, or social harm to an individual or to the people close to him or her. Drug addiction is the use of drugs despite the social, emotional, or physical harm they may cause the individual. The addictive nature of drugs varies from substance to substance, and from individual to individual. Some drugs are more addictive than others, and some people are more likely to become addicted than others. Some legal substances, such as medicines, caffeine, cigarettes and alcohol may be abused.

Drug addiction has two parts: physical dependency and psychological dependency. Physical dependency occurs when a drug has been used habitually and the body has become accustomed to its effects. The addict must then continue to use the drug in order to feel normal, or its absence will trigger the symptoms of withdrawal. Psychological dependency occurs when a drug has been habitually used and the mind has become dependent on the effects and does not feel capable of functioning without it. Its absence produces intense cravings, which are often brought on or magnified by stress. A dependent person may have physical dependency, psychological dependency, or both.

\section{Drug and Alcohol Abuse}

It is important to note that "use" and "abuse" of drugs and alcohol are not the same. Use of drugs may come before abuse of drugs and does not necessarily lead to abuse. Drug abuse is not defined by frequency of drug use alone but also considers the age of the drug user, physiological responses, levels of dependency, attitudes about substance use, and the effects that the drug uses has on other areas of the user's life.

Some predictors of drug and alcohol experimentation use and abuse include:

Family factors: Adolescents who observe their parents using or abusing drugs, alcohol, and other addictive substances are more likely to use or abuse them. Other family risk factors include parental absence, inconsistent discipline, poor or lack of communication, conflict between parents and adolescents, death of parents due to HIV and AIDS, and family breakup. However, family disruption may not directly lead to drug use, rather, family problems may lead to disenchantment with traditional values and the development of deviant attitudes, which may lead to drug use.

Early antisocial behaviour: Adolescents who show early antisocial behaviour may be more likely to use or abuse drugs. Drug use may occur as part of many other self-destructive behaviours. 
School factors: A range of school problems, such as poor performance, frequent absences, early drop out or little interest in school, may result in use or abuse of drugs by adolescents. However, it may be more likely that social factors that are linked to poor performance in school are independently linked to drug use.

Peer factors: Spending time with peers who use drugs is perhaps the strongest predictor of adolescent substance use. Peers who are already involved with drugs may encourage others to use drugs through peer pressure, by providing drugs, and by showing others how to use them.

Attitudes, beliefs, and personality traits: Some attitudes, beliefs, and personality traits may make adolescents more likely to use or abuse drugs. Some characteristics include poor relationship with parents, low interest in education, and feelings of being different from others.

Response to stress: Substance and drug use in adolescents may be the result of feeling out of control, a sense of meaninglessness, or a lack of direction in life. Adolescents may use drugs to feel better about life events, which they see as being out of their control.

\section{Consequences of Adolescent Substance Abuse}

Adolescents face unique risks associated with substance abuse. The use of substances may cause negative consequences during an adolescent's mental and emotional development. In addition, adolescents are at risk for a number of direct and indirect problems, including the following:

School-related problems: Adolescent substance abuse is associated with declining grades, absenteeism from school, and dropping out of school.

Risky sexual practices: Adolescents who use drugs and alcohol are more likely than non-using teenagers to have sex, initiate sex at a younger age, and have multiple sex partners. This places them at greater risk for unplanned pregnancies, HIV and other sexually transmitted infections.

Delinquent behaviour and juvenile crime: Drug use can lead to selling drugs, stealing and violence.

Developmental problems: Substance abuse may negatively impact an adolescent's mental and physical development.

Physical and mental consequences: Doing drugs can have negative effects on the user's mind and body. The effects can be short-term, such as memory loss, or long-term, such as cancer, infertility, or HIV-infection from unclean needles.

Future use disorders: The younger a person is when he or she first drinks alcohol, the more likely that person is to develop a problem with alcohol abuse later in life.

\section{Signs and Symptoms of Substance Abuse}

People who interact with adolescents in the home or community need to be alert to changes in an adolescent's behaviour and appearance that may signal substance abuse. By recognizing the signs and symptoms of substance use, you may be able to get help for a young person in need of treatment. The following behaviour changes, when extreme or lasting for more than a few days, may indicate alcohol-related or drug-related problems and the need for further screening by a professional.

Sudden changes in personality without another known cause

Loss of interest in favourite hobbies, sports, or other activities

Sudden decline in performance or attendance at school or work

Changes in friends and reluctance to talk about new friends

Deterioration of personal grooming habits

Difficulty paying attention or forgetfulness

Sudden aggressive behaviour, anger, nervousness or giddiness

Increased secretiveness, heightened sensitivity to being asked questions 
Alcohol, Drugs, and HIV

Adolescents and young adults are at the age when trying new things is especially inviting. Alcohol and drugs may be particularly attractive to young people. Although alcohol and drugs do not cause people to become infected with HIV, people who use them increase their risk of becoming infected with HIV. They may be influenced by drugs to have risky sexual intercourse, be forced into prostitution to support a drug habit, or become HIV-infected by sharing needles. Drugs and alcohol also negatively affect the immune system, making a person less able to fight disease.

\section{Instructions}

\section{Commonly Abused Drugs (15 minutes)}

1. Ask learners to define "drug" and "drug abuse." Write all the responses on the board without making any comments. Tell the learners that drug abuse is the non-medical use of drugs that interferes with a healthy and productive life.

2. Ask them to name the different types of drugs that people use (adolescents in particular) in their communities. Add to their list what they may have missed from the following list. They should also include street names of drugs.

Medical drugs (pain relievers, cold medicines, sleeping pills)

Alcohol, spirits

Miraa (gomba)

Marijuana (bhang, kaya, ganja)

Inhalants (glue, nail polish remover, lighter fluid, petrol, etc.)

Chang'aa (puya, kumi kumi)

Tobacco (fegi, mozos)

Kuber

Busaa

Cocaine (Mataptap)

Caffeine

Heroin

3. Explain that drugs have been used throughout human history and are used for different reasons. The problem now is that there are more varieties of illegal drugs, most of them are very strong and often abused.

4. Explain that this session is not concerned with the medical uses of drugs but with the misuse and abuse of drugs.

\section{Myths and Facts about Drugs (35 minutes)}

1. Point out that some substances, such as vitamins and medications, have a positive effect on health when used as prescribed, but can be harmful if abused or taken in excess.

2. Explain that this activity will test learners' knowledge about drugs and their effects on health. Read the directions below out loud:

Two teams will compete to see which knows more about drugs. Teams get a point for each correct answer.

Individual team members will listen to a statement about drug use. Some of the statements are true and others are myths.

After reading a statement, the team member should talk with the entire team to decide on the best answer. There is a time limit to answer (30-60 seconds). 
3. Ask learners to give their team a name and move to opposite sides of the room. After teams are named, have the first person move forward and read them a statement from the Myths and Facts on Drugs sheet on the following pages. Ask him or her to talk with team members to decide on the best answer. If the answer is correct, give the team a point. If the team member can provide additional information about why the statement is a myth or a fact, his or her team will win an additional point.

4. When teams do not know the correct answer, provide additional information from the list of myths and facts.

5. Ask members of the other team to have someone step forward and repeat the process. Read the next statement on the list and continue alternating teams until every participant has had a turn. Keep the activity moving; do not allow much time for answers (30-60 seconds). Do encourage discussion about the statements.

\section{Discuss the following points with learners:}

What drugs or substances do your friends talk about?

Which myths do your friends still believe?

Which myths are the most harmful? Why?

How can you help friends who do not have accurate information about drugs and drug use?

\section{Optional Activity}

\section{\#1 Making Decisions about Drugs}

1. Explain to learners that knowing information about drugs and their dangers is not enough to help them when people start pressuring them. Write the word 'skills' on the board and ask what skills young people need in order to resist pressure to use drugs. List their responses, which should include decision making, communication and assertiveness.

2. Ask learners to describe different scenarios when someone could be pressured to try drugs. Once you have four scenarios, divide the class into four groups and assign one scenario to each group. Review the Three C's to Good Decision Making. Either write it on the board or make copies of the handout. Go over the instructions to this activity:

Working in four groups, use the decision-making model to make a difficult decision, based on the pressure scenario assigned to your group. Decide what choices young people have and what might be the positive and negative consequences of these choices.

Come to agreement about the best decisions for your scenario and be prepared to share it and your reasons with the entire group.

Take about 10 minutes to make your decision.

3. Ask each group to describe their scenarios and ask them to describe the decision making process. Repeat this for each group. Allow 5 minutes for discussion after each scenario.

4. Facilitate a discussion with the following questions:

How difficult or easy was it to make these decisions? Which one was the toughest?

What parts of the decision-making model seem to be the most useful in these kinds of situations?

What were the negative consequences for each of the situations?

Can anyone share a difficult decision that you have made in the last three years?

Do you know someone facing a drug issue right now? What are his or her options? 


\section{Myths and Facts on Drugs}

Alcohol is an addictive substance, not a drug.

Myth. Alcohol is a drug, as is any substance that affects the mind or body.

More adolescents use alcohol than bhang.

Fact. Alcohol is the most frequently used drug among adolescents because it is readily available.

Coffee, tea, and many sodas contain drugs.

Fact. Coffee, tea and many sodas and diet sodas contain caffeine, which is a stimulant. Caffeine is addictive; headaches are a common sign of withdrawal when people stop using it.

It is rare for a young person to be an alcoholic.

Myth. Many young people use alcohol weekly and many are addicted to it.

\section{Cigarette smoking can be addictive.}

Fact. More people are addicted to cigarettes than any other substance. Cigarette smoking is a very difficult habit to break but stopping is essential for good health.

Many adults addicted to drugs feel like smoking bhang was the first step to their addiction. Fact. Bhang is viewed as a drug that opens the gate to the use of other drugs, by addicts and researchers alike.

\section{Alcoholism is a disease.}

Fact. Alcoholism is a disease, just as diabetes or epilepsy are diseases. It can respond to treatment, which includes eliminating all alcohol consumption.

\section{Drugs help people handle their problems better.}

Myth. Drugs help people forget about their problems or reduce the pain caused by problems. The problems do not go away and often get worse with drug use.

Inhalants are basically harmless even though adults make a big deal about them.

Myth. Using inhalants (like glue and petrol) can be extremely dangerous because they can cause permanent damage to organs like the liver, brain or nerves.

\section{A cup of coffee and a cold shower will sober a drunkard.}

Myth. Only time will cause a person to become sober. It takes one hour for the liver to process onehalf ounce of pure alcohol.

\section{Alcohol affects some people more than others.}

Fact. Factors that influence how alcohol affects the individual include: body weight, amount of alcohol consumed, the presence of other drugs in the system, the general health of the individual at the time and how recently she or he has eaten.

\section{Alcohol is a sexual stimulant.}

Myth. Alcohol, like cocaine and other drugs, can actually depress a person's sexual response. The drug may lessen inhibition with a sexual partner, but it causes problems such as a lack of erection, or loss of sexual feeling. In addition, alcohol or drugs may cause a person to do something sexually that he or she would not do when sober.

When people stop smoking they can reverse some of the damage to the body. Fact. If there is no permanent heart or lung damage, the body begins to heal itself when a person stops smoking.

\section{Cigarette smoking will hurt a pregnant woman, but will not hurt her baby.}

Myth. Smoking by pregnant women may result in premature birth and low birth weight babies. 
Drinking only beer will prevent problems with alcohol.

Myth. Ethyl alcohol affects anyone who drinks it, and ethyl alcohol is present in beer, as well as in wine and liquor. Drinking beer can cause the same problems as wine or liquor.

\section{Smoking cigarettes every now and then is not harmful.}

Myth. As soon as people start smoking, they experience yellow staining of teeth, bad breath and a shortness of breath that may affect their physical performance. Addiction to nicotine is quick. People who smoke for any period of time have a greater risk of lung cancer and other lung diseases, cancer of the tongue and throat and heart disease.

\section{Bhang is not harmful.}

Myth. Although research is ongoing, many experts believe that long-term use of bhang is potentially dangerous and may lead to: a decrease in motivation, memory loss, damage to coordination, impaired judgement, damage to the reproductive system, and throat and lung irritation.

Drugs like alcohol, miraa and cocaine wouldn't be a problem for young people if they did not cause addiction.

Myth. Drugs interrupt normal growth and development for young people, cause problems with school and in relationships, and often result in unplanned pregnancies or STIs, including HIV, because their use can lead to risk-taking behaviour.

\section{Alcohol becomes a problem only after years of use.}

Myth. When a person takes a drink, alcohol immediately slows reaction times, affects balance and decreases coordination. That means an athlete, student, musician or driver may lose normal ability and performance will be affected.

Driving after using miraa is much safer than driving after drinking alcohol.

Myth. Like alcohol, miraa affects motor coordination, slows reflexes and affects the way we see and interpret events around us. Any of these changes increases the likelihood of an accident while driving. 
Three C's for Decision Making

Describe the CHALLENGE (or decision) you are facing

List three CHOICES you have and the consequence of each choice:

1)

Consequences

2)

Consequences

3)

Consequences

96 


\section{Session 22 Sexual Violence and Rape}

\section{Learning Objectives}

By the end of the session, learners will be able to:

Define sexual exploitation, rape, date rape, and incest

Differentiate between a "good touch," "bad touch," and "confusing touch"

Describe at least three ways to get out of an uncomfortable sexual situation

Describe ways to prevent and deal with sexual abuse and rape

\section{Materials Required}

Handout 22.1 Sexual Abuse and Family Violence Scenarios

Handout 22.2 Preventing Date Rape

\section{Time 75 minutes}

\section{Background Notes}

For many young people, sex is not a choice. Rape is defined by the Kenyan law as having sex with a woman or girl without her consent or with consent obtained under threat, force, intimidation, fear of bodily harm or misrepresentation. Defilement happens when sex occurs with a person that the law defines as too young to legally consent (in Kenya, girls below 16 and boys below 14) even with his or her permission. Date or acquaintance rape refers to rape that occurs between individuals who are dating or who know each other. Sexual violence includes the use of sexual contact by one person to another against his or her will. It can result in serious physical injuries, profound psychological trauma, unwanted pregnancy and infection with STI including HIV.

Some adolescents are forced to have sexual relations, feel pressured to have sex in exchange for good grades or pocket money, are assaulted if they refuse to have sex or sell sex in order to survive. Every adolescent should know that his or her sexual organs are private and personal property. Nobody should touch them without permission. Some victims of sexual abuse are assaulted by family members or acquaintances. Often young children are the victims of incest (a young person may be forced to touch, kiss or feel the sex organs, or have actual sexual intercourse with a relative). Because of the older person's position in the family, he or she may be able to pressure the child into doing sexual things without actually having to use force. These crimes, including rape, are the fault of the perpetrator or older person and not the fault of the victim or child.

For girls and women, the short-and long-term consequences of sexual violence can be physically and emotionally damaging. Because of the sexual nature of rape crimes, victims often suffer from serious mental issues. If someone is raped and reports it to you, you should encourage them to go to a hospital or health centre. At the hospital they will have a medical evaluation and attention to any injuries, counselling support for the survivor and her family, and treatment to prevent infection with HIV, pregnancy and other sexually transmitted infections. Referrals to other services may be required.

Note: If a young person has been raped, it is important that he or she receives medical attention as soon as possible. Emergency Contraceptives (EC) can prevent pregnancy within 120 hours (5 days) and Post Exposure Prophylaxis (PEP) can prevent HIV infection. PEP is the administration of one or a combination of anti-retroviral drugs for 28 days after exposure HIV. 


\section{Instructions}

\section{Quiz on Sexual Violence (30 minutes)}

1. Read the following questions from and ask learners to write true or false on a piece of paper.

1. Being drunk and "out of control" is not an excuse for rape.

2. If a person gives in to sexual intercourse out of fear, it is considered consent and is not rape.

3. Men are not ever really raped.

4. Physical force is used in most rapes.

5. Most victims of rape are adolescents and young adult women.

6. Women are most likely to be raped when out alone in a dangerous place, especially at night.

7. Having sexual intercourse with a woman after pressuring her to get high or drunk is not rape.

2. Ask learners to share their answers and facilitate a discussion around each of the questions.

1. True - Being drunk and "out of control" makes it harder for people to communicate effectively. However, it is not an excuse to force a person to into sexual intercourse.

2. False - Consent is based on choice, when two people have equal power. If a powerless person gives in out of fear, that is not consent.

3. False- Some rapes are committed against boys and men but few ever acknowledge it.

4. True - There is often some form of physical force or verbal threat of force. Sometimes a victim is pressured to give in to the sexual act.

5. True - Young women between the ages of 16 and 24 are three times as likely to be raped as other women. However, children as young as a few months or adults as old as 98 years have been raped.

6. False - Rape can occur anywhere. Over half of all rapes occur inside a residence, most often the victim's home or compound.

7. False - As long as a woman has not given consent, it is rape.

\section{Define Sexual Exploitation (5 minutes)}

1. Ask learners to define sexual exploitation. Their definition should be similar to the following:

Sexual Exploitation is when someone uses another person to make him/herself feel good or to get something from the other person without concern about how that person feels.

Sometimes, people trick or pressure others into "bad touches". This is another type of sexual exploitation. People also force others into sex, which they did not want to be engaged in.

That is called "sexual abuse" or "rape."

\section{Good, Confusing, and Bad Touches (20 minutes)}

1. Ask learners to explain whether there are different kinds of touches.

2. Draw three columns on the board and have learners provide examples of good touches, confusing touches, and bad touches.

Some of these types of touches could be good touches or bad touches depending on the intention of the person touching. If a kiss is started by an older man with a child, it could be a bad touch. If a back rub is intended to lead to sexual activities it could be a bad touch. 


\begin{tabular}{|l|l|l|}
\hline \multicolumn{1}{|c|}{ Good touches } & \multicolumn{1}{c|}{ Confusing touches } & \multicolumn{1}{c|}{ Bad touches } \\
Hugging & Tickling & Hitting, slapping or punching \\
Holding hands & Touching private parts & Kicking \\
Hair brushing & Handshake with a pinch & Biting \\
Kissing & Back rubs & Pinching \\
A pat of the back & A long hug & Forced sex \\
A doctor's examination & & \\
\hline
\end{tabular}

\section{Explain that exploitation:}

Usually happens gradually. Starts with a good touch, then a confusing touch and into a bad touch. Usually involves tricks, threats, or treats.

Usually involves a person known to the exploited, even though it also happens with strangers.

Often involves secrecy.

Can involve boys and girls.

\section{Ways to Get out of an Exploitative Situation (20 minutes)}

1. Read the following scenario on prevention and reporting sexual exploitation.

Jomo and Emily were sent by their mother to get some sugar from their neighbour. They have been sent there many times before. When they arrive, the neighbour (an elderly man) invites them for some fruit in the house. While they are eating the fruit, he starts rubbing Emily's leg. Ask learners to describe how they think Emily and Jomo felt?

2. Continue with the scenario. Just before Emily and Jomo left, the neighbour offered to give them some money if Emily would remove her clothes. Ask learners what they would have done if they were Emily? Jomo? Discuss their responses.

3. Continue with the scenario. After Emily refused, the neighbour left them alone but then gave them the money he had offered so that they would not tell anyone about the incident. Ask learners what they would do if they were Emily and Jomo.

4. Make sure the group decides the incident should be reported, for two reasons: 1) to protect themselves from another incident with the neighbour, and 2) to protect other children from him.

5. Facilitate a discussion with the following questions:

Who would they report it to?

Where do they report it?

Why could it be difficult for them to decide who to report it to?

How can the difficulties be resolved?

Remind learners that there are other people, like teachers, religious leaders, community members, who can help them resolve the problem. Emphasize the need to seek help. 
6. Summarize this section by emphasizing that:

Not all touches are good and it is important for adolescents to know the difference between good and bad touches.

It is important to report bad touches to a parent, guardian, teacher, or trusted relative as soon as possible because these touches normally lead to more and can develop into actions such as forced sex.

Talking with a trusted adult about confusing touches can help young people decide what to do about them.

Reporting helps to protect themselves and others.

\section{Rape and Gender Violence (45 minutes)}

1. Explain that rape is sexual intercourse on an unwilling male or female by the use of force, coercion, intimidation, or any kind of threat. Rape happens to a person when they do not give consent to have sex. Facilitate a discussion with the following questions: Can men or boys be raped? Can a husband rape his wife?

2. Explain that gender violence is any act done on a woman with the aim of hurting her because she is a woman. This may be physical, or psychological harm including threats and intimidation in public or private.

3. Explain that in Kenya sexual intercourse with girls below 16 years and sexual intercourse with boys below 14 are both criminal offences whether there was force used or not.

4. Emphasize that as long as one person is unwilling to have sexual intercourse, it is rape regardless if it is a husband, boy, girl, wife, acquaintance, relative, neighbour or stranger committing the act. Ask the learners to identify the crime that occurs when a romantic partner forces another to have sex. If no one answers correctly, write "date rape" on the board. Make the following clear: Acquaintance rape, also known as date rape, is forced oral, anal or vaginal sexual intercourse by someone the person knows and may even have a romantic relationship with.

\section{Emphasize the following:}

Rape is an act of aggression that uses sex to show the victim that the rapist has power.

Rape is a crime punishable by law.

Many girls in Kenya are forced or tricked into their first sexual experience.

Nothing a woman does, including using drugs or alcohol, going to "risky" places, wearing certain clothes, kissing and sexually touching or even having previously had sex with a man, gives a man the right to force her to have intercourse against her will.

Alcohol and drugs are often involved when date rape occurs. Being drunk or high makes women less able to set clear boundaries and men less inclined to listen to those boundaries.

Books and movies often suggest that women are excited by the power and force of rape and may even fall in love with the rapist, but a victim of rape never experiences the act in a positive way, even in a date situation in which the beginning of the sexual encounter was pleasant. 


\section{Ways to Prevent and Deal with Sexual Abuse (25 minutes)}

1. Distribute the handout on "Preventing Date Rape." Let the learners take it home to read if copies are available. If no copies are available, read over the handout with the learners.

2. Ask participants to discuss why they think most rape cases are not reported:

Fear of being blamed

Fear of consequences

A false sense of obligation to protect a relative or acquaintance

Fear that no one will believe them

Fear that everyone will know about it

Fear that no one will care or listen

3. Divide the group into small groups and assign one "Sexual Abuse and Family Violence" case to each group. Ask each group to discuss the options and decide what they would do, considering the positive and negative consequences. Ask each group to present their case and their decision.

4. Facilitate a discussion with the following questions:

What if you do all the right things and are unable to stop your date from raping or assaulting you? Does that mean you did not try hard enough? What should you do? (Answer: Whenever rape occurs, regardless of what was or was not said or done to prevent it, it is never the victim's fault. If you are raped, get help immediately and do not feel guilty.)

What are some of the things that we have discussed that have changed the way you think about rapists? How has your opinion of rape victims changed?

What are some of the things you have heard people say about girls or women who have been raped and how do you feel about the things these people say?

What precautions can girls and women take against stranger rape? (Answer: Be alert to the surroundings; avoid dark, lonely places at night; keep doors and windows locked; walk in groups; scream for help if cornered; take a self defence class; or keep a loud whistle on a key ring.)

What are some things that girls and women can do to help prevent date rape? (Answers may include: communicate with your date, state expectations clearly, listen carefully, ask questions if things get confusing, avoid using alcohol and other drugs that cloud your judgment, and let the man know your intentions - "I like dancing with you, but I don't want to have sex with you.")

Remind learners that:

No matter what the circumstances, they have the right to choose when, with whom, and how they want to be sexual.

When first getting to know someone, go out with other people or groups rather than alone.

Trust your feelings - if you begin to feel nervous or uncomfortable about the way things are going, do something about it right away. Let your date know how you feel and get away from the situation to a place where you feel more comfortable. 
5. Ask learners to list what they think someone should do if he or she is assaulted or harmed. Allow several volunteers to share the steps that they should follow. Then review the following information with the learners.

\section{What to Do if Assaulted or Harmed}

Talk to a parent or trusted adult and go to the nearest hospital or health facility for a medical exam and treatment. A doctor should confirm the assault.

Take the medical report to the police station and collect a P3 form. If severely hurt, the police should be asked to visit the health facility with a P3 form to record the crime

Have a P3 form filled and take it to the police doctor to record the assault. (If up country, go to the District Government Hospital.)

Take back the P3 form to the police station for the arrest of the perpetrator (and keep a copy of the form for yourself if possible).

Identify the accused for arrest.

Attend court when the accused is charged.

6. Ask learners to list what they think someone should do if he or she has been raped. Allow several volunteers to share the steps that they should follow. Then review the following information:

\section{What to Do if Raped}

Do not shower. Do not wash any clothes, including underwear.

Talk to a parent or trusted adult.

Go to the nearest hospital or health facility for a medical exam and treatment. A doctor should provide treatment, confirm the rape, and obtain evidence. A PRC1 (Post Rape Care) form should be completed in duplicate at this time. A PRC1 form allows the P3 form to be completed effectively because it contains all clinical notes. You should be given the original PRC1.

Take the PRC1 to the police station where a report is entered into the Occurrence Book. You will be issued a P3 form, which should be free of charge. An OB number should be given to you. Bring the clothes worn at the time wrapped in newspaper (not nylon or plastic). If severely hurt, the police should be asked to visit the health facility with a P3 form to record the crime.

The police should record your statement and and that of any witnesses. Only sign it when you are satisfied with what is written.

Take the P3 form to be completed by an authorized health worker based on the PRC1 form. (If up country, go to the District Government Hospital.). The P3 form does not have to be completed immediately. This can be done at a later date after the medical evaluation is completed.

Identify the accused for arrest and attend court when the accused is charged.

7. Remind students that rape crimes need to be reported early so that EC and PEP treatment can begin, investigations can start, and culprits can be arrested if known.

*NOTE: Be aware that one or more of your students may have been raped or molested. If a student becomes upset during this discussion, you may want to speak quietly to that person and make plans to talk privately at a later time. You may want to find local resources (maendeleo ya wanawake, FIDA, police, or spiritual leaders) for rape victims (location and phone numbers) before presenting this topic. 


\section{Handout 22.1 Preventing Date Rape}

Date rape is one of the most common types of sexual assault. It occurs when someone you know forces you into unwanted sexual activity of any kind. This includes unwanted sexual touch or oral, vaginal, or anal penetration, or forcing you to touch him/her in a sexual way. The rapist could be a teacher, a friend, boyfriend or girlfriend, a neighbour, a spouse, a co-worker, or a relative. Rape happens because of a need for power and control over someone else. It is never the victim's fault.

\section{How Can I Protect Myself?}

Trusting your instincts is your best protection. If you feel uncomfortable with a situation or threatened by someone, get to a safe place as soon as possible. Some other things you can do are:

Avoid being alone with a new boyfriend or girlfriend before you are ready. It is a good idea to go out in groups with friends, especially when dating someone new. Avoid secluded places including someone's home when parents or adults are not their, secluded areas or empty buildings.

Always make sure that someone (parents, siblings, friends, guardian) knows where you are going, who you will be with, and when you expect to be back. Carry a friend's phone number with you to call if you need help.

Think about your sexual limits. Before going out on a date, think about what you want to do and do not want to do. A decision to be sexual in any way should be made together and never forced.

Be clear about your sexual limits. Give the message that no means no, not try harder for a yes.

Trust your instincts. If you feel pressured or threatened in any way, do not hesitate to say what you feel or to leave if necessary.

Do not worry about being polite. Use strong nonverbal techniques to reinforce what you are saying such as pushing away, not smiling and using a firm voice.

\section{Danger Signs}

The following are some actions and attitudes to watch out for. If your partner or acquaintance engages in any of these behaviours, it may be a warning sign that the partner is potentially abusive.

Threats. Verbal or physical threats to force you into sexual activity you do not want. Threats such as "If you don't have sex with me I'll break up with you."

Jealousy. Constant demands to know where you are and who you will be with. Watch out for someone who gets very jealous easily.

Criticism. Disapproval about your actions, your clothing or your friends.

Controlling. Does not acknowledge your needs and wants, or not letting go when you try to pull away.

Anger or violence. Frequent and noticeable anger or violent acts, including small disagreements possibly with threats to hurt you or people you know. She or he may later apologize for the behaviour, but it is still abusive.

Verbal abuse. Jokes about your physical appearance, your gender or constant criticism.

Manipulation. There are many ways in which people can be manipulative in an abusive way. For example, she or he could intentionally try to upset you by flirting with other people. 


\section{Handout 22.1 Sexual Abuse and Family Violence Scenarios}

1. All night Nekesa had been listening to her stepfather yelling and slapping her younger brother, Andahi. "He picks on Andahi all the time, but this is different," she thought. She noticed last weekend that Andahi had several bruises on his face and she wondered what happened, but her mother said "nothing" when she asked. Tonight there has been so much yelling, and poor Andahi was screaming and crying. Nekesa was scared because she didn't want Andahi hurt. She didn't know what to do.

2. Ayesha started crying softly after her father left her room. She felt like she always did when he came into her room and touched her; she wanted to die. He would always do the same things that he had been doing since she was nine. She hated it and always felt so dirty and disgusted with herself when he left. He told her that it was her fault and that she made him do these things. He also told her that if she told anyone, she would be made to leave the family. Ayesha had thought about telling her mother, running away, or killing herself. But she was always too scared to do anything but lie in her bed and pretend she was asleep. She was so miserable. She wanted help. What should she do?

3. Charity wondered all the way home what she should do. Boniface had forced her to have oral sex with him and she had told him over and over again that she didn't want to. He said it was her fault for kissing and touching and letting him get so excited. He said she wanted it, too, and besides, it was her place to please him. Afterward, she had felt numb and only stopped crying when he finally told her he loved her, but she felt no love, not anymore. She felt hurt, used, and betrayed. Would anyone care that he had made her do this? Would anyone believe she had told him no? He said it was her fault. Was it? She wanted to talk to someone so badly, but she couldn't bear to tell any of her friends. What would they think of her? What should she do?

4. Mulamba heard the sounds again. He knew what was going on. His mother's friend, Bwire, had come in around 9:00 p.m. and he had already been drinking. Mulamba's mother had given Bwire food and another beer. Mulamba always got angry when he watched his mother try to please this crazy man. Now it was almost midnight and he knew what was happening. He knew where his mother's last split lip and swollen eye came from. But he didn't know what made the most sense, whether to go in there and break it up, or to plead with his mother in the morning to leave this guy. Only tonight, things sounded worse than usual. Mulamba was really worried about his mother. What should he do? 


\section{Facilitator Notes - Sexual Abuse and Family Violence Scenarios}

\section{Suggested Actions and Responses}

\section{Nekesa and her stepfather}

Nekesa needs to get help immediately. She should go to a neighbour's house. Her stepfather will be angry, but someone might be able to help her brother. Once the immediate danger is past, the family may need counselling and Nekesa's mother may have to separate from the stepfather to keep her children safe.

Intervening in an abusive situation like this is always difficult. However, many children are in danger of abusive parents and other adults. Get help immediately. Calling a neighbour or the police to stop a parent from abusing a child may save a life.

\section{Ayesha and her father}

Ayesha is in a very difficult family situation. Since her father has been abusing her for so long, Ayesha may feel like she has given permission for the sexual contact, and she may be too embarrassed to tell anyone. Her father may even argue that Ayesha likes what he does to her. As her father, it is illegal for him to have sexual contact of any kind with her. He has been forcing her to have sex against her will, even though he hasn't used a weapon or physical force. Giving in to unwanted sex out of fear is not giving consent.

Ayesha should talk to a trusted relative, counsellor or teacher who can suggest a safe place for her to go to report the abuse. Several things may happen: Ayesha's father might stop the abuse as soon as it is reported and he is confronted with his abnormal sexual behaviour; he might go to jail; or Ayesha might have to go live with a relative for a while. She may receive counselling to help her deal with some of the anger, shame, and sadness she feels; she will eventually recover and feel much better about herself.

\section{Charity and Boniface}

She may not think so, but Charity has just been raped and she can do something about it. Forced sex of any kind is called rape. Even though Boniface was Charity's boyfriend, he had no right to force her into any kind of sexual act and she can have him arrested. It is up to her to decide whether she wants to prosecute Boniface. Only about one in 100 rapes is reported - but it is an option. Not reporting rape or sexual assault may encourage the perpetrator to do it again. Women always have the right to refuse any kind of sexual contact, regardless of the nature of the relationship or the situation they are in.

\section{Mulamba and his mother}

Like Mulamba, some children witness family violence. According to research, these children often grow up with deep psychological scars, even when they have not been abused themselves.

Mulamba should take immediate action by getting help for his mother, who is in danger from her boyfriend and appears to be powerless to stop the battering. If Mulamba fears that his mother's life is at risk at this moment, he should get out of the house and ask relatives or neighbours to go back to his house with him, even if it may be embarrassing to have the neighbours or relatives see what is happening. Mulamba should not try to interrupt the fight himself. He might get hurt or hurt Bwire more than he wants to. 


\section{Session 23 Teenage Pregnancy}

\section{Learning Objectives}

By the end of this session, learners will be able to:

Explain how pregnancy occurs by explaining the terms fertilization and implantation

Explain why adolescent girls have unintended pregnancy

List five physical risks associated with teenage pregnancy

Time 75 minutes

\section{Background Notes}

Ten thousand girls drop out of school every year in Kenya because of pregnancy. Several factors contribute to this problem: parents do not generally talk to their sons and daughters about sex, children lack information about their changing bodies, and adolescents may not understand how to control the sexual urges that come up naturally at puberty. The issue of teenage pregnancy can be addressed by teaching young people skills that will help them make appropriate decisions, be assertive, and resist early sexual activity.

Several studies have shown that the outcomes for adolescents who receive good antenatal care are no different from those of older women. However, antenatal care may not be available, and even if it is available, adolescents are more likely to seek care later in their pregnancies or to not seek antenatal care at all. They may not recognize the signs of pregnancy, may want to hide a pregnancy, may not realize care is available or may not be able to afford the fees charged. There are several medical and social reasons to delay childbearing.

Medical reasons to delay childbirth include:

A young woman under age 16 has not reached physical maturity. A small pelvis can lead to a difficult delivery, as well as lead to health problems or death of the mother or the infant.

Young women, especially those under age 15, are more likely than women age 20 and older to experience premature labour, spontaneous abortion (miscarriage), and stillbirths.

First births are typically more risky than subsequent births. Women giving birth for the first time have a higher probability of developing health problems.

Infant death rates are typically higher for adolescent mothers than for older women.

Some social reasons to delay childbearing include:

Delaying childbearing can give young women the opportunity to pursue formal education, work outside the home, and achieve their future goals.

Men can pursue education and jobs without the pressure of providing for a family.

Delayed pregnancy can mean smaller families and can offer economic benefits.

Pregnant girls may be expelled from or drop out of school and few girls return to school later.

The responsibility for caring for a child, as well as limited education, reduce a young woman's access to jobs and income-earning opportunities.

Some young women find themselves rejected by the father of the child or by their own families. 


\section{Instructions}

\section{Fertilization and Implantation (20 minutes)}

1. Ask learners how a female becomes pregnant. Ask for a volunteer to explain how fertilization occurs. Ask another volunteer to explain how implantation occurs. After learners have explained both terms, read the definitions below aloud to the group.

Fertilization takes place when a male sperm cell meets a female egg. Millions of sperm cells are deposited into the vagina during sexual intercourse. After the male ejaculates in the vagina, ejaculated sperm swim up through the cervix into the uterus. The woman's body helps guide the sperm through the uterus and to the fallopian tubes. If a mature egg (or more than one egg in the case of twins) is present, fertilization can take place. Although thousands of sperm may be present, only one sperm cell can penetrate the egg. Sperm can fertilize an egg up to seven days after intercourse. If an egg is fertilized, it will move from the fallopian tube into the uterus (womb) where it will grow.

Implantation takes place when a fertilized egg attaches itself to the lining of the woman's uterus. The nutrients in the lining of the uterus are used to support the growth of the egg into a foetus and then a baby. The woman will not experience periods during pregnancy because the lining of the uterus, which normally sheds during menstruation, is not shed at all during pregnancy. The implanted egg grows in the uterus for nine months and becomes a baby. It then comes out of the mother's body through the process of childbirth.

\section{Teenage Pregnancy (35 minutes)}

1. Ask if they know of any girls who have gotten pregnant. Follow up with the questions below:

What happened to the girls after they became pregnant?

Is unplanned pregnancy a common problem for adolescent girls in their community?

What circumstances caused them to get pregnant?

2. Ask learners to discuss why adolescent girls have sex. The following may be mentioned:

In some communities girls get married while they are still teenagers.

Many girls are forced, or coerced, into having sex.

Teenage girls experiment with sex.

Sometimes teenage girls are unable to set or communicate their limits and have sexual intercourse even though they did not plan to.

3. Ask learners to list major physical and emotional risks of teenage pregnancy and delivery.

\section{Myths about Sex and Conception (20 minutes)}

1. Read the myths and facts below out loud one at a time. Ask learners whether each one is a myth or a fact. Have them explain why they think it is a myth or a fact then read the explanation given.

\section{A girl can become pregnant if she has unprotected sexual intercourse before she has her first period.}

Fact - Before a girl's first period, her ovaries release the first egg during ovulation. She can become pregnant if she has unprotected sexual intercourse around the time of her first ovulation, even before she ever has her first menstrual period. She also risks getting an STI whether she has menstruated or not. 


\section{It is unhealthy for a girl to bathe or swim during her period.}

Myth - There is no reason that a girl should need to restrict any activity during her period. She should bathe every day and keep her private parts clean.

\section{Abstinence is the only method of contraception that is $100 \%$ risk-free.}

Fact - Avoiding sexual intercourse of any kind is the only way to absolutely avoid pregnancy or an STI, including HIV. Practicing abstinence does not require giving up all sexual contact, but it does mean expressing sexual feelings in ways other than having intercourse.

\section{A girl can get pregnant if she has sex while she is bleeding.}

Fact - There are two types of bleeding. The first is menstrual bleeding. During menstruation, it is unlikely, though not impossible, that a girl will get pregnant. There may also be bleeding during ovulation. If a girl has intercourse during this type of bleeding, she can get pregnant.

\section{A woman is not at risk of pregnancy unless a man ejaculates inside or right outside her vagina.} Myth - If a man ejaculates near the opening to a woman's vagina or touches her vulva while he has semen on his fingers, it is possible for sperm to find their way inside and fertilize an egg. Girls have become pregnant without ever actually having intercourse. Some STIs can be transmitted if there is an exchange of body fluids with or without penetration.

6. Once a boy is sexually aroused and gets an erection, he has to have sex or it will be harmful. Myth - There is no harm in not acting on every sexual urge; semen cannot get "backed up" and demand ejaculation. 0ccasionally a boy might feel some discomfort if he is sexually excited for a long period of time. This will disappear when he is able to relax.

\section{A girl cannot get pregnant the first time she has sex.}

Myth - It is possible to become pregnant anytime you have unprotected sex, even the first time. 


\section{Session 24 Parenthood}

\section{Learning Objectives}

By the end of the session, learners will be able to:

List responsibilities associated with being a parent

Describe ways in which parenthood can affect a person's life

Describe qualities of a good father and good mother

Time 80 minutes

\section{Instructions}

\section{Introduction to Parenthood (30 minutes)}

1. Explain that some of the most important life decisions they will make are: (1) whether or not to become parents, (2) who to become a parent with, (3) when to have a child or children, and (4) how many children to have. Explain that the next few activities will help them think about parenting.

2. Write "To be a good parent means to be...." on the board. Ask volunteers to complete the sentence.

3. Read the following statements out loud and ask learners to vote after each statement. Ask learners to use thumbs up to agree, thumbs down to disagree, and folded arms to show that they are not sure. After each statement, ask two or three volunteers to share the reasons for their votes. There are no right or wrong answers. The purpose of this activity is to hear different opinions about parenting and to think about what you believe.

Raising children is the responsibility of the woman.

There are some people who should never be allowed to be parents.

Parenting takes up your time, energy and money.

Every man needs a son to carry on his name.

Parenting is the biggest responsibility a person can have.

People who decide not to have children are selfish.

Without children, a woman will never feel fulfilled, satisfied, or content.

4. Facilitate a discussion with the following questions:

What did you learn from this activity?

What did you learn about parenting from your family? Was it positive, negative, or both?

Give an example of a parenting belief or practice that is important in your home or community.

\section{Parenting Challenges (15 minutes)}

1. Explain that parenting is a choice we make and it has many challenges. Young people may become parents without ever thinking about it by having unprotected sex. They may have limited experience with child-care and unrealistic ideas about the costs associated with being a parent.

2. Ask learners to take out a piece of paper and write down the answers to the following questions. Explain that they should explain the reasons for each answer and not just write a yes or no. 
Do you like children?

Do you have the patience to raise a child?

Would you beat your child if he or she misbehaved or if you lost your temper?

Are you financially able to support a child?

Would having a child interfere with your future goals or plans?

Would you expect your child to take care of you in your old age?

Can you find happiness in teaching and guiding a child, a teenager, a young adult?

Would you be willing to devote a large part of 18 years of your life to being a devoted parent?

Could you accept and love a child who was physically or mentally disabled?

3. Ask volunteers to share some of their answers with the group. Ask learners to discuss whether they think most people make the decision to become parents or it happens unexpectedly.

\section{Qualities of a Good Father or Mother (35 minutes)}

1. Ask learners to brainstorm the specific characteristics of a good father and list their responses on the board. Add any others that you feel are appropriate from this list:

He takes responsibility for the children.

He cares about the children and tries to provide them with a better life than he has.

He spends time with the children and helps them to develop knowledge and skills.

He knows the importance of showing love and affection.

He financially supports the children.

He tries to maintain a good relationship with the children's mother.

He makes decisions based on what is good for the children.

He knows how to care for children or is willing to learn.

He is willing to give up things to be a good father.

He wants to keep his family healthy by not exposing himself or their mother to diseases like HIV.

He plays with his children, reads to them, and engages in youth-centred activities.

2. Divide the learners into groups and read them the three case studies below. Tell them to choose the candidate who would make the best father and to make a list of the qualities that make him the choice. Ask each group to share their findings. List the qualities on the board.

Candidate 1: Kefa is 19 and unemployed. His girlfriend Wangechi just had his child. At first, he denied it was his child, but later came to accept it. He is looking for work, but has no qualifications. He wants to support the child, but he has to help his brothers who are still in school.

Candidate 2: Mutuma is a Form Four student. His girlfriend Stella is in Form Three. During the holidays when they met she told him that she was pregnant and would not be returning to school. Mutuma wants to finish his exams and then look for a job so that he can marry Stella and look after his family. Mutuma said his grandmother would be willing to look after the child, but Stella wants the child to stay with her mother.

Candidate 3: Joseph is a clerk in a government office in town. His mother and father stay on a farm. He visits them once a month and sends money whenever he can. His girlfriend, Mary, is pregnant. He says he will marry her, but Mary knows that he spends a lot of money on alcohol and she is afraid that she will not have enough money to support the child. 
3. Ask learners to brainstorm the specific characteristics of a good mother and list their responses on the board. Add any others that you feel are appropriate from this list:

She cares about the children and tries to provide them with a better life than she has.

She spends time with the children and helps them to develop knowledge and skills.

She knows the importance of showing love and affection.

She tries to maintain a good relationship with the children's father.

She makes decisions based on what is good for the children.

She knows how to care for children or is willing to learn.

She is willing to give up things to be a good mother.

She wants to keep her family healthy by not exposing herself or their father to diseases like HIV.

She plays with her children, reads to them and engages in youth-centred activities.

4. Facilitate a discussion with the following questions:

What were some of the qualities of the best mothers? Fathers?

How would you describe an ideal mother? Father?

How can potential parents be prepared for parenting roles?

\section{Optional Activity}

\section{\#1 Rock Babies}

Learners will simulate parenthood in this activity. Let school staff know this activity is taking place. Young people will be carrying a rock baby with them at all times. Ask each learner to bring a rock to this session.

\section{Session 1}

1. Explain this activity will simulate being a parent. Review the instructions for the activity:

Your rock will represent a baby. The babies can be decorated and dressed as you wish.You can choose whether your baby is a boy or a girl.

Keep the baby warm, dry, and protected from harm at all times. Never leave it alone.If you must leave your baby, you must find someone to care for him or her.

Every four hours spend 15 minutes feeding the baby. During this time do not do anything else.

2. Tell learners how many days they will be responsible for their rock babies ( 3 to 5 days), then, before ending the session, allow them about 15 minutes to decorate.

\section{Session 2}

1. After the time is over, bring the group back together and ask the following questions.

What was it like to care for a baby all the time? How would it be different with a real baby?

How was your normal routine changed by this parenting experience?

With a real baby, would you give up some of your social activities? Would you have a choice?

What things would you have needed to buy for a real baby? Would you have the money?

How would your life have been different if your "baby" had been born with a disability?

How would a baby affect your family? A relationship with a partner? Your friendships?

How would a baby affect your future plans? Would you be able to continue in school or hold a job?

Do you plan to have a baby one day? If so, at what age would you like to become a parent? 


\section{Session 25 Unsafe Abortion}

\section{Learning Objectives}

By the end of this session, learners will be able to:

Define abortion

Describe five complications of unsafe abortion

Time 30 minutes

\section{Background Notes}

The term abortion in its common usage refers to the deliberate early termination of a pregnancy. Abortion is currently legal in many countries around the world and is practiced safely by trained health care providers. Abortion is legally very restrictive in Kenya (only to save the life of the mother) and is often practiced under unsafe and unhygienic conditions. Some unsafe methods of abortion that have been tried by girls include:

\section{Chemical abortions}

Overdose of quinine (malaria medication)

Herbal medications

Mechanical methods including piercing the uterus using sharp objects

Taking concentrated solutions such as quencher, millet chuff and tea leaves

Many women have died from unsafe abortions or have developed health problems. Some immediate health complications include severe bleeding or infection, which can lead to death. Some women suffer from long-term problems that mean that the woman may never get pregnant again or that she may live in constant pain.

A girl or woman who has recently had an abortion needs to consider contraception options to avoid unplanned pregnancy in the future. She should make a plan for getting contraception immediately after the procedure. If the abortion was not carried out by a skilled provider, the woman may not have access to contraceptives. An adult who is aware of this situation can assist the girl in seeking medical care and contraceptive counselling.

Whatever the circumstances of the pregnancy, having an abortion is a serious decision that requires careful consideration of one's values, beliefs, and life situation. A girl or woman faced with an unwanted pregnancy should seek counselling to learn about all the safe and legal options that are available to her.

\section{Instructions}

\section{Define Abortion (30 minutes)}

1. Ask learners to define and describe abortion.

Abortion refers to a pregnancy that ends spontaneously (called a miscarriage) or that happens by choice before the foetus is able enough to live outside the uterus (before 28 weeks). Most abortions occur naturally or spontaneously in the first 12 weeks of pregnancy. An induced abortion is a pregnancy that is ended for medical reasons to save the mother's life or is done voluntarily because the pregnant woman and/or father do not want the baby. The safest way to induce an abortion is to have it performed by a trained health provider. 
2. Explain that abortion is currently legal in many countries around the world and is performed safely under sterile conditions. Abortion is legally very restrictive in Kenya (only to save the life of the mother) and is often practiced under unsafe and unhygienic conditions. Also mention that although some girls and women procure an abortion to control their fertility, there are safe methods of contraception available.

3. Divide participants into three groups. Ask each group to list methods they have heard that adolescent girls use to abort. Ask each group to share their responses with the larger group. Write the answers on the board.

4. Ask learners to discuss each method. For each method ask if it is safe and what happens to girls who have used this method.

5. Ask learners if they know any young women who have had an abortion and to share what happened to them?

6. Ask learners to list the risks of unsafe abortion. Some answers are:

Bleeding to death from cuts on the uterus or cervix

Anaemia - iron deficiency

Pelvic abscess from using unclean materials

Tetanus from unclean materials

Infertility

7. Facilitate a discussion about unsafe abortion using the following questions:

How can unwanted pregnancies be prevented?

Where can adolescents find more information about ways to prevent pregnancy? 


\section{Session 26 HIV and AIDS}

\section{Learning Objectives}

By the end of this session, learners will be able to:

Define HIV and AIDS

Explain modes of transmission of HIV

Identify risky and non-risky behaviours

Describe the common symptoms of AIDS

\section{Materials Required}

Index cards

Large sheets of paper

Time 105 minutes

\section{Background Notes}

There are over 40 million people living with HIV and AIDS worldwide and over 24 million of them live in sub-Saharan Africa. A survey in 2003 found that 7 percent of Kenyan adults are infected. Over half of all new infections are in young people 24 and under. AIDS is spreading among young people in Africa faster than in any other age group. Young women are even more vulnerable.

HIV stands for Human Immunodeficiency Virus. HIV is a virus that is passed between people through contact with infected blood, semen, vaginal fluids and breastmilk. HIV weakens the immune system, making it easier for people to become sick. When a person with HIV becomes sick with many illnesses that do not respond to treatment, he or she is said to have AIDS. AIDS stands for Acquired Immunodeficiency Syndrome. Acquired refers to the fact that you get the disease from somewhere else; it does not develop on its own. Immunodeficiency means the immune system is weak and unable to fight off infections and illnesses. Syndrome means a specific collection of symptoms and diseases, such as weight loss combined with skin cancer and pneumonia. AIDS is a term used to indicate the most serious stage of a person's infection with HIV. It means that they have a particular collection of symptoms and diseases defined medically as AIDS.

After years of living normally with HIV, a person's immune system begins to weaken and they start developing AIDS an become vulnerable to opportunistic infections, which can attack any part of the body. Opportunistic infections are infections that take attack the body when the immune system is weak. These infections could range from simple medical conditions like fungal infections and colds to more serious diseases like tuberculosis or cancer. Though the person is HIV positive, these conditions can be treated and often cured. There is no cure for HIV or AIDS.

\section{How is HIV Transmitted?}

HIV is passed between people in three ways:

Sex. Penetrative sex with an HIV-infected person where the penis enters the vagina, anus, or mouth of another person.

Blood to blood. From an HIV infected person's blood to another person's blood through an opening in the body such as a cut, from a transfusion or by sharing something that cuts or pierces the skin (knife, razor, needle). This includes sharing circumcision knives, needles, tattooing or ear piercing, with someone who has HIV.

Mother to child. HIV can be passed from a mother who is HIV infected to her baby during pregnancy, at the time of birth, or through breastfeeding. 
The majority of people are infected with HIV by having sex with someone who is HIV infected. It is important to note that people with other STIs are more likely to contract HIV.

You cannot get HIV infection from:

Touching, hugging, talking to or sharing a home with a person who is HIV infected or has AIDS.

Sharing plates, utensils, glasses or towels used by someone with HIV or AIDS.

Using swimming pools, toilet seats, doorknobs, telephones or other items used by people with HIV or AIDS.

Having someone with HIV or AIDS spit, sweat or cry on you.

Being bitten by mosquitoes.

Donating blood.

Being sneezed at or coughed on by a person with HIV or AIDS.

\title{
Protecting Yourself Against HIV
}

The only certain way to protect yourself against HIV transmission is to abstain from sexual activity.

\section{What is Safer Sex?}

People who have decided to be sexually active can make choices to practice safer sex. Safer sex describes a range of ways that sexually active people can protect themselves from infection with all sexually transmitted infections, including HIV infection. Practicing safer sex also provides protection against pregnancy. There are many ways for loving and sexual feelings to be shared that are not risky. Some of them include:

\author{
Hugging \\ Holding hands \\ Kissing \\ Massaging \\ Rubbing against each other with clothes on \\ Sharing fantasies \\ Touching your partner's genitals, if males do not ejaculate near any opening or broken skin
}

Using a latex condom correctly for every act of sexual intercourse is called protected sex because when used correctly for each sexual act, condoms can significantly reduce the risk of HIV infection. However, condoms are not 100 percent effective in preventing HIV infection. Unprotected sexual intercourse (without a condom) exposes people to the bodily fluids in which HIV lives.

\section{What Does HIV-Positive Mean?}

When the body's defence system (immune system) comes into contact with a disease, it produces germ fighters, called antibodies, which fight off and destroy various viruses and germs that invade the body. An antibody is found in the blood and it tells us that the person has been infected with a particular germ or virus.

HIV tests look for HIV antibodies. If the body is making antibodies to fight HIV, then someone is considered HIV positive. However, there is a "window period" between when a person is infected with HIV and when a blood test shows that a person is HIV-positive, because it takes the body a little while to start producing antibodies to fight the virus. It is possible for someone to test HIV-negative during this window period but be infected with HIV, this is called a false negative. During this time, people who are HIV infected are able to transmit the virus to others. The window period is generally three months but in very rare cases could be six months. People who have a negative test result and have had unprotected sex during the past three months are advised to go for another test in three months. While waiting through the window period, they must avoid being exposed to HIV. 
When are People with HIV Infectious to Others?

People with HIV can infect others as soon as they are infected with the virus. People with HIV may not know they are infected and may look, act and feel healthy for a long time, possibly longer than 10 years. It is impossible to tell from looking at someone if he or she is infected.

\section{From HIV to AIDS}

As with other infections, when HIV enters the body, the immune system produces a response to try to fight off the infection, by producing antibodies. However, these are insufficient to battle against the growth and multiplication of the virus, which slowly destroys key cells in the immune system. HIV slowly weakens the immune system and eventually the body cannot fight off even mild infections. At this point, people become very sick from a range of different illnesses, including the common cold, fungal infections, cancer, or tuberculosis.

Most people who have HIV do not become sick right away. In some cases, it can take as many as 10 years or more for a person to develop AIDS. People can stay healthy longer by eating well and getting prompt treatment of illnesses and infections. The most common signs that someone has AIDS are diseases such as tuberculosis or pneumonia. However, the following can also be signs that someone has AIDS:

Sudden, unexplained weight loss

Fever for more than one month

Diarrhoea for more than one month

Genital or anal ulcers for more than one month

Cough for more than one month

Enlarged lymph nodes

Skin infections that are severe or recurring

Although the above can all be symptoms of AIDS, the only way to tell if a person is infected with HIV is by testing, because the above can be symptoms of other illnesses or diseases.

\section{What is Stigma?}

People who are HIV-positive may be discriminated against or shunned in their communities because of misunderstandings or misconceptions about HIV and AIDS in the community. Adolescents may be particularly susceptible to negative attitudes and may be forced out of their school or home. They are typically less aware of their legal rights, more vulnerable to financial hardships, and less able to find and purchase care.

\section{Tips for Teaching about HIV and AIDS}

The topic of HIV and AIDS can seem overwhelming. It seems like everyday the newspaper reports a new fact about the disease. This curriculum provides basic background information about HIV and AIDS to help you teach about HIV prevention and transmission. If your discomfort with the subject of HIV and AIDS makes it difficult to help young people, find another person in your school or community who can conduct the HIV and AIDS education activities in this session. Remember that even if we try to tell all the youth in our community about the risk of HIV and AIDS or to abstain, many will still go ahead and have sex. It is more important to inform sexually active adolescents about how to prevent HIV and how to protect themselves than to avoid talking about the topic because it makes people uncomfortable. When teaching young people about HIV and AIDS, there will be many opportunities for reassessing your personal beliefs and values. Explore your own feelings and seek the support of another teacher if necessary.

It is important to acknowledge that there will be a wide range of sexual experiences in any group of young people. For example, some will be dating; others may not yet be interested in romantic relationships. Be realistic about the numbers of young people in your group who are having sexual intercourse. In a group of 16 year olds, half are likely to have not yet had sexual intercourse and half are likely to be engaging in sexual intercourse. You can help those who are not sexually active delay sexual activity and help those who are already sexually active practice safe sex. 
You can help young people understand the risk of becoming infected and how to practice safer sex. Any type of sex between two uninfected partners is safe. The difficulty is that most people, teenagers and adults, do not know if they have been exposed to the virus. 'Knowing someone well' or 'asking your partner about AIDS' is an unrealistic way to assess potential risk, especially for young people. They need to understand that it is impossible to tell if someone is HIV-infected just by looking at her or him. Avoid emphasizing monogamous relationships as safe, since young people think each time they have a relationship with a person, they are being monogamous. Emphasize that abstaining from sexual intercourse is the only way to completely avoid the risk of infection.

Help young people understand that there are many ways to express sexual feelings that do not risk unplanned pregnancy or sexually transmitted infections. Touching, fantasizing, caressing, massaging, masturbating, talking, kissing, whispering, hugging, singing, dancing, and holding hands are ways of showing and receiving affection from a partner. Abstinence from all types of sexual intercourse is the best and only certain way to prevent HIV infection.

Latex condoms have been proven to be an effective barrier of HIV. They can, however break or leak especially when used incorrectly. It is important for older, sexually active adolescents to understand how to use a condom correctly and that they must be used for every act of sexual intercourse to protect against HIV infection. Condoms offer the best protection against the spread of HIV during sexual intercourse with a partner whose HIV status is unknown.

\section{Instructions}

\section{HIV and AIDS (20 minutes)}

Advance preparation: Prepare a small piece of paper for each learner in the group. Each paper will have some thing marked on it:

One piece with a small ' $x$ ' in the corner

One piece with a small ' $z$ ' in the corner

Three pieces with a small ' $c$ ' in the corner

Three pieces with the instructions 'Don't follow any of my directions until I say return to your seats'

On the rest of the pieces write 'follow all of my directions'

1. Distribute one piece of paper to each learner. Tell them to keep the special instructions on their paper a secret and to follow the instructions. Ask the group to stand and shake hands with three people and ask each to sign the piece of paper. Make sure they move around the room.

2. When all the learners have collected three signatures, have them take their seats. Ask people with the ' $z$ ' and ' $x$ ' on their papers to stand up. Ask everyone who shook hands with those persons to stand up. Ask everyone who shook hands with a standing person to stand up and so on until everyone is standing, except for the designated non-participants with pieces reading 'do not follow any of my instructions.'

3. Tell them to pretend that the person with the paper marked with an ' $x$ ' was infected with HIV and that instead of shaking hands that person had unprotected sexual intercourse with the three people whose signatures she or he collected. Do the same with the paper marked ' $z$ ' (genital herpes).

4. Ask those that are still seated why they haven't been standing. Someone should say they were told 'do not follow my directions...' Explain that these people had chosen to abstain from sexual intercourse, and were therefore protected from these STIs.

5. Ask learners to check if they had a ' $c$ ' marked on their paper. If so, tell them they can sit down. Explain that fortunately, these people had used condoms and were not at significant risk for infection. Tell all the learners to sit and remind them that this was only a game. 
6. Facilitate a discussion with the following questions:

How did person ' $x$ ' feel? Person ' $z$ '? How did you feel towards others when you found out they were infected?

How did people who were instructed not to participate in the exercise feel at beginning? How did those feelings change during the course of the exercise? How did the group feel towards those people initially? And then later?

Who had a 'do not follow my instructions' paper but got signatures anyway? Why? What does this tell us about people's behaviour?

How did the people who discovered they had used condoms feel?

How did the people feel to find out they might have been infected?

Is it possible to know who is infected and who is not by looking at them?

\section{HIV and AIDS Overview (20 minutes)}

1. Give two slips of paper to each learner and ask them to write something they have heard people in their community say about HIV or AIDS (this does not have to be something they agree with) on each slip of paper. Collect all the cards and shuffle them.

2. Divide learners into groups and deal out the cards at random. Ask each group to sort out the slips of paper into three groups: 'AGREE', 'DISAGREE' and 'DON'T KNOW'.

3. When all the groups are finished, reassemble. Ask each group to present any statement they found difficult to agree on. The main group can offer opinions on the difficult statements. Or suggest they hold their questions to see if the rest of the discussion answers some of the misinformation.

\section{Definition of HIV and AIDS and Modes of Transmission (45 minutes)}

1. Ask learners to explain what HIV is.

Human Immunodeficiency Virus (HIV) - The name indicates that it is a virus found in humans, that makes the immune system deficient (lacking in something) and therefore weakens the system. The immune system is the body's defence against disease. With a damaged immune system the body is exposed to a range of infections and diseases. The person becomes weaker and eventually develops AIDS.

2. Ask learners to explain what AIDS is:

Acquired Immune Deficiency Syndrome (AIDS) - Acquired means that it is passed from one person to another; it does not just develop spontaneously. It is passed from exposure to an infected person's blood, sexual fluids or breastmilk. AIDS is a condition where the body's immune system is destroyed by HIV. It has no cure and eventually kills the infected person. It can be controlled with drugs, but they are costly and not widely available.

3. Ask for 5 volunteers to conduct a role-play. Outside the room, explain the scenario below to the volunteers.

A group of people are sitting around discussing the following rumours about HIV and AIDS. In the course of the discussion, the correct information gets presented. The rumours are:

You cannot get HIV if you only have sex one time.

You can get HIV from kissing someone.

You can tell if someone has HIV by looking at them.

Once you have become HIV positive you can feel it in your body.

4. Ask the volunteers to conduct the role-play above making sure that the correct information is discussed.

5. Ask learners what specific behaviours can expose you to HIV. The following should be mentioned: 
Having unprotected sex with an infected person

Sharing knives, needles, syringes (for circumcision or drug use)

Having a blood transfusion with infected blood (donated blood is now screened)

Mothers can pass the virus to their babies during pregnancy, childbirth, or breastfeeding

6. Ask learners whether HIV is easy or difficult to catch and to explain why.

7. Explain that HIV is different from most other diseases because it is difficult to catch, because:

It does not pass through the air

We cannot catch it from being in the same room as an infected person

We cannot catch it by touching or hugging

We cannot catch it from an infected person coughing or sneezing on us or by drinking from the person's cup

8. Emphasize that we can choose not to become infected:

Abstaining from sex

Never having sex without a condom

Being in a mutually faithful relationship with an uninfected person

Never sharing needles or other equipment such as razors, circumcision knives

\section{Risky and Non-Risky Behaviours (20 minutes)}

1. Tell the learners they will have the chance to assess their own risk of being infected with HIV, if they do certain things. Read out loud the following questions, one by one. Before each statement, ask the learners "If I do this, am I at risk of being infected with HIV?" Ask volunteers to share their opinions and discuss with the group.

If you hug, kiss or massage your friend.

If you don't protect yourself when handling blood.

If your sexual partner has sex with others.

If you drink beer or other kinds of alcohol.

If you masturbate.

If you are bitten by mosquitoes.

If you allow semen or vaginal fluid to touch your normal skin (not your mucus membranes around the penis, vulva, anus or the mouth).

If you have sex with more than one person.

If you or your partner has had an STI in the past.

If you share a razor with a person with HIV or AIDS.

If you only have sex with one partner.

If you live, work or play with a person with HIV or AIDS.

If you don't know if your sexual partner is HIV positive or has an STI.

If you have injections, tattoos, or piercings.

2. Facilitate a discussion with the following questions:

Does knowing that some things are definitely or probably a risk worry you?

Did you learn any new information? Do you have any questions about any behaviours we did not talk about today?

If you were explaining information on risky or non-risky behaviours to a friend, what would you say first? 


\section{Risky and Non-Risky Behaviours}

\section{Definitely a Risk}

Having sexual intercourse with multiple partners without condoms.

Sharing needles for drug use.

Sharing needles for circumcision or ear piercing.

\section{Probably a Risk}

Being born to a mother who is HIV positive.

Getting a blood transfusion.

\section{Probably Not a Risk}

Sharing a toothbrush.

Having sexual intercourse with a person using a condom.

Deep or (open mouth) kissing.

\section{Definitely Not a Risk}

Abstaining from sexual intercourse.

Kissing.

Being close to a person with HIV who is coughing.

Donating blood.

Using a public telephone.

Shaking hands with a person with HIV.

Hugging a person with HIV or AIDS.

Living with a person with AIDS.

Going to school with a person who has AIDS.

Being bitten by a mosquito.

Having a mutually monogamous and faithful relationship with a person who has tested negative for HIV. 


\section{Optional Activities}

\section{\#1 HIV and AIDS in Kenya}

1. Ask learners to describe the situation of HIV and AIDS in Kenya or in their community.

Some people still refuse to accept that the disease exists.

There is no cure for it.

It ends in death.

It is killing people in their 20s, 30s, and 40s, when they are most productive.

It kills couples and leaves many orphans.

Because so many people are sick with the disease, the hospitals cannot help them all.

Even those who know about the disease have not changed their behaviours.

The impact of HIV and AIDS affects everybody.

2. Facilitate a discussion with the following questions:

Why is it that relatives of those who die of AIDS do not wish to talk about it? (stigma)

Are people generally reluctant to talk about HIV and AIDS? Why do you think so? (fear)

3. Explain that fear leads people to not think clearly, run away from things, get angry, deny that it can happen to them or the people they love. Emphasize that there is no need to fear or be scared of AIDS because:

We know a lot about HIV and AIDS. We do not have a cure but we know what causes it.

We know that HIV infection can be prevented by making healthy decisions and avoiding risky behaviours.

We know how people become infected with HIV and we know how to keep ourselves safe.

\section{\#2 If Someone Says...}

In advance, write the following statements on the board.

“I'm not worried about having sex with Mary - she's a nice girl and her mother is a teacher. You only have to worry about dirty girls."

"You hugged that guy with AIDS. Are you crazy?"

"I don't believe James has HIV. He looks so healthy."

"I feel sorry for people who got AIDS from a blood transfusion. But most other people have brought it on themselves."

“I know you're not supposed to be able to get HIV from eating with someone, but I'm not eating any food with Jomo, especially if he has cooked it. Suppose these doctors are wrong and two years from now they find out you can get AIDS that way."

"If we really wanted to get rid of AIDS, we'd test everybody and take everyone who was HIV positive to a deserted island."

1. Divide learners into groups of six. Explain that they will practice being HIV and AIDS peer educators who are responding to inaccurate or judgemental statements about HIV and AIDS.

2. Explain that each member of their group will take turns reading a statement from the list above and practice responding to it as if they were a peer educator. After each response, other group members can react to the response by answering the following questions: What part of the statement did you react to? How did you feel about the peer educator's response? Continue until each group member has had a chance to answer a question and ask a volunteer to respond as a peer educator. 
3. Facilitate a discussion with the following questions:

Which statements were difficult to respond to? Which statements made you angry? Embarrassed? Confused?

Does the statement try to make other people angry or embarrassed? If not, why would people say these kinds of things?

What kind of statements about HIV or AIDS do you hear from your friends and acquaintances? How will you respond to these statements?

\section{Answering Sensitive Questions}

Young people today receive a lot of information on HIV and AIDS from many different sources. People can misunderstand even the best messages. It is important for adults to remain open to the questions of young people so that we can help them understand accurately. However, it is not always easy to answer some questions, especially on topics that are socially restricted. Below are some tips on answering adolescents' questions.

You might want to think about a question for a while before giving an answer. But, do not leave the answer for more than a day, as young people will look for the answer somewhere else.

Sometimes it is better to have a colleague, parent or health specialist answer a question.

Even if a question is asked in front of the group, it might be best to answer it in a smaller group depending on the group's experiences.

Always find out what the young people already know or think is the answer before you answer the question. Then you can build on what they have told you and explain what they do not understand.

In your answer use the words the young people have used either in their question or when they have explained to you what they know.

Be honest and ready to explain. 


\section{Frequently Asked Questions on HIV and AIDS}

\section{Where did AIDS come from?}

No one really knows for sure where AIDS came from or how long it has been around. What is important to understand is that it affects people from all over the world, regardless of how much money or education they have or what religion they are. It is draining the resources of families, communities and countries. AIDS is an issue that demands the attention of each and every one of us.

\section{What is the immune system?}

All people are born with an immune system to protect the body from disease. Some people have stronger immune systems than others. During a lifetime, a person's immune system may be stronger or weaker at different times. The immune system is sometimes referred to as a defence system. In the way that a country's defence system protects it from enemies, the immune system protects the body from diseases. The immune system works like an army by first detecting the enemy, then by sounding the alarm, and lastly by attacking the enemy. A healthy body has its own way to attack invading germs and viruses that make the body sick. The HIV virus works to weaken the body's ability to attack other germs and viruses. Eventually the body becomes unable to fight off other diseases, which overwhelm the body and cause the HIV positive person to finally die.

\section{Is HIV passed through kissing?}

HIV is not transmitted through saliva. It might be risky, however, to kiss someone if there is a chance for blood contact if the person with HIV has an open cut or sore in the mouth or on the gums. It would be even more risky if both people had bleeding cuts or sores in their mouths. People should use common sense and should wait until any sores or cuts have healed before kissing.

\section{Can a person get HIV infection from a mosquito?}

No. When mosquitoes bite someone they do not inject the blood of the previously bitten person into the next person. They use their saliva as a lubricant. Diseases like malaria are spread through mosquito saliva. HIV gets digested in the mosquito's stomach before it can find its way to the saliva.

\section{What is the 'window period'?}

Most HIV tests do not detect HIV but the HIV antibodies produced by the immune system. It is assumed that if a person has the HIV antibody, then they are infected with the virus. It can take as little as 6 weeks or as many as 18 weeks before the body has enough HIV antibodies to be detected by an HIV test. Until this time, tests will give a false negative result. The period between infection by HIV and the presence of enough HIV antibodies to be detected by an HIV test is known as the 'Window Period'. The majority of HIV infections are believed to be transmitted during this period.

\section{Does a person with HIV have AIDS?}

The difference between HIV and AIDS is that one is a virus and the other is a condition or syndrome. A person with HIV may or may not have AIDS. However a person with AIDS will always have HIV in his or her blood. An HIV positive person who does not yet have AIDS may feel and look perfectly healthy, have an active and effective immune system, can work and support his or her family. A person with AIDS may have the symptoms of various diseases which he or she has acquired such as TB, meningitis and cancer. A person with AIDS may be weak and thin and may feel sick. The immune system of a person with AIDS is rapidly become less and less able to protect his or her body.

\section{If a person tests negative for HIV does it mean they cannot catch it?}

No. It only means they have not got it now or possibly that they have the infection and it is still in the window period. They can still catch it when they have unprotected sex.

\section{Is there a cure for AIDS?}

There is still no cure for AIDS. Many healers and unscrupulous people have claimed over the years to be able to cure AIDS. All their claims have proved false. We often hear of people who have developed a cure for AIDS. People should be very cautious about claims that a "cure" for AIDS has been discovered unless they have been medically proven. 


\section{Learning Objectives}

By the end of this session, learners will be able to:

Define Voluntary Counselling and Testing

Explain why people should be tested for HIV

Explain the VCT process

Explain what it means to test positive and to test negative

Define the window period

Time 40 minutes

\section{Background Notes}

It is not possible to know if a person has HIV by looking at him or her. The only way for people to know if they have HIV is to have a test for HIV. In Kenya, HIV testing is accompanied by counselling, which usually refers to in-depth discussions with a trained person who can help individuals cope with their HIV status. Individuals learn how to take care of themselves if they are positive or prevent the disease if they are negative. This process is called voluntary counselling and testing, or VCT. The test is reliable, accurate, safe and painless. The health worker takes a small amount of blood from an individual's finger. The person tested cannot get weak from blood loss because so little blood is taken. Depending on the type of test used, the result may be available in just 30 minutes or after a week.

In order for an individual to know whether they are truly free from HIV, they will also be asked to come back in another 3 to 6 months for another test when the window period is over. The window period is the time between when HIV enters the body and the moment when the test can detect HIV antibodies. Usually the test can detect antibodies within three months of infection and in rare occasions, up to six months. This means that for months after infection, the test may not be able to tell whether or not someone is infected. These months are known as the window period. During this window period, it is possible to infect others with HIV. There are many reasons to get tested for HIV. If a person has had unprotected sex and is worrying constantly about HIV infection and is nervous about every spot or cough, the only way to put his or her mind at ease might be to have an HIV test. If a person has had sex with someone who has fallen sick and has AIDS, then that per-son will also worry. Perhaps the only way for that person to put his or her mind at ease is to go for VCT. People should never assume that they are infected or that they are not infected. They should always go for a test.

HIV testing is recommended for people who engage in high risk behaviour including:

Sexual activity with multiple partners

Encounters with sex workers

STI infection

Blood transfusions

Anal sexual activity (male or female)

Injection drug use

Sexual activity with partners having any of the above

Children born to women with any of the above 


\section{Instructions}

Note: Identify the nearest VCT centre, its opening times and other information before this session.

\section{Define Voluntary Counselling and Testing (10 minutes)}

1. Ask if anyone knows what VCT is. If anyone says yes, ask if he or she can explain it to the group.

VCT stands for Voluntary Counselling and Testing. It is the process by which a person can learn whether or not he or she is infected with HIV, the virus that causes AIDS. A person is always counselled before and after the test regardless of the results. The decision to go for testing and to receive the results is voluntary.

If the test is negative, the counsellor will discuss the importance of prevention of HIV and other STIs in detail with the person in order to reduce his or her risks of infection in the future. The discussion will cover not only the methods available but the person's individual situation, concerns and attitudes which may influence whether or not these methods are acceptable and will be used. Remember: Testing does not prevent you from contracting HIV but what you do between tests does.

If the result is positive, the counsellor will discuss with the person all of the behaviours to avoid in order that he or she avoids infecting his or her partner (or children). In addition to this, the major task for the counsellor will be to offer compassion, support, and practical advice, including referral to appropriate medical services, to enable him or her to cope with stress and anxiety and to make personal decisions. Follow-up sessions to ensure meaningful and long-term support will be necessary.

\section{Why Get Tested for HIV? (30 minutes)}

1. Ask learners to list advantages of being tested for HIV. Write the reasons on the board. The following should be included:

If your result is negative, you know you were not infected three months before the test.

Some of us think we would feel better if we knew our HIV status even if the result is positive.

If we have a family we may want to know our status so we can plan for our children's future.

Some of us want to know our status in order to make changes in our lives that will help us preserve our health and ensure that we live longer, better lives.

It allows for early treatment of HIV and of HIV associated infections like TB or pneumonia.

It helps infected people protect others from being infected and to live positively.

2. Ask learners to list disadvantages of being tested. These could include:

Learning that a person is infected with HIV can be very upsetting. The degree of distress depends on how well the person is prepared for the news, how well the person is supported by family and friends, and the person's cultural and religious attitudes towards illness and death.

A person who learns he or she is infected with HIV is likely to suffer from feelings of doubt, fear, grief, depression, denial and anxiety.

Partners and family members are likely to suffer from the consequences of an HIV-positive test result as well as the infected person; regardless of their status, they are affected.

A person who has tested positive for HIV may be discriminated against if others find out.

3. Ask learners to brainstorm the benefits of VCT to the community. Possible answers could include:

It encourages discussion on prevention, testing, risk reduction, and living with HIV.

It reduces stigma as more people go public about being HIV positive.

It serves as a catalyst for the development of care and support services like (aid to orphans).

It generally reduces the rate of transmission of HIV. 
1. Explain that talking with your partner, family and others about HIV and AIDS prevention can bring up strong emotions and issues. Although it is difficult, it is important to have open and honest conversations about HIV and AIDS with people who are important to you. If you, or someone important to you, has practiced high-risk behaviours, it is important to be tested. Often it is best to get tested together with your partner. There are four steps to agreement that may help you make a decision together with your partner:

Step 1: Say what you feel and want.

Step 2: Listen to what the other person feels and wants.

Step 3: Restate your point. Do not get distracted on other points of conflict.

Step 4: Agree to what each of you will do.

2. Read the following story to the group while focusing on the steps above:

\section{Mary's Story}

My name is Mary. I know my boyfriend, Thomas, has other partners, so I decided to talk to him about HIV and AIDS in order to protect myself. One day, when Thomas was relaxed and in a good mood, I said to him: Thomas, I have been hearing about HIV and AIDS, and I feel afraid. I want us to protect ourselves from getting it. What do you feel we should do?

I listened respectfully to Thomas. 'What do I feel?' he said, 'I think you are trying to cover up the fact that you have other boyfriends!'

His words were painful to me, but I did not get angry. Instead, I restated what I felt and what I wanted. 'Thomas, I can see you are upset, but we must talk about this. I am afraid and do not want you or me to die. What can we do to protect ourselves?'

I continued to listen respectfully to Thomas' response. 'You are just changing the subject!' he said to me in a loud voice. 'You have other boyfriends! Next you will be wanting me to use a condom!'

I restated what I felt and wanted and said to Thomas, 'Because I am so worried about getting AIDS - believe me, I will be faithful! I really want to protect both of our lives.'

While Thomas was listening to me, I suggested what we could do. I said to him: 'Would you use a condom until we both get tested and make sure we do not have HIV? Then we can talk about what we need to do after that. How do you feel about that?'

Thomas and I finally agreed. 'I do not like it,' Thomas said, 'but I will wear a condom until we know we do not have the virus.'

3. Review the four steps to agreement once more. Divide learners into pairs and ask them to roleplay the same scenario using the four steps.

4. After the pairs finish role-playing, ask the larger group:

What suggestions do you have to make the chances of reaching an agreement more likely? In what other situations could you use these steps to resolve conflicts and problems? 


\section{Session 28 Care and Support for People with HIV}

\section{Learning Objectives}

By the end of this session, learners will be able to:

Understand the care and support needs of people living with HIV and AIDS

Describe stigma and ways to reduce it

Define positive living

Explain the use of anti-retroviral treatments

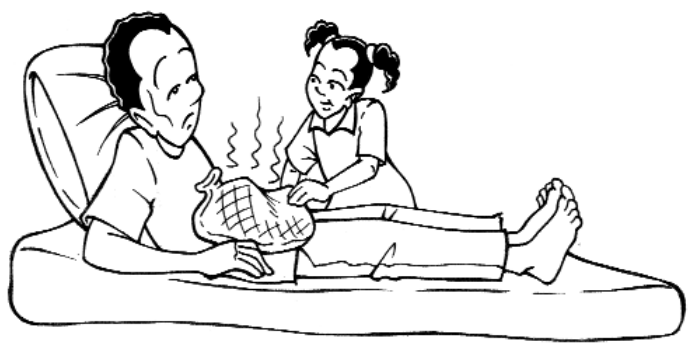

Time 70 minutes

\section{Background Notes}

\section{A Positive HIV Test}

Many people who learn that they are HIV positive are unaware that it can be many years before their infection turns to AIDS. Thinking that they will die soon, they may give up on life. In Kenya, thousands of young men and women who test positive stop working, leave home, abandon their families, begin living recklessly, or commit suicide because they feel they have nothing to live for. With support from family and friends, and continued counselling, an HIV-positive person can overcome his or her feelings, and return to life with new determination and optimism.

Testing HIV positive can be a shattering experience. Studies have shown that people who have received news of their imminent death go through five emotional stages:

Denial: Refusal to accept the result. Asking for a re-test, refusing to talk about it, or telling themselves and others that it is surely a mistake.

Depression: Spend a lot of time alone, and behave as though they have opted out of life.

Anger: A strong, aggressive reaction may blame other people for his or her infection.

Negotiation: Bargaining with God, pleading for more time in return for living a good life.

Acceptance: With guidance and counselling during these difficult times, the person could begin to accept what it means to be positive, decide to make the best use of their time left, make healthy choices, and seek prompt treatment for illnesses and infections.

It is important for people with HIV to understand that it is normal to have a variety of different feelings. With counselling and support, a person can begin to accept his or her condition and make the best of the remaining time. Acceptance means adding more life to your days rather than trying to add more days to your life.

\section{Treatment}

A cure means that the germ that causes a disease has been completely killed or eliminated from the body and will not return unless a person is re-infected. There is no cure for AIDS, however there are ways to treat the symptoms. Treatment means the use of a drug, injection, or intervention that can cause symptoms to become less painful or pronounced or cause them to disappear altogether. A treatment may not always lead to a cure (in the case of HIV and AIDS, it will not lead to a cure).

When looking at health in a broader sense, physical health is only one component of total wellbeing and is influenced by the other components. Treatment in its broadest sense can mean any intervention that helps improve any aspect of our well-being. There are many strategies people can use to prolong their life and improve its quality even if they are infected with HIV. This concept is very important, especially for those struggling to cope with HIV without access to anti-retroviral therapy. 
Well-being is determined by four different aspects. The table below lists ways to improve the overall well-being of people living with HIV and AIDS:

\begin{tabular}{|l|l|l|l|}
\hline \multicolumn{1}{|c|}{ Physical } & \multicolumn{1}{c|}{ Psychological } & \multicolumn{1}{c|}{ Social } & \multicolumn{1}{c|}{ Spiritual } \\
Proper nutrition & Having a positive attitude & Supportive family and & Having faith or a belief \\
Rest & Building self-esteem & friends & system \\
Exercise & Counselling & A social system that & Prayer \\
Preventing and treating & Reducing stress & discrimination & Meditation \\
infections and illnesses & & Continuing productive & \\
Avoiding drugs and alcohol & & work & \\
Proper hygiene & & Being involved in & \\
ART & & advocacy & \\
\hline
\end{tabular}

People with HIV and AIDS can live long, healthy lives if they take care of themselves by eating well, practicing good hygiene, staying active, and going to the doctor as soon as they have symptoms of infection or fall ill. The goal of living positively is to be free of illness, to be productive, and to stay emotionally and physically healthy.

\section{Staying Healthy}

It is important for people with HIV and AIDS to eat a nutritious diet to fight infection and disease and to stay energetic, strong, and productive. Nutrition and HIV are strongly related to each other. People who are malnourished are more likely to progress faster to AIDS, because their bodies are weak and cannot fight infection. People with HIV and AIDS are at risk of malnutrition because they eat less, have infections that require more energy, and their bodies do not use food properly. People with HIV and AIDS need to eat more than people who are not infected. Eating small meals often and a variety of food can help people with HIV and AIDS to get all the energy and nutrients they need.

People with HIV should:

Eat at least three meals a day, and have snacks between meals.

Eat even when they are sick or have no appetite. Eating small but frequent meals can help.

Eat plenty of fruits and vegetables of different colours.

Eat fats, oils and sugars in small amounts and limit processed foods, salt, coffee, tea, and sodas.

Avoid alcohol, smoking, raw eggs, raw fish, and partially cooked meat.

Practicing good hygiene is important for everyone to avoid infection. It is especially important for people with HIV and AIDS because they have weak immune systems and are more vulnerable to infection.

Handle and store food and water properly to avoid contamination and further infection.

Only use water from a clean source, and store it in a container with a lid.

Boil water for at least 5-10 minutes to kill germs before drinking it.

Always wash hands with soap before and after touching food.

Cook all animal products (meat, chicken, fish, and eggs) completely using high temperatures.

Thoroughly wash utensils and surfaces used for preparing and cooking foods.

Use clean water to wash all fruits and vegetables that will be eaten raw or remove the skin.

Store cooked food at most for one day and re-heat before eating.

Use bowls, plates, glasses, and utensils that have been cleaned and well dried.

Infections can be avoided by practicing good personal hygiene:

Take baths everyday to keep the body clean.

Wear shoes to avoid small injuries that could result in infection.

Brush teeth after meals.

Wash hands with soap after going to the toilet and after handling pets and animals. 
Anti-retroviral therapy

ART (anti-retroviral therapy) is a combination of medicines that slow down HIV from spreading in the body. ART helps the immune system get strong so it can fight infections and illness. ART is not a cure for HIV. ART reduces the numbers of HIV in the blood, but cannot eliminate it. ART does not prevent against re-infection from HIV.

Although anti-retroviral therapy can prevent some of the serious illnesses that often come with AIDS, there are some challenges that HIV-positive individuals must be prepared for:

Duration: ART is a lifetime commitment. People on ART will need to swallow pills every day according to a strict schedule.

Adherence: Skipping only a few of these pills can trigger the development of new strains of HIV that are immune to these drugs. These new strains could eventually lead to death.

Costs: Anti-retroviral drugs can be very expensive and many people cannot afford them.

Side Effects: headaches, dry mouth, skin rash, diarrhoea, anaemia, dizziness, hair loss, tingling in the hands and feet, nausea and vomiting, unusual or bad dreams, feeling tired, and feelings of sadness or worry.

\section{AIDS in the Home}

The home is a very important place for a person with AIDS. If a person with AIDS has a caring and supportive family it can be very helpful. A person with AIDS will need both moral support and physical care. As there is no cure for AIDS, relatives can often give the best care. The person will feel more secure at home where he or she is among loved ones.

\section{Instructions}

\section{Care and Support (25 minutes)}

1. Ask learners what would be the most difficult feeling or issue if a friend or a relative of theirs had AIDS.

2. Ask learners to discuss what some of the difficulties would be for the person with AIDS.

3. Looking at the list, ask participants to describe the kinds of support they could give to a friend or relative with AIDS.

4. Review the progression of HIV to AIDS. HIV is the first phase. A person can live with HIV for a long time without being sick or looking unhealthy. When HIV progresses to AIDS they may look sick and have colds, TB or pneumonia. They may need additional care and support at this time. Ask participants to think about the difference in the kinds of support someone with HIV needs compared with someone with AIDS? Emphasize that:

People with HIV need emotional support and should be encouraged to eat healthy, stay active and practice good hygiene to prevent infections. They should also be encouraged to go to the doctor as soon as they have any symptoms of infection or illness. During this time people with HIV should try to maintain a healthy and strong immune system.

People with AIDS need emotional support and physical support, as well, but their physical support needs will be much greater since they will be suffering from a variety of infections and illnesses.

It is important for people with HIV and AIDS to have emotional support to encourage them to stay healthy and seek treatment.

5. Ask learners the following questions: Have they heard of any treatments for HIV and AIDS? Can they name any? What treatments do people in their community use when they are HIV-positive? Is there a cure for AIDS?

6. Ask learners to brainstorm the common symptoms of AIDS and write them on the board. Remind them that many people won't show symptoms for a very long time. Make sure they mention: 
General: general weakness, weight loss, swollen lymph nodes, swelling of the limbs, hair loss, shingles or herpes zoster

Skin and Hair: itching, boils, rashes, wounds, infections due to bacteria, thinning of the hair, early graying of hair

Chest: cough, chest pain, difficulty breathing, tuberculosis (TB)

Digestive system: diarrhoea, difficulty swallowing, poor appetite, sore mouth, nausea, vomiting, abdominal pain

Head and nervous system: headache, memory loss and confusion, tingling and numbness of limbs, convulsions, confusion, coma, weakness of one side of the body, anxiety and depression, meningitis

Reproductive System: genital discharge, genital ulcers, pain when urinating

Cancers: cancer of cervix, Kaposi's sarcoma, lymphomas

NOTE: The above symptoms are a general guide. Many people have these symptoms but do not have HIV or AIDS. The only sure way to know if someone is HIV positive is to have an HIV test.

7. Ask learners what influences how long a person can live with HIV and AIDS.

Getting medical care and anti-retroviral drugs (medicines for treatment not cure)

Abstaining from sexual activities or using condoms to prevent re-infection of HIV of another strain or type

Eating a balanced diet and exercising

Living positively

Avoiding of pregnancy

Avoiding of drugs and alcohol

Genetic make-up of the individual

8. Divide participants into three groups and ask them to think about how they can support someone who is HIV positive. Assign each group one of the following kinds of support: emotional, physical, or caregiving. Ask each group to present what they discussed. Ensure that the following are mentioned:

\section{Physical Support}

Appetite loss: Ask what they would like to eat and drink, when and how much. Eat with them when possible. Physical exercise helps improve appetite.

Nausea, vomiting and diarrhoea: Smaller meals with little fat or spice may reduce vomiting and diarrhoea. Encourage eating dry foods like toast or biscuits. Sucking on a lemon may reduce nausea. Encourage drinking liquids between meals if they cannot eat. Notice when nausea occurs and avoid foods at this time. Use gloves to clean up vomit and wash hands with soap after using the restroom.

Sores in the mouth: Gargle with warm, salty water. Avoid acidic foods. Eat warm soft foods. Use mouth washes.

Persistent cough: Rest in a well-aerated room. Seek medical treatment.

Fevers: Sponge bath. Drink extra fluids. Panadol may be used. See a doctor.

Weakness: Encourage activity. Have rest periods. Use a bath chair.

Skin problems: Change sleeping positions to avoid sores. Encourage short walks. Wash sores but use gloves if sores are open. Apply soothing lotions to dry skin.

Confusion and forgetting: AIDS and depression may affect the brain, causing confusion. Keep clocks and calendars and remind the person of the day, time and where they are. Make sure all safety precautions are taken. For example, remove loose rugs, stairs, medicines and sharp objects. 
Emotional Support

Ask the person to talk about how he or she feels and what they can do for themselves and what they need help with.

Encourage him or her to do as much as possible for themselves. Do not do for the ill person what they can do for themselves.

Give support and praise when deserved.

Ask the person how they prefer to have things done (food preparation or cleaning).

When feelings of anger and crying occur, encourage them to express them.

The most common feelings are fear, anger, hopelessness, sadness, and loneliness. Let them know you are there to listen and talk to them, and their feelings are normal.

\section{Caregiver Duties}

Garbage: Things for cleaning (gloves and other soiled things) should be burned or placed in a double plastic bag. Tie the bag well.

Washing: Wash with warm, soapy water before and after contact.

Laundry: If soiled with body fluids wear gloves, use bleach and soap, keep separate from other laundry. If not soiled, wash as normal.

Instruments: If injections are given, sterilize needles and syringes by boiling them; store them in a plastic or metal box that will not puncture. Used disposable needles and syringes should be placed in thick cardboard, glass, plastic or metal containers and thrown away. Wash thermometers with soap.

Cleaning: Cover open wounds with a bandage or cloth. Clean bathroom area often, using gloves and bleach. Wash dishes with hot soapy water.

\section{Stigma (15 minutes)}

1. Read the following story that describes a situation caused by HIV and AIDS:

When Anna's husband died, she thought that he may have died from AIDS. She was very worried that she may also be infected. After several weeks of worrying, she went for VCT. Anna learned that she was HIV-positive. It was difficult to know the truth about her status but it was better than worrying about it. Anna was determined to work hard while she was still strong and to save as much money as she could.

Right after her husband died, Anna had had joined a group that helped her start her own business. Her business is important because it is her family's only source of income. When Anna joined the group, everyone was friendly and helpful. She was chosen as a group leader. However, after they began to suspect that Anna was HIV-positive, they acted differently. Some of the women whispered when Anna came in and no one would sit near her at the meetings.

Anna's son, Peter told her that everyone in the village knew that his father, Paul, had died of AIDS. Some of them were saying that Anna gave the disease to her husband! She often thought, "How can they think this? I have always been a faithful wife. Paul was the only man I have ever had sex with in my life!"

Worse yet, Anna's business was not going well. Even her best customers stopped buying from her. People who used to greet her warmly now turn away when they see her. It seems they are afraid to be near her, afraid they will get AIDS if they touch anything she has touched.

2. Ask learners to think about how they would feel if they were treated this way. Ask several learners to take turns pretending to be Anna and share how they would feel.

3. Ask one of the volunteers who played Anna to sit in front. Ask the others to think about supporting Anna. Ask for volunteers to come up and visit with her and tell her some practical things she can do to comfort and help her. Treat her as you would like to be treated if you were in her situation.

4. Ask all of the volunteers to return to their places. Thank the volunteers for their comments and suggestions. 


\section{Positive Living (30 minutes)}

1. Ask two volunteers to role play a person who is giving her HIV positive friend encouragement and advice on how to take care of herself and live positively with HIV.

2. Tell the learners that positive living is the conscious decision that even though one has tested positive for HIV, life can and should go on. This is accompanied by determination to do all the positive things one needs to do to stay healthy longer. The five Ls of positive living include:

BeLieve in yourself - you can do it

Learning all you can

Listening to your doctor

Leaning on others - counselling, support from friends and families

Letting be - accepting the situation you are in.

3. Tell learners that people that have recently been tested positive should:

Not believe people who say they can cure HIV and AIDS. Do not waste money on false cures. Take simple medications that can help your symptoms, such as aspirin for fever and medicines that control diarrhoea. Treat infections as soon as they develop.

Follow a healthy diet with fresh fruits, vegetables, and protein (meat, fish, eggs). Drink lots of clean water.

Exercise to improve physical fitness, improve appetite, improve immune system function and increase feeling of well being.

Avoid stress.

Get enough rest. 


\section{Session 29 Sexually Transmitted Infections (STIs)}

\section{Learning Objectives}

By the end of the session, learners will be able to:

Describe the most common sexually transmitted infections

Describe the "typical symptoms" of common STIs

Explain the treatment and management of STIs

Time 60 minutes

\section{Background Notes}

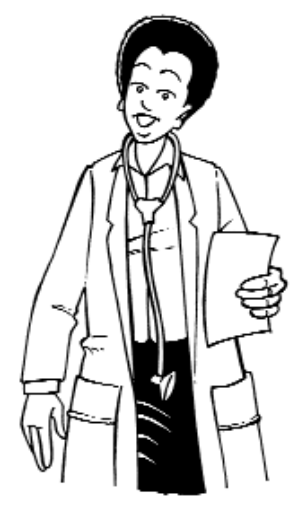

\section{What are Germ, Viruses, and Bacteria?}

Germs are tiny living organisms, or things, that cause disease when they enter the body. They are so tiny you cannot see them. Bacteria and viruses are both types of germs.

Viruses are the smallest germs known to man. In order to multiply, viruses must find a home inside a living organism, like a human cell. Some of the diseases caused by viruses include measles, polio, hepatitis, chicken pox, the common cold (homa) and HIV.

Many bacteria are useful, such as those that ferment beer or turn milk into yoghurt. However, many also cause disease in humans. Some diseases caused by bacteria include gonorrhoea, syphilis, meningitis, diarrhoea, pneumonia, and leprosy.

\section{What are STIs?}

Sexually transmitted infections (STIs) are infections transmitted by having unprotected sex with an infected partner. STIs are some of the most common communicable diseases in Kenya, particularly among young people aged 15-24. The human immunodeficiency virus (HIV) is an STI that leads to AIDS, which is fatal. (See Module 26 for more information on HIV and AIDS). In addition to HIV, there are more than 20 other diseases that can be transmitted sexually, including chancroid, chlamydia, gonorrhoea, genital herpes, the human papilloma virus, syphilis, and trichomoniasis, among others.

A sexually transmitted infection occurs when bacteria, viruses, or other disease-causing organisms pass from one person to another. STIs can have devastating health consequences, including pelvic inflammatory disease, infertility, chronic abdominal pain, cervical cancer, and in some cases, death. In addition some STIs can be transmitted to infants during pregnancy or birth.

It is possible to catch an STI even after only one act of sexual intercourse with an infected person. Some STIs can no longer be treated successfully with the medicines that were used in the past, because the germs that cause the disease are now resistant to the medicines.

\section{Why are Girls More at Risk?}

Women are at higher risk for and more affected by STIs than men for several reasons. Differences in their bodies make detection more difficult in women, infection has more serious consequences for women than for men, the risk of transmission is greater from a man to woman, and many women have little power to protect themselves in sexual situations. Additionally, because a man's sexual fluids stay inside a woman's body after sex, she is more likely to get an infection. Younger girls are even more at risk for getting an STI because they are more likely to suffer from tears in the vagina during sex. 


\section{Signs and Symptoms of STIs}

Most men can tell when they have an STI because there are usually clear signs. Women, however, often have an STI without knowing it, because there are often no signs that they have the disease. Sometimes only an experienced and trained health care provider can find signs of an STI in a woman. This is especially true during pregnancy, when many STI symptoms (for example, an increase in the amount of fluid produced in the vagina) are mistaken for side effects of pregnancy. Sometimes it is necessary to examine samples of a woman's blood or vaginal discharge to find out if she has an STI, and which type of STI she has. For this reason, it is important to recognize the signs of an STI and to visit a doctor as soon as possible if you see any of the signs or suspect that you have been exposed to an STI.

Risk factors for STIs include:

Having a partner with an STI

Having more than one partner

Having had a new partner during the last three months

Suspecting a partner has other partners

Many STIs can be cured or treated. A health provider will give medicine to a person who has been diagnosed with an STI. It is essential that a person with an STI finish all the medicines that the health worker gives and abstain from sexual activity or have protected sex until the health worker says they are cured. If a person finds out that they have an STI, they should also make sure that their partner (or partners) goes for treatment.

Any of the following may be a sign for a person who has had sexual intercourse that she or he may have an STI and should consult a doctor or clinic:

Redness or soreness of the genitals

Pain at urination or cloudy or strong-smelling urine

A sore or blisters on or around the genitals, near the anus, or inside the mouth

Excessive itching or a rash

Abdominal cramping/pain

A slight fever and an overall sick feeling

A sexual partner with symptoms

Note: Both men and women can have an STI without physical symptoms. However, women are more likely to be symptom free. The complications from STIs are more severe in women than in men.

\section{STI Prevention}

The only completely effective way to prevent STIs is to abstain from oral, anal, and vaginal sexual intercourse. Contact with another person's body fluids can result in STI infection.

For people who have decided to engage in sexual activity, condoms can protect against many, but not all, STIs. For minimal protection, inspect your partner's genitals, wash your genitals after sexual intercourse, use contraceptives jellies, limit your sexual partners to one person, avoid partners who have sex with other partners, talk to your partner about his or her sexual habits and health. Get tested for sexually transmitted infections with your partner if you have worries or suspicion.

Men can play a particularly important role in preventing STIs by maintaining a monogamous relationship or using condoms to protect their partner and themselves. Maintaining a mutually monogamous relationship - one way of preventing STIs - requires the commitment of both partners. Men can show respect for their partners' health by limiting their sexual relations to one partner. 


\section{If You Have an STI}

Seek medical treatment immediately and complete your treatment. Do not share your medicine with a partner or anyone else.

Inform your sexual partner(s).

Strongly encourage your partner(s) to get treatment.

Abstain from sexual contact while infectious.

Abstain from sex or protect yourself every time you have sex.

\section{Instructions}

\section{STI Symptoms and Prevention (60 minutes)}

1. Divide learners into groups. Give each group a sheet of paper and pen. Ask learners to write down signs of STIs, both things you can see and things you can feel ways. Ask: How do these STIs differ for men and women? Do they know any names for these infections (either common names or medical names)? How do people get STIs?

2. Call everyone back into the main group and ask someone from each group to present their discussions. Ask: Does everyone agree? Are there any other ways of telling if someone has an STI?

\section{Make sure the group covers the following ideas:}

Seeing: a sore on penis, vagina or opening of vagina (or any part of the body near by), pus coming from penis, seeing brown insects slowly moving in pubic hair and small white eggs on hairs (pubic lice), end of penis being red, small cauliflower-like growths on or near the genitals (men and women), swollen glands at the top of the legs (men and women), heavy and smelly discharge on a woman's panties.

Feelings: Itchiness inside vagina or itchy pubic hair (men and women), burning pain when passing urine and feeling like you have to urinate the time (men and women), pain in the womb and lower part of the abdomen, sometimes also with fever, pain when having sex, and painful swollen testicles.

Names: The learners will definitely know some names, these may be medical, such as syphilis or gonorrhoea, or these may be street names like Dafrau, radi, moto, break.

4. Explain that unfortunately STIs often have no obvious signs, particularly in women, which is why they are so easy to catch and pass to others. Many people only discover that they have an STI when they are told by a partner, or are examined by a doctor for the cause of infertility or when they have a routine syphilis test in pregnancy.

Make sure learners understand that not all of these signs mean that someone has an STI. For example, any type of urinary infection may cause it to burn when you pass urine, you may get swelling at the top of your leg if you have an infected cut or sore on the leg, and women can get itching in their vagina and a thick discharge which looks like sour milk from yeast infections which are not sexually transmitted.

5. Ask learners to list ways to prevent STIs and what people should do if they think they have an STI. Record their answers on the board. Ask learner to think about why people often do not go for treatment and why they often stop their tablets before they are finished.

The only way to prevent STIs is to abstain from sexual activity or to practice safer sex by using a condom when you have sexual intercourse. Condoms can protect against most, but not all STIs.

It is very important to get treatment as soon as we think we may have an STI or if a sexual partner tells us that he or she has an STI. We should first go to a health centre or hospital for treatment. It is not possible to treat yourself. It is also important to take all of the medication given by the health provider. 
It is important tell our partners if we have an STI and ensure that they are treated too.

Otherwise we can catch the STI from them again later on.

There are many negative consequences of getting an STI. If STIs are not treated a man or woman may become infertile, if a woman gets pregnant she may miscarry or her baby may die, and they may give it to others. If a person has an STI and has sex with someone who has HIV, he or she is much more likely to be infected with HIV than someone who did not have an STI. Sores or wounds caused by STIs can make it easier for HIV to be transmitted.

6. Remind learners that:

STIs can affect both sexes.

A person can get an STI even after a single unprotected sexual act with an infected partner. The more a person exposes him or herself, the more likely he or she is to get infected.

You cannot tell if a person has an STI just by looking at him or her as she or he will probably look normal.

There are no vaccines or immunity against STIs.

\section{Optional Activities}

\footnotetext{
15-19

\#1 Talking to your partner about STIs: Role-play

15-19 1. Divide the group into male-only and female-only groups. Ask each group to discuss:

'What would you do or say, if you noticed that your sexual partner had sores or an unusual discharge or smell in the genital area?'
}

2. Ask the groups to explore this through role-play, and practice the best ways of discussing sexual health with their partners.

3. Allow 20 minutes for this activity. Then allow time for the male and female groups to share their role-play and discuss.

4. Facilitate a discussion with the following questions:

What are the three most effective ways to avoid STIs?

Abstain from sexual intercourse of any kind

Use condoms every time you have any kind of intercourse

Be faithful to one partner who is also faithful to you

What three things should you do if you think that you have been infected with an STI?

Seek proper medical treatment right away

Inform your sexual partner(s)

Abstain from sexual contact until there are no signs of infection and the medicine has been finished. 
STI Symptoms and Consequences

\begin{tabular}{|c|c|c|}
\hline STI & Symptoms & Consequences \\
\hline HIV & $\begin{array}{l}\text { Symptoms begin several months to years } \\
\text { after infection and may include: } \\
\text { Persistent tiredness } \\
\text { Loss of over } 10 \% \text { of body weight } \\
\text { Persistent diarrhea } \\
\text { Persistent fever }\end{array}$ & $\begin{array}{l}\text { There is no cure } \\
\text { You can give HIV to your sexual } \\
\text { partner or someone with whom } \\
\text { you share a needle. } \\
\text { Can be passed from a pregnant } \\
\text { woman to her unborn child }\end{array}$ \\
\hline Gonorrhea & $\begin{array}{l}\text { Symptoms begin 2-21 days after infection: } \\
\text { Discharge from penis or vagina } \\
\text { Pain/burning sensation during urina- } \\
\text { tion or bowel movement } \\
\text { Difficulty urinating } \\
\text { Lower abdominal pain (pelvic area) } \\
\text { Most women and some men have no symptoms }\end{array}$ & $\begin{array}{l}\text { Damage to reproductive organs } \\
\text { Sterility } \\
\text { Blindness in babies of infected } \\
\text { mothers } \\
\text { You can give gonorrhea to your } \\
\text { sexual partner } \\
\text { Heart trouble, blindness, skin } \\
\text { disease, arthritis }\end{array}$ \\
\hline Syphilis & $\begin{array}{l}\text { 1st Stage } \\
\text { Symptoms begin 1-12 weeks after infection: } \\
\text { Painless, open sore on the mouth or } \\
\text { sex organ } \\
\text { Sore goes away after } 1-5 \text { weeks } \\
\text { 2nd Stage } \\
\text { Symptoms begin } 1-6 \text { months after sore } \\
\text { appears: } \\
\text { Non-itchy rash on the body } \\
\text { Flu-like symptoms }\end{array}$ & $\begin{array}{l}\text { Increased risk of ectopic preg- } \\
\text { nancy } \\
\text { You can give syphilis to your sex- } \\
\text { ual partner } \\
\text { Heart disease, brain damage, } \\
\text { blindness, death } \\
\text { Can be passed from pregnant } \\
\text { woman to her unborn child }\end{array}$ \\
\hline Herpes & $\begin{array}{l}\text { Symptoms begin 2-30 days after infection: } \\
\text { Painful blister-like lesions on or around } \\
\text { the genitals or in anus or mouth } \\
\text { Flu-like feelings } \\
\text { Itching and burning around the sex } \\
\text { organs before the blisters appear } \\
\text { Blisters last 1-3 weeks } \\
\text { Blisters disappear but the individual } \\
\text { still has herpes } \\
\text { Blisters may recur }\end{array}$ & $\begin{array}{l}\text { There is no cure for herpes } \\
\text { Recurring outbreaks of painful } \\
\text { blister occur in } 50 \% \text { of those } \\
\text { who contract herpes } \\
\text { May be transmitted to sexual } \\
\text { partner } \\
\text { May be transmitted to a baby } \\
\text { during childbirth } \\
\text { May increase the risk of cervical } \\
\text { cancer }\end{array}$ \\
\hline
\end{tabular}




\section{STI Symptoms and Consequences (continued)}

\begin{tabular}{|c|c|c|}
\hline STI & Symptoms & Consequences \\
\hline Chlamydia & $\begin{array}{l}\text { Symptoms begin 7-21 days after infection: } \\
\text { Discharge from the sex organs Burning } \\
\text { or pain while urinating Unusual bleed- } \\
\text { ing from the vagina Pain in the pelvic } \\
\text { area Most women and some men have } \\
\text { no symptoms }\end{array}$ & $\begin{array}{l}\text { You can give chlamydia to your } \\
\text { sexual partner } \\
\text { Damage to reproductive organs } \\
\text { Sterility } \\
\text { Passed from mother to child dur- } \\
\text { ing childbirth }\end{array}$ \\
\hline $\begin{array}{l}\text { Genital } \\
\text { Warts }\end{array}$ & $\begin{array}{l}\text { Caused by the human papilloma virus (HPV) } \\
\text { Small, painless, fleshy bumps on and } \\
\text { inside the genitals and throat } \\
\text { Often no visible symptoms }\end{array}$ & $\begin{array}{l}\text { Some strains are associated with } \\
\text { cervical cancer and some other } \\
\text { genital cancers; these strains may } \\
\text { not produce visible warts } \\
\text { Can be detected during gyneco- } \\
\text { logic exam } \\
\text { Can be removed by physical or } \\
\text { chemical means but virus cannot } \\
\text { be cured and warts often reappear }\end{array}$ \\
\hline Hepatitis B & $\begin{array}{l}\text { Spread by sex, exposure to infected blood, } \\
\text { and to child during pregnancy or delivery. } \\
\text { Mild initial symptoms: headache and } \\
\text { fatigue Later symptoms: dark urine, } \\
\text { abdominal pain, jaundice } \\
\text { Often no visible symptoms }\end{array}$ & $\begin{array}{l}\text { Can develop chronic liver disease } \\
\text { Causes inflammation of liver and } \\
\text { sometimes leads to liver failure } \\
\text { and death } \\
\text { No cure }\end{array}$ \\
\hline
\end{tabular}

From CEDPA's Choose a Future: Issues and Options for Adolescent Girls, 1996. 


\section{Session 30: Myths and Facts on STIs}

\section{Learning Objective}

By the end of the session, learners will be able to differentiate between facts and myths about STIs

Time 50 minutes

\section{Background Notes}

Adolescents may think they are too young or too sexually inexperienced to get STIs. They may also think they are not at risk, because they incorrectly believe that STIs only occur among people who are promiscuous or who engage in 'bad' behaviours. You can play an important role in helping them learn about the myths around STIs. Young people are particularly at risk of STIs because:

They lack information about how to prevent STIs.

They are less likely to seek information or treatment due to fear, ignorance, or inexperience.

The risk of acquiring an STI is greater at first exposure.

Adolescent females are more susceptible to infections than older women due to their immature reproductive organs.

Early sexual experience can result in trauma to vaginal tissue, increasing adolescent women's vulnerability to STIs.

Adolescents who begin sexual activity early are likely to have a greater number of lifetime sexual partners

Other risk factors for STIs are:

Unprotected sex (without a condom)

Sex with multiple partners

Having a partner with STI symptoms

Sex with a new partner or more than one partner in the last three months

Sex with strangers

Sex in exchange for money or gifts

Vulnerability to sexual violence and abuse

A history of STIs or pelvic inflammatory disease (PID)

\section{Instructions}

\section{Facts and Myths (50 minutes)}

1. Divide learners into four or five groups and have each group sit together. Explain that they are going to play a game. Each team will be read a statement (from the list below) and they must answer it. The team must decide whether the statement is true or false (they will receive1 point for a correct answer). The team must explain why the statement is true or false (and can receive another point for a correct answer). If the answer or explanation is incorrect, another team can try for an extra point. Continue until all the statements have been read. When the game is over, announce the points and winning team.

\section{A person can always tell if she or he has an STI.}

False. People can and do have STIs without having any symptoms. Women often have STIs without symptoms because their reproductive organs are internal, but men infected with some diseases like Chlamydia may also have no symptoms. People infected with HIV generally have no symptoms for years after infection. 


\section{With proper medical treatment, all STIs except HIV can be cured.}

False. Genital warts and herpes, STIs caused by viruses, cannot be cured at the present time.

\section{The organisms that cause STIs can only enter the body through either the woman's} vagina or the man's penis.

False. STI bacteria and viruses can enter the body through any mucus membranes, including the vagina, penis, anus, mouth, and in some rare cases, the eyes. HIV can also enter the body when injected into the bloodstream from shared needles. It can also be passed from mother to child during pregnancy, delivery or through breast-feeding.

4. You cannot contract an STI by masturbating, holding hands, talking, walking, or dancing with a partner.

True. STIs are only spread by close sexual contact with an infected person. Anyone can be infected by having oral, anal, or vaginal intercourse with a partner who is infected.

\section{Practicing good personal hygiene after having intercourse should be encouraged.}

True. While personal cleanliness alone cannot prevent STIs, washing away your and your partner's body fluids right after intercourse is good hygiene. Washing does not, however, prevent pregnancy or stop HIV from entering the body through the mucus membranes in the mouth, anus, penis, or vagina.

\section{It is possible to contract some STIs from kissing.}

True. It is rare, but possible to be infected by syphilis through kissing if the infected person has small sores in or around the mouth. The herpes virus can be spread by kissing if sores are present. HIV is not passed through saliva, and could only be transmitted through kissing if both people had open sores in their mouths or bleeding gums.

\section{The most important thing to do if you suspect you have been infected by an STI is inform your partner.}

False. The most important thing to do is seek immediate medical treatment. Symptoms of an STI may never appear, or may go away after a short time, but the infection continues inside the person's body. After starting medical treatment, the person should inform his or her sexual partner(s). In the meantime, it is also important for the infected person to abstain from any sexual contact until the treatment has been completed.

\section{Only people who have sexual contact can contract an STI.}

False. Babies can contract STIs such as herpes, gonorrhoea, and HIV during pregnancy or delivery or through breastfeeding.

9. Condoms are the most effective protection against the spread of STIs.

False. Abstinence from sexual intercourse is the best way to prevent the spread of STIs. Condoms are the next best thing, but only abstinence is 100 percent effective.

\section{Using latex condoms will help prevent the spread of STIs.}

True. Latex condoms can help prevent the spread of STIs, but they must be used correctly for every sexual act. Latex condoms are not 100 percent effective because they can occasionally break or come off during intercourse. Lambskin condoms are ineffective for protection from STIs and should not be used.

11. A woman using oral contraceptives should insist that her partner use a condom to protect against STIs.

True. Oral contraceptives do not prevent STIs, so a condom would be necessary for protection unless both partners know they are faithful to one another and are currently infection-free. 
12. Abstinence is the only method of contraception that is $100 \%$ risk free.

True. Avoiding sexual activity is the only way to absolutely prevent pregnancy or STIs.

13. Once you have had gonorrhoea, you cannot get it again.

False. A person can get gonorrhoea as many times as he or she has sex with an infected person. It is important that anyone who is treated for gonorrhoea or any other STI make sure that his or her sexual partner is also treated.

14. There is still a significant risk of HIV transmission with condoms, since the pores in the condoms are large enough for the virus to pass through.

False. HIV cannot pass through latex condoms. The reason condoms are not 100 percent effective in preventing HIV infection is because they can sometimes come off or break during intercourse because they are not being used properly. Condoms provide over 10,000 times more protection against HIV infection than not using a condom. There is a strict manufacturing process that is followed when making condoms and HIV is too big to pass through latex.

\section{There is no known cure for genital herpes.}

True. While there are drugs available to treat the symptoms of genital herpes, there is no cure for the disease.

16. Condoms have been laced or coated with HIV that causes AIDS.

False. Condoms are scientifically tested by the companies that manufacture them. There is strict quality control. Many more people who use condoms would have already become sick or died if condoms had HIV inside them.

17. You will not get HIV if your girlfriend or boyfriend is clean.

False. A person's risk of HIV cannot be determined by looking at a person and checking her or his reputation. Some people get HIV when they have only had sex once or with one partner.

\section{It is women who are spreading HIV and STIs.}

False. Both women and men may have HIV and may pass it to their sexual partner. Our society often blames women for spreading sexually transmitted infections, but a woman must first become infected from her partner before she can pass it to someone else.

\section{Having sex with a virgin cleans a man of HIV and cures him.}

False. There is no cure for HIV. Having sex with a virgin only risks giving HIV to that person and will not cure the man.

\section{If you have unprotected sex with a person who has HIV you will definitely catch it.}

False. Not everyone who has unprotected sex with someone with HIV will become infected. Some people can stay in a relationship with a person who has HIV for a long time and not become infected, others catch it the first time they have sex with someone who is infected. Becoming infected with HIV is always a risk but it is important not to assume that just because a person's partner has HIV that he or she will have it too.

\section{STIs are a curse from god.}

False. STIs are caused by germs, which are transmitted during sexual contact and can be prevented by abstaining from or practicing safe sexual practices. 
2. Conclude the activity by facilitating a discussion with the questions below:

What are the signs and symptoms of STIs? (Answers include: redness or soreness of the genitals, pain when urinating (mostly with men), strong smelling or cloudy urine, unusual discharge from the penis or vagina, sores or blisters on or around the genitals, mouth or anus, a sexual partner with symptoms)

What are the two most effective ways to avoid STIs? (Answers include: abstain from sexual intercourse of any kind, use condoms every time you have intercourse or be faithful to one faithful partner)

What things should you do if you are worried that you have been infected with an STI?

(Answer include: seek medical treatment right away, inform your sexual partner (s), and abstain from sexual contact until there is no evidence of infection)

How could you talk about using condoms if you were to have sexual intercourse with a partner you cared about? How would you feel if your partner brought up condom use when you were about to have sex? What would you say to him or her?

What would be most difficult about having an STI? 
Facilitator Resources 


\section{Resource 1 Facilitation Techniques}

This section provides an overview of facilitation techniques and approaches for participatory training. It contains information on the following:

Principles of Experiential Learning

Four participatory training techniques

Ways to encourage participation

Setting ground rules

The art of asking questions

Principles of responding to learners questions

How to respond to learners responses

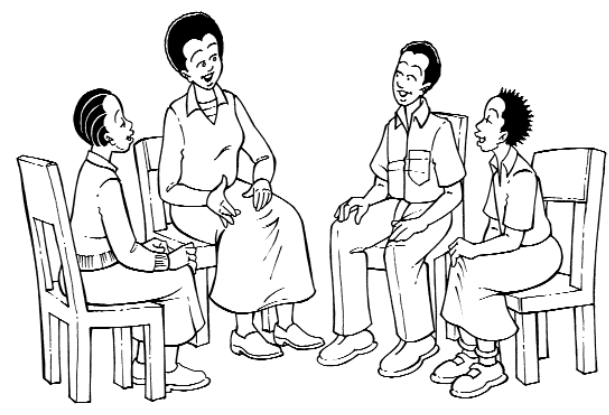

How to deal with learners behaviours

Time management in participatory training

\section{Experiential Learning}

The principles behind experiential learning is:

What I hear, I forget.

When I hear and see, I remember a little.

What I hear, see, and talk about with others, I begin to understand.

What I hear, see, discuss, and do allows me to acquire knowledge and skills.

What I teach to another, I master.

Experiential activities are designed to help the learner gain information, examine attitudes, and practice skills. Experiential learning is learner-oriented.

The learner chooses what to participate in, based on their needs and usefulness of what is offered

The learner asks questions and weighs the pros and cons of what they are told. Such participation and reflection contributes to their learning and is to be encouraged.

Young people have experience. Ignoring their experience (treating them like children) may create resistance to learning.

Young people face real problems. If training cannot help them to resolve these problems, they may feel their time has been wasted.

In experiential learning, involving learners in their own education is essential. Each learner goes through four stages:

Do a task (experience)

Identify what happens

Analyze what happened - identify principles learned from the exercise

Discuss the application to their lives

To enhance this process of learning there are some end of lesson wrap up exercises that can be useful. The activities assist the learner to think about what they learned from the lesson and to review the usefulness of what they have learned. 


\section{Daily Wrap-Up Exercise 1}

Divide learners into two groups and ask them to write down key learning points from the day. Ask the two groups to share their lists and compare them.

Review the objectives list posted earlier and ask learners to comment on whether the activity met the objectives.

\section{Daily Wrap-Up Exercise 2}

Ask learners to think about their personal key learning points from the day.

Ask learners to form a circle.

Explain that you want each of them to offer a single brief response to the sentence stem you will give in a whip-like or round-robin fashion.

Show the following sentence stem: "My biggest learning point today was..."

After everyone has contributed, comment on the common themes.

\section{Daily Wrap-Up Exercise 3}

Write the words, "After today's session, I will...." on the board.

As a group, ask learners to brainstorm things that they will do as a result of the new information they have learned in the session.

\section{Four Participatory Learning Techniques}

Because experiential learning is learner-oriented, it is important that the learner participates in the process. There are several techniques that enhance participation and which are used in this curriculum. They include the Mini-Lecture, Group Discussion, Role Play, and Brainstorming. Here is a description of these techniques.

\section{MINI - LECTURE}

What is it? A brief presentation given for the purpose of assisting learners to acquire certain knowledge, or to expose them to a principle, process or situation relevant to their learning.

Teacher characteristics

Uses several presentation techniques (oral as well as visual)

Indicates if learners should take notes (or if handouts will be provided)

Shares the objectives of the lecture

Links this session to the preceding session

Often begins with a question

Follows a plan

Cites references as appropriate; uses diagrams to show relationships between ideas and to show processes and procedures

Defines new terms

\section{Mini-Lectures are used to:}

Introduce an activity/group experience (if the activity/experience needs an introduction. Note: one should never share in advance the principles to be drawn from the experience before doing the experience. The principles must come out of the discussion that follows the experience [respect the experiential learning cycle!]

Explain and/or resume a particular point during the summary of a group activity/experience (especially in the case of a concept which is new to the group)

Provide additional information 


\section{ADVANTAGES}

Economize on time

Present facts in an orderly manner

Reinforce the relationship between a learning experience and complex concepts or principles or application to learners' life.

\section{DISADVANTAGES}

Can be boring

May not solicit group participation

\section{How to use a mini-lecture}

\section{Preparation}

Ensure that the mini-lecture:

1. Is relevant, that it responds to the learning needs of the group; that it corresponds to their level of knowledge and experience, and to the activities they have just done as well as to those that follow.

2. Is well-prepared.

3. Is brief (less than 30 minutes). Do not give more material than the group can assimilate.

4. Encourages group participation by asking and answering questions and encouraging learners to share experiences and examples.

5. Is supported by visual aids.

\section{Instructions}

1. Pay attention to the reaction and the understanding of the group as well as the ambiance. It may be necessary to go a bit faster, a bit slower, introduce certain activities or solicit learner input or examples in order to ensure effective understanding of the material presented

2. Present the material in an organized and clear manner, using simple words, concrete examples, and a logical sequence. Visual aids reinforce principal points. Handouts (distributed at the end of the day) give essential points and eliminate the need for learners to take notes (which can be distracting to them)

3. Change the tone of voice, maintain eye contact with the group, and use gestures to support the message.

\section{GROUP DISCUSSION}

What is it? Group discussion is a part of nearly all training activities. It is used for:

Learning facts, concepts and principles

Discussing issues, solving problems and sharing experiences

Developing attitudes

Developing communication skills

Group discussions can be used to:

Introduce an activity

Bring out learners' knowledge

Draw a link between an activity or concept and a previous session and/or another skill already taught

Orient the group to a task

Analyze the activity and its application to learners' work 


\begin{tabular}{|l|l|}
\hline \multicolumn{1}{|c|}{ ADVANTAGES } & \multicolumn{1}{c|}{\begin{tabular}{c}
\multicolumn{1}{c|}{ DISADVANTAGES } \\
Active participation of everyone
\end{tabular}} \\
$\begin{array}{l}\text { Brings out the knowledge, experience and atti- } \\
\text { tudes of participants }\end{array}$ & $\begin{array}{l}\text { subject to the point that it even loses its pur- } \\
\text { pose }\end{array}$ \\
\hline
\end{tabular}

\section{How to use group discussion}

\section{Preparation}

1. Prepare discussion questions based on session objectives; note key points to discuss.

2. Plan for summary of the discussion that includes a conclusion and how the new information can be applied to their lives.

\section{Instructions}

1. Introduce the subject and draw a link between it and the last session and/or its relevance to the work of the learners.

\section{Ask open and relevant questions.}

3. Ensure that everyone is given the possibility to express themselves and that no one dominates the discussion. Ask questions to those who participate/respond less and ask others to allow everyone to participate.

4. If there are differences of opinion, ensure that the different opinions are freely expresses.

5. Do not judge the learners.

6. Do a summary at the end.

\section{ROLE-PLAY}

What is it? A teaching method in which the trainers or learners act out roles in a simulated situation. There are three types of role-plays:

1. Spontaneous: the trainer or a learner decides spontaneously to demonstrate something through a role play

2. Structured - Open: all of the information is known to all the learners/players (in the role play): there are no unknowns, hidden facts nor special instructions. The role play occurs in an organized fashion; the players coordinate their efforts to arrive at a predetermined ending (often to show a particular situation to the audience).

3. Structured - Blind: the trainer gives to each player individual instructions that are not shared with the other player. Each player follows his/her instructions (plays his/her role) without knowing what the other player's specific instructions are. (This type of role play is often used for the purpose of teaching certain competencies in interpersonal communication).

Role-plays are used to:

Practice competencies in interpersonal communication

Examine a problem or situation in order to learn how one could have reacted to it better

Become more aware of the effects of attitudes and/or behavior on others in order to facilitate changes in attitude and/or behavior

Evaluate the performance of personnel in certain interpersonal situations ( to improve them) Facilitate reflection about a difficult decision (by acting it out) 
ADVANTAGES

Active participation of participants

A key method for developing interpersonal communication skills

May reduce the threat of learning certain interpersonal competencies. (In a role play, one can experiment with certain behaviors in a safe situation without the risk of embarrassment)

Provides an occasion to learn by observation and feedback

\section{DISADVANTAGES}

Participants may not take the learning seriously. The trainer can minimize this problem by asking participants to submit the cases to be used for the role play

The roles sometimes reinforce existing stereotypes

Roles must be realistic and players must portray them accurately

When role plays are conducted before a passive audience, learning may be minimal. Members of the audience must have an active role of observation. In order for participants to master the specific competencies, role plays must be conducted in small groups of three to four learners.

Role play may personalize a particular situation too much. The players may perceive the roles and the feedback too personally; or reveal things that they later regret. The trainer must clearly define the learning environment.

\section{How to conduct a role-play}

\section{Preparation}

1. Ensure that the role-play:

Responds to the learning objectives for the session

Is realistic in terms of the identified problems of the learners

Is interesting

Offers a challenge to the player as well as to the audience

2. To write up the scenario:

Describe the situation

Describe the role of each player

Prepare an observation guide to help the players and audience analyze the role play

3. Prepare a plan for the discussion following the role play, in order to be sure of developing the essential points.

Instructions

1. Give the instructions to the group:

Goal of the role play

Structure of the role play (who plays which role? How much time is allowed?)

Post the observation questions and rules for feedback

Distribute the cases to the players (according to the type of role play) 


\section{Conduct the role play (10-15 minutes maximum)}

3. Facilitate a discussion, including the reaction of the players followed by that of the observers, based on the observation questions and the experiential learning cycle

Problems

Questions raised

Effectiveness of the intervention and alternative strategies

4. Have learners de-role by saying, "I am no longer $x$ (name used in the role-play/character), I am $y$ (the learners name). This is particularly essential, because role-plays can involve a lot of emotions that can remain with the players for hours or days.

\section{Brainstorming}

What is it? A teaching method used to help learners to reflect in a creative manner. This technique is composed of two steps:

The brainstorming of ideas: the group puts forth all the ideas and/or solutions possible relative to a given subject/problem. One person writes all the ideas on the board. No one comments on the ideas nor indicates whether they are good or bad, relevant or irrelevant.

The analysis: when the group has exhausted their ideas, the group proceeds to the analysis of the ideas. The group discusses the ideas and decides which of them are valid.

Brainstorming is used to:

Help a group think of the largest number possible of new ideas

Help persons who are extremely practical to think in a more creative manner

Resolve a difficult problem when the traditional problem solving techniques have failed

\begin{tabular}{|l|l|}
\hline \multicolumn{1}{|c|}{ ADVANTAGES } & \multicolumn{1}{c|}{ DISADVANTAGES } \\
$\begin{array}{l}\text { May be effective for the resolution of a prob- } \\
\text { lem when the group is blocked }\end{array}$ & $\begin{array}{l}\text { People who like to be practical may be uncom- } \\
\text { fortable }\end{array}$ \\
Engages the participation of everyone & $\begin{array}{l}\text { Many of the suggestions may not be useful } \\
\text { Criticizing ideas during the analysis step } \\
\text { makes some people uncomfortable }\end{array}$ \\
\hline
\end{tabular}

\section{How to brainstorm}

1. The trainer introduces the subject to be discussed

2. The trainer explains the goal and the process of brainstorming (including why and how it will be used)

3. The group shares all of their ideas related to the subject

4. The ideas are written on the board without comment. No one indicates whether the ideas are good or bad

5. When the group has exhausted its ideas, the trainer leads a discussion of the ideas one by one. The group decides which are valid/relevant in relationship to the objectives/subject. They eliminate the rest

6. The trainer helps the group to summarize the subject 


\section{Ways to Encourage Participation}

Many young people are accustomed to classroom-type lectures in which the teacher is the expert and the learners are the recipients. Participatory activities might limit their willingness to fully participate in discussions and other activities.

The following tips can encourage participation.

\section{Nonverbal encouragement}

Eye contact: Be attentive in making eye contact with all learners.

Head nodding: Nod your head to show understanding and to encourage learners to continue.

Posture: Avoid defensive postures, such as folded arms.

Body movement: Move toward people to draw them into discussion. Avoid distracting movements such as too much walking or pacing.

Smile: Concentrate on smiling to encourage and relax the group.

\section{Verbal encouragement}

Praise or encouragement:

“I'm glad you brought that up"

"Tell me more"

"Good point. Who else has an idea?"

"I would like to hear your thoughts about..."

Accept and use ideas suggested by another learner:

"To build on your point, Mary..."

"As Fatma mentioned earlier..."

Accept feelings, using statements that communicate acceptance and clarifications of feelings:

"I sense that you are upset by/in disagreement with what I just said."

"You seem to feel strongly about this issue." 


\section{Setting Ground Rules}

Setting ground rules for the activities is essential for managing group discussions. Before starting any of the sessions, conduct a session on the ground rules of participation. Ask learners to brainstorm a list of rules they think will make the sessions more successful. Write these rules on the board. Feel free to add any important rules that learners may have omitted (see below). These rules should be kept visible for all sessions and referred to as needed throughout the modules.

The following are some sample ground rules:

Listen to what other people say.

No talking when someone else is talking.

Be kind and give support.

If people do not want to say anything, they do not have to.

Do not laugh at what other people say.

Insults are not allowed.

The opinions and statements of boys and girls are valued equally.

All experiences will be shared in a climate of privacy and trust.

If you wish to speak, raise your hand and wait to be called upon.

Questions are encouraged and may be asked at any time. There is no such thing as a stupid question.

It is okay for the facilitator and learners to blush, feel embarrassed, or not know the answers to all of the questions.

The facilitator also may choose not to answer a question in front of learners.

Things shared will be kept strictly confidential. They will not be discussed outside the group.

Do not judge people because of what they do or say.

Explain to the learners that they might also have questions that they are afraid to ask in front of their peers and friends. Let them know that they can write questions anonymously and place them in a designated spot (Question Box, Teacher's pigeon hole, etc) that has been set up especially for their questions. Explain how you will answer these questions, either after each session or when appropriate.

\section{The Art of Asking Questions}

The ability to ask meaningful questions that stimulate discussion, and relate to the objectives of the learning session, is an important skill for a facilitator. Effective, stimulating questions are openended and can start with "what" and "how." Questions that start with "why" may put learners on the defensive. There are four types of questions:

1) Close-ended questions: At what age do boys begin puberty?

Closed-ended questions solicit yes or no responses or very short answers.

2) Open-ended questions: What are some physical changes that occur during puberty?

Open-ended questions solicit more information.

3) Probing questions: Can you tell me what you know about menstruation.

Probing questions solicit more in-depth information and encourage in-depth thinking.

4) Leading questions: Isn't it normal for boys to have wet dreams?

Leading questions lead the respondent to say what they think you want them to say and not what they really think or feel. 
A facilitator asks questions in order to:

Verify the learners understanding of the topic

Clarify a point or reinforce essential points

Stimulate learners thinking

Encourage group participation and maintain interest and attention

Assist learners to review topics/concepts what they have not mastered well

Draw relationships between classroom learning and application to learners' life

The purpose of asking questions is not to interrogate. Questions are directed at the learners and therefore the facilitator should not jump in to answer the question. Even when faced with some silence, the facilitator should be patient and remain silent for at least 10-15 seconds. It is likely that someone will break the silence and attempt to answer the question.

The facilitator should ask questions:

During the introduction of the lesson (to help learners make the connection between the content of the session and their own experience/needs).

Throughout the session (to encourage participation)

At the end of the session (to draw conclusions and application of the learning process). Questions should require thought, allow the group to draw their own conclusions, and encourage reflection so the information can be applied to their lives.

\section{Responding to Learners' Questions}

In participatory learning, learners should be encouraged to ask questions. It is important for the facilitator to keep the following principles in mind when responding to questions:

Listen carefully to understand the purpose of the question/what's behind the question.

Do not answer too quickly. Take a moment to reflect on your answer.

Ask the question in a different way to be sure you have understood it.

Thank the person asking the question.

Choose words carefully and think about the impact they have on an individual.

Never belittle or embarrass someone for asking a question.

If you do not know the answer, admit it, and promise to look for more information.

Ask a learner, or the group, to respond to the question or to give their point of view.

Make an effort to take questions from all parts of the group (right, left, center).

\section{Responding to Learner Responses}

Once the facilitator asks a question, it is important to listen to the responses very carefully. There are four types of responses that a facilitator can expect:

Correct Response: Repeat the learner's response to positively reinforce it and ensure that everyone heard the response. Comment positively on the response to encourage the learners. The facilitator can also ask the learner to repeat the response loudly enough to ensure all learners have heard.

Partially Correct Response: Compliment the learner for the correct part, and then reformulate the rest of the question to the same learner or someone else. Or ask, "Is there anyone who wants to add more information?"

Incorrect Response: Indicate in a constructive way that the response is not quite correct and reformulate the question to put the learners on the right track.

A response that adds a rich but unexpected idea: Thank the learner and recognize his/her idea. 


\section{How to Deal with Difficult Behaviours}

Every group will have people with different personalities who behave differently, some of whom may disrupt the learning process. A few of these behaviors and how to deal with them are listed below:

1. Talkative: Has something to say about everything. Always volunteers to be group leader, answer questions, and offer suggestions.

Say, "I appreciate your comments but let's hear from some other people." Suggest further discussion outside of class, "In order to stay on schedule, let's discuss this further during break."

2. Clueless: Seems to have no idea what is going on, misunderstands the question or topic.

Say, "Something I said must have led you off track. What I was trying to say is..."

3. Rambling: Talks about things that do not relate to the topic. Differs from clueless because they know what is going on but prefers to follow their own agenda.

Say, “I don't understand. How does this relate to what we're talking about." Use the car park.

4. Hostile: Acts and says things to challenge and argue. Questions the facilitator's knowledge.

Do not become hostile as well. Say, "I understand and appreciate your point of view. What do some of the rest of you think?" (Gives others opportunity to exert peer pressure.)

5. Stubborn: Refuses to see anyone else's point of view. Is difficult to deal with in groups.

Say, "I appreciate your point of view, but for the sake of the activity/discussion, I'm going to insist that we move on. We can talk about this more."

6. Silent: Seems attentive and alert but will not comment or answer questions; happy to listen.

Say, "I know you have some experience in this area. It would be helpful if you would share your thoughts with the group". Putting participants in small groups often encourages shy people to participate more.

7. Know-it-all: Views self as authority on every subject and knows more than the group and facilitator.

Do not let your annoyance show. Acknowledge his/her contribution by saying, “That's one point of view. However, there are other ways of looking at it." May ask other participants for their opinions and move on.

8. Class clown: Makes a joke out of everything and tries to get attention.

Say, "We all enjoy a little fun. But right now, let's get serious and concentrate on the topic."

9. Negative: Complains about everything and may frown, keep arms crossed, and look away.

Say, “I understand your point. What suggestions do you have to change the situation?"

10. Indifferent: Makes no attempt to participate or contribute. May engage in activities separate from the group. (Often has been forced to attend).

As for the silent type, say, "I know you have some experience in this area. Please tell us about it."

11. Personality clashes: Some people in a group may not get along: engage in verbal battles, directly or indirectly, with personal and hurtful remarks.

Address personality clashes early by having ground rules or saying, "I suggest that we keep personalities out of the discussion. Let's get back to the topic."

12. Side conversations: Two or more learners have their own conversation while another learner or the facilitator is talking.

Sometimes just walking over to the individuals will cause them to stop their conversation. If not, try saying, "(persons' names), we were just talking about. . . What are your thoughts?" 


\section{Time Management in Participatory Training}

In successfully facilitating participatory training, the group dynamics and processes can in many ways threaten time management and one great challenge is to manage the time reserved for a session.

The following are some suggestions to deal with time management threats:

Make sure group work is timed and the learners know the time allocated. Stick to it.

Supervise group work and individual exercises to make sure learners are on track.

Make sure that learners know "which groups they belong to."

Make sure the instructions are clear and understood by all learners.

Use the guidelines for addressing difficult behaviours to avoid distractions.

Make sure you follow to the session guides and do not divert unnecessarily.

Prepare all the materials you need before the session and keep them in an orderly manner.

Use a "car park." If you do not have enough time to address all comments and questions, write them down on the board or piece of paper and call them the car park. Explain to learners that you will talk about these at another time and they will not be forgotten.

\section{Energizers and Games}

Energizers and games are an important part of participatory training. They are used to keep the level of motivation of the learners high and to raise their energy levels (eg. to wake up learners in the morning, to renew concentration after lunch or when changing from one topic to another). Energizers are supposed to be quick and must be well prepared with clear instructions. The following are short descriptions of energizers. Learners may also have some energizers that they can contribute to the group.

\section{The Human Web}

Learners form a wide circle facing inward. They then stretch out and cross their arms in front of them. They are asked to close their eyes, slowly advance towards the middle of the circle and grasp one person with each of their hands. The facilitator should ensure that three hands do not join and that the hands are grasps not wrists. When everyone has grasped two other hands firmly, the facilitator tells the learners to open their eyes and the human web has to be entangled. The web may end up in a number of smaller circles of learners, sometimes intertwined. This exercise brings people close together and makes them feel like equals.

\section{Life Boat}

The learners are told they are on a ship that is sinking. They have to get into life boats, but their capacity is limited. Depending on the size of the group the facilitator calls out the life boats are only 2,3 or 5 people, for example. Then in five seconds, learners have to form groups of 2, 3 or 5 . The facilitator eliminates those who have drowned, groups which are bigger or smaller than the announced numbers. The facilitator then announces new numbers so that regrouping is necessary until there is only one group left. This exercise allows people to move around quickly, interact with each other and make quick decisions.

\section{The Mail}

Learners and facilitator sit in a circle on the exact number of chairs minus one. One person (the facilitator to begin with) stands in the middle and announces, "I have a letter for those who (for example): are wearing black shoes, don't like fish, are wearing a white shirt. The learners who are wearing black shoes, for example, have to change chairs. The person in the middle seizes the opportunity to sit on one of the empty chairs. The one who is left without a chair now stands in the middle and delivers another letter. This exercise gets people to move around and to discover things about each other. 


\section{Simon says...}

All stand in a circle. The facilitator says: Simon says, e.g. touch your nose with your left hand, hold up two hands, form a fist, say hello, etc., demonstrating the action at the same time. Everyone is asked to follow the orders as demonstrated. But if the facilitator does not mention "Simon" and some learners follow the orders, those learners are out. The game goes on until only a few learners are left and the facilitator cannot trick them any longer. This exercise increases concentration and energizes the learners for the next task.

\section{Bang}

The learners sit in a circle on the floor, counting out loudly, beginning with "one" and going around the circle, each person saying the next number. However, every time they come to a number which can be divided by 3 , such as 12 , or contains a 3 , such as 13 , the person whose turn it is has to say "bang" instead of the number. If the person fails, he/she is removed from the group. This exercise demands concentration and is useful at the beginning of serious group work.

\section{Person A and Person B}

Each person privately selects one person out of the group as "Person A" and another as "Person B". No one else should know their choice. Then everyone tries to get as close to their "person A" as possible. Once that has happened, and the learners have stopped moving, the facilitator tells them to get as far away as their "person B". The group will do two opposite movements: contracting and expanding. This is a quick humorous exercise. The learners should not be asked to reveal who they picked for some may feel left out.

\section{Association}

The group sits in a circle. Someone says the name of a fellow learner and a word, whatever comes to mind. The next says the name of another learner and a word he/she associates with the first word. The next person does the same and so on. If someone does not answer quickly he/she is removed from the game. This exercise helps with creative thinking and gets the learners to call each other by name. Negative word associations should be discouraged from the beginning of the game.

\section{Question Box}

Setting up a question box in a school is an way for students to anonymously ask questions that are important to them that they may not be comfortable asking in front of their peers or teachers. A question box is a box where students are able to ask questions about health, HIV and AIDS, STIs, decision making, relationships, or other challenges they are facing. Students are able to write their questions and place them in the question box without embarrassment. The answers can be posted on a bulletin board, discussed at a school assembly, or addressed through another forum. It is important that the method for answering questions is well understood by the students and that it is followed consistently so that students feel that their questions are being answered in a timely way.

The question box should be located in a place that is accessible to all students at anytime. Questions should be collected on a regular schedule (every day or once a week).

Answers should be posted or shared on a regular schedule (one a week or every two weeks). One person should be responsible for collecting the questions.

A team of people should be responsible for answering questions.

A health worker should be identified to help answer questions.

Questions should be answered in an honest and informative way, without judgement. 


\section{Ten Suggestions for Improving a Lecture}

Lecturing is one of the most time-honoured yet ineffective ways to teach. By itself, it will never lead to active learning. For a lecture to be effective, the trainer should build interest first, then maximize understanding and retention, involve learners during the lecture, and reinforce what has been presented. There are several ways to do just that.

\section{Building interest}

1. Lead-off story or interesting visual. Provide a relevant anecdote, fictional story, cartoon, or graphic that captures the audience's attention.

2. Initial case problem. Present a problem around which the lecture will be structured.

3. Test question. Ask learners a question (even if they have little prior knowledge) so that they will be motivated to listen to your lecture for the answer.

\section{Maximizing Understanding and Retention}

4. Headlines. Reduce the major points in the lecture to keywords that act as verbal subheadings or memory aids.

5. Examples and analogies. Provide real-life illustrations of the ideas in the lecture and, if possible, create a comparison between your material and the knowledge and experience that the learners already have.

6. Visual backup. Use handouts and demonstrations that allow learners to see as well as hear what you are saying.

\section{Involving Learners During the Lecture}

7. Spot challenges. Interrupt the lecture periodically and challenge learners to give examples of the concepts presented thus far or to answer spot quiz questions.

8. Illuminating activities. Through the presentation, intersperse brief activities that illuminate the points you are making.

\section{Reinforcing the Lecture}

9. Application problem. Pose a problem or question for learners to solve based on the information given in the lecture.

10. Learner review. Ask learners to review the contents of the lecture with one another or give them a self-scoring review test. 


\section{Ten Tips when Facilitating a Discussion}

Your role during a group discussion is to facilitate the flow of comments from learners. Although it is not necessary to make a comment after each learner speaks, periodically assisting the group with their contributions can be helpful. Here are ten tips to use as you lead group discussions.

1. Paraphrase what a learner has said so that he or she feels understood and so that the other learners can hear a concise summary of what has been said.

So, what you're saying is that you have to be very careful when talking about sensitive issues like sexual health. You also told us that it is important to sensitize parents and other community members before you begin talking about these issues with young people.

2. Check your understanding of learners' statements or ask them to clarify what they are saying.

Are you saying that this plan is not realistic? I'm not sure that I understand exactly what you meant. Could you please explain it to us again?

3. Compliment an interesting or insightful comment.

That's a good point. I'm glad that you brought that to our attention.

4. Elaborate on a learner's contribution to the discussion with examples, or suggest a new way to view the problem.

Your comments also provide an interesting point from the parent's perspective. It could also be useful to consider how a young person would view the same situation.

5. Energize a discussion by quickening the pace, using humour, or, if necessary, prodding the group for more contributions.

Oh my, we have lots of humble people in this group! Here's a challenge for you. For the next two minutes, let's see how many ways you can think of to incorporate adolescent reproductive health activities into your schools.

6. Disagree (gently) with a learner's comments to stimulate further discussion.

I can see where you are coming from, but I'm not sure that what you are describing is always the case. Has anyone else had an experience that is different from John's?

7. Mediate differences of opinion between learners and relieve any tension.

I can see that Margaret and Mary are not really disagreeing with each other but are just bringing out two different sides of this issue.

8. Pull together ideas, showing their relationship to each other.

As you can see from Juma and Carole's comments, personal goal setting is very much a part of time management. You need to be able to establish goals for yourself on a daily basis in order to more effectively manage your time.

9. Change the group process by altering the method for obtaining participation or by having the group evaluate ideas that have been presented.

Let's break into smaller groups and see if you can come up with some examples of counselling skills that were identified during the presentation this morning.

10. Summarize (and record, if desired) the major views of the group.

I have noted four major reasons that have come from our discussion as to why you think that young people do not abstain: (1) peer pressure, (2) low self esteem, (3) wanting to show their love for their partner, and (4) wanting to feel like an adult.

From Silberman 1995 


\section{Ten Steps to Use when Facilitating Experiential Activities}

Experiential activities help to make training active. It is often better for learners to experience something rather than to hear it talked about. Such activities typically involve role-playing, games, simulations, visualization, and problem-solving tasks. The following ten steps will help to make your experiential activities a success.

1. Explain your objectives. Learners like to know what is going to happen and why.

2. Talk about the benefits. Explain why you are doing the activity and how the activity connects with any preceding activities.

3. Speak slowly when giving directions. You might also provide visual backup. Make sure the instructions are understood.

4. Demonstrate the activity if the directions are complicated. Let the learners see the activity in action before they do it.

5. Divide learners into the groups before giving further directions. If you do not, learners may forget the instructions while the subgroups are being formed.

6. Inform learners how much time they have. State the time you have allotted for the entire activity and then periodically announce how much time remains.

7. Keep the activity moving. Do not slow things down by endlessly recording learner contributions on the board and don't let a discussion drag on for too long.

8. Challenge the learners. More energy is created when activities generate a moderate level of tension. If tasks are easy, learners will get tired and lose interest.

9. Always discuss the activity. When an activity has concluded, invite learners to process their feelings and to share their insights and learning.

10. Structure the first processing experiences. Guide the discussion carefully and ask questions that will lead to learner involvement and input. If learners are in subgroups, ask each person to take turns sharing his or her responses. 


\section{Resource 2 Guidance and Counselling}

Adolescence is an exciting, yet challenging time for students, their parents, and their teachers. During this time young people are deciding who they are, what they do well, and what they will do when they finish school. They begin to evaluate their strengths, skills, and abilities. The biggest influence is their peer group. They are searching for a place to belong and rely on peer acceptance and feedback. They face increased pressures regarding risk behaviours involving sex, alcohol, and drugs while exploring the boundaries of more acceptable behaviour and mature, meaningful relationships. They need guidance in making decisions.

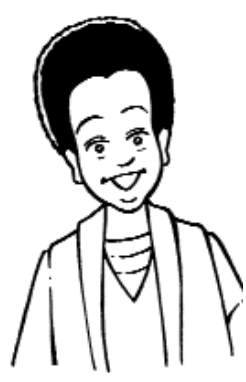

Guidance and counselling teachers can respond to the challenges faced by today's students by providing academic skills support; organizational, study and test-taking skills; education in understanding themselves and others; communication, problem-solving, decision-making and conflict resolution skills; education in adolescent reproductive health; career awareness, exploration and planning; substance abuse education; goal-setting; and academic and career planning.

\section{What is Guidance and Counselling?}

Guidance means giving direction, helping, advising, caring, providing information, encouraging, giving assurance, and instilling confidence. When done effectively, guidance can:

Give knowledge

Influence behaviour

Help with goal planning

Offer emotional support

Change behaviour

Identify and develop talents in individuals

Help make correct choices

Help live a fulfilling life

Build confidence

Explore different professions and jobs available

Counselling is one person helping another by talking person-to-person. When you help someone make a decision or solve a problem, you are counselling. Through counselling, you help people make choices based on their own needs and wants. Young people face many decisions and make many decisions that can impact their lives; they can make better decisions with your help.

Counselling has two basic goals: 1) Help them manage a specific problem, and 2) help them become better at helping themselves in their every day lives.

The difference between guidance and counselling is that counselling helps people make decisions but does not tell them what to do, whereas guidance tells people what they need to do in order to achieve a certain goal.

Everyone can learn good counselling skills. You counsel well when you:

Show that you understand and care about them.

Build trust.

Give useful, correct information and help students understand what this information means to them. Help them make choices, based on clear information and their own feelings, situation, and needs. Help them remember what to do. 
Although counselling is a skill that can be learned and improved with practice, it is important to realize when a problem or situation is beyond your experience and ability. Be familiar with other services and refer students as needed.

\section{How to Counsel}

The six elements of counselling can be remembered with the letters in the word GATHER. Not everyone will need to be counselled in this order and not everyone will need all six GATHER steps. Some may need a step repeated. Counselling can change to fit individual needs.

G - Greet: Give your full attention immediately; be polite, friendly, and respectful; tell them that you will not tell others what they say.

A - Ask questions: Ask about their reasons for coming to you; help them identify the decisions they face; keep questions open, simple, and brief; look at them; ask them what they want to do; show your interest and understanding at all times; and avoid judgments and opinions.

T - Tell them about their choices: To make informed choices and good decisions, people need clear, accurate, specific information about their options that relates to their own lives.

H - Help them choose: Explain that the choice is theirs; offer advice, but do not make decisions for them; encourage them to think about their future plans; help them think about the results of their options; finally ask, "What have you decided to do?"

E - Explain what to do: After they made their decision, explain how they can do what they have decided; mention additional support services that are available to them, let them know they can come back anytime, but agree on a time to return for a follow-up visit.

R - Return for follow-up: Ask if they have any questions or anything else to discuss.

\section{Counselling Young People}

Often young people face more and different issues than adults. Thus, counselling young adults requires being even more open, more flexible, more knowledgeable, and more understanding. Counselling young adults can be challenging, but it can be very rewarding to help young people make wise and healthy decisions.

Be open. Let young people know that no question is wrong, and even embarrassing topics can be discussed.

Be flexible. Talk about whatever issues the young person wants to discuss.

Give simple, direct answers in plain words. Learn to discuss puberty and sex comfortably.

Be trustworthy. Honesty is crucial to young people. You, and the information you give, need to be believable. If you do not know an answer, say so. Then find out.

Stress confidentiality. Make clear that you will not tell anyone about your discussion or their decisions.

Be approachable. Do not get upset or excited. Keep calm.

Show respect. Do not talk down to young people.

Be understanding. Recall how you felt when you were young. Avoid judgments.

Be patient. Young people may take time to talk or reach a decision. Sometimes several meetings are needed. 


\section{Guidance and Counselling Teachers}

Young people may not always say aloud what they are feeling, so guidance and counselling teachers need the ability to listen - to words, body language, unspoken words, and attitudes. Guidance and counselling teachers can help students by really listening to them whether they are talking or not.

Empathy, along with listening, is a key skill needed to effectively counsel and provide guidance. Empathy is the ability to experience the feelings of others as if they were your own, and the ability to understand why others do what they do and think the way they do. Without the ability to understand what the young person is experiencing, a guidance and counselling teacher cannot do an effective job. Empathy leads to good listening and a better ability to help young people find solutions. It also helps them feel more comfortable and willing to open up to a guidance and counselling teacher.

The ability to build trusting relationships with students and other members of the school community is important for the success of guidance and counselling teachers. They must be approachable, inviting, and trustworthy. Students must want to seek out that person when they are in need. Students need to feel that there are adults who they can turn to and will be there for them without passing judgement. Students can tell if we are warm and inviting and whether or not they can trust us with their stories.

\section{The Role of Guidance and Counselling Teachers}

Guidance and counselling teachers support all students in their educational, career, personal and social development thus enabling them to become life-long learners and productive citizens in our communities and around the world. Guidance and counselling teachers can meet the needs of all students by:

Assisting students with career development and planning for the future

Presenting life skills and adolescent reproductive health lessons in the classroom, small groups and individually

Counselling students individually and in small groups

Consulting with other teachers, administrators, school support personnel, parents, and community agencies

Referring students to appropriate services when circumstances are beyond their capacity

Working with parents in teaching effective parenting skills, creating a positive environment, and encouraging parent participation

Providing staff development in areas related to life skills, adolescent reproductive health, and guidance and counselling

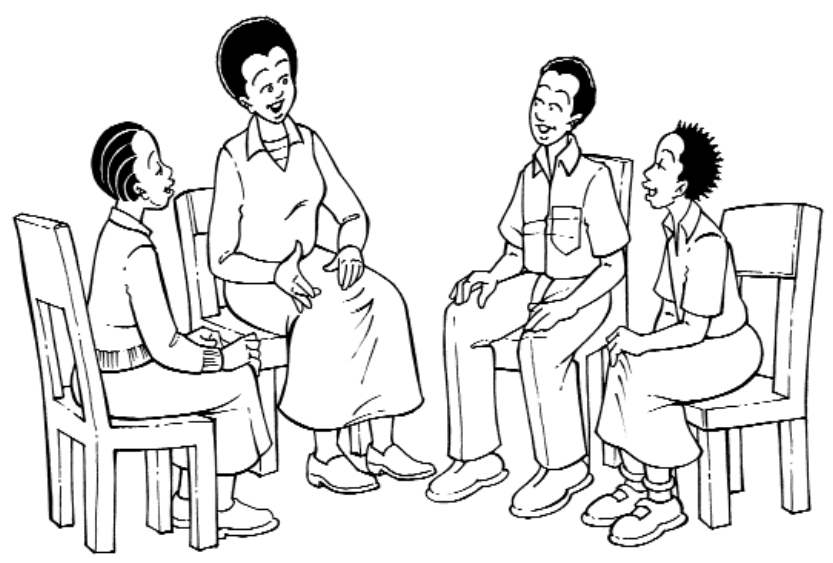




\section{Resource 2 Condoms}

\section{Learning Objectives}

By the end of this session, learners will be able to:

Use a condom correctly

Negotiate condom use with a partner

Explain how to use a female condom

\section{Materials Required}

Cards or small pieces of paper

Time 130 minutes

\section{Background Notes}

\section{Condoms}

Abstinence is the best and only certain way to prevent HIV infection and unwanted pregnancy. However, if young people have decided to have sexual intercourse and are sexually active, they should have information about how to use condoms correctly to reduce, but not eliminate the risk of HIV transmission. Using condoms correctly for every act of sexual intercourse can significantly reduce the risk of HIV transmission, STIs, and unwanted pregnancy.

There are currently two types of condoms available for use: a male condom and a female condom. A male condom is a soft, tube-like sheath made out of latex (a type of rubber) that is put on a man's erect penis before sexual intercourse. When the man ejaculates, the sperm is deposited in the condom. Because the sperm is collected in the condom, there is no contact between the man's and the woman's body fluids and this reduces the risk of STIs, including HIV, and unwanted pregnancy.

A female condom is a plastic pouch that covers the cervix, the vagina, and part of the external genitals. A woman uses the female condom during intercourse to prevent HIV, STIs, and unwanted pregnancy. The female condom is a relatively new form of contraception, which is still not available in many areas. It is a thin polyurethane (a kind of plastic) sheath with two flexible rings, one attached to each end. One ring, at the closed end of the sheath, is placed inside the woman's vagina and serves as an anchor. The other ring at the open end of the sheath stays outside the vagina and partially covers the lips of the vagina. It is used once and then thrown away. The condom catches the man's sperm so that it does not enter the vagina.

Many men and women are afraid to use condoms because they do not know how to use them or because they are uncomfortable or worried about talking with their partner about using them. There are many excuses people use to not use a condom. For example, a man may tell a woman that she should trust him, and that she has nothing to worry about. He might try to make her feel guilty by asking her why she does not trust him, whether she thinks he has other girlfriends, or whether she thinks that she is infected with HIV. It is important to remember that either person could have an STI or be infected with HIV from a previous relationship without noticing any symptoms. Therefore, it is in everyone's best interest to use condoms. Condoms offer protection to both people involved. Using a condom is a sign of trust, respect, and caring for your partner. 
Correct and Consistent Use

To be effective, condoms must be stored properly and used correctly for every act of intercourse. Condoms effectively prevent STIs that are transmitted through body fluids including HIV, gonorrhoea, and chlamydia. They are less effective against STIs that are transmitted through skinto-skin contact like genital herpes or warts because the condom may not cover the affected areas.

Most condoms for sale are latex. Condoms made of natural products such as sheepskin are effective as contraceptive methods but do not prevent HIV or other STIs.

Condoms can break, leak and slip. Condom failure can be caused by not being used correctly, or can result from manufacturing defects or poor storage conditions. All condoms are tested in the factory for defects to reduce the risk of breaking. Even accounting for these failures, condoms provide the best protection against HIV and other STIs after abstinence.

Important facts about condoms:

No penis is too big or too small for a male condom. Male condoms can be stretched to fit over a forearm.

Asking a partner to use a condom does not mean you do not trust your partner. You are making a responsible statement about both your futures by using condoms.

HIV cannot pass through LATEX or RUBBER condoms; however, the virus can pass through sheepskin or animal skin condoms.

Most condoms are lubricated. However, if extra lubrication is desired, use a water-based lubricant such as KY jelly. Water and saliva are good substitutes. Never use any lubricant that is oil or petroleum based like Vaseline, valon or any other petroleum jelly in the market. This will immediately start to weaken the rubber, and the condom can break.

Condoms are tested in the factory. When stored properly, the risk of a condom breaking is very low. Keep them away from heat or sunshine. Never leave condoms near a window or in a wallet in your back pocket that you sit on continuously. All these places will cause the condom to tear or lose its lubrication.

There is a correct way to use condoms. Emphasize that using a condom incorrectly may lead to pregnancy or infection with a disease.

\section{Instructions}

\section{He Said, She Said: Role Play (60 minutes)}

Write the following statements on small pieces of paper:

What's that?

I don't like using them.

It doesn't feel as good.

But we've never used a condom before.

Don't you trust me?

I'll pull out in time.

Only prostitutes use condoms.

Condoms aren't romantic.

It just isn't as sensitive.

It's like taking tea without sugar.

It's like eating a banana with the peel on.

I don't stay hard when I put on a condom.

I guess you don't really love me.

We're not using a condom, and that's it. 
1. Explain that in this activity we will explore condom negotiation skills using role-plays. In each role-play, one person will play the male, and the other a female part of a couple. The female's task is to persuade the male to use a condom. The male will be given a card containing a line that he must say when the female tries to introduce the condom into the conversation.

2. Select two learners at random, and ask them to choose a male role and a female role. Give one of the cards to the male (or read one of the responses), and ask them to perform a skit lasting between 3 and 4 minutes, showing a successful condom negotiation.

3. After the role-play, have a brief discussion with the learners about their reactions to the quality of the role-play, the realism, and the effectiveness of the negotiation strategy. Ask them what did you see? What did you hear the two characters say? Does this happen here in our community? What else could she/he have said to strengthen the negotiation? Ask them to suggest ways the negotiation could have been improved.

4. Repeat steps 2 and 3, using different cards for each. Switch so that for some role-plays boys are trying to convince girls to use condoms and in other role-plays it is girls trying to convince boys. Continue with additional role-plays for the time allotted.

5. Ask learners which of the role-play situations are common in real life. Which strategies have been most successful in real life? Are there any situations in which negotiation is not possible? What are the woman's options in such cases? Note: Someone may mention the option of a female condom. If not, the teacher should introduce it, and say that will be discussed next.

\section{Using Condoms Correctly (50 minutes)}

1. Ask for volunteers to come forward and give each one a piece of paper onto which you have written the following points (mix up the order first).

Steps for using a male condom:

Discuss condom use with partner.

Have condoms with you.

Have an erection.

Check expiry date and open the condom wrapper carefully (do not use teeth, nails, or other sharp objects).

Squeeze out the air from the tip of condom while rolling the condom down the shaft.

Roll condom on erect penis all the way down to the base of the penis.

Have sexual intercourse.

Immediately after ejaculation, withdraw penis from partner, holding on to condom at base of penis so it does not fall off.

Be careful not to spill semen.

Remove condom from penis away from partner.

Dispose of condoms in a place outside of children's reach (pit latrine, dustbin, or burn it). Never flush a condom down a toilet.

Open another condom (if you have sex again). Never try to wash or re-use a condom. You must use a new condom each time you re-enter your partner (if you come out for a while), or start to have sex again. 
Female Condom (20 minutes)

1. Ask learners if women have other options for protecting themselves if their partners refuse to use a male condom. Allow learners to share their views. Note: If the idea of using a female condom does not come from the learners, introduce it.

2. Ask learners what they know about female condoms, using the following questions as a guide:

How are female condoms different from male condoms?

Are female condoms available in Kenya?

How are female condoms supposed to be used?

What are the advantages of the female condom?

Is a female condom preferable to a male condom for protection?

What is the cost of a female condom?

What are the disadvantages of a female condom?

\section{Optional Activities}

\section{\#1 Condom Demonstration}

1. Demonstrate proper condom use with a penis model (broom handle, test tubes, or bottle). Follow these steps, explaining what you are doing at each step:

Discuss condom use with partner.

Have condoms with you.

Have an erection.

Check expiry date and open the condom wrapper carefully (do not use teeth, nails, or other sharp objects).

Squeeze out the air from the tip of condom while rolling the condom down the shaft.

Roll condom on erect penis all the way down to the base of the penis.

Have sexual intercourse.

Immediately after ejaculation, withdraw penis from partner, holding on to condom at base of penis so it does not fall off.

Be careful not to spill semen.

Remove condom from penis away from partner.

Dispose of condoms in a place outside of children's reach (pit latrine, dustbin, or burn it). Never flush a condom down a toilet.

Open another condom (if you have sex again). Never try to wash or re-use a condom. You must use a new condom each time you re-enter your partner (if you come out for a while), or start to have sex again.

2. Divide the group into pairs and give each pair a condom and a penis model. Ask the pairs to take turns demonstrating and explaining how to use the condom correctly.

3. Facilitate a discussion with the following questions:

How easy or difficult was it to demonstrate condom use?

How do men feel when they get or buy condoms? What about women?

What would you say to a friend who said it was not cool to get and use condoms?

Which behaviour is more comfortable, having unprotected sex and risking STIs, HIV, and pregnancy or using a condom? 
\#2 Female Condom Demonstration

1. Pass around female condom packs, and ask learners to follow you step by step as you open it. Take the following steps:

Check the expiry date.

Locate the notch along the edge that makes it easy to open the packet. To avoid accidentally tearing the condom, do not use sharp objects (like fingernails or a knife) to open the packet. Open the packet and take out the condom.

Point out that one end is closed, and the other open and that there are two rings: the outer ring at the open end, and the inner ring near the closed end.

Explain that the inner ring is meant to be inserted into the vagina, and the outer ring is to remain outside.

\section{Frequently Asked Questions about Male Condoms}

\section{What are male condoms made of?}

Male condoms are made of latex, polyurethane, or natural animal membranes.

What condoms are recommended for preventing HIV transmission?

Only latex condoms are recommended for HIV prevention.

\section{Is wearing two condoms safer than wearing one?}

Wearing two condoms is not safer than wearing just one. The friction between the two condoms could cause them to tear.

\section{How long does a latex condom last?}

Latex condoms expire 5 years after the date they are manufactured, unless they are packaged with spermicide. Latex condoms with spermicide expire after 3 years. Always check the expiry date before using a condom.

\section{Should circumcised men use condoms in the same way as uncircumcised men?}

Men who are not circumcised should push their foreskin back before putting on a condom. By pushing back the foreskin before putting on a condom, uncircumcised men can allow the fore-skin to move without breaking the condom.

\section{How should condoms be disposed of?}

After use, condoms should be thrown away. Used condoms can be burned, buried, or wrapped in tissue and placed in a closed container or pit latrine. Do not flush down a toilet. Never reuse a condom.

\section{How effective are condoms in preventing HIV infection?}

Even in couples where one partner is infected with HIV, if they use condoms correctly and consistently the HIV infection rate is less than 1 percent a year. In couples where one partner is infected with HIV and if they do not use condoms consistently the HIV infection rate is about 10-15 percent a year. 


\section{How to Use a Male Condom}
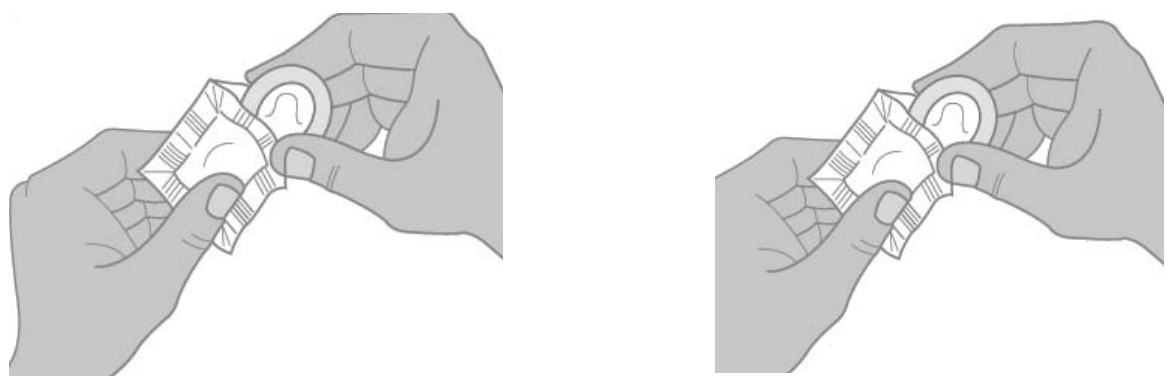

1. Open the packet carefully. Do not use anything sharp like a knife or nails. Ensure that the part to be unrolled is on the outside.

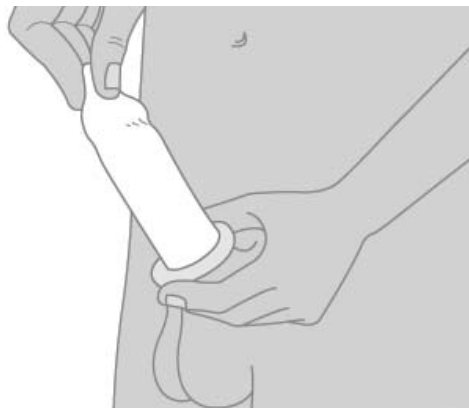

3. Unroll the condom all the way to the base of the penis.

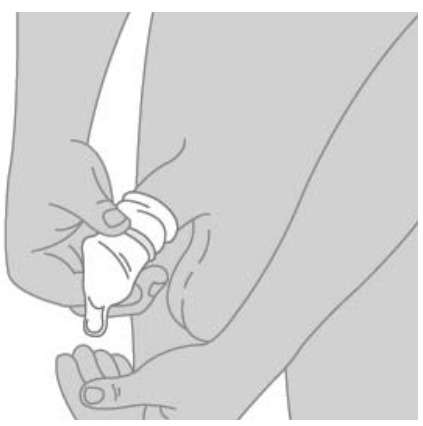

5. While still holding the base, pull off the condom gently so as not to spill the contents.
2. Pinch the tip of the condom. Place it on the hard penis.

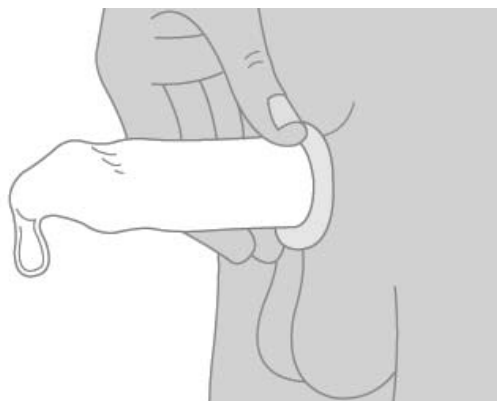

4. After ejaculation, hold the condom at the base of the penis so it does not slip off.

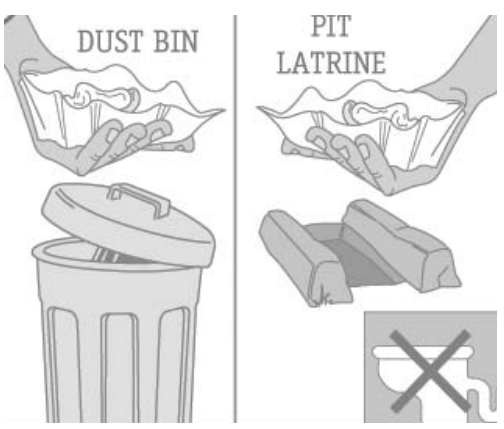

6. Wrap condom in tissue paper and throw it away in a latrine or somewhere out of reach of children. Never flush a condom down the toilet. 


\section{Frequently Asked Questions about Female Condoms}

What are female condoms made of?

They are made of a thin plastic called polyurethane, which is stronger than rubber or latex.

\section{What is the purpose of the soft rings inside the female condom?}

The ring at the closed end is used to insert the female condom inside the vagina and hold it in place during sex. The ring at the open end stays outside the vagina and is where the penis enters during intercourse.

Are there any side effects from using the female condom?

No. The female condom does not have any side effects.

\section{Why is the female condom bigger than the male condom?}

The female condom is wider than the male condom, but it is the same length. This is so it will stick to the vaginal wall during intercourse. Many men report they like this width because it does not constrict the penis.

How many sizes do female condoms come in?

The female condom comes in only one size and will fit all women.

\section{Can I use the female condom without my partner's knowledge?}

Some women have reported using the female condom without their partners' knowledge. However, in most cases the female condom requires communication with and cooperation from a woman's partner.

Can I use more than one female condom to increase the effectiveness?

No. Only one female condom should be used at a time. Using more than one can cause them to move out of place or break.

\section{When am I supposed to insert the female condom?}

The female condom can be inserted right before sex, or up to eight hours before. Most women insert it 2 to 20 minutes before actually engaging in sex.

Can a couple use the male and female condoms at the same time?

No. If you use the male condom and the female condom at the same time, neither will work properly. If either the female condom or the male condom is used properly, no additional barrier is necessary.

\section{Can I use the female condom during my period?}

The female condom can be used when you have your period. However, it should be inserted right before intercourse.

\section{Can the female condom get lost in the vagina?}

The outer ring holds the female condom in place even with intense movements. But if the female condom does get inside, it can be removed with two fingers and a new female condom should be used.

\section{How do I remove the female condom?}

The female condom should be taken out before the woman stands up to avoid the semen spilling out. The outer ring should be twisted, to seal the condom so that no semen comes out and then gently pulled out.

\section{How do I dispose of female condoms?}

Female condoms can be disposed of in the same clean and private way as sanitary pads. The female condom can be wrapped in the packet it came in or in tissue and then disposed of in waste containers or pit latrines, or burned. It should not be placed in a toilet.

\section{What kind of lubricant can I use with the female condom?}

You can use water or oil-based lubricants with the female condom. The female condom is made from a thin plastic (polyurethane), so oil-based lubricants will not damage it. 


\section{How to Use a Female Condom}

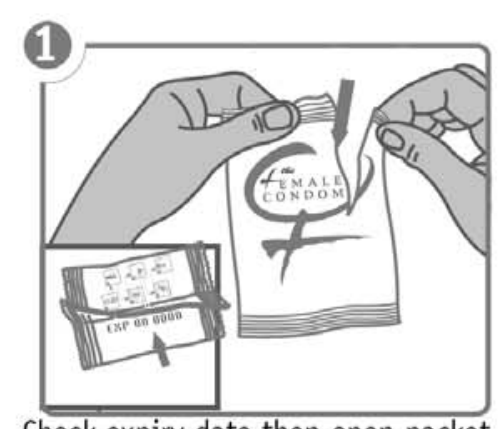

Check expiry date then open packet. Do not use sharp objects or teeth.

Push the inner ring up into the vagina as far as it will go. Do not twist it.
2

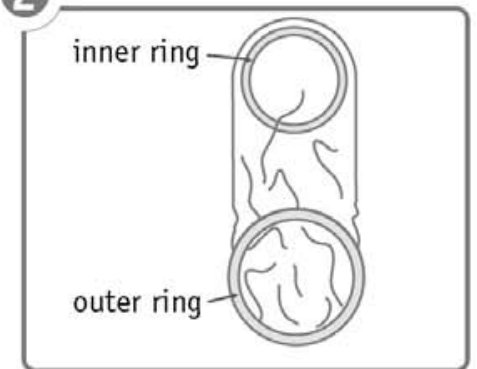

Remove the female condom from the packet. Rub the condom to spread the jelly.

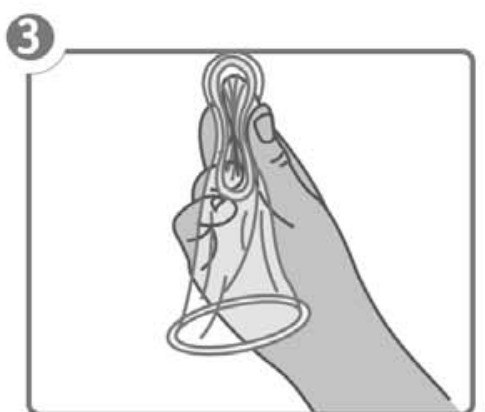

Hold the female condom as shown above, making the inner ring long and narrow.

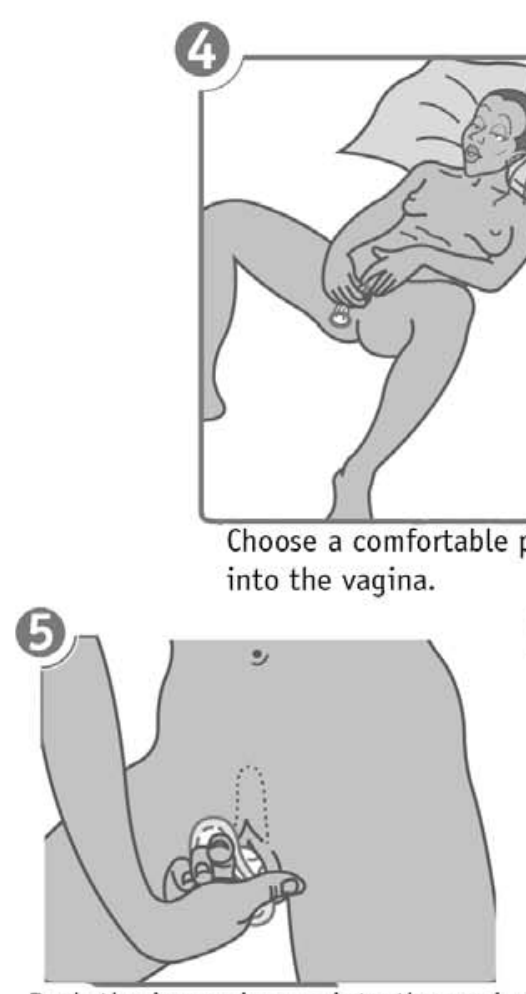

8

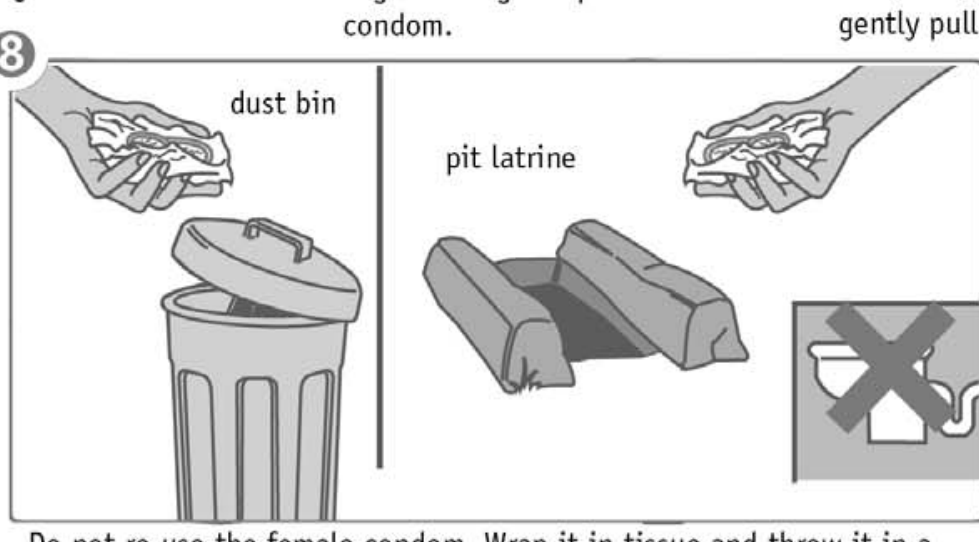

Do not re-use the female condom. Wrap it in tissue and throw it in a dust bin or pit latrine. Never throw it in a flush toilet.
6

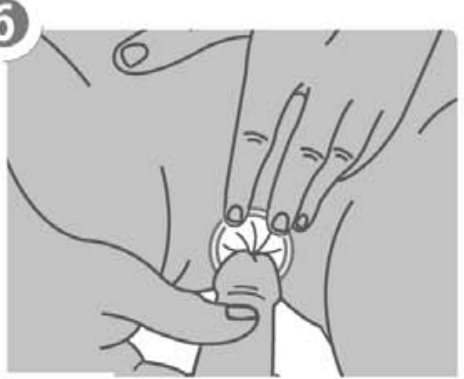

Hold the outer ring outside the vagina and guide penis into female condom.

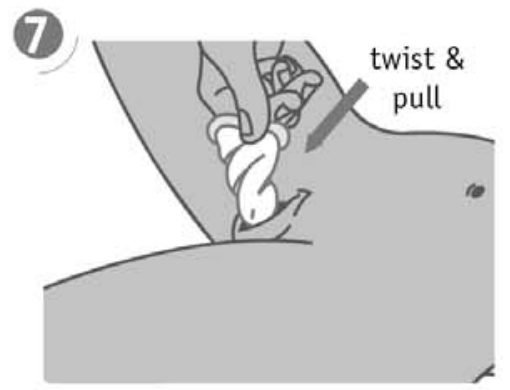

Immediately after intercourse, twist the outer ring to avoid spillage and gently pull condom.

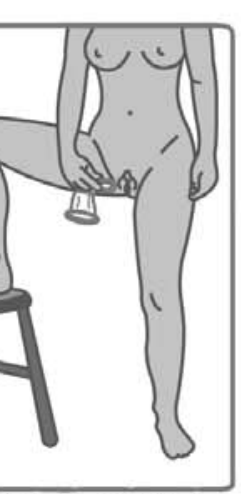




\section{Resource 3 Other Ways to Prevent Pregnancy}

\section{Learning Objectives}

By the end of the session, learners will be able to:

Explain some of the methods for preventing unwanted pregnancy

Identify myths about sexual intercourse and conception

\section{Time 130 minutes}

\section{Background Notes}

As you begin to talk with adolescents, you may find that you do not share the same values. You may want to encourage adolescents to delay sexual activity, but young people may already be sexually active when you begin presenting this material. It is important to guard against letting personal biases influence professional behaviour. You can play an important role by providing them with factual information and supporting young people to make their own decisions and good choices for their future, based on their knowledge and reproductive goals. Adolescents can safely use any contraceptive method. However, while all methods are medically safe for young people, some may be more appropriate than others. Sterilization is not recommended for young people because it is permanent and could lead to regret.

\section{What is Contraception?}

Contraception means preventing pregnancy. A contraceptive is a drug, device, or a method used to prevent pregnancy or reduce the chances of getting pregnant without avoiding sexual intercourse. There are many different contraceptive methods. Most are reversible; that is, a woman is able to become pregnant after she has stopped using the method. Some methods, such as surgical sterilization, are permanent, meaning a woman cannot become pregnant ever again. All methods are designed to work in one of two ways: either they prevent the man's sperm and the woman's egg from coming together, or they prevent the fertilized egg from implanting in the womb. Contraception allows women and men to determine the number and spacing of their children freely and responsibly.

\section{Contraceptive Choices}

Many family planning methods exist, including condoms, implants, injectables, IUCDs, natural family planning, oral contraceptives, spermicides, vaginal barrier methods, voluntary surgical sterilization, and withdrawal. Each of these has their advantages and disadvantages. Some provide temporary contraceptive protection while others are permanent. Some, such as the male and female condom, protect against sexually transmitted infections while others do not. Some are for women and some for men. Some must be used at the time of sexual intercourse, others can be used independently of intercourse. Some contraceptive methods are highly effective at preventing pregnancy, while others are only moderately effective. Effectiveness is closely linked to correct and consistent use for some methods, such as condoms, injectables, natural family planning, oral contraceptives, spermicides, vaginal barrier methods, and withdrawal. Health workers can help clients use their chosen methods effectively by providing information on correct method use and counselling about issues that may prevent consistent use, such as how to talk to a partner about condoms.

\section{Men's Responsibility in Family Planning}

Men can participate in family planning by sharing in decision-making about contraceptive use. Men can take responsibility for using some methods of contraception and can support their partners in using other methods. Although the overwhelming majority of contraceptive methods are designed for use by women, a few require the active cooperation of men. Methods that require active participation by men include male and female condoms, vasectomy, natural family planning, and withdrawal. Men also can participate in women's use of other methods. For instance, men can help their partner remember to take the pill everyday or to return to the clinic for regular injections. Men also can help their partners by organizing transportation to the clinic and paying for family planning methods and services. 
Teaching Contraception

Keep the following suggestions and guidelines in mind as you begin to teach this material:

The subject of contraception is a sensitive one for many. Teaching contraceptive information to adolescents can be controversial. Some adults believe young people should not have sexual intercourse and they fear that giving them information about contraception encourages young people to experiment sexually. There is no evidence to suggest that teaching this material causes young people to have sexual intercourse. In fact, studies from many countries show that good family life education classes actually postpone or delay sexually activity. Do not assume that anyone in the group is having sex or that no one in the group is having sex. Make it clear that since most people have sexual intercourse at some point, it is important to know about contraception.

Always present abstinence as the most effective and most appropriate method of contraception for young people. Stress that when young people do choose to have sexual intercourse, they have a responsibility to themselves, their partner(s), and future children to keep themselves safe from unintended pregnancy and disease. Make it clear that unprotected intercourse is neither safe nor smart.

Always keep the diversity of religious and cultural values in mind. As you talk about making decisions about contraceptives, remind students that couples must always consider their personal, family and religious values.

Use the third person. For example, say things like 'If a couple goes to a family planning clinic...' or 'when two people decide to have intercourse...' Refrain from saying 'If you decide....' or 'When you go to a family planning clinic'.

Keep your personal values regarding contraception out of the discussion. Provide factual information about all the different methods and continue to reinforce the concept that people who choose to have sexual intercourse should act responsibly and use contraception. Do not share your own personal experience with contraceptive use. You can say things like 'Many women(couples, men) who use this method find...' or '0ne of the problems I've heard about it is...' Sharing personal sexual experience with the group is inappropriate.

\section{Instructions}

\section{Methods of Contraception (60 minutes)}

1. Ask learners to brainstorm all the methods they have heard of for preventing pregnancy. Write these on the board. If they mention traditional methods such as the calendar method or using lemon juice, ask the person suggesting it to explain how it is used. Refer to the tables below to be sure each of the methods were listed.

2. Divide learners into pairs and assign each pair one of the medical methods of contraception. Ask each pair to discuss what they know about the method and how it is used, how effective it is, and whether it would be appropriate for an adolescent. Some pairs may be assigned a contraceptive they know nothing about; tell them not to worry and that they should make suggestions for how it might be used and work.

3. Bring the group together. Each pair reports back. Does everyone agree? Does anyone know anything else about the method being discussed? Does anyone have any worries or concerns or questions about the method?

NOTE: It is important, as far as possible, to allow learners to share what they know. Correct misleading information and give additional information, especially on questions such as side effects and correct usage. 


\section{Advantages and Disadvantages of Contraceptives (40 minutes)}

1. Explain that this exercise is about making choices about contraceptives and that we are going to look at factors that might influence our decisions. Say that everyone recognizes that there is no perfect contraceptive and different contraceptives are better for some people at some times in their lives than others.

2. Ask the group to divide into 3-4 groups. Give each small group one of the following life situations (add your own as appropriate) and ask the learners what might be important to these people in making their decision about a contraceptive method:

An adolescent schoolgirl not in a stable relationship

A breastfeeding woman

A person in a stable, monogamous relationship

An older woman with several children

A woman who sees her husband four times a year

An older woman who has no regular partner

A person not on contraceptives who is raped

3. Bring the learners together. Ask each group to share what they thought were most important. Draw a table on the board with the contraceptives mentioned in the previous exercise along the top and the criteria given by the group along the side.

\begin{tabular}{|l|l|l|l|l|}
\hline & Pills & Injectables & Condoms & IUCD \\
\hline Easy to use & & & & \\
\hline Effective & & & & \\
\hline Secret & & & & \\
\hline Doesn't affect menstruation & & & & \\
\hline Protects against STs, including HIV & & & & \\
\hline Overall Choice & & & & \\
\hline
\end{tabular}

4. Starting with each criterion, ask the group what score they would give each contraceptive method. Use this to generate a discussion about the pros and cons of contraceptive methods at different life stages by probing further as to the reasons for the choices made by the groups.

5. Remind learners that sexual health is sex that is pleasurable and free from infection, unwanted pregnancy and abuse. Thinking about this: which method or combination of methods is best for achieving sexual health?

6. Add up the scores for each method. What would the score be if a person used a condom and another method? 


\section{Myths and Misconceptions about Contraceptives (30 minutes)}

1. Ask learners to talk about the different rumours or myths they heard about how to prevent pregnancy. After each learner brings up one myth they have heard for avoiding pregnancy, ask them if what they have heard is true or false, and why, and correct any misinformation with facts. (For instance some learners feel that using witchcraft; using pawpaw leaves in the vagina or using herbs from elders or from an herbalist can prevent pregnancy. Other myths about preventing pregnancy include use of prayer, not being able to get pregnant the first time you have sex, not getting pregnant if you have sex while standing up, or not even knowing that unprotected sexual intercourse is what causes pregnancy.)

2. Ask learners to stand up from their seats. Explain to learners that you will read the following statements. If the learners believe the statements are true ask them to continue standing. If they believe the statements are false ask them to sit down. Read each statement one at a time and wait for the learners to move. For each question, ask a couple learners to share why they think the statement is true or false. Go through each statement and respond with the correct answer after the learners have shared their reasons. All of the statements below are myths that are false.

Oral contraceptives can accumulate in a woman's body and make her sick.

A condom can get lost in a woman's body.

Oral contraceptives can cause cancer.

An IUCD can leave the uterus and travel through a woman's body.

Use of contraceptives makes a woman not want to have sex.

Use of contraceptives makes a woman promiscuous.

Learning about contraceptive methods makes young people want to have sex.

Using a condom makes a man less of a man.

The first time you have sex you cannot get pregnant.

You cannot get pregnant if you have sex in water.

If you pray before and after you have sex you can't get pregnant. 


\section{Contraceptive Methods Overview}

\begin{tabular}{|c|c|c|c|}
\hline Method & Effectiveness & Advantages & Limitations \\
\hline $\begin{array}{l}\text { Abstinence: Do not engage in penetrative sex- } \\
\text { ual activity. To prevent pregnancy avoid vaginal } \\
\text { intercourse. To prevent STIs and HIV avoid } \\
\text { anal, vaginal and oral sex.Can engage in hand } \\
\text { holding, hugging, massaging, kissing, and } \\
\text { mutual masturbation. }\end{array}$ & $\begin{array}{l}100 \% \text { with con- } \\
\text { sistent use }\end{array}$ & $\begin{array}{l}\text { Most effective method } \\
\text { for preventing pregnan- } \\
\text { cy and STIs. Can be used } \\
\text { by those who have } \\
\text { already had sexual } \\
\text { intercourse (secondary } \\
\text { virginity). }\end{array}$ & $\begin{array}{l}\text { Requires high level of } \\
\text { motivation and self con- } \\
\text { trol. }\end{array}$ \\
\hline $\begin{array}{l}\text { Male condom: Fits over erect penis and pre- } \\
\text { vents sperm from entering vagina. Most are } \\
\text { made of latex rubber. Also known as socks, } \\
\text { gum boots, rubbers, raincoat, daddy's coat. }\end{array}$ & $\begin{array}{l}97 \% \text { with correct } \\
\text { and consistent } \\
\text { use; } 88 \% \text { with } \\
\text { normal use }\end{array}$ & $\begin{array}{l}\text { Easy to buy. Easy to use, } \\
\text { easy to carry. } \\
\text { Immediately effective. } \\
\text { Latex condoms are } \\
\text { highly protective } \\
\text { against HIV and other } \\
\text { STIs. }\end{array}$ & $\begin{array}{l}\text { Must be put on during } \\
\text { sex. Some men say it } \\
\text { reduces sexual feelings. } \\
\text { Condoms with spermi- } \\
\text { cide may irritate vagina } \\
\text { and penis. }\end{array}$ \\
\hline $\begin{array}{l}\text { Female condom: Made of thin, transparent soft } \\
\text { plastic and inserted into the vagina. }\end{array}$ & $\begin{array}{l}95 \% \text { with correct } \\
\text { and consistent } \\
\text { use; } 79 \% \text { with } \\
\text { normal use }\end{array}$ & $\begin{array}{l}\text { Immediately effective. } \\
\text { Woman controlled. Easy } \\
\text { to use with a little prac- } \\
\text { tice. Highly protective } \\
\text { against HIV and STIs. }\end{array}$ & $\begin{array}{l}\text { Requires insertion } \\
\text { before sexual inter- } \\
\text { course. Is expensive. }\end{array}$ \\
\hline $\begin{array}{l}\text { Spermicides: Immobilize and kills sperm. Not } \\
\text { recommended for use alone. Not recommended } \\
\text { for frequent use. }\end{array}$ & $\begin{array}{l}94 \% \text { with correct } \\
\text { and consistent } \\
\text { use; } 74 \% \text { with } \\
\text { normal use }\end{array}$ & $\begin{array}{l}\text { Effective immediately. } \\
\text { Women controlled. Easy } \\
\text { to use. Protects against } \\
\text { some STIs. }\end{array}$ & $\begin{array}{l}\text { Local irritation possible. } \\
\text { Does not protect against } \\
\text { HIV. }\end{array}$ \\
\hline $\begin{array}{l}\text { Diaphragm with spermicide: Small rubber cup } \\
\text { fits inside vagina, over the opening to the } \\
\text { womb. Used with contraceptive cream or jelly } \\
\text { that kills sperm. Must be fitted by clinician. }\end{array}$ & $\begin{array}{l}94 \% \text { with correct } \\
\text { and consistent } \\
\text { use; } 80 \% \text { with } \\
\text { normal use }\end{array}$ & $\begin{array}{l}\text { Woman controlled. Can } \\
\text { be put in } 2 \text { hours before } \\
\text { sex.May help protect } \\
\text { against STIs. }\end{array}$ & $\begin{array}{l}\text { Requires initial fitting. } \\
\text { More bladder infections } \\
\text { for some women.May be } \\
\text { hard to put in and take } \\
\text { out. Spermicide may irri- } \\
\text { tate vagina and penis. }\end{array}$ \\
\hline $\begin{array}{l}\text { Pills: Made of artificial hormones. Stop ovaries } \\
\text { from releasing an egg each month. Must be } \\
\text { prescribed by a clinician. }\end{array}$ & $\begin{array}{l}\text { More than } 99 \% \\
\text { with correct and } \\
\text { consistent use; } \\
97 \% \text { with normal } \\
\text { use }\end{array}$ & $\begin{array}{l}\text { Simple and easy to use. } \\
\text { Doesn't interfere with } \\
\text { sexLess bleeding and } \\
\text { cramping during period. } \\
\text { Protects against Pelvic } \\
\text { Inflammatory Disease, } \\
\text { ovarian and endometri- } \\
\text { al cancers. }\end{array}$ & $\begin{array}{l}\text { Small chance of blood } \\
\text { clots, heart attacks, } \\
\text { strokes and high blood } \\
\text { pressure. May have } \\
\text { weight changes, moodi- } \\
\text { ness, spotting, more } \\
\text { vaginal infections. Must } \\
\text { be taken every day. }\end{array}$ \\
\hline $\begin{array}{l}\text { Emergency contraceptive pills: Provide emer- } \\
\text { gency contraception when taken within } 5 \text { days } \\
\text { of unprotected sexual intercourse. Prevents } \\
\text { ovulation and inhibits transport of the egg } \\
\text { and/or sperm through the fallopian tubes. }\end{array}$ & $85 \%$ & $\begin{array}{l}\text { Provides emergency } \\
\text { contraception if used } \\
\text { within } 120 \text { hours after } \\
\text { unprotected sex. Can be } \\
\text { purchased over the } \\
\text { counter. }\end{array}$ & $\begin{array}{l}\text { May cause nausea vomit- } \\
\text { ing. Use with care with } \\
\text { women with cardiovas- } \\
\text { cular complications, } \\
\text { angina, migraines and } \\
\text { liver disease. Not meant } \\
\text { for repeated use. }\end{array}$ \\
\hline
\end{tabular}




\begin{tabular}{|c|c|c|c|}
\hline Method & Effectiveness & Advantages & Limitations \\
\hline $\begin{array}{l}\text { Injectables: Artificial hormones injected by a } \\
\text { clinician. Stop ovaries from releasing egg each } \\
\text { month. Thicken mucus so it's hard for sperm to } \\
\text { enter the womb. }\end{array}$ & More than $99 \%$ & $\begin{array}{l}\text { Does not interfere with } \\
\text { sex. Lasts } 3 \text { months. } \\
\text { Can be used while } \\
\text { breastfeeding. }\end{array}$ & $\begin{array}{l}\text { Should not be used by } \\
\text { women with liver dis- } \\
\text { ease, heart disease, } \\
\text { breast cancer, blood } \\
\text { clots. Irregular bleeding, } \\
\text { amenorrhoea and weight } \\
\text { gain may occur. May } \\
\text { affect bone development } \\
\text { in women under 18. May } \\
\text { be delay in getting preg- } \\
\text { nant after stopping use. }\end{array}$ \\
\hline $\begin{array}{l}\text { Implants: Tiny capsules of artificial hormones } \\
\text { put under skin of arm by a clinician. Capsules } \\
\text { slowly release hormones into bloodstream and } \\
\text { stop ovaries from releasing an egg each month. } \\
\text { Also, thickens mucus so it's hard for sperm to } \\
\text { enter the womb. }\end{array}$ & More than $99 \%$ & $\begin{array}{l}\text { Can stay in for } 5 \\
\text { years. Can be removed } \\
\text { anytime. Pregnancy } \\
\text { possible immediately } \\
\text { after removal. Always in } \\
\text { place. Does not inter- } \\
\text { fere with sex. }\end{array}$ & $\begin{array}{l}\text { For the first few months, } \\
\text { may have irregular peri- } \\
\text { ods. Beginning costs are } \\
\text { high. Minor surgery } \\
\text { required to insert or } \\
\text { remove. Should not be } \\
\text { used by women with } \\
\text { liver disease, heart dis- } \\
\text { ease, breast cancer or } \\
\text { blood clots. }\end{array}$ \\
\hline $\begin{array}{l}\text { IUCD (Intrauterine Contraceptive Device): } \\
\text { Small device put inside womb by a trained serv- } \\
\text { ice provider. Stops sperm from joining egg or } \\
\text { fertilized egg from implanting and growing in } \\
\text { womb. }\end{array}$ & $97-99 \%$ & $\begin{array}{l}\text { Always in place. Does } \\
\text { not interfere with sex. }\end{array}$ & $\begin{array}{l}\text { Increased chance of } \\
\text { tubal infection (which } \\
\text { may lead to sterility) for } \\
\text { women with more than } \\
\text { one partner or whose } \\
\text { partner has other part- } \\
\text { ners. Can puncture } \\
\text { womb. May have more } \\
\text { bleeding and cramping } \\
\text { during period or spot- } \\
\text { ting between periods. }\end{array}$ \\
\hline $\begin{array}{l}\text { Lactational amenorrhea method (LAM): } \\
\text { Temporary method for the } 6 \text { months following } \\
\text { childbirth, for women who are not menstruat- } \\
\text { ing and are fully or nearly fully breastfeeding. }\end{array}$ & $\begin{array}{l}98 \% \text { during } 6 \\
\text { months after } \\
\text { childbirth, if } \\
\text { used correctly }\end{array}$ & $\begin{array}{l}\text { No cost. No side effects. } \\
\text { Provides proper nutri- } \\
\text { tion for baby. }\end{array}$ & It is temporary. \\
\hline $\begin{array}{l}\text { Natural family planning: Methods to deter- } \\
\text { mine when woman can and cannot get preg- } \\
\text { nant (includes charting temperature, vaginal } \\
\text { mucus, menstrual bleeding); can abstain from } \\
\text { sex or use contraceptives during fertile time. }\end{array}$ & $\begin{array}{l}91-97 \% \text { with cor- } \\
\text { rect and consis- } \\
\text { tent use. } 80 \% \\
\text { with normal use. }\end{array}$ & $\begin{array}{l}\text { Improved knowledge of } \\
\text { reproductive system. No } \\
\text { cost. No devices or } \\
\text { chemicals. }\end{array}$ & $\begin{array}{l}\text { Need cooperation of the } \\
\text { couple. Requires daily } \\
\text { record keeping and } \\
\text { training. Requires peri- } \\
\text { ods of abstinence or use } \\
\text { of other methods. } \\
\text { Cannot use with irregu- } \\
\text { lar periods or tempera- } \\
\text { ture patterns. }\end{array}$ \\
\hline $\begin{array}{l}\text { Withdrawal: Man interrupts intercourse and } \\
\text { withdraws his penis from his partner's vagina } \\
\text { before he ejaculates. }\end{array}$ & $81 \%$ & $\begin{array}{l}\text { No cost. Is a back-up } \\
\text { contraceptive that is } \\
\text { always available. }\end{array}$ & Difficult to practice. \\
\hline $\begin{array}{l}\text { Sterilization: Operation that makes a person } \\
\text { unable to have a baby. Both men and women } \\
\text { can be sterilized. }\end{array}$ & $99.6 \%$ & $\begin{array}{l}\text { No other method will } \\
\text { ever be needed. No } \\
\text { physical effect on sexu- } \\
\text { al desire or ability. }\end{array}$ & $\begin{array}{l}\text { Permanent. Small risk of } \\
\text { infection or bleeding } \\
\text { after surgery. Chance of } \\
\text { tubal pregnancy. }\end{array}$ \\
\hline
\end{tabular}




\section{Resource 4 Accommodating Youth with Special Needs}

The sexual development of special needs youth is often overlooked under the assumption that youth who have disabilities are not able to or should not be allowed to engage in loving, sexual relationships. It is important, however, to give special attention to these youth in order to provide them with correct and easy-to-understand information so that they make the best choices when faced with decisions about sexuality.

Sexual education for special needs youth should be tailored to each individual with particular attention to his or her disability. This is a decision that should be made with much involvement from parents or guardians. It is important to encourage an open discussion in order to make parents and youth comfortable providing information about the youth's disability.

Some factors to consider when providing sexual education to youth with disabilities include:

How the adolescent's disability may affect his or her sexuality and sexual development. Young people with disabilities may go through puberty much later or much earlier than their peers or may experience different changes during puberty.

How the adolescent's disability may affect his or her ability to understand sexual and reproductive health education. For example, some young people with disabilities may perform better with different types of learning materials, such as lower-literacy or large print materials.

Any additional information that may be needed to address the specific disability of the individual adolescent with regard to his or her development. For example, some disabilities could prevent young people from becoming pregnant.

Sexual education for youth with special needs should cover anatomy and reproductive physiology, changes during puberty, information about sexually transmitted infections, and knowledge about the correct way to use contraception to prevent pregnancy and STIs, including HIV. Life skills, such as decision-making, self-esteem, negotiating skills, and setting goals should also be incorporated into any sexual education program for special needs youth.

\section{Tips for Talking with Special Needs Youth}

Encourage them to speak openly about their disability and to share any concerns they have about changes they are noticing in their bodies.

Present information in a simple and clear format.

Be sure to use pictures to help explain the information (if appropriate). Use repetition to help young people understand important information. 


\section{References}

\section{Session 2: Life Cycle}

Kenya Scouts Association and PATH. Reproductive Health Manual for Scout Leaders. Nairobi: PATH; 1999.

\section{Session 3: Adolescence and Puberty}

Institute for Reproductive Health. My Changing Body: Fertility Awareness for Young People. Washington, DC: Georgetown University; 2003.

Mayle P. What's Happening to Me? An Illustrated Guide to Puberty. Kensington Publishing Corporation: New York; 1975.

\section{Session 4: Male and Female Reproductive Systems}

Institute for Reproductive Health. My Changing Body: Fertility Awareness for Young People. 2003.

Hendrix-Jenkins A, Clark S, Gerber W. Games for Adolescent Reproductive Health: An International Handbook, Washington, DC: PATH; 2002.

Kenya Scouts Association and PATH. Reproductive Health Manual for Scout Leaders. Nairobi; 1999.

Mayle P. What's Happening to Me? An Illustrated Guide to Puberty. Kensington Publishing Corporation: New York; 1975.

Teenwise website. Available at: www.teenwise.com.

\section{Session 6: Healthy Relationships}

AMKENI. Field Agent's Handbook. Nairobi; 2002.

\section{Session 7: Communication}

AMKENI. Field Agent's Handbook. Nairobi; 2002.

Government of Namibia and United Nations Children's Fund (UNICEF). My Future is My Choice: Extra Curricular Life Skills Training Manual. UNICEF; 1999.

\section{Session 8: Friendship}

African Medical and Research Foundation (AMREF). Parents of Tomorrow: A Guide to Adolescent Sexual and Reproductive Health. Nairobi: AMREF; 1996.

\section{Session 10: Love and Infatuation}

AMKENI. Field Agent's Handbook. Nairobi; 2002.

\section{Session 11: Managing Anger, Stress, and Conflict}

American Psychological Association website. Available at: www.apa.org

Happy Guy website. Available at: www.thehappyguy.com/anger-management-tips.html

Mohawk College website. Available at www.mohawkcollege.ca/dept/stdev/Dispute/DRtips.html Texas A\&M University website. Available at www.studentlife.tamu.edu/scrs/sms/tips.htm

University of Texas website. Available at: ww.utexas.edu/student/cmhc/booklets/stress/stress.html 
Session 12: Introduction to Gender

AMKENI. Field Agent's Handbook. Nairobi; 2002.

\section{Session 13: Gender Stereotypes}

AMKENI. Field Agent's Handbook. Nairobi; 2002.

\section{Session 14: Sexuality and Behaviour}

AMKENI. Field Agent's Handbook. Nairobi; 2002.

Centre for British Teachers. PSABH Course A: School and Community Training Notes. Nairobi; 2002.

PATH. Life Planning Skills: A Curriculum for Young People in Africa, Ghana Version. Facilitator's Manual. Washington, DC: ; 2003.

\section{Session 15: Self-Esteem}

AMKENI. Field Agent's Handbook. Nairobi; 2002.

PATH. How Can We Prevent Cervical Cancer? A Guide for Community Facilitators. PATH/PAHO/Peru Ministry of Health; 2002.

\section{Session 16: Being Assertiveness}

AMKENI. Field Agent's Handbook. Nairobi; 2002.

\section{Session 17: Decision Making}

Advocates for Youth. Life Planning Education: A Youth Development Programme. Washington, DC; 1995.

PATH. Life Planning Skills: A Curriculum for Young People in Africa, Ghana Version. Facilitator's Manual. Washington, DC; 2003.

AMKENI. Field Agent's Handbook. Nairobi; 2002.

\section{Session 20: Resisting Peer Pressure}

Advocates for Youth. Life Planning Education: A Youth Development Programme. Washington, DC; 1995.

\section{Session 21: Drug Use}

Advocates for Youth. Life Planning Education: A Youth Development Programme. Washington, DC; 1995.

Child Welfare League of America. A Mentor Manual: For Adults who Work with Pregnant and Parenting Teens. Washington, DC; 1995.

\section{Session 22: Sexual Exploitation, Rape, and Gender Violence}

Division of Reproductive Health, Ministry of Health, Government of Kenya. National Guidelines: Medical Management of Rape and Sexual Violence. Nairobi; 2004.

\section{Session 23: Teen Pregnancy}

AMREF. Parents of Tomorrow: A Guide to Adolescent Sexual and Reproductive Health. 1996.

Family Health International (FHI). Meeting the Needs of Young Clients: A Guide to Providing Reproductive Health Services to Adolescents. Arlington, VA: 2000. 


\section{Session 26: HIV and AIDS}

Advocates for Youth. Life Planning Education: A Youth Development Programme. Washington, DC; 1995.

AMKENI. Field Agent's Handbook. Nairobi; 2002.

Central Bureau of Statistics (CBS) [Kenya], Ministry of Health (MOH) [Kenya], and ORC Macro. Kenya Demographic and Health Survey 2003. Calverton, MD: CBS, MOH and ORC Macro; 2004.

Centre for British Teachers. PSABH Course A: School and Community Training Notes. Nairobi; 2002.

Family Health International (FHI). Meeting the Needs of Young Clients: A Guide to Providing Reproductive Health Services to Adolescents. Arlington, VA; 2000.

IMPACT Project. Discussion Guides for Peer Educators. Nairobi: PATH and FHI; 2003.

IMPACT Project. Kenya Girl Guides Association Training of Guide Leaders on Participatory Peer Education for HIV and AIDS prevention. Nairobi; 2001.

IMPACT Project. Understanding Opportunistic Infections [brochure]. Nairobi: FHI; 2003.

Jackson H. AIDS Africa: Continent in Crisis. SAfAIDS: Harare, Zimbabwe; 2002.

van Vuuren L, Davis R, Denman V, et al. Facing AIDS Together: HIV/AIDS Prevention and Care. Baltimore: World Relief, Freedom from Hunger; 2002.

Session 27: Voluntary Counselling and Testing

AMKENI. Field Agent's Handbook. Nairobi; 2002.

\section{Session 28: Care and Support for People Living with HIV}

AMKENI. Field Agent's Handbook. Nairobi; 2002.

IMPACT Project. Understanding Opportunistic Infections [brochure]. Nairobi: FHI; 2003.

Peace Corps. Life Skills Manual. Washington, DC; 2001.

van Vuuren L, Davis R, Denman V, et al. Facing AIDS Together: HIV/AIDS Prevention and Care. Baltimore: World Relief, Freedom from Hunger; 2002.

\section{Session 29: Other Sexually Transmitted Infections}

AMKENI. Field Agent's Handbook. Nairobi; 2002.

CEDPA. Choose a Future! Issues and Options for Adolescent Girls. A Sourcebook of Participatory Learning Activities. Washington, DC; 1996.

FHI. Meeting the Needs of Adolescent Clients: A Guide to Providing Reproductive Health Services to Adolescents. Arlington, VA: 2000.

Medical Research Council (MRC). Stepping Stones: A Training Manual for Sexual and Reproductive Health Communication and Relationship skills. MRC: Pretoria; 2002.

\section{Session 30: Facts and Myths about STIs}

FHI. Meeting the Needs of Adolescent Clients: A guide to providing reproductive health services to adolescents. 2000. 
Resource 1: Facilitation Techniques

Lawson K. The Trainer's Handbook. San Francisco: Jossey-Bass Pfeiffer; 1998

Silberman M. 101 Ways to Make Training Active. San Francisco: Jossey-Bass Pfeiffer; 1995.

\section{Resource 2: Guidance and Counselling}

American School Counselor Association website. Available at http://www.schoolcounselor.org

Education World website. Available at http://www.educationworld.com/a_curr/curr198.shtml

Jefferson County Schools website. Available at http://classroom.jc-schools.net/guidance/counselors.html

Ministry of Education, Science, and Technology (MOEST), Government of Kenya. Guidance and Counselling National Guidelines (Draft). Nairobi: MOEST; 2005.

PATH. KARHP Facilitation Manual: A Guide for Trainers of Guidance and Counselling Teachers. Nairobi: PATH and Population Council; 2005.

Population Information Program, Center for Communication Programs, The Johns Hopkins School of Public Health. Pop Reports: GATHER Guide to Counseling. Volume XXVI, Number 4. December 1998. Available at http://www.infoforhealth.org/pr/j48edsum.shtml

\section{Resource 3: Condoms}

AMKENI. Field Agent's Handbook. Nairobi; 2002.

IMPACT Project. Discussion Guides for Peer Educators. Nairobi: PATH and FHI; 2003.

\section{Resource 4: Other Ways to Prevent Pregnancy}

AMKENI. Field Agent's Handbook. Nairobi; 2002.

IMPACT Project. Kenya Girl Guides Association Training of Guide Leaders on Participatory Peer Education for HIV and AIDS Prevention Life Skills Manual. Nairobi; 2001.

CEDPA. Choose a Future! Issues and Options for Adolescent Girls. A Sourcebook of Participatory Learning Activities. Washington, DC; 1996.

WH0. Orientation Programme on Adolescent Health for Health-care Providers. Geneva; 2003.

\section{Resource 5: Special Needs Youth}

The Center for Children with Special Needs Linkages Newsletter, Volume 11, Number 1. Winter 2005. Available online at: http://www.cshcn.org/linkages/winter-05/Story1.cfm 